Aus der Klinik für Kardiologie und Pneumologie

(Prof. Dr. med. G. Hasenfuß)

der Medizinischen Fakultät der Universität Göttingen

\title{
Differenzielle Expression proatherogener Zellmarker auf Monozytensubpopulationen bei Patienten mit stabiler koronarer Herzkrankheit
}

\author{
INAUGURAL - DISSERTATION \\ zur Erlangung des Doktorgrades \\ der Medizinischen Fakultät der \\ Georg-August-Universität zu Göttingen
}

vorgelegt von

Hendrik Kuschicke

aus

Göttingen

Göttingen 2016 
Dekan:

Betreuerin:

Korreferent:

Tag der mündlichen Prüfung:
Prof. Dr. rer. nat. H. K. Kroemer

PD Dr. med. F. S. Czepluch

Prof. Dr. med. M. Oppermann

30. März 2017 


\section{DiE INHALTE DER VORLIEGENDEN DISSERTATIONSSCHRIFT WURDEN WIE FOLGT PUBLIZIERT:}

Originalpublikationen

- Czepluch FS, Kuschicke H, Dellas C, Riggert J, Hasenfuss G, Schäfer K (2014): Increased proatherogenic monocyte-platelet crosstalk in monocyte subpopulations of patients with stable coronary artery disease. J Intern Med 275, 144-154

- Czepluch FS, Kuschicke H, Dellas C, Riggert J, Hasenfuss G, Schäfer K (2013): Atheroprotective Krueppel-like factor 4 is downregulated in monocyte subsets of patients with coronary artery disease. Thromb Haemost 110, 1080-1082

\section{Kongressbeiträge}

- Czepluch FS, Kuschicke H, Dellas C, Riggert J, Hasenfuß G, Schäfer K (2013): Verminderte Expression des atheroprotektiven Transkriptionsfaktors Krüppel-Like Factor 4 in zirkulierenden Monozyten-Subgruppen von Patienten mit koronarer Herzkrankheit. Clin Res Cardiol 102, Suppl 1, April 2013, P1800. 79. Jahrestagung der Deutschen Gesellschaft für Kardiologie Herz- und Kreislaufforschung, Mannheim, 03. -06.04.2013

- Czepluch FS, Kuschicke H, Schlegel M, Mueller M, Bernhardt M, Bremmer F, Riggert J, Hasenfuss G, Schaefer K (2012): Krueppel-like factor 4 is downregulated in circulating monocyte subsets of patients with coronary artery disease. Eur Heart J 33, Suppl 1, August 2012, P4327. European Society of Cardiology Congress 2012, München, 25. - 29.08.2012

- Czepluch FS, Kuschicke H, Riggert J, Hasenfuß G, Schäfer K (2012): Vermehrtes Vorkommen von zirkulierenden $\mathrm{CD} 14++\mathrm{CD} 16+$ und $\mathrm{CD} 14(+) \mathrm{CD} 16+$ Monozyten-Plättchen-Aggregaten bei Patienten mit stabiler koronarer Herzkrankheit. Clin Res Cardiol 101, Suppl 1, April 2012, P1741. 78. Jahrestagung der Deutschen Gesellschaft für Kardiologie - Herz- und Kreislaufforschung, Mannheim, 11. - 14.04.2012 


\section{INHALTSVERZEICHNIS}

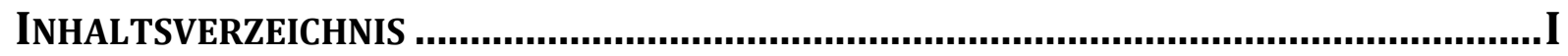

ABKÜRZUNGSVERZEICHNIS ................................................................................. V

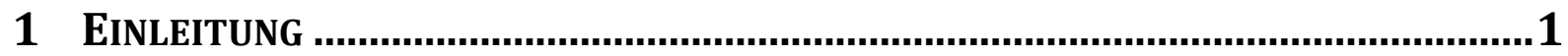

1.1 Epidemiologische Bedeutung von Herz-Kreislauf-Erkrankungen...........................................1

$1.2 \quad$ Atherosklerose, koronare Herzkrankheit und Myokardinfarkt ..............................................2

1.3 Monozyten - Klassifikation und Bedeutung für die Atherosklerose .....................................6

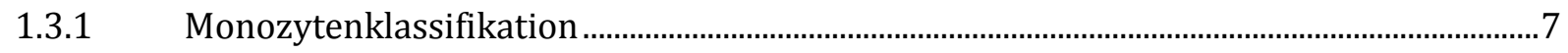

1.4 Thrombozyten und die Bedeutung von Monozyten-Thrombozyten-Aggregaten .............8

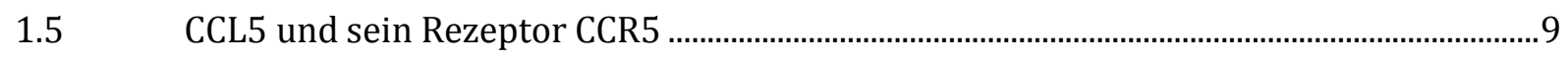

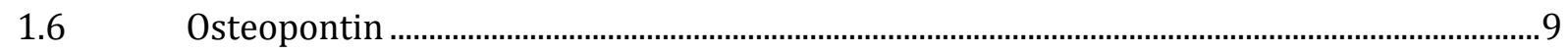

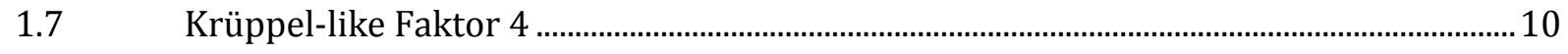

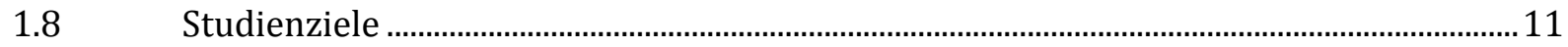

2 MATERIAL UND METHODEN ........................................................................... 13

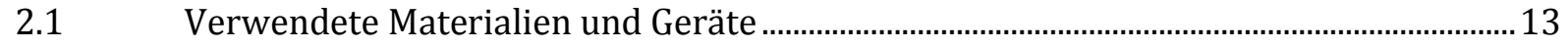

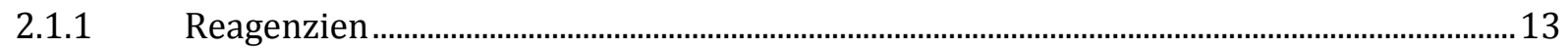

2.1.2 Elektrische Geräte und Software …................................................................................... 13

2.1.3 Materialien zur Blutentnahme und Probengewinnung....................................................... 14

2.1.4 Verbrauchsmaterialien ............................................................................................. 15

2.1.5 Materialien für die durchflusszytometrischen Analysen......................................................15

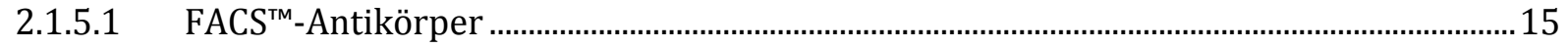

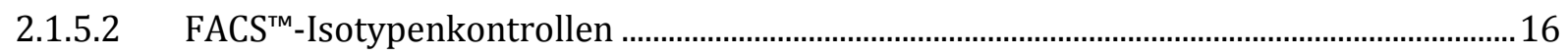

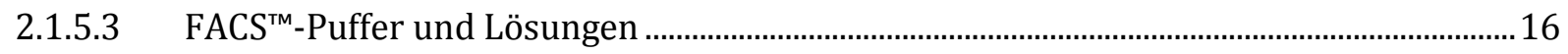

2.1.6 Materialien für ELISA-Versuche............................................................................................ 17

2.1.6.1 Eingesetzte ELISA-Kits.......................................................................................................... 17

2.1.6.2 Puffer und Lösungen für ELISA-Analysen....................................................................................17

2.2 Angewandte Methoden und Versuche.................................................................................. 17

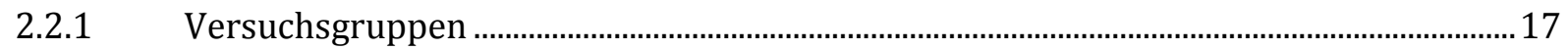

2.2.1.1 Probandenrekrutierung ................................................................................................ 17

2.2.1.1.1 Versuchskollektiv der Patienten mit stabiler KHK.............................................................. 18

2.2.1.1.2 Versuchskollektiv der gesunden Blutspender .........................................................................19 
2.2.1.1.3 Versuchskollektiv der altersadaptierten Patienten ohne KHK ...........................................19

2.2.2 Probandeneinwilligung, Sicherheit und Votum der Ethikkommission .............................20

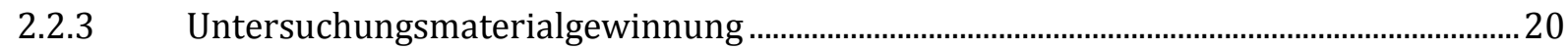

2.2.4 Maschinelles Differenzialblutbild...........................................................................................2

2.2.5 Klinisch-chemische Laborparameter ................................................................................... 21

2.2.6 Durchflusszytometrische Analysen ......................................................................................21

2.2.6.1 Prinzip der Durchflusszytometrie .........................................................................................21

2.2.6.2 Gewinnung mononukleärer Zellen und deren Aufarbeitung...............................................24

2.2.6.3 Detektion von Monozyten und Monozytensubgruppen aus PBMCs sowie deren CCR5- und CD44-Expression .....................................................................................25

2.2.6.4 Detektion der Monozytensubgruppen aus PBMCs und deren KLF4-Expression ...........26

2.2.6.5 Detektion der monozytären Subgruppen und deren Bildung von MonozytenThrombozyten-Aggregaten in citratantikoaguliertem Vollblut

2.2.6.6 Monozytäre CCR5- und KLF4-Expression nach in vitro-Inkubation mit Kontrollprobanden- bzw. KHK-Patientenplasma …….........................................................28

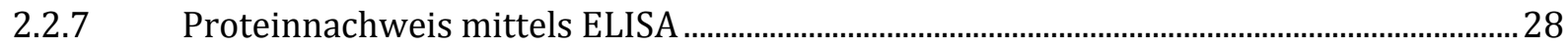

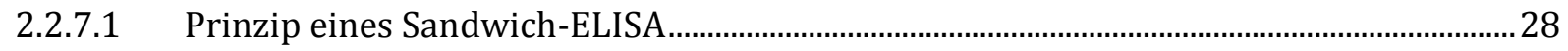

2.2.7.2 Durchführung der verschiedenen ELISA-Versuche ..................................................................30

$2.3 \quad$ Statistische Auswertung .................................................................................................... 31

2.3.1 Eingesetzte statistische Testverfahren .................................................................................... 31

2.3.2 p-Wert-Berechnung, Konfidenzintervall und Signifikanzniveau .......................................... 32

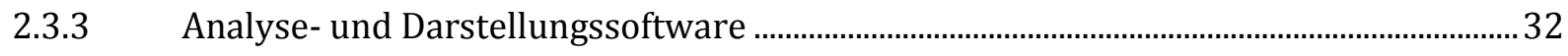

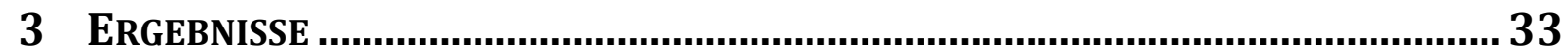

3.1 Charakteristika der verschiedenen Studiengruppen ........................................................... 33

3.2 Generelle Gatingstrategien bei der Analyse durchflusszytometrisch gewonnener Ergebnisse.

3.3 Detektion der Monozyten per Durchflusszytometrie und ihre Zuordnung zu den drei monozytären Untergruppen

3.4 Verteilung der Monozytensubgruppen bei KHK-Patienten und gesunden Kontrollprobanden

3.5 Monozytäre CCR5-Expression und CCL5-Serumspiegel

3.5.1 Durchflusszytometrische Quantifizierung der monozytären CCR5-Expression .............39

3.5.2 Einfluss der in vitro-Plasmastimulierung auf die monozytäre CCR5-Expression ........... 41

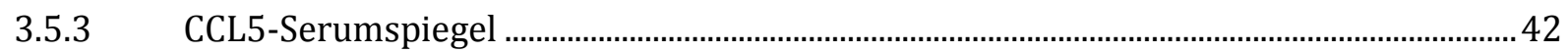

3.5.4 Einfluss cholesterinsenkender Medikation auf die Verteilung der monozytären Untergruppen und deren CCR5-Expression. 
3.5.4.1 Therapie mit HMG-CoA-Reduktasehemmern und ihre Auswirkungen auf die monozytäre CCR5-Expression

3.5.4.2 Einfluss von Ezetimib auf die prozentuale Verteilung der Monozytensubgruppen...... 44

3.6 Quantifizierung der monozytären CD44-Expression ............................................................. 45

3.7 Analyse der intrazellulären KLF4-Expression humaner Monozyten ................................. 46

3.7.1 KLF4+-Monozyten und ihre Subgruppenverteilung.............................................................. 46

3.7.2 Einfluss der in vitro-Plasmastimulierung auf die monozytäre KLF4-Expression .......... 48

3.7.3 Einfluss kardiovaskulärer Risikofaktoren auf die monozytäre KLF4-Expression ......... 48

3.7.4 Zusammenhang zwischen KLF4+-Monozyten und Leukozytenzahl................................... 49

3.8 Quantifizierung der Monozyten-Thrombozyten-Aggregatbildung .....................................50

3.8.1 Einfluss von Vorhofflimmern auf die Bildung von Monozyten-

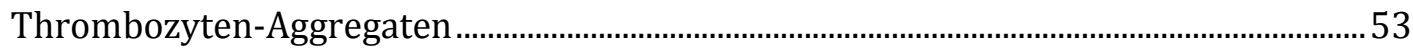

$3.9 \quad$ sPECAM-1- und sP-selectin-Serumspiegel............................................................................ 54

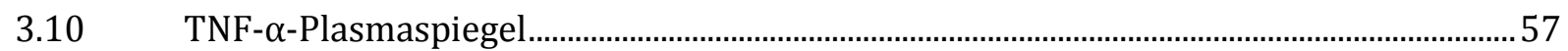

4 DISKUSSION …............................................................................................. 58

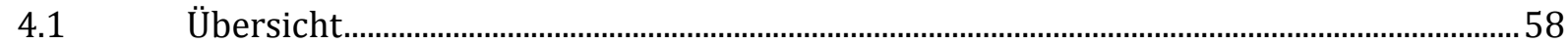

4.2 Einordung relevanter klinisch-chemischer und hämostaseologischer

Blutparameter in den klinischen Kontext ........................................................................ 59

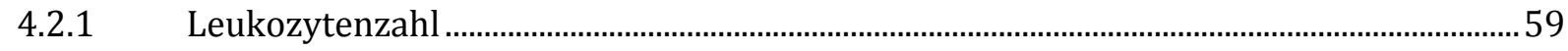

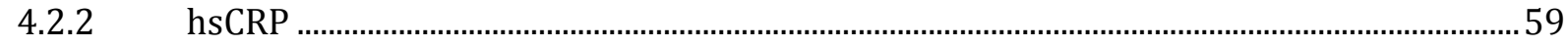

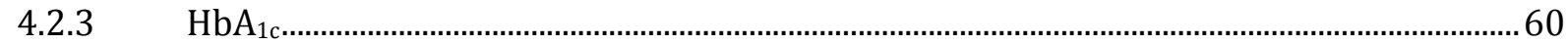

4.3 Prozentuales Vorkommen der drei Monozytensubgruppen im Kontext der aktuellen Forschung.

4.4 Bedeutung der CCR5-Expression auf den verschiedenen Monozytensubgruppen sowie der im Blut detektierten CCL5-Serumspiegel.

4.5 Cholesterinsenkende Medikation und ihr Einfluss auf die monozytäre CCR5Expression sowie den prozentualen Anteil der Monozytensubgruppen

4.5.1 Statine und ihr Einfluss auf den Anteil CCR5+-Monozyten ..................................................64

4.5.2 Ezetimibe reduzieren den relativen Anteil nicht-klassischer Monozyten......................... 65

4.6 CD44 auf Monozyten - Verbesserung der durchflusszytometrischen Monozytendetektion mithilfe von CD44?

4.7 Bedeutung der KLF4-Expression in Monozyten und ihre Beziehung zu den detektierten TNF- $\alpha$-Plasmaspiegeln

4.8 Die Bildung von Monozyten-Thrombozyten-Aggregaten als Ausdruck chronischpathologischer Plättchenaktivierung im Kontext zirkulierender Thrombozytenaktivitätsmarker

4.8.1 Aktivierte Thrombozyten und ihre Interaktion mit Monozyten 
4.8.2 Zirkulierende Thrombozytenaktivitätsmarker und ihre Bedeutung im Rahmen der Atherosklerose.

$4.9 \quad$ Ausblick und Perspektiven........................................................................................................... 74

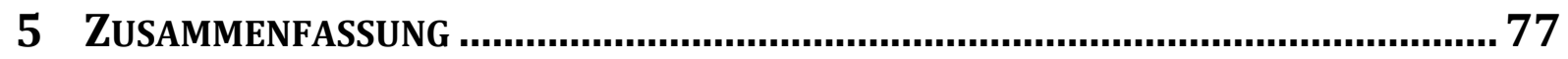

6 LITERATURVERZEICHNIS _.......................................................................... 79

7 ABBILDUNGSVERZEICHNIS ..........................................................................100

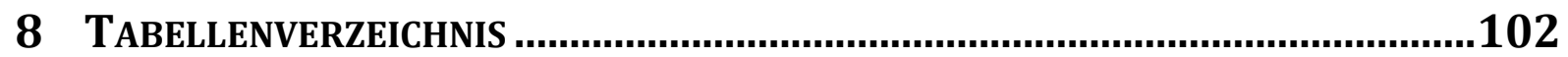




\section{ABKÜRZUNGSVERZEICHNIS}

\begin{tabular}{|c|c|c|}
\hline Abkürzung & Englisch/Latein & Deutsch/deutsche Übersetzung \\
\hline aaKtr. & & Altersadaptierte Kontrollgruppe \\
\hline Abb. & & Abbildung \\
\hline Abk. & & Abkürzung \\
\hline ACE & angiotensin converting enzyme & Angiotensinkonversionsenzym \\
\hline APC & allophycocyanin & Allophycocyanin \\
\hline ApoE & apolipoprotein $E$ & Apolipoprotein E \\
\hline ASS & & Acetylsalicylsäure \\
\hline AST & aspartate transaminase & Aspartataminotransferase \\
\hline $\mathrm{AT}_{1}$ & & Angiotensin-II-Rezeptor-Subtyp-1-Antagonist \\
\hline BMI & body mass index & Körpermasseindex \\
\hline BSA & bovine serum albumin & Rinderserumalbumin \\
\hline bspw. & & beispielsweise \\
\hline bzw. & & beziehungsweise \\
\hline $\mathrm{CCL}$ & CC chemokine ligand & CC-Chemokinligand \\
\hline CCR & CC chemokine receptor & CC-Chemokinrezeptor \\
\hline$C D$ & cluster of differentiation & \\
\hline CK & creatin kinase & Kreatinkinase \\
\hline CK-MB & creatin kinase-muscle/brain & Kreatinkinase-Muskel/Gehirn \\
\hline $\mathrm{CO}_{2}$ & carbon dioxid & Kohlenstoffdioxid \\
\hline CRP & C-reactive protein & C-reaktives Protein \\
\hline CX3CR & CX3C chemokine receptor & CX3C-Chemokinrezeptor \\
\hline DGK & & $\begin{array}{l}\text { Deutsche Gesellschaft für Kardiologie - Herz- und } \\
\text { Kreislaufforschung }\end{array}$ \\
\hline DNS & & Desoxyribonukleinsäure \\
\hline EDTA & ethylenediaminetetraacetic acid & Ethylendiamintetraessigsäure \\
\hline ELISA & enzyme-linked immunosorbent assay & enzymgekoppelter Immunadsorptionstest \\
\hline ESC & European Society of Cardiology & Europäische Gesellschaft für Kardiologie \\
\hline FACS $^{\text {TM }}$ & fluorescence-activated cell sorting & fluoreszenzaktivierte Zellsortierung \\
\hline $\mathrm{Fc \gamma R}$ & $\begin{array}{l}\text { fragment crystallisable-gamma re- } \\
\text { ceptor }\end{array}$ & kristallisierbares Fragment gamma-Rezeptor \\
\hline FITC & fluorescein isothiocyanate & Fluoresceinisothiocyanat \\
\hline $\mathrm{FL}$ & fluorescence & Fluoreszenz \\
\hline FSC & forward scatter & Vorwärtsstreulicht \\
\hline G & gauge & Gauge \\
\hline GFR & glomerular filtration rate & glomeruläre Filtrationsrate \\
\hline $\mathrm{HbA}_{1 \mathrm{c}}$ & glycated hemoglobin & glykosiliertes Hämoglobin \\
\hline HDL-C & high density lipoprotein cholesterol & Lipoprotein hoher Dichte-Cholesterin \\
\hline
\end{tabular}




\begin{tabular}{|c|c|c|}
\hline HIV & human immunodeficiency virus & humanes Immundefizienzvirus \\
\hline HLA-DR & human leukocyte antigen-DR & humanes Leukozytenantigen-DR \\
\hline HMG-CoA & $\begin{array}{l}\text { 3-hydroxy-3-methylglutaryl- } \\
\text { coenzyme A }\end{array}$ & 3-Hydroxy-3-Methylglutaryl-Coenzym-A \\
\hline HRP & horseradish peroxidase & Meerrettichperoxidase \\
\hline Hrsg. & & Herausgeber \\
\hline hsCRP & high-sensitivity C-reactive protein & hochsensitives C-reaktives Protein \\
\hline IE & & Internationale Einheit \\
\hline IFN- $\psi$ & interferon gamma & Interferon gamma \\
\hline $\operatorname{lgG}$ & immunoglobulin $G$ & Immunglobulin G \\
\hline iNOS & $\begin{array}{l}\text { cytokine-inducible nitric oxide syn- } \\
\text { thase }\end{array}$ & zytokininduzierte Stickstoffmonoxidsynthase \\
\hline KHK & & koronare Herzkrankheit \\
\hline KLF & Krueppel-like factor & Krüppel-like Faktor \\
\hline Ktr. & & Kontrollgruppe \\
\hline L & ligand & Ligand \\
\hline LDL-C & low density lipoprotein cholesterol & Lipoprotein niedriger Dichte-Cholesterin \\
\hline LPS & lipopolysaccharid & Lipopolysaccharid \\
\hline LRP1 & $\begin{array}{l}\text { low density lipoprotein receptor- } \\
\text { related protein } 1\end{array}$ & $\begin{array}{l}\text { Lipoprotein niedriger Dichte-Cholesterin-Rezeptor- } \\
\text { verbundenes Protein } 1\end{array}$ \\
\hline L-selectin & lymphocytes-selectin & Lymphozyten-Selektin \\
\hline Ly-6C & $\begin{array}{l}\text { lymphocyte antigen } 6 \text { complex, lo- } \\
\text { cus } C\end{array}$ & Lymphozytenantigen-6-Komplex, Position C \\
\hline MCP & monocyte chemoattractant protein & Monozyten-Chemoattraktionsprotein \\
\hline M-CSF & $\begin{array}{l}\text { makrophage colony-stimulating } \\
\text { factor }\end{array}$ & makrophagenkolonienstimulierender Faktor \\
\hline MEM & $\begin{array}{l}\text { Eagle's Minimum Essential } \\
\text { Medium }\end{array}$ & Eagles Minimales Essentielles Medium \\
\hline MFI-FMO & $\begin{array}{l}\text { mean fluorescence intensity- } \\
\text { fluorescence-minus-one }\end{array}$ & $\begin{array}{l}\text { mediane Fluoreszenzintensität minus korrespon- } \\
\text { dierender Isotypenkontrolle }\end{array}$ \\
\hline MPA & monocyte-platelet aggregat & Monozyten-Thrombozyten-Aggregat \\
\hline$n$ & numerus & $(A n-)$ Zahl \\
\hline NO & nitric oxide & Stickstoffmonoxid \\
\hline NPC1L1 & Niemann-Pick C1-like protein 1 & Niemann-Pick C1-ähnliches Protein 1 \\
\hline n. s. & & nicht signifikant \\
\hline NSTEMI & $\begin{array}{l}\text { non-ST elevation myocardial infarc- } \\
\text { tion }\end{array}$ & Nicht-ST-Hebungsinfarkt \\
\hline OPN & osteopontin & Osteopontin \\
\hline $\mathrm{p}(-$ Wert $)$ & & Wahrscheinlichkeits-/Signifikanzwert \\
\hline pAVK & & periphere arterielle Verschlusskrankheit \\
\hline PBMC & peripheral blood mononuclear cell & mononukleäre Zelle des peripheren Blutes \\
\hline PBS & phosphate buffered saline & phosphatgepufferte Salzlösung \\
\hline $\mathrm{PE}$ & phycoerythrin & Phycoerythrin \\
\hline PECAM & $\begin{array}{l}\text { platelet endothelial cell adhesion } \\
\text { molecule }\end{array}$ & Thrombozyten-Endothelzellen-Adhäsionsmolekül \\
\hline
\end{tabular}




\begin{tabular}{|c|c|c|}
\hline PerCP-Cy ${ }^{\mathrm{TM}} 5.5$ & $\begin{array}{l}\text { peridinin chlorophyll protein complex } \\
+ \text { cyanin-5.5 }\end{array}$ & Peridinin-Chlorophyll-Komplex + Cyanin5.5 \\
\hline PFA & paraformaldehyde & Paraformaldehyd \\
\hline $\mathrm{pH}$ & potentia Hydrogenii & $\begin{array}{l}\text { negativer dekadischer Logarithmus der Wasser- } \\
\text { stoffionenaktivität }\end{array}$ \\
\hline PMT & photomultiplier tube & Photomultiplierröhrchen \\
\hline PP & polypropylene & Polypropylen \\
\hline PS & polystyrene & Polystyrol \\
\hline P-selectin & platelet-selectin & Thrombozyten-Selektin \\
\hline r & $\begin{array}{l}\text { Spearman's rank correlation coeffi- } \\
\text { cient }\end{array}$ & Spearmans Rangkorrelationskoeffizient \\
\hline RANTES & $\begin{array}{l}\text { regulated on activation, normal } T \\
\text { cell expressed and secreted }\end{array}$ & \\
\hline rcf & relative centrifugal force & relative Zentrifugalkraft \\
\hline rpm & revolutions per minute & Umdrehungen pro Minute \\
\hline $\mathrm{RR}$ & & Riva-Rocci \\
\hline RT & room temperature & Raumtemperatur \\
\hline s & soluble & löslich \\
\hline$S$ & standard & Standard \\
\hline S. & & Seite \\
\hline SMC & smooth muscle cell & glatte Muskelzelle \\
\hline s. o. & & siehe oben \\
\hline SSC & side scatter & Seitwärtsstreulicht \\
\hline STEMI & ST elevation myocardial infarction & ST-Hebungsinfarkt \\
\hline $\mathrm{T}$ & thymus & Thymus \\
\hline Tab. & & Tabelle \\
\hline TMB & tetramethylbenzidine & Tetramethylbenzidin \\
\hline TNF- $\alpha$ & tumor necrosis factor alpha & Tumornekrosefaktor alpha \\
\hline $\mathrm{U}$ & unit & Einheit \\
\hline u. a. & & unter anderem \\
\hline UMG & & Universitätsmedizin Göttingen \\
\hline v. a. & & vor allem \\
\hline VEGF & vascular endothelial growth factor & vaskulärer endothelialer Wachstumsfaktor \\
\hline vgl. & & vergleiche \\
\hline VHF & atrial fibrillation & Vorhofflimmern \\
\hline vs. & versus & gegen, im Vergleich zu \\
\hline WHO & World Health Organization & Weltgesundheitsorganisation \\
\hline$x$ & & -fach \\
\hline z. B. & & zum Beispiel \\
\hline Z. n. & & Zustand nach \\
\hline z. T. & & zum Teil \\
\hline
\end{tabular}




\section{Einleitung}

\subsection{Epidemiologische Bedeutung von Herz-Kreislauf- Erkrankungen}

Herz-Kreislauf-Erkrankungen und insbesondere die von Atherosklerose hervorgerufene koronare Herzkrankheit [KHK] mit ihrer Akutmanifestation, dem Herzinfarkt, stellen in Industrienationen die mit Abstand häufigste Todesursache dar (Lange und Ziese 2014; Löwel et al. 2006; World Health Organization 2011, 2014).

Weltweit waren im Jahr 2012 laut Weltgesundheitsorganisation (engl. World Health Organization [WHO]) 17,5 Millionen Tote, d. h. drei von zehn Todesfällen, aufgrund von Herz-Kreislauf-Erkrankungen zu beklagen. Davon bedingte die KHK als weltweit führende Todesursache 7,4 Millionen Verstorbene, was 13,2 \% aller globalen Todesfälle entspricht (WHO 2014).

Im Jahr 2013 starben in Deutschland 354493 Menschen infolge einer Erkrankung des Kreislaufsystems, was einer Gesamtmortalität von 39,7 \% entspricht, davon 128808 (14,4 \% Gesamtmortalität) aufgrund einer ischämischen Herzerkrankung (Statistisches Bundesamt 2014).

Obwohl die Atherosklerose als Ursache der KHK seit mehr als 500 und ihre pathologischen Zusammenhänge seit mehr als 150 Jahren bekannt sind (Faxon et al. 2004), nahm die weltweite Zahl der Todesopfer durch ischämische Herzerkrankungen zwischen 2000 und 2012 um 23,3 \% auf 7,4 Millionen zu (WHO 2014). Bis zum Jahr 2030 wird eine weitere Zunahme kardiovaskulär bedingter Todesfälle auf bis zu 23,3 Millionen Tote weltweit befürchtet (Mathers und Loncar 2006).

In Deutschland und anderen westlichen Ländern ist dagegen seit etwa 1990 ein z. T. deutlicher Rückgang von Inzidenz, Letalität und Mortalität KHK-bedingter Myokardinfarkte zu beobachten (Abildstrom et al. 2003; Gaber 2011; Kuch et al. 2008; Lange und Ziese 2014; Löwel et al. 2005; Löwel et al. 2006; Muller-Riemenschneider et al. 2010; Unal et al. 2004). Dieser Trend wird auf eine vermehrte Risikofaktorreduktion, v. a. aber verbesserte therapeutische und sekundärprophylaktische Möglichkeiten zurückgeführt (Bandosz et al. 2012; Capewell und O'Flaherty 2008; Palmieri et al. 2010; Smolina et al. 2012). Die Krankheitsprävalenz dagegen bleibt nahezu unverändert hoch (Gößwald et al. 2013).

Die Lebenszeitprävalenz eines 40-49-jährigen Mannes in Deutschland für eine atherosklerotische Herzkrankheit liegt nach neuesten Auswertungen im Rahmen der Studie zur Gesundheit Erwachsener in Deutschland bei 3,0\%, bei einem 70-79-jährigen bei 30,5\%. Die Prävalenzen der weiblichen 
Bevölkerung sind mit 1,6 \% bei den 40-49-jährigen bzw. 15,5 \% bei den 70-79-jährigen Frauen etwa halb so groß wie die der Männer (Gößwald et al. 2013).

Der volkswirtschaftliche Schaden durch Krankheitskosten, die jährlich wegen Herz-KreislaufErkrankungen entstehen, belief sich 2008 in Deutschland auf knapp 37 Milliarden Euro (Statistisches Bundesamt 2010). Dieses verdeutlicht die sozioökonomische Bedeutung der KHK und den dringenden Bedarf, verbesserte Präventions- und Therapiemöglichkeiten zu schaffen.

\subsection{Atherosklerose, koronare Herzkrankheit und Myokard- infarkt}

Die Atherosklerose beschreibt die Bildung atheromatöser Veränderungen und Plaques in der Tunica intima arterieller Gefäßwände (Ross und Glomset 1973; Ross und Harker 1976; Ross und Glomset 1976a, 1976b). Bei dieser Plaquebildung, die chronisch progredient verläuft, spielen - wie in Abb. 1.1 dargestellt - inflammatorische Prozesse und Mediatoren eine herausragende Rolle (Fuster et al. 1992; Ross 1976, 1999).

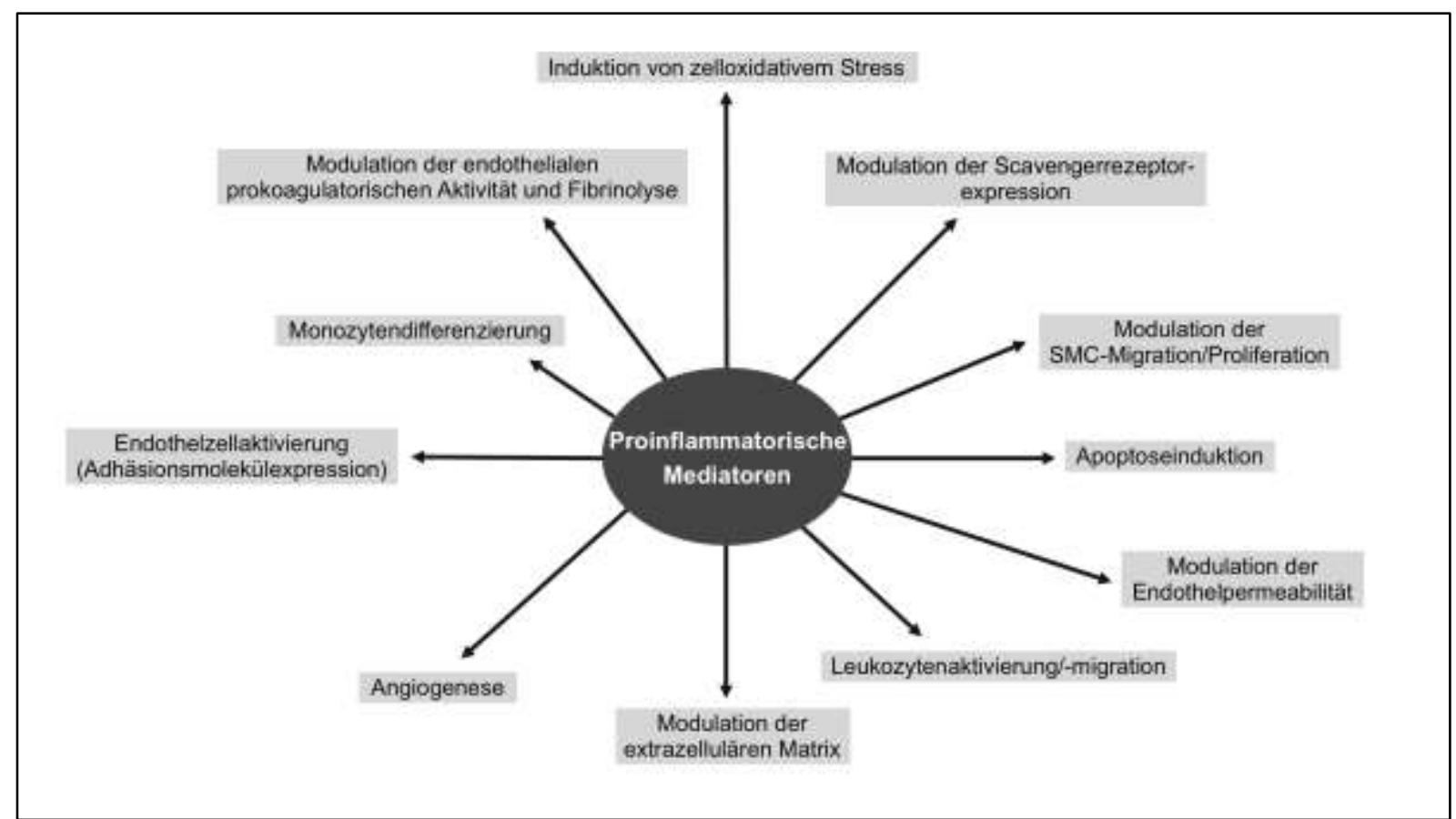

Abb. 1.1 Einfluss- und Modulationsmöglichkeiten proinflammatorischer Mediatoren im Rahmen der Atheroskleroseentwicklung

(modifiziert nach Ait-Oufella et al. 2012, S. 207)

Abk. SMC: glatte Muskelzelle 
Die pathogenetischen Prozesse der Krankheitsentstehung, die schon 1865 von Rudolph Virchow formuliert (Virchow 1856) und dessen Theorien bis heute vielfach ergänzt und moduliert wurden und werden (Duff und McMillan 1951; Libby et al. 2011; Plutzky 2003; Ross und Glomset 1976a, 1976b), sind immer noch nicht in Gänze geklärt und verstanden (Syverson von Gemmingen-Guttenberg 2013).

Nach der von Ross et al. aufgestellten response-to-injury-Hypothese ist für die Entstehung atherosklerotischer Läsionen eine chronische Schädigung und Dysfunktion des Endothels pathogenetisch bedeutsam, da diese u. a. zu einer erhöhten endothelialen Durchlässigkeit für Plasmabestandteile (v. a. Lipoprotein niedriger Dichte-Cholesterin, engl. low density lipoprotein cholesterol [LDL-C]) führt (Ross und Glomset 1976a, 1976b; Ross et al. 1977). Auch kommt es dadurch zur Anlagerung von Monozyten und anderen Leukozyten über Adhäsionsmoleküle am Endothel und deren Migration in das darunter liegende Bindegewebe (Ross 1979; Ross und Harker 1978; Ross et al. 1984). Die Monozytenrekrutierung und -extravasation spielt v. a. in den Initialphasen der Genese atherosklerotischer Läsionen eine herausragende Rolle (Hilgendorf et al. 2015; Libby et al. 2011; Zhu et al. 2009).

Gefäßschädigende Faktoren sind seit Längerem bekannt (Ridker und Libby 2012), wobei besonders die kardiovaskulären Hauptrisikofaktoren Rauchen (Assmann et al. 1999; Hammond und Horn 1988), Hyperlipoproteinämie (Furberg et al. 1994; Sacks et al. 1996), arterielle Hypertonie (Kannel et al. 1980; Stamler et al. 1993) und Hyperglykämie bzw. Diabetes mellitus (Kannel und McGee 1979b; The Pooling Project Research Group 1978) einen großen Einfluss auf die vaskuläre Integrität besitzen. Aber auch hämodynamische und hämatologische Faktoren (Meade et al. 1986; Rainer et al. 1987; Yarnell et al. 1991), Übergewicht (Noppa et al. 1980), hoher Alkoholkonsum (Shirpoor et al. 2013) und vieles mehr stellen Stressoren des Endothels und Risikofaktoren für die Entstehung einer Atherosklerose dar (Ridker und Libby 2012). Darüber hinaus sind auch das männliche Geschlecht und ein höheres Alter mit einem verstärken Risiko für die Entwicklung einer Atherosklerose behaftet (Kannel und McGee 1979b; Löwel et al. 2006; Tegos et al. 2001). Physiologisch hohe Blutkonzentrationen an Lipoprotein hoher Dichte-Cholesterin (engl. high density lipoprotein cholesterol [HDL-C]) wirken dagegen atheroprotektiv (Castelli et al. 1986).

Aus dem Blutstrom durch das geschädigte Endothel in die Gefäßwand diffundiertes LDL-C oxidiert in mehreren Schritten in der Intima und führt zur Produktion und Ausschüttung proinflammatorischer Entzündungsmediatoren (Goldstein et al. 1979; Wang N et al. 1996; Woenckhaus et al. 1998). Außerdem scheint es die monozytäre Oberflächenrezeptorexpression auf noch nicht endgültig geklärte Art und Weise zu beeinflussen und zu verändern (Han et al. 2000; Weber C et al. 1999). Die per Adhäsionsmoleküle an die Gefäßwand angelagerten Lympho-, Mono- und Thrombozyten transmigrieren, gesteuert von ausgeschütteten Chemokinen, darunter CC-Chemokinligand [CCL] 5 und das Mono- 
zyten-Chemoattraktionsprotein [MCP]-1, aus dem Blut in die Gefäßwand (Gerszten et al. 1999; Imhof und Aurrand-Lions 2004). Dort wandeln sich Monozyten zu gewebsständigen Makrophagen um (Jelkmann 2010).

Joseph Leonard Goldsteins lipoprotein-induced-atherosclerosis-Hypothese (Goldstein und Brown 1975, 1977), deren Elemente ebenso wie die der Theorie von Ross et al. in Abb. 1.2 dargestellt sind, basiert auf der Feststellung, dass Makrophagen durch die Aufnahme oxidierter Lipoproteine in sogenannte Schaumzellen differenzieren, die, geformt als Fettstreifen (engl. fatty streaks), bereits makroskopisch sichtbar sind (Lusis 2000).

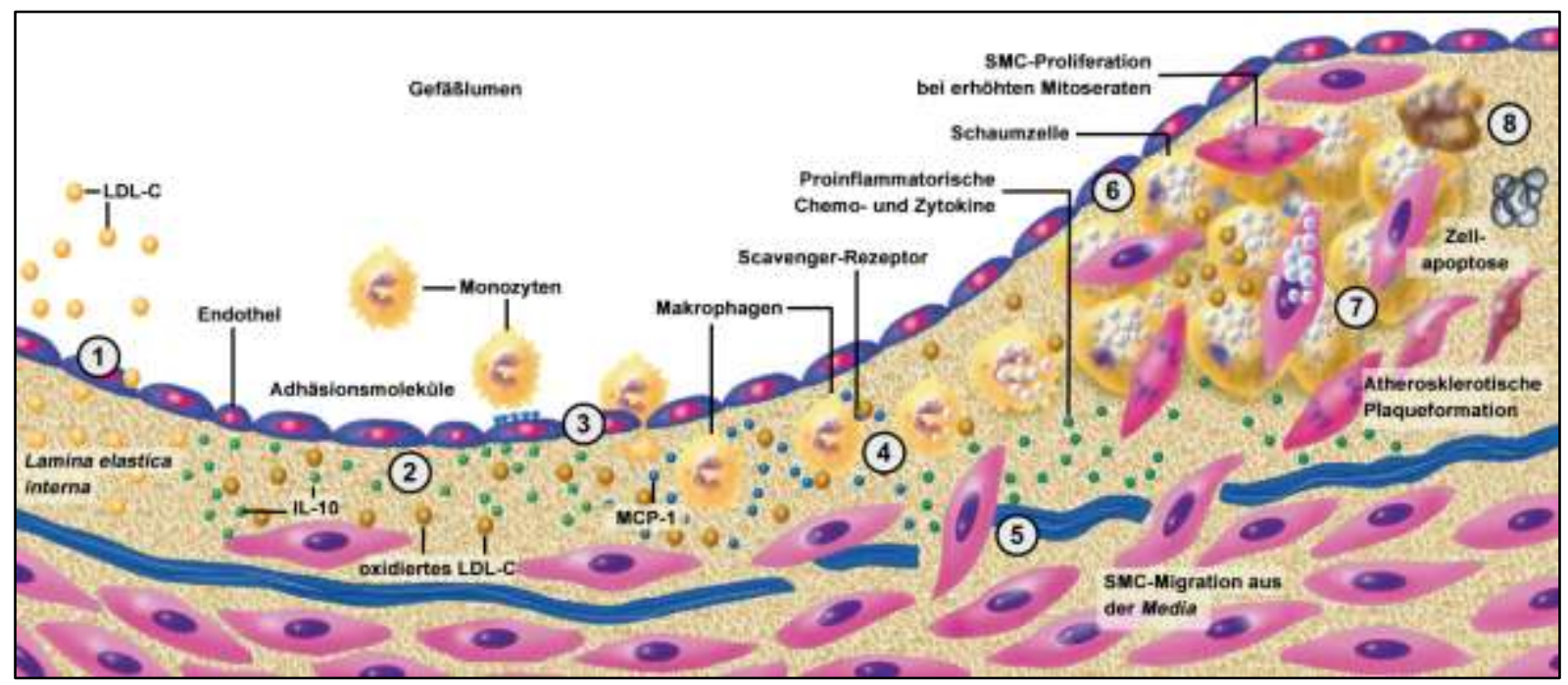

\section{Abb. 1.2 Schematische Darstellung der Entstehung einer atherosklerotischen Plaque}

(1) Transmigration, Akkumulation und Oxidation von LDL-C in der Tunica intima, (2) wodurch oxidativer Stress entsteht, der zu einer vermehrten Produktion und Ausschüttung lokaler Zyto- und Chemokine (z. B. IL-1) führt. (3) Diese bewirken eine gesteigerte Expression leukozytärer Adhäsionsmoleküle und eine vermehrte Permeabilisierung des Endothels. Über chemoattraktive Stimuli (z. B. MCP-1) binden im Blut zirkulierende Monozyten vermehrt an Adhäsionsmoleküle, passieren das Endothel und (4) wandeln sich schließlich in gewebsständige Makrophagen um. Interaktionen mit M-CSF bewirken eine vermehrte Expression von Scavengerrezeptoren an der Makrophagenoberfläche, über die die makrophagozytäre Aufnahme oxidierten LDL-Cs erfolgt. (5) Das inflammatorische Milieu führt zur Migration von SMCs aus der Tunica media in die Tunica intima, (6) die sich dort teilen, vermehren und zum Anwachsen atherosklerotischer Läsion führen. (7) Aus LDL-C-gesättigten Makrophagen entstehende Schaumzellen können in fettig-fibrotische Läsionen übergehen und werden ebenso wie akkumulierte SMCs irgendwann nekrotisch und sterben ab, wodurch es abermals zu einer massiven Zytokinausschüttung kommt, die den circulus vitiosus weiter verstärkt. (9) Die wachsende atherosklerotische Plaque bildet in späteren Stadien eine intraluminal gelegene fibröse Kappe, die den lipidreichen Kern der Läsion umschließt. Es kann zu (Teil-) Sklerosierungen und damit Stabilisierung der Läsion kommen oder aber zum häufig tödlich verlaufendem Myokardinfarkt bei Ruptur einer instabilen Plaque (modifiziert nach Libby 2012, S. 902).

Abk. IL: Interleukin; LDL-C: Lipoprotein niedriger Dichte-Cholesterin; MCP: Monozyten-Chemoattraktionsprotein; M-CSF: makrophagenkolonienstimulierender Faktor; SMC: glatte Muskelzelle 
Mit LDL-C gesättigte Schaumzellen nekrotisieren schließlich und entleeren ihren Inhalt in das umliegende Gewebe (Libby 2000). Auf diese inflammatorischen und andere chemotaktische Reize reagieren u. a. glatte Muskelzellen (engl. smooth muscle cell [SMC]), die, natürlicherweise in der Tunica media vorkommend und nun in die Tunica intima eindringend, per Gewebeumbau zusammen mit Fibrinen eine intraluminal gelegene lipidkernhaltige Kappe ausbilden (Kim und Iwao 2000; Libby 2000). Sowohl von dem Schaumzelluntergang als auch der SMC-Aktivierung werden autolog oder über externe Mechanismen chemotaktisch weitere Monozyten, Thymus [T]-Lymphozyten und SMCs rekrutiert (Fowler et al. 1985; Libby 2012; Libby et al. 1986).

Während sich v. a. aufgrund erhöhter LDL-C-Blutkonzentrationen und hämodynamisch ungünstigen Fließverhaltens des Blutes mit erhöhten Reibungskräften (Caro et al. 1969; Gimbrone MA 1999) initiale Endothelschäden und fatty streaks an der abdominalen Aorta bereits im ersten Lebensjahrzehnt entwickeln und potenziell reversibel sind (Napoli et al. 1997; Stary et al. 1995), finden sich bekappte, das Gefäßlumen zunehmend einengende lipid- und nekrosereiche bzw. teilweise auch kalzifizierende Atherome gewöhnlich erst ab der dritten Lebensdekade und stellen eine irreversible Erscheinung dar (Stary et al. 1995).

Um eine KHK (Synonyme: koronare Herzerkrankung, ischämische oder atherosklerotische Herzkrankheit/-erkrankung), die sich klinisch-morphologisch nach Stary et al. einteilen lässt (Stary et al. 1994; Stary et al. 1995), handelt es sich per definitionem, wenn die Herzkranzgefäße atherosklerotisch verändert sind (Bundesärztekammer et al. 2014). Ab einer Lumenverengung von $\geq 50 \%$ kann es zu einer bedeutsamen Sauerstoffminderversorgung des Myokards kommen, sodass von einer hämodynamisch relevanten Koronarstenose gesprochen wird (Antman et al. 2010; Bonzel et al. 2008).

Häufig verläuft die KHK viele Jahre lang asymptomatisch. Sie kann aber auch symptomatisch werden (Cannon und Braunwald 2012) und sich entweder als stabile Angina pectoris, als akutes Koronarsyndrom mit seinen drei Unterformen, der instabilen Angina pectoris, dem Nicht-ST-Hebungsinfarkt (engl. non-ST elevation myocardial infarction [NSTEMI]) und dem ST-Hebungsinfarkt (engl. ST elevation myocardial infarction [STEMI]) als weltweit häufigste Todesursachen (Badimon und Vilahur 2014; WHO 2014), ausgelöst durch einen Koronargefäßverschluss oder -spasmus aufgrund der Bildung plättchenreicher Thromben nach atherosklerotischer Plaqueruptur, oder als plötzlichen Herztod äußern (Dalager-Pedersen et al. 1998; Davies 2000; Etsuda et al. 1993; Falk 1991; Falk et al. 1995; Lusis 2000). 


\title{
1.3 Monozyten - Klassifikation und Bedeutung für die Atherosklerose
}

Monozyten, wie beispielhaft in Abb. 1.3 abgebildet, stellen mit einem Durchmesser bis $20 \mu \mathrm{m}$ die morphologisch größte Untergruppe humaner Leukozyten dar und machen physiologisch etwa 2-10 \% der Gesamtleukozytenpopulation im Blut aus (Gordon und Taylor 2005; Jelkmann 2010). Die sich aus granulopoetisch determinierten Stammzellen entwickelnden Monozyten zirkulieren für ein bis drei Tage im Gefäßsystem, nachdem sie das Knochenmark, in dem sie gebildet werden, verlassen haben (Jelkmann 2010; Pries und Zakrzewicz 2008). Neueste humane in vitro-Studien sowie Mausversuche könnten darauf hin deuten, dass etwa die Hälfte der Monozyten in der roten Milzpulpa (zwischen-) gespeichert werden, bevor sie zur Antigenbekämpfung in perivaskuläre Gewebe einwandern und dort zu Makrophagen oder dendritischen Zellen ausdifferenzieren, die wiederum für mehrere Wochen im Gewebe verbleiben können (Swirski et al. 2009; van der Laan et al. 2014).

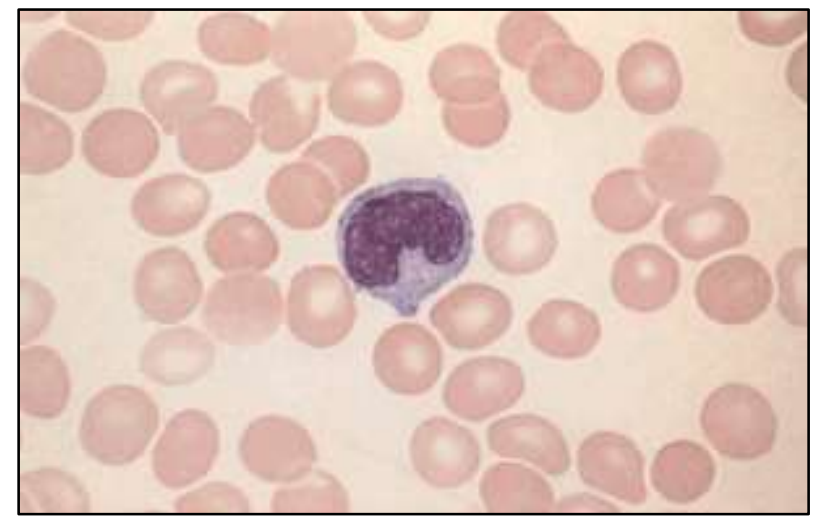

\begin{abstract}
Abb. 1.3 Monozyt im Blutausstrich
Panoptische Färbung nach Pappenheim.

Zwischen mehreren Erythrozyten ist ein singulärer Monozyt mit typischem graublauen, unscharf begrenzten Zytoplasma zu erkennen. Die bis $20 \mu \mathrm{m}$ im Durchmesser großen Zellen weisen eine zarte Azurgranulation auf und sind häufig ebenso polymorph wie ihr Zellkern, der chromatinarm erscheint und für gewöhnlich keine Kernkörperchen enthält (modifiziert nach Löffler H et al. 2004, S. 55).
\end{abstract}

Monozyten sind Immuneffektorzellen des angeborenen mononukleären Phagozytensystems (Gasteiger und Rudensky 2014; Murphy et al. 2012). Ausgestattet mit zahlreichen chemokin- und antigenbindenden Rezeptoren können sie das vaskuläre System über endotheliale Zelladhäsionsmoleküle verlassen und - getriggert von immunologischen, metabolischen oder chemo- bzw. zytokinen Transmittern und Stimuli, u. a. CCL5 und Osteopontin [OPN] - zu Orten inflammatorischer Prozesse wandern (Imhof und Aurrand-Lions 2004). Neben ihrer Differenzierungsmöglichkeit in Makrophagen und dendritische Zellen besitzen sie die Fähigkeit zur Phagozytose, Zytokinproduktion und Antigenpräsentation, weshalb sie auch als Teil des spezifischen Immunsystems gezählt werden (Gasteiger und Rudensky 2014; Gulbins und Lang 2010; Hansson et al. 2002; Murphy et al. 2012). 


\subsubsection{Monozytenklassifikation}

Basierend auf dem an der Zelloberfläche exprimierten, nach cluster of differentiation [CD] definierten, Lipopolysaccharidrezeptor CD14, der auf Monozyten stets zu detektieren ist, sowie CD16, dem Immunglobulin $\mathrm{G}[\mathrm{IgG}]$ bindenden kristallisierbaren Fragment gamma-Rezeptor (engl. fragment crystallisable-gamma receptor $[\mathrm{Fc \gamma R}]) \mathrm{III}$, werden humane Monozyten seit 2010 in drei international anerkannte Subgruppen unterteilt: klassische $\mathrm{CD} 14^{++} \mathrm{CD} 16^{-}$, nicht-klassische $\mathrm{CD} 14^{+} \mathrm{CD} 16^{++}$- und intermediäre Monozyten mit dem Expressionsmuster $\mathrm{CD} 14^{++} \mathrm{CD} 16^{+}$(Ziegler-Heitbrock et al. 2010).

Diese drei Subgruppen unterscheiden sich nicht nur hinsichtlich ihrer CD14- und CD16-Expression und der prozentualen Verteilung im Blut, sondern auch in ihren funktionellen und migratorischen Eigenschaften (Auffray et al. 2009; Czepluch et al. 2011; Gordon und Taylor 2005).

Die klassischen $\mathrm{CD}_{14}{ }^{++} \mathrm{CD} 16^{-}$-Monozyten stellen die größte Untergruppe aller Monozyten dar. Ihr prozentuales Vorkommen ist in der Literatur nicht völlig einheitlich und meist im Bereich von 70-90 \% der Monozytengesamtpopulation angegeben (Ghattas et al. 2013; Hilgendorf und Swirski 2012; Passlick et al. 1989; Wong KL et al. 2011). Sie exprimieren den CC-Chemokinrezeptor [CCR] 2 , CD64 (FcyRI mit hoher Affinität zur IgG-Bindung und großer Ähnlichkeit zu FcүRIII), CD115 (Rezeptor für makrophagenkolonienstimulierender Faktor, engl. makrophage colony-stimulating factor [M-CSF]) und Lymphozyten-Selektin (engl. lymphocytes-selectin [L-selectin]; Synonym: CD62L), ein Leukozyten-/Lymphozytenadhäsionsmolekül (Wong KL et al. 2011). Allerdings wird der CX3CChemokinrezeptor [CX3CR] 1, der Fraktalkin - einen Leukozytenadhäsion und -diapedese initiierenden Botenstoff, der dadurch direkt in die Monozytenextravasation involviert ist (Bazan et al. 1997; Imai et al. 1997) - bindet, nicht an ihrer Oberfläche exprimiert, sodass die CD14 ${ }^{++} \mathrm{CD} 16^{-}$-Monozyten zur Migration CCR2 nutzen, den Rezeptor von CCL2 mit Synonym MCP-1 (Swirski et al. 2007). Ihre Bedeutung scheint in antiinflammatorischen und proangiogenetischen Prozessen zu liegen.

Die nicht-klassischen Monozyten bilden zusammen mit den intermediären etwa 10-20 \% der Monozytengesamtpopulation im humanen Blut und sind charakterisiert über ihre oberflächliche CD16Expression (Ziegler-Heitbrock et al. 2010). CD16 ${ }^{+}$-Monozyten sind eine wichtige Quelle des multifunktionalen lokalen sowie systemischen Entzündungsmediators Tumornekrosefaktor alpha [TNF- $\alpha$ ] (Belge et al. 2002) und bei inflammatorischen Prozessen konnten angestiegene CD16 ${ }^{+}$Monozytenzahlen im Blut detektiert werden (Gordon und Taylor 2005; Nahrendorf et al. 2007; Santos-Gallego et al. 2014; Wong KL et al. 2012), sodass von proinflammatorischen Eigenschaften dieser Monozytenphänotypen ausgegangen wird.

CD14 ${ }^{+} \mathrm{CD} 16^{++}$-Monozyten exprimieren weder CCR2 noch CD62L, dafür aber CX3CR1 (Ancuta et al. 2006; Ancuta et al. 2003). Dieser ist für die nicht-klassischen Monozyten, die eine wichtige Rolle bei 
reparativen Prozessen und in der späten Entzündungssituation bei KHK spielen, wichtig für die Migration (Gordon und Taylor 2005; Santos-Gallego et al. 2014).

Die intermediäre $\mathrm{CD} 14^{++} \mathrm{CD} 16^{+}$-Monozytenpopulation exprimiert stark CCR2, CD115 und CX3CR1, allerdings kein CD62L (Ghattas et al. 2013). Ihre Rolle in der Pathogenese der Atherosklerose ist bislang noch nicht hinreichend erforscht. Vermutet wird ein proinflammatorischer Einfluss ähnlich den CD14 ${ }^{+}$CD16 ${ }^{++}$-Monozyten (Gordon und Taylor 2005; Santos-Gallego et al. 2014).

Die aktuelle Datenlage zu Vorkommen und Eigenschaften der verschiedenen Monozytensubgruppen ist allerdings - trotz zahlreicher Studien - weiterhin nicht eindeutig. In diesem Kontext gewonnene Informationen über murine Monozyten sowie deren Untergruppen und spezifische Eigenschaften lassen sich nicht direkt auf den Menschen und dessen Monozytenklassen übertragen bzw. zeigen zu diesen z. T. gänzlich konträre Verhaltensweisen (Auffray et al. 2007; Geissmann et al. 2003; Ingersoll et al. 2010; Nahrendorf et al. 2007; Sunderkotter et al. 2004), sodass weitere Untersuchungen nötig sind, um humane Monozyten näher charakterisieren und sie anhand ihrer Eigenschaften und Bedeutung für die Atherosklerose therapeutisch nutzbar machen zu können.

\subsection{Thrombozyten und die Bedeutung von Monozyten- Thrombozyten-Aggregaten}

Die zellkernlosen Thrombozyten, mit einem Durchmesser von ca. 2-3 $\mu \mathrm{m}$ (Paulus 1975) die kleinsten Zellen des humanen Blutes (White 2007), spielen aufgrund von Adhäsion und Aggregation nicht nur eine lebenswichtige Rolle bei der Blutgerinnung (Bouchard et al. 2007). Wegen ihrer Bindungseigenschaften können sie auch potenziell lebensbedrohlich in Erscheinung treten (Goldschmidt et al. 2007). So sind sie entscheidend in die Genese von Embolien und Thrombosen involviert (Sobel 2007) und spielen - u. a. durch Interaktion mit Monozyten - in jeder Phase der Entstehung und Progredienz atherosklerotischer Läsionen eine Rolle (Badimon und Vilahur 2014; Huo et al. 2003). Aktivierte und adhärierte Thrombozyten schütten vermehrt das Chemokin CCL5 aus, wodurch Monozyten gehäuft am atherosklerotisch geschädigten Endothel gebunden werden (von Hundelshausen et al. 2001) und es zu einer verstärkten Monozytenrekrutierung in geschädigte Gefäßregionen kommt (Kuckleburg et al. 2011). Williams et al. zeigten, dass Thrombozyten (und SMCs) Monozyten zur Differenzierung stimulieren und bspw. Einfluss auf die monozytäre Oberflächenmarkerexpression nehmen (Williams et al. 2014).

Die Bindung aktivierter Thrombozyten an Monozyten führt zur Bildung von MonozytenThrombozyten-Aggregaten (engl. monocyte-platelet aggregate [MPA]), die im peripheren Blut nachgewiesen werden können (van Gils et al. 2009). Eine Detektion dieser Aggregate hat sich als früher 
und sensibler Marker der Plättchenaktivierung in vivo herausgestellt (Michelson et al. 2001). MPAs führen nicht nur zu einer monozytären Funktionsänderung (Kuckleburg et al. 2011) und der Induktion inflammatorischer Monozytenphänotypen (Stephen et al. 2013), sondern modulieren und modifizieren auch direkt vaskuläre Entzündungsreaktionen, Atherosklerose und Thrombose (Huo et al. 2003; Nording et al. 2015). Bislang konnte allerdings noch nicht gezeigt werden, ob Thrombozyten mit allen drei Monozytenuntergruppen gleich oder primär mit einer der monozytären Subgruppen interagieren.

\subsection{CCL5 und sein Rezeptor CCR5}

Der von Samson et al. 1996 erstmalig beschriebene Chemokinrezeptor CCR5 (Samson et al. 1996) ist auf den Oberflächen vieler Leukozyten, darunter auch Monozyten und Makrophagen, verbreitet (Le et al. 2004). Sein Ligand, CCL5, wird v. a. von aktivierten Thrombozyten ausgeschüttet und trägt daher auch im englischen Sprachraum die Bezeichnung regulated on activation, normal T cell expressed and secreted [RANTES] (Karshovska et al. 2013). CCL5 interagiert nicht spezifisch mit CCR5, sondern bindet bspw. auch an CCR1 und CCR3 (Soria und Ben-Baruch 2008). Aufgrund ligandengesteuerter Rezeptoraktivierung ist CCR5 in unterschiedlichste Entzündungsgeschehen des menschlichen Körpers involviert, sodass inm als Co-Rezeptor nicht nur bei der Genese der Atherosklerose (Combadiere et al. 2008; Veillard et al. 2004b; von Hundelshausen und Schmitt 2014), sondern auch bei der Übertragung des humanen Immundefizienzvirus [HIV] (He et al. 1997) und weiterer Infektionskrankheiten (Karshovska et al. 2013), bei der Entstehung maligner Tumoren (Karnoub et al. 2007; Sales et al. 2014) und diverser Autoimmunerkrankungen wie bspw. Typ-1-Diabetes mellitus (Solomon et al. 2010) eine entscheidende Rolle zuzukommen scheint.

Obwohl bereits einige Tierversuche die große Bedeutung von CCR5 und dessen Liganden CCL5 für die Atheroskleroseentstehung und -entwicklung gezeigt haben (Mack et al. 2001; Veillard et al. 2004a) und auch humane Studiendaten ähnliches suggerieren (Braunersreuther et al. 2007; Simeoni et al. 2004), ist die Expression von CCR5 auf den unterschiedlichen humanen Monozytensubgruppen bislang noch ebenso wenig hinreichend erforscht, wie die Bedeutung des proinflammatorischen Zytokins CCL5 für die einzelnen monozytären Untergruppen.

\subsection{Osteopontin}

OPN ist ein asparaginsäurereiches Protein mit vielen verschiedenen physio- und pathophysiologischen Funktionen, welches u. a. an den Hyaluronsäurerezeptor CD44, ein Adhäsionsmolekül, das z. B. auf Monozyten exprimiert wird, bindet (Weber GF et al. 1996). OPN kommt, neben dessen Haupt- 
aufgabe, der Biomineralisation, als Chemokin eine besondere Rolle für Aktivierung, Adhäsion, Migration, Gewebeumbau und Zellüberleben vieler an Entzündungsprozessen beteiligten Zellen zu, darunter im Besonderen Monozyten, Makrophagen, SMCs und Endothelzellen (Liaw et al. 1994; Liaw et al. 1995; Weintraub et al. 1996).

Erstmalig wurde OPN 1985 in Rinderknochenmatrix isoliert und verlieh dem Protein seinen Namen (Franzen und Heinegard 1985). Die von Calcitriol, der physiologisch aktiven Form von Vitamin $D_{3}$ (Lang und Murer 2010), stimulierte OPN-Synthese übernehmen viele verschiedene Zelltypen, in atherosklerotischen Läsionen vor allem SMCs, angiogenetische Endothelzellen und Makrophagen (Giachelli et al. 1995; Giachelli et al. 1993). Obwohl OPN ein sehr starker Migrationsstimulus für zirkulierende Monozyten ist, wird es von diesen selbst nicht produziert (Scatena et al. 2007). Makrophagen hingegen, auf welche es ebenfalls starke chemotaktische Wirkungen erzielt und deren Aktivierung und Infiltration in entzündetes Gewebe es reguliert, exprimieren sehr viel OPN (Crawford et al. 1998; Giachelli et al. 1995; Murry et al. 1994; Wang X et al. 1996).

OPN hat - ähnlich CCL5 - eine herausragende Bedeutung für diverse chronisch-entzündliche Prozesse, wie bspw. Tumorleiden (Fedarko et al. 2001), Autoimmunerkrankungen (Comabella et al. 2005; Wong CK et al. 2005) und Übergewicht (Gomez-Ambrosi et al. 2007). Unabhängig der traditionellen kardiovaskulären Risikofaktoren (siehe Kapitel 1.2) finden sich erhöhte OPN-Plasmaspiegel bei Patienten mit KHK, wobei vermutet wird, dass die OPN-Spiegel mit dem Ausmaß atherosklerotischer Veränderungen korrelieren und sie Anteil am Fortschreiten kardiovaskulärer Erkrankungen und atherosklerotischer Plaquebildung haben (Ohmori et al. 2003; Scatena et al. 2007). Darüber hinaus sind auch im Rahmen akuter Myokardinfarkte (Coskun et al. 2006), Aneurysmata der abdominellen Aorta (Golledge et al. 2007) oder koronarer Re-Stenosen nach perkutaner Koronararterienintervention (Kato et al. 2006) erhöhte OPN-Spiegel beschrieben.

Bislang ist allerdings noch nicht hinreichend erforscht, in welchem Maße der OPN-Rezeptor CD44 auf den einzelnen Monozytenuntergruppen bei Patienten mit KHK vorliegt und ob dessen Expression Unterschiede zwischen den einzelnen Monozytenklassen zeigt.

\subsection{Krüppel-like Faktor 4}

Der desoxyribonukleinsäurebindende Zinkfinger-Transkriptionsfaktor Krüppel-like Faktor [KLF] 4 erstmals 1996 u. a. in Darm- und Hautepithelzellen beschrieben (Garrett-Sinha et al. 1996; Shields et al. 1996) - spielt bei der Regulation verschiedenster zellulärer Funktionen eine Rolle. So ist der Faktor 4 der bislang 18 Faktoren umfassenden Krüppel-like-Familie (Pei und Grishin 2013) u. a. in monozytäre Differenzierungs-, Proliferations- und Aktivierungsprozesse eingebunden (Cao et al. 
2010; Feinberg et al. 2007). Hauptsächlich liegt KLF4 intranukleär vor, es sind aber auch zytoplasmatische Lokalisationen (u. a. in SMCs) als Reaktion auf zytokine Stimulationen beschrieben (Behr et al. 2007; Garvey et al. 2010; Liu et al. 2013).

KLF4 vermittelt in humanen Makrophagen eine zelluläre Antwort auf proinflammatorische Signale (Autieri 2008; Feinberg et al. 2005), wobei die KLF4-Expression u. a. von Interferon gamma [IFN- $\psi$ ], Lipopolysaccharid [LPS] und TNF- $\alpha$ induziert wird (Chen et al. 2000; Chen et al. 2002; Feinberg et al. 2005). KLF4 ist sowohl in Phasen akuter als auch chronischer Gefäßschädigung heraufreguliert (Cao et al. 2010). Auch in Endothelzellen führen proinflammatorische Zytokine sowie Scherkräfte zu einer Zunahme von KLF4 (Hamik et al. 2007). In vitro-Experimente an humanen Zellen zeigen, dass KLF4 u. a. die Genexpression und Proliferation von vaskulären SMCs inhibiert und über die Aktivierung der zytokininduzierten Stickstoffmonoxidsynthase (engl. cytokine-inducible nitric oxide synthase [iNOS]) bewirkt der Transkriptionsfaktor eine verstärkte vaskuläre Antwort auf Stickstoffmonoxid (engl. nitric oxide [NO]) und damit eine Relaxation der SMCs (Feinberg et al. 2005). Da KLF4 an den Promotor des monozytären Oberflächenrezeptors CD14 binden kann, hat es direkten Einfluss auf dessen Expression und die Monozytendifferenzierung (Feinberg et al. 2007). Darüber hinaus werden auch die zytokininduzierte Adhäsionsmolekülexpression und die Synthese entzündungsfördernder Mediatoren von KLF4 gehemmt (Hamik et al. 2007).

Dass KLF4 ex vivo und in vivo bei Mäusen inflammatorische Prozesse mindert und Thrombosen vorbeugt, konnte wissenschaftlich bereits belegt werden (Zhou et al. 2012). In wieweit KLF4 auf den unterschiedlichen humanen Monozytensubgruppen exprimiert wird, ist bisher noch nicht erforscht, stellt aber im Kontext mit den unterschiedlichen Eigenschaften der Monozyten in Bezug auf Inflammation und Atheroskleroseentwicklung einen wichtigen pathogenetischen Punkt im Verständnis der Atherosklerose dar.

\subsection{Studienziele}

Obwohl bereits einige Studien zu den drei verschiedenen humanen Monozytenuntergruppen publiziert wurden, sind bis heute deren genaue Bedeutungen und Funktionen in Bezug auf die Entstehung und das Fortschreiten atherosklerotischer Läsionen und der Volkskrankheit Arteriosklerose noch nicht in Gänze erforscht. Ziel der im Rahmen dieser Arbeit durchgeführten und präsentierten Studien ist es, die Verteilung der unterschiedlichen Monozytensubgruppen und deren Interaktion mit Thrombozyten als MPAs zu eruieren und zu vergleichen zwischen Patienten mit stabiler KHK und gesunden Probanden. Darüber hinaus liegt ein besonderes Augenmerk auf der monozytären Rezeptorexpression für pro- und antiinflammatorische Zytokine und Liganden. Daher wird die subgruppen- 
spezifische Verteilung des CCL5-Rezeptors CCR5 und des Rezeptors für OPN, CD44, auf den jeweiligen Monozytenklassen evaluiert. Auch die KLF4-Expression in den einzelnen Monozytenuntergruppen ist von großem wissenschaftlichen Interesse und ggf. von klinischer Relevanz und wird daher im Rahmen dieser Studien ebenfalls untersucht. Neben der Detektion und dem Vergleich der drei Monozytensubgruppen und der genannten Rezeptoren werden im Serum und Plasma der Probanden des Weiteren mehrere proinflammatorische, monozyten-, makrophagen- und thrombozytenaktivierende Marker bestimmt, um die Aussagekraft der erzielten Ergebnisse erweitern, besser einordnen und deren klinisch-wissenschaftliche Bedeutung untermauern zu können.

Diese Untersuchungen dienen dazu, die Kenntnisse über die spezifischen Charakteristika der einzelnen Monozytenuntergruppen und deren Relevanz für pro- und antiinflammatorische Prozesse bei atherosklerotischen Gefäßschäden und Thrombusbildung zu vergrößern. 


\section{Material und Methoden}

\subsection{Verwendete Materialien und Geräte}

\subsubsection{Reagenzien}

\begin{tabular}{|c|c|c|}
\hline Artikel & Nummer & Firma \\
\hline $\begin{array}{l}\text { 2,2'-Azino-bis(3-Ethylbenzothiazoline-6- } \\
\text { Sulfonsäure) }\end{array}$ & A3219 & Sigma-Aldrich, Corp., St. Louis, MO, USA \\
\hline Antikörper Durchflusszytometrie & & siehe Kapitel 2.1.5.1 FACS ${ }^{\text {TM}}$-Antikörper \\
\hline BD FACS ${ }^{\mathrm{TM}}$ Lysing Solution, 10X & 349202 & BD Biosciences, Corp., San Jose, CA, USA \\
\hline Bromphenolblau & B0126 & Sigma-Aldrich, Corp., St. Louis, MO, USA \\
\hline BSA & A7906 & Sigma-Aldrich, Corp., St. Louis, MO, USA \\
\hline ELISA-Versuche & & siehe Kapitel 2.1.6.1 Eingesetzte ELISA-Kits \\
\hline Ethanol, $99 \%$ & $603-002-00-5$ & $\begin{array}{l}\text { CVH Chemie-Vertrieb GmbH \& Co. KG, } \\
\text { Hannover, DE }\end{array}$ \\
\hline Flow Cytometry Permeabilization/Buffer I, 1X & FC005 & R\&D Systems, Inc., Minneapolis, MN, USA \\
\hline Histopaque ${ }^{\circledR}-1077$ & 10771 & Sigma-Aldrich, Corp., St. Louis, MO, USA \\
\hline Isotypenkontrollen Durchflusszytometrie & & $\begin{array}{l}\text { siehe Kapitel 2.1.5.2 } \text { FACS }^{\mathrm{TM}} \text {-Isotypenkon- } \\
\text { trollen }\end{array}$ \\
\hline Opti-MEM $^{\circledR} \mathrm{I}, 1 \mathrm{X}$ & $31985-047$ & $\begin{array}{l}\text { GIBCO }^{\circledR} \text { by Life Technologies } \\
\text { TM } \\
\text { Carlsbad, CA, USA }\end{array}$ \\
\hline PBS, pH 7,4, 10X & 70011 & $\begin{array}{l}\text { GIBCO }^{\circledR} \text { by Life Technologies } \\
\text { Carls }, \text { Corp., } \\
\text { Carlsbad, CA, USA }\end{array}$ \\
\hline PFA & F1268 & Sigma-Aldrich, Corp., St. Louis, MO, USA \\
\hline
\end{tabular}

Abk. BSA: Rinderserumalbumin; ELISA: enzymgekoppelter Immunadsorptionstest; FACS ${ }^{\text {TM }}$ : fluoreszenzaktivierte Zellsortierung; MEM: Eagles Minimales Essentielles Medium; PBS: phosphatgepufferte Salzlösung; PFA: Paraformaldehyd; pH: negativer dekadischer Logarithmus der Wasserstoffionenaktivität; X: -fach

\subsubsection{Elektrische Geräte und Software}

\begin{tabular}{|c|c|}
\hline Artikel & Firma \\
\hline$\mu Q$ uant $^{\mathrm{TM}}$ Mikroplattenspektrophotometer & BioTek $^{\circledR}$ Instruments, Inc., Winooski, VT, USA \\
\hline BD FACSCanto ${ }^{\mathrm{TM}}$ II & BD Biosciences, Corp., San Jose, CA, USA \\
\hline BD FACSCanto $^{\mathrm{TM}}$ II Software, Version 2.2 & BD Biosciences, Corp., San Jose, CA, USA \\
\hline BD FACSDiva $^{\mathrm{TM}}$ Software, Version 6.1.3 & BD Biosciences, Corp., San Jose, CA, USA \\
\hline EndNote $\mathrm{X7}$ & Thomson Reuters, Corp., New York City, NY, USA \\
\hline GraphPad Prism 5 für Windows, Version 5.01 & GraphPad Software, Inc., La Jolla, CA, USA \\
\hline GraphPad Prism 6 für Mac OS X, Version 6.0f & GraphPad Software, Inc., La Jolla, CA, USA \\
\hline
\end{tabular}




\begin{tabular}{|c|c|}
\hline IBM $^{\circledR}$ SPSS $^{\circledast}$ Statistics, Versionen 20.0 und 22.0 & International Business Machines Corp., Armonk, NY, USA \\
\hline $\mathrm{KC}^{\mathrm{TM}}{ }^{\mathrm{M}}$, Version 3.4 Rev. 21 & BioTek ${ }^{\circledR}$ Instruments, Inc., Winooski, VT, USA \\
\hline Microsoft ${ }^{\circledR}$ Office für Mac 2011, Version 14.4.8 & Microsoft Corp., Redmond, WA, USA \\
\hline $\begin{array}{l}\text { Microsoft }^{\circledR} \text { Office Professional Plus 2010, Version } \\
\text { 14.0.7015.1000 }\end{array}$ & Microsoft Corp., Redmond, WA, USA \\
\hline Mikroskop (Olympus BX51) & Olympus Corp., Tokio, JP \\
\hline Plattformschüttler (Titramax 1000) & Heidolph Instruments GmbH \& Co. KG, Schwabach, DE \\
\hline Temperatur-Magnetrührer (RCT basic) & IKA ${ }^{\circledR}$-Werke GmbH \& Co. KG, Staufen, DE \\
\hline Vakuum-Absaugpumpe (CUV-O-MAT 300B) & Hellma GmbH \& Co. KG, Müllheim, DE \\
\hline Vortexmixer (Vortex-Genie 2) & Scientific Industries, Inc., Bohemia, NY, USA \\
\hline Waage (Extend) & Sartorius AG, Göttingen, DE \\
\hline Wasserbad (D8) & Gebr. Haake GmbH, Karlsruhe, DE \\
\hline Wippschüttler (SSL4) & Stuart ${ }^{\circledR}$ by Bibby Scientific, Ltd., Staffordshire, GB \\
\hline Zentrifuge (5415 D) & Eppendorf AG, Hamburg, DE \\
\hline Zentrifuge (5702 R) & Eppendorf AG, Hamburg, DE \\
\hline Zentrifuge (5810 R) & Eppendorf AG, Hamburg, DE \\
\hline Zentrifuge (Rotanta/S) & Andreas Hettich GmbH \& Co. KG, Tuttlingen, DE \\
\hline
\end{tabular}

\subsubsection{Materialien zur Blutentnahme und Probengewinnung}

\begin{tabular}{|c|c|c|}
\hline Artikel & Nummer & Firma \\
\hline $\begin{array}{l}\text { Quadruple Pack OptiPure RC, Top \& Bottom } \\
\text { Blutbeutelsystem mit integriertem Erythrozy- } \\
\text { tenfilter RC Soft. PL146/PL1240 }\end{array}$ & NGR6428B & Fenwal, Inc., Lake Zurich, IL, USA \\
\hline Safety-Multifly ${ }^{\circledR}$-Set, 21 G x 3/4" & 85.1638 .235 & Sarstedt AG \& Co. KG, Nümbrecht, DE \\
\hline S-Monovette $^{\circledR}$ Gerinnung, 3,0 ml, Citrat 1:10 & 05.1165 & Sarstedt AG \& Co. KG, Nümbrecht, DE \\
\hline S-Monovette ${ }^{\circledR}$ Hämatologie, 2,7 ml, EDTA $\mathrm{K}_{3}$ & 05.1167 & Sarstedt AG \& Co. KG, Nümbrecht, DE \\
\hline S-Monovette ${ }^{\circledR}$ Plasma, 9 ml, Lithium-Heparin & 02.1065 & Sarstedt AG \& Co. KG, Nümbrecht, DE \\
\hline $\begin{array}{l}\text { S-Monovette }{ }^{\circledR} \text { Serum, 7,5 ml, Gerinnungsakti- } \\
\text { vator }\end{array}$ & 01.1601 & Sarstedt AG \& Co. KG, Nümbrecht, DE \\
\hline
\end{tabular}

Abk. G: Gauge; EDTA: Ethylendiamintetraessigsäure 


\subsubsection{Verbrauchsmaterialien}

\begin{tabular}{|c|c|c|}
\hline Artikel & Nummer & Firma \\
\hline $\begin{array}{l}\text { BD Falcon }{ }^{\mathrm{TM}} \text {-Röhrchen (Synonym: } \text { FACS }^{\mathrm{TM}} \text { - } \\
\text { Röhrchen), PS, mit Deckel, } 5 \mathrm{ml}\end{array}$ & 352058 & BD Biosciences, Corp., San Jose, CA, USA \\
\hline $\begin{array}{l}\text { BD Falcon }{ }^{\mathrm{TM}} \text {-Röhrchen (Synonym: } \text { FACS }^{\mathrm{TM}}{ }_{-} \\
\text {Röhrchen), PS, ohne Deckel, } 5 \mathrm{ml}\end{array}$ & 352052 & BD Biosciences, Corp., San Jose, CA, USA \\
\hline Deckgläser, 24 x 24 mm & BB024024A1 & Gerhard Menzel GmbH, Braunschweig, DE \\
\hline Leucosep ${ }^{\mathrm{TM}}$-Röhrchen, $12 \mathrm{ml}$ & 163290 & Greiner Bio-One GmbH, Frickenhausen, DE \\
\hline Mikro-Schraubröhre, PP, $2 \mathrm{ml}$ & 72.694 .006 & Sarstedt AG \& Co. KG, Nümbrecht, DE \\
\hline Neubauer Zählkammer & 1300000 & LO - Laboroptik Ltd., Lancing, GB \\
\hline Nunc MaxiSorb ${ }^{\circledR}$ Mikrotiterplatte, Flachboden & $44-2404-21$ & eBioscience, Inc., San Diego, CA, USA \\
\hline Probenröhrchen, PP, 2,0 ml & 710011 & $\begin{array}{l}\text { Biozym Scientific GmbH, } \\
\text { Hessisch Oldendorf, DE }\end{array}$ \\
\hline Reagenz- und Zentrifugenröhren, PP, $15 \mathrm{ml}$ & 62.554 .002 & Sarstedt AG \& Co. KG, Nümbrecht, DE \\
\hline Reagenz- und Zentrifugenröhren, PP, $50 \mathrm{ml}$ & 62.547 .004 & Sarstedt AG \& Co. KG, Nümbrecht, DE \\
\hline Röhrchen, PP, 14 ml & 187261 & Greiner Bio-One GmbH, Frickenhausen, DE \\
\hline Safe-Lock Eppendorf Tubes ${ }^{\circledR}, 1,5 \mathrm{ml}$ & 0030120.086 & Eppendorf AG, Hamburg, DE \\
\hline Safe-Lock Eppendorf Tubes ${ }^{\circledR}, 2,0 \mathrm{ml}$ & 0030120.094 & Eppendorf AG, Hamburg, DE \\
\hline Schraubverschlüsse, orange & 710035 & $\begin{array}{l}\text { Biozym Scientific GmbH, } \\
\text { Hessisch Oldendorf, DE }\end{array}$ \\
\hline Schraubverschlüsse, rot & 710031 & $\begin{array}{l}\text { Biozym Scientific GmbH, } \\
\text { Hessisch Oldendorf, DE }\end{array}$ \\
\hline
\end{tabular}

Abk. FACS ${ }^{\mathrm{TM}}$ : fluoreszenzaktivierte Zellsortierung; PP: Polypropylen; PS: Polystyrol

\subsubsection{Materialien für die durchflusszytometrischen Analysen}

\subsubsection{FACS $^{\mathrm{TM}}$-Antikörper}

\begin{tabular}{lllll}
\hline Antikörper & Konjugat & Epitop & Nummer & Firma \\
\hline CD14 & FITC & CD14-Antigen & 345784 & $\begin{array}{l}\text { BD Biosciences, Corp., } \\
\text { San Jose, CA, USA }\end{array}$ \\
\hline CD16 & PE & IgG bindende FcyRIII & 555407 & $\begin{array}{l}\text { BD Biosciences, Corp., } \\
\text { San Jose, CA, USA }\end{array}$ \\
\hline CD42b & APC & Glykoprotein 1b- $\alpha$ & 551061 & $\begin{array}{l}\text { BD Biosciences, Corp., } \\
\text { San Jose, CA, USA }\end{array}$ \\
\hline CD44 & PerCP-CY ${ }^{\mathrm{TM} 5.5}$ & Phagozytotisches Glykoprotein 1 & 560531 & $\begin{array}{l}\text { BD Biosciences, Corp., } \\
\text { San Jose, CA, USA }\end{array}$ \\
\hline CD195 & APC & CCR5 & 556903 & $\begin{array}{l}\text { BD Biosciences, Corp., } \\
\text { San Jose, CA, USA }\end{array}$ \\
\hline KLF4 & APC & KLF4 & IC3640A & $\begin{array}{l}\text { R\&D Systems, Inc., } \\
\text { Minneapolis, MN, USA }\end{array}$ \\
\hline
\end{tabular}

Abk. APC: Allophycocyanin; CCR: CC-Chemokinrezeptor; CD: cluster of differentiation; FcyR: kristallisierbares Fragment gamma-Rezeptor; FITC: Fluoresceinisothiocyanat; IgG: Immunglobulin G; KLF: Krüppel-like Faktor; PE:

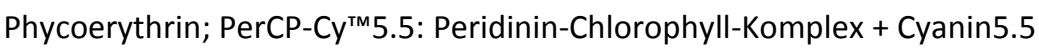




\subsubsection{FACS $^{\mathrm{TM}}$-Isotypenkontrollen}

\begin{tabular}{|c|c|c|c|c|}
\hline $\begin{array}{l}\text { Isotypen- } \\
\text { kontrolle }\end{array}$ & Konjugat & Epitop & Nummer & Firma \\
\hline $\lg G 2 b$ & FITC & --- & 555742 & $\begin{array}{l}\text { BD Biosciences, Corp., } \\
\text { San Jose, CA, USA }\end{array}$ \\
\hline $\operatorname{lgG1}$ & PE & --- & 555749 & $\begin{array}{l}\text { BD Biosciences, Corp., } \\
\text { San Jose, CA, USA }\end{array}$ \\
\hline $\operatorname{lgG1}$ & APC & --- & 555751 & $\begin{array}{l}\text { BD Biosciences, Corp., } \\
\text { San Jose, CA, USA }\end{array}$ \\
\hline $\lg G 2 b$ & PerCP-Cy ${ }^{\text {TM }} 5.5$ & --- & 558304 & $\begin{array}{l}\text { BD Biosciences, Corp., } \\
\text { San Jose, CA, USA }\end{array}$ \\
\hline $\lg G 2 a$ & APC & --- & 555576 & $\begin{array}{l}\text { BD Biosciences, Corp., } \\
\text { San Jose, CA, USA }\end{array}$ \\
\hline IgG & APC & --- & IC108A & $\begin{array}{l}\text { R\&D Systems, Inc., } \\
\text { Minneapolis, MN, USA }\end{array}$ \\
\hline
\end{tabular}

Abk. APC: Allophycocyanin; FITC: Fluoresceinisothiocyanat; IgG: Immunglobulin G; PE: Phycoerythrin; PerCP$\mathrm{Cy}^{\mathrm{TM}}$ 5.5: Peridinin-Chlorophyll-Komplex + Cyanin5.5

\subsubsection{FACS ${ }^{\mathrm{TM}}$-Puffer und Lösungen}

\begin{tabular}{|c|c|c|}
\hline FACS $^{\mathrm{TM}}$-Fixierungslösung & $1,0 \%$ & $\begin{array}{l}\text { PFA } \\
\text { in aqua dest. }\end{array}$ \\
\hline FACS $^{\mathrm{TM}}$-Lysierungslösung & & $\begin{array}{l}\text { BD FACS }{ }^{\mathrm{TM}} \text { Lysing Solution, } 1 \mathrm{X} \\
\text { in aqua dest. }\end{array}$ \\
\hline FACS $^{\text {TM}}$-Permeabilisierungslösung & & Flow Cytometry Permeabilization/Wash Buffer I, 1X \\
\hline $\begin{array}{l}\text { FACS }^{\text {TM }} \text {-Puffer } \\
=\text { PBS } 1 X / B S A 1 \% \text {-Puffer }\end{array}$ & $1,0 \%$ & $\begin{array}{l}\text { BSA } \\
\text { in PBS, } \mathrm{pH} 7,4,1 \mathrm{X} \\
\text { in aqua dest. }\end{array}$ \\
\hline
\end{tabular}

Abk. aqua dest.: destilliertes Wasser; BSA: Rinderserumalbumin; FACS ${ }^{\text {TM: }}$ fluoreszenzaktivierte Zellsortierung; PBS: phosphatgepufferte Salzlösung; PFA: Paraformaldehyd; $\mathrm{pH}$ : negativer dekadischer Logarithmus der Wasserstoffionenaktivität; $X:-f a c h$ 


\subsubsection{Materialien für ELISA-Versuche}

\subsubsection{Eingesetzte ELISA-Kits}

\begin{tabular}{lll}
\hline Artikel & Nummer & Firma \\
\hline Humaner RANTES Mini ELISA & $900-M 33$ & PeproTech, Inc., Rocky Hill, NJ, USA \\
\hline Humaner sPECAM-1 Platinum ELISA & BMS229 & eBioscience, Inc., San Diego, CA, USA \\
\hline Humaner sP-selectin Platinum ELISA & BMS219/4 & eBioscience, Inc., San Diego, CA, USA \\
\hline Humaner TNF- $\alpha$ Platinum ELISA & BMS223/4CE & eBioscience, Inc., San Diego, CA, USA \\
\hline
\end{tabular}

Abk. ELISA: enzymgekoppelter Immunadsorptionstest; PECAM: Thrombozyten-Endothelzellen-Adhäsionsmolekül; P-selectin: Thrombozyten-Selektin; RANTES: regulated on activation, normal $T$ cell expressed and secreted; s: Iöslich; TNF- $\alpha$ : Tumornekrosefaktor alpha

\subsubsection{Puffer und Lösungen für ELISA-Analysen}

\begin{tabular}{lll}
\hline \hline Probenpuffer, 1X & $\begin{array}{ll}0,0005 \% \\
0,005 \%\end{array}$ & $\begin{array}{l}\text { Tween 20 } \\
\text { BSA } \\
\text { in PBS, pH 7,4, 1X } \\
\text { in aqua dest. }\end{array}$ \\
\hline Stopplösung & $1 \mathrm{M}$ & Phosphorsäure \\
\hline Substratlösung & & TMB \\
\hline Waschpuffer, 1X & $0,0005 \%$ & $\begin{array}{l}\text { Tween 20 } \\
\text { in PBS, pH 7,4, 1X } \\
\text { in aqua dest. }\end{array}$ \\
\hline
\end{tabular}

Abk. aqua dest.: destilliertes Wasser; BSA: Rinderserumalbumin; M: molare Masse; PBS: phosphatgepufferte Salzlösung; $\mathrm{pH}$ : negativer dekadischer Logarithmus der Wasserstoffionenaktivität; TMB: Tetramethylbenzidin; $X$ : -fach

\subsection{Angewandte Methoden und Versuche}

\subsubsection{Versuchsgruppen}

\subsubsection{Probandenrekrutierung}

Der Studienaufbau umfasst drei standardisiert rekrutierte Versuchsgruppen: Die erste bestehend aus Patienten mit stabiler KHK (Anzahl $[n]=60)$. Eine Kohorte junger gesunder Probanden $(n=64)$ stellt die Kontrollgruppe [Ktr.] und in der dritten Fraktion finden sich ältere Patienten mit kardialen und/oder weiteren internistischen Erkrankungen - allerdings ohne signifikant verengte Herzkranzgefäße - die als altersadaptierte Kontrollgruppe [aaKtr.] dienen ( $n=9)$. 
Die Teilnahme an der Studie beinhaltet neben einer einmaligen, freiwilligen Blutspende auch das Ausfüllen eines Fragebogens zum aktuellen Gesundheitsstatus, relevanten Vorerkrankungen, Familienanamnese, Allergien und Medikamenteneinnahmen. Diese Informationen werden bei den KHKPatienten und den altersadaptierten Kontrollprobanden z. T. ergänzend den Krankenakten entnommen.

\subsection{Versuchskollektiv der Patienten mit stabiler KHK}

Die 60 Versuchspersonen der KHK-Patientengruppe wurden während ihres Aufenthaltes auf den kardiologischen Normalstationen der Universitätsmedizin Göttingen [UMG] rekrutiert. Eine KHK ist im Rahmen der Studie als $\geq 50$ \%ige Stenose mindestens einer Koronararterie definiert worden. Die Abgrenzung einer stabilen von einer instabilen KHK, die u. a. mit einer erhöhten Leukozytenzahl und veränderten Hämostaseparametern einhergeht und damit Einfluss auf Anzahl und Verhalten von Mono- und Thrombozyten hat (Sagastagoitia et al. 2008; Seropian et al. 2015), erfolgte klinisch und ggf. per Elektrokardiogramm, laborchemisch oder per Herzkatheterdiagnostik nach den gängigen Kriterien der Deutschen Gesellschaft für Kardiologie - Herz- und Kreislaufforschung [DGK] und der European Society of Cardiology [ESC] (Achenbach et al. 2012; Hamm et al. 2011; Montalescot et al. 2013; Steg et al. 2012; Thygesen et al. 2012). Studienausschlusskriterien sind der Tab. 2.1 zu entnehmen.

\section{Studienausschlusskriterien der KHK-Patienten-Versuchsgruppe}

Akutes Koronarsyndrom innerhalb der letzten drei Monate vor Studieneinschluss

Niereninsuffizienz (GFR $<50 \mathrm{ml} /$ Minute $/ 1,73 \mathrm{~m}^{2}$ )

hsCRP > $30 \mathrm{mg} / \mathrm{l}$

Aktuelle Infektionen und Antibiotikatherapie

Z. n. Koronararterien- oder Herzklappenintervention oder operativer Myokardrevaskularisation innerhalb der letzten drei Monate vor Studieneinschluss

Typ-1-Diabetes mellitus

Autoimmunerkrankungen mit Immunsuppression, starke Allergien, aktive Tumorerkrankungen

Z. n. Herztransplantation

\section{Tab. 2.1 Studienausschlusskriterien der KHK-Patienten-Versuchsgruppe}

Abk. GFR: glomeruläre Filtrationsrate; hsCRP: hochsensitives C-reaktives Protein; Z. n.: Zustand nach 


\subsection{Versuchskollektiv der gesunden Blutspender}

Die 64 Probanden der Kontrollgruppe wurden in der Abteilung Transfusionsmedizin der UMG rekrutiert. Die Studienausschlusskriterien für die Gruppe der gesunden Blutspenderinnen und Blutspender sind in Tab. 2.2 dargestellt. Um die Studiengruppen anhand ihrer Gliederungsmerkmale, wie dem Geschlecht, dem Körpermasseindex (engl. body mass index [BMI]), der von Keys et al. definiert wurde (Keys et al. 1972), oder auch dem Alter, ähnlich zu bestücken, wurde versucht, möglichst ältere Blutspender für die Studienteilnahme zu gewinnen, da das Kollektiv der KHK-Patienten typischerweise mehrheitlich höheren Alters (siehe Kapitel 1.1) ist.

\section{Studienausschlusskriterien des Versuchskollektivs gesunder Blutspender}

Alter $<40$ Jahre

$\mathrm{BMI}<18,5$ oder $\geq 30,0 \mathrm{~kg} / \mathrm{m}^{2}$

Aktives oder vor weniger als sechs Monaten eingestelltes Rauchen

Typ-1- oder Typ-2-Diabetes mellitus

Arterielle Hypertonie (RR $>140 / 90 \mathrm{mmHg}$ )

Hyperlipoproteinämie (LDL-C > 3,9 $\mathrm{mmol} / \mathrm{l}$ )

Niereninsuffizienz (GFR $<90 \mathrm{ml} /$ Minute/1,73 $\mathrm{m}^{2}$ )

Hyperurikämie (Serumharnsäurekonzentration $\geq 6,5 \mathrm{mg} / \mathrm{dl}$ )

Autoimmunerkrankungen mit Immunsuppression, starke Allergien, aktive Tumorerkrankung

Kardiovaskuläre Vorerkrankungen (Herzrhythmusstörungen, Herzinsuffizienz, KHK)

Einnahme kardiovaskulär wirksamer Arzneimittel

\section{Tab. 2.2 Studienausschlusskriterien des Versuchskollektivs gesunder Blutspender}

Abk. BMI: Körpermasseindex; GFR: glomeruläre Filtrationsrate; KHK: koronare Herzkrankheit; LDL-C: Lipoprotein niedriger Dichte-Cholesterin; RR: Riva-Rocci

\subsection{Versuchskollektiv der altersadaptierten Patienten ohne KHK}

Um ein altersentsprechendes Kontrollkollektiv betrachten zu können, wurden darüber hinaus auf den kardiologischen Stationen der UMG neun Patienten ohne Koronarstenosen rekrutiert, die 63 Jahre oder älter waren (und damit oberhalb des 0,25-Quartils des medianen KHKPatientengruppenalters lagen).

Die Studienausschlusskriterien dieser Kontrollgruppe entsprachen - abgesehen vom Alter - denen der gesunden, jüngeren Probanden. Bei allen Studienteilnehmern dieser Gruppe wurde mittels Koronarangiographie eine KHK ausgeschlossen worden. Um die Studiengruppe anhand ihrer Gliede- 
rungsmerkmale der KHK-Probandengruppe entsprechend zu bestücken, wurde v. a. auf einen ähnlichen BMI-Wert und eine prozentual analoge Häufigkeit kardiovaskulärer Risikofaktoren geachtet.

\subsubsection{Probandeneinwilligung, Sicherheit und Votum der Ethik- kommission}

Vor Aufnahme in die Studie wurden die allesamt volljährigen und einwilligungsfähigen Probanden mündlich und schriftlich über Ablauf, Nutzen und Risiken der Studienbeteiligung aufgeklärt und gaben ihr mündliches sowie schriftliches Einverständnis zur Teilnahme.

Intention und Ablauf der Studien wurden vor Beginn der wissenschaftlichen Untersuchungen von der Ethikkommission der UMG geprüft und genehmigt (Nummer des Ethikantrages: 11/8/10; Antragstellerin/Prüfärztin: Frau Dr. med. Frauke Czepluch) und entsprechen den ethischen Grundsätzen und Richtlinien der Declaration of Helsinki (World Medical Association 2013).

\subsubsection{Untersuchungsmaterialgewinnung}

Den kardiologischen Patienten wurde nach kurzer Stauungszeit des Oberarms von maximal 30 Sekunden mit einem 21 Gauge [G] Safety-Multifly ${ }^{\circledR}$-Set, dem sogenannten Butterfly, nach üblicher Desinfektion eine Kubitalvene punktiert (Robert Koch-Institut 2011) und anschließend vier SMonovetten ${ }^{\circledR}$ mit frischem venösen Vollblut gefüllt. Die Blutentnahme erfolgte ausschließlich an Extremitäten, an denen aktuell keine Venenverweilkanülen etc. eingebracht waren.

Die Reihenfolge der abgenommenen S-Monovette ${ }^{\circledR}$ betrug:

1. $\quad 7,5 \mathrm{ml} \mathrm{S-Monovette}{ }^{\circledR}$ mit Gerinnungsaktivatoren zur Blutserumgewinnung

2. $\quad 3,0 \mathrm{ml} \mathrm{S-Monovette}{ }^{\circledR}$ gefüllt mit Tri-Natriumcitrat-Lösung

3. $2,7 \mathrm{ml} \mathrm{S-Monovette}{ }^{\circledR}$ gefüllt mit $1,6 \mathrm{mg}$ Ethylendiamintetraessigsäure [EDTA]/ml Vollblut

4. $9,0 \mathrm{ml} \mathrm{S-Monovette}{ }^{\circledR}$ gefüllt mit 16 Internationale Einheiten [IE] Heparin/ml Vollblut

Den gesunden Blutspendern wurde von dem mit der Blutspende betrauten Pflegepersonal nach kurzer Venenstauung eine $16 \mathrm{G}$ Venenpunktionsnadel in die Kubitalvene eingebracht. Über ein am Vakuumbeutelsystem für die Blutspende angebrachtes Schlauchsystem wurde den Studienteilnehmern zusätzlich venöses Vollblut in ebenfalls vier S-Monovetten ${ }^{\circledR}$ (s. o.) entnommen. Erst nachdem alle vier S-Monovetten ${ }^{\circledR}$ für die vorliegende Studie abgenommen waren, begann die Füllung des $450 \mathrm{ml}$ fassenden Beutelsystems für die eigentliche Blutspende. 


\subsubsection{Maschinelles Differenzialblutbild}

Um nähere Informationen über die Zusammensetzung der zellulären Bestandteile des Blutes zu erhalten und um die prozentualen Ergebnisse der FACS ${ }^{\text {TM}}$-Analysen auf absolute Werte beziehen zu können, wurde von jedem Studienteilnehmer ein maschinelles Differenzialblutbild bei der Abteilung Hämatologie der UMG angefordert. Dazu wurden $500 \mu$ l venösen Vollbluts der EDTA-antikoagulierten S-Monovetten ${ }^{\circledR}$ jedes Studienteilnehmers in Eppendorf Tubes ${ }^{\circledR}$ überführt und zur Analyse eingereicht.

\subsubsection{Klinisch-chemische Laborparameter}

Analog zur Anforderung der Differenzialblutbilder wurden von allen Studienteilnehmern auch klinisch-chemische Laborparameter zur Kontrolle der Studienausschlusskriterien und weiteren Charakterisierung angefordert. Der Abteilung Klinische Chemie der UMG wurden dazu von jedem Probanden $2,0 \mathrm{ml}$ venöses Vollblut der heparinpräparierten S-Monovetten ${ }^{\circledR}$ zur Verfügung gestellt. Neben Kreatinin, glykosyliertem Hämoglobin $\left[\mathrm{HbA}_{1 c}\right]$ und hochsensitivem C-reaktiven Protein [hsCRP] wurden auch das Gesamtcholesterin sowie LDL-C und HDL-C, Gesamt-Kreatinkinase (engl. creatine kinase [CK]), Kreatinkinase-Muskel/Gehirn (engl. creatine kinase muscle/brain [CK-MB]) und Aspartataminotransferase $[\mathrm{AST}]$ bestimmt.

\subsubsection{Durchflusszytometrische Analysen}

\subsubsection{Prinzip der Durchflusszytometrie}

Die von Wolfgang Göhde 1968 entwickelte und patentierte fluoreszenzbasierte Durchflusszytometrie (engl. flow cytometry; (inkorrekter) Synonymgebrauch: fluoreszenzaktivierte Zellsortierung, engl. fluorescence-activated cell sorting [FACS]; FACS ${ }^{\mathrm{TM}}$ ist ein geschütztes Markenzeichen von Becton, Dickinson and Company) dient der Analyse und Beurteilung von Zellen, Partikeln und Zelleigenschaften unterschiedlichster Probenarten (z. B. peripheres Vollblut, Knochenmarkaspirat, Gewebe, Liquor etc.) mittels eines Laserstrahls (Spyropoulos 2011). Dazu werden die zu untersuchenden Zellen bzw. Zellbestandteile über die Kanüle eines Durchflusszytometers aufgenommen und in einem stark beschleunigten Flüssigkeitsstrom perlenschnurartig aufgereiht (hydrodynamische Fokussierung). So separiert werden die Zellen nun einzeln in einer Messküvette an einem mit einem Laser versehenen Messpunkt vorbeigeleitet. Der Laserstrahl trifft am Kreuzungspunkt auf die Einzelzellbestandteile, wodurch Streulicht in zwei verschiedenen Winkeln abgegeben wird: als Vorwärtsstreulicht (engl. forward scatter [FSC]) und als Seitwärtsstreulicht (engl. side scatter [SSC]). Die Wellenlänge und da- 
mit die Farbe des angeregten Lichts werden bei diesem Prozess nicht verändert (Leach et al. 2013; Macey 2010). Abb. 2.1 zeigt den schematischen Aufbau eines Durchflusszytometers.

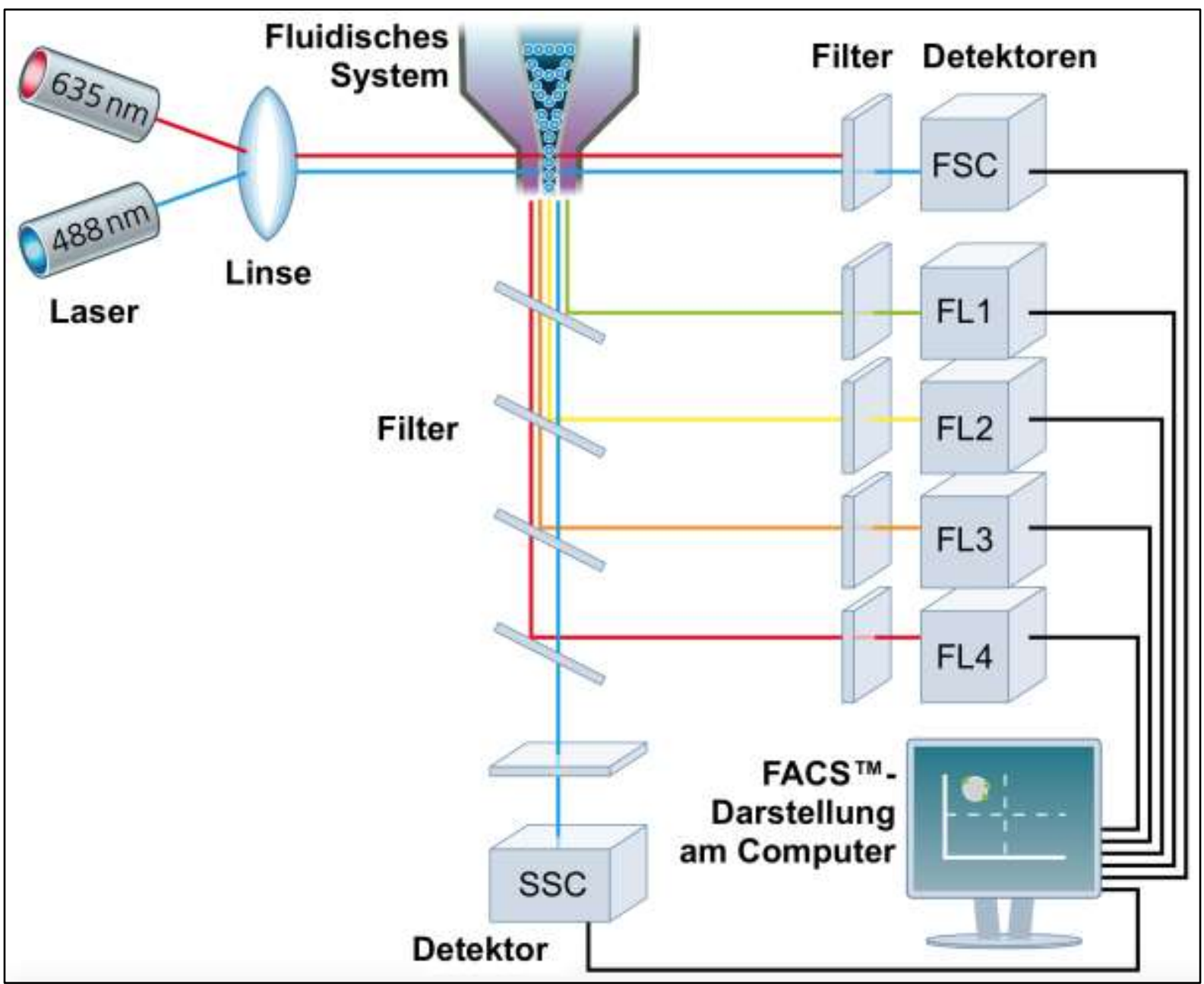

\section{Abb. 2.1 Schematischer Aufbau eines Durchflusszytometers}

Die im fluidischen System per hydrodynamischer Fokussierung perlenschnurartig aufgereihten Probenbestandteile passieren singulär einen Laserstrahl, der verschiedene Wellenlängen detektieren kann. Durch den Lichtaufprall auf die Probe entstehen Energie und Streulicht. Das Streulicht wird, über mehrere Filter geleitet, von FSC- und SSC-Detektoren registriert. Über verschiedene Fluoreszenzkanäle, denen ebenfalls Filter vorgeschaltet sind, können fluoreszenzspezifische Eigenschaften des Probenmaterials ebenso detektiert werden wie fluoreszierende Antikörper. Mittels der verschiedenen Laser und ihrer Detektoren lassen sich die Charakteristika des Probenmaterials evaluieren und per Computer berechnen und darstellen (modifiziert nach Rahman 2014, S. 7).

Abk. FACS ${ }^{\mathrm{T}}$ : fluoreszenzaktivierte Zellsortierung; FL: Fluoreszenz; FSC: Vorwärtsstreulicht; SSC: Seitwärtsstreulicht

Anhand der Streulichteigenschaften lassen sich Aussagen über Zellgröße und -struktur sowie die Granularität der gemessenen Substanzen treffen. Der FSC-Anteil ist v. a. ein Maß für die Zellgröße. Kleinere Zellen oder Partikel verursachen relativ weniger FSC als größere Zellen. Je mehr intrazellulä- 
re Granularität vorhanden ist, desto relativ mehr Streulicht wird von den SSC-Detektoren aufgefangen. Einen kleineren Einfluss auf SSC hat darüber hinaus die Beschaffenheit der Zellmembranen und des Zellkerns der untersuchten Zellen. Abb. 2.2 gibt ein Beispiel für die Darstellung einer durchflusszytometrisch analysierten Probe lysierten humanen Vollblutes und deren Auftragung nach FSC und SSC.

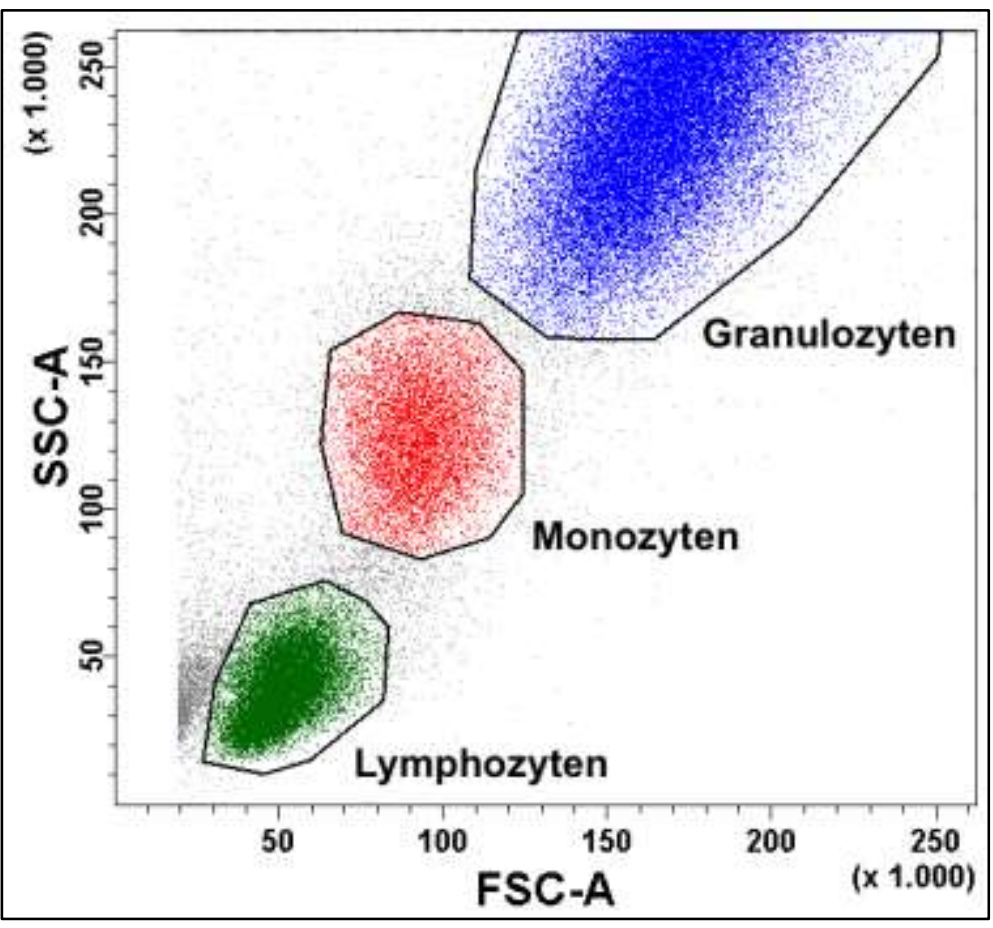

Abb. 2.2 Durchflusszytometrische Darstellung der morphologischen Charakteristika humaner Vollblutbestandteile nach Lyse anhand ihrer Streulichteigenschaften

In der Scatter-Plot-Darstellung sind deutlich drei verschiedene Zellpopulationen zu erkennen, die sich anhand ihrer morphologischen Eigenschaften in der Auftragung FSC vs. SSC unterscheiden: Lymphozyten (klein, granulationsarm $\rightarrow$ wenig FSC und SSC), Granulozyten (groß, granulationsreich $\rightarrow$ viel FSC und SSC) und die zwischen diesen beiden Streulichteigenschaften liegende Monozytenpopulation.

Abk. FSC: Vorwärtsstreulicht; SSC: Seitwärtsstreulicht

Durch verschiedene Laser und Detektoren lassen sich Zellen zusätzlich auch anhand bekannter Emissionsspektren von Fluorochromen unterscheiden, die entweder selbst Bestandteil der Zellen sind oder in vivo an diese binden/gebunden sind.

Fluorochrome lassen sich aber auch an mehr oder weniger spezifische Antikörper konjugieren, welche in vitro an definierte Zellantigene binden und diese dadurch detektabel machen. Der Einsatz unterschiedlicher Fluorochrome und die damit verbundenen verschiedenen Emissionsspektren sind besonders gut durchflusszytometrisch zu separieren, wenn sich die einzelnen Emissionsmaxima der Fluorochrome deutlich voneinander unterscheiden. Mittels der durchflusszytometrischen Emissionsdetektion kann man Auskunft über unterschiedlichste Eigenschaften und Marker - u. a. nach dem Prinzip des cluster of differentiation - verschiedenster Zellen, Zellbestandteile oder Probensuspensionen erhalten. Erst solche Mehrfarbenfluoreszenzanalysen ermöglichen die Korrelation verschie- 
denster Zelleigenschaften und sind z. B. nutzbar im Rahmen der Analyse von Zellsubpopulationen, Zellproliferation, Zellaktivierung und Immunphänotypisierung.

Das im Rahmen dieser Arbeit eingesetzte Durchflusszytometer ist ein mit einem blauen Laser $(488 \mathrm{~nm})$ u. a. für die Detektion von Fluoresceinisothiocyanat [FITC], Phycoerythrin [PE] und Peridinin-Chlorophyll-Komplex + Cyanin5.5 [PerCP-Cy $\left.{ }^{\mathrm{TM}} 5.5\right]$, einem roten Laser (633 nm) u. a. für Allophycocyanin [APC]-Analysen sowie einem violetten Laser $(405 \mathrm{~nm})$ ausgestattetes BD FACSCanto ${ }^{\mathrm{TM}} \mathrm{II}$. Die fluorochromkonjugierten Antikörper sind in der nachfolgenden Tab. 2.3 aufgeführten.

\begin{tabular}{ccccc}
\hline Fluorochrom & $\begin{array}{c}\text { Exzitations- } \\
\text { maximum }\end{array}$ & $\begin{array}{c}\text { Emissions- } \\
\text { maximum }\end{array}$ & Farbe & Laser \\
\hline FITC & $488 \mathrm{~nm}$ & $518 \mathrm{~nm}$ & grün & blau (488 $\mathrm{nm})$ \\
\hline PE & $488 \mathrm{~nm}$ & $578 \mathrm{~nm}$ & gelb & blau (488 $\mathrm{nm})$ \\
\hline APC & $633 \mathrm{~nm}$ & $660 \mathrm{~nm}$ & rot & rot $(633 \mathrm{~nm})$ \\
\hline PerCP-Cy 5.5 & $488 \mathrm{~nm}$ & $695 \mathrm{~nm}$ & tiefrot & blau (488 $\mathrm{nm})$ \\
\hline
\end{tabular}

Tab. 2.3 Verwendete Fluorochrome, deren detektable Wellenlängen sowie die generierten Wellenlängen der genutzten Laser

Abk. APC: Allophycocyanin; FITC: Fluoresceinisothiocyanat; PE: Phycoerythrin; PerCP-Cy ${ }^{\text {TM} 5.5: ~ P e r i d i n i n-~}$ Chlorophyll-Komplex + Cyanin5.5

\subsubsection{Gewinnung mononukleärer Zellen und deren Aufarbeitung}

Zur Gewinnung mononukleärer Zellen des peripheren Blutes (engl. peripheral blood mononuclear cell [PBMC]) wird heparinisiertes peripher-venöses Vollblut in ein mit Histopaque ${ }^{\circledR}$ befülltes Leucosep ${ }^{\text {TM }}$ Röhrchen gegeben. Dabei befindet sich das zur Dichtegradientenzentrifugation genutzte Histopaque ${ }^{\circledast}$ unterhalb einer fest in dem Leucosep ${ }^{\mathrm{TM}}$-Röhrchen verankerten Trennscheibe, über die das Vollblut vorsichtig pipettiert wird (siehe Abb. 2.3 a).

Anschließend wird das Röhrchen für zehn Minuten bei Raumtemperatur [RT] und 2500 Umdrehungen pro Minute (engl. revolutions per minute [rpm]) ohne Bremse zentrifugiert. Nach der Zentrifugation ergibt sich innerhalb des Leucosep ${ }^{\mathrm{TM}}{ }^{-R o ̈ h r c h e n s ~ d i e ~ i n ~ A b b . ~} 2.3$ b dargestellte Gliederung der Blut- und Reagenzienbestandteile. 


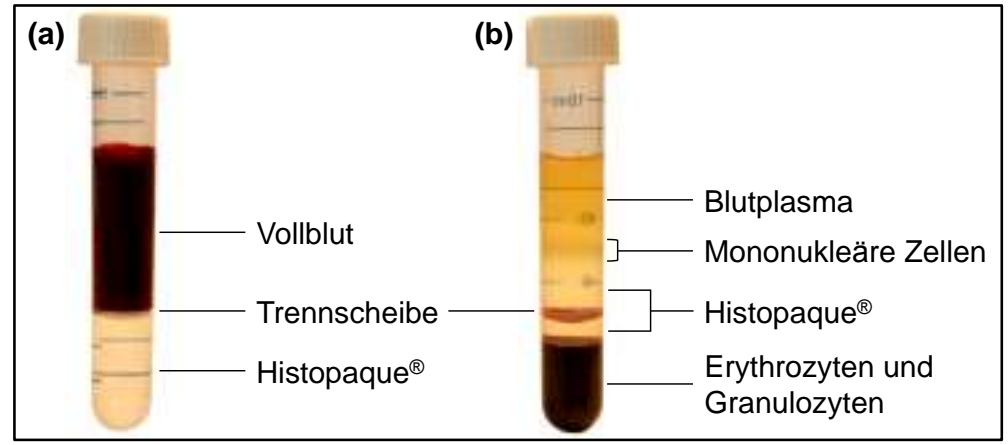

\section{Abb. 2.3 Leucosep ${ }^{T M}$-Röhrchen zur PBMC-Gewinnung}

(a) Vor der Dichtegradientenzentrifugation befinden sich unterhalb der fest mit dem Röhrchen verbundenen Trennscheibe $3 \mathrm{ml}$ Histopaque ${ }^{\circledR}$, darüber $5 \mathrm{ml}$ heparinisiertes Vollblut. (b) Nach der Zentrifugation finden sich am Röhrchenboden Erythrozyten und Granulozyten. Um die Trennscheibe herum hat sich das Histopaque ${ }^{\circledR}$, das leichter als die Erythro- und Granulozyten, aber schwerer als die mononukleären Zellen und das Blutplasma ist, angesammelt. Nach Entfernung des Plasmaüberstandes lassen sich die mononukleären Zellen leicht und verunreinigungsarm gewinnen.

Der Plasmaüberstand oberhalb der PBMCs wird vorsichtig abgesaugt und verworfen und die PBMCs samt dem sich oberhalb der Trennscheibe befindlichen Histopaque ${ }^{\circledR}$ in ein mit $1 \%$ Paraformaldehyd [PFA] gefülltes Polypropylen [PP]-Röhrchen zur zehnminütigen Fixation überführt, um die gewonnenen Zellen zeitlich stabil zu halten.

Nach der Fixierung werden die Zellen mit FACS ${ }^{\mathrm{TM}}$-Puffer, bestehend aus $1 \mathrm{X}$ phosphatgepufferter Salzlösung [engl. phosphate buffered saline [PBS]) und 1 \% Rinderserumalbumin [engl. bovine serum albumin [BSA]), zweimalig gewaschen und für fünf Minuten bei RT und 1000 relative Zentrifugalkraft (engl. relative centrifugal force [rcf]) zentrifugiert. Das nun aufgereinigte Pellet mononukleärer Zellen wird in FACS ${ }^{\mathrm{TM}}$-Puffer resuspendiert.

\subsubsection{Detektion von Monozyten und Monozytensubgruppen aus PBMCs sowie deren CCR5- und CD44-Expression}

Bevor die drei pro Proband benötigten Probenröhrchen mit jeweils $50 \mu \mathrm{l}$ Zell-PBS 1X/BSA $1 \%$ Suspension gefüllt werden, wird jedes Röhrchen, wie in der Tab. 2.4 aufgeführt, mit Antikörpern bzw. Isotypenkontrollen bestückt. Anschließend werden die Volumina jedes Röhrchens mit FACS ${ }^{\mathrm{TM}}$-Puffer vergrößert und die Zellen bei RT im Dunkeln für 30 Minuten inkubiert.

Die CD14- und CD16-Antikörper dienen der qualitativen und quantitativen Diskrimination der Monozytenuntergruppen. CD195 ist ein Oberflächenmarker und Synonym für CCR5. CD44 detektiert einen OPN-Rezeptor. 


\begin{tabular}{|c|c|c|c|}
\hline Isotypen/Antikörper & $\begin{array}{c}\text { 1. Röhrchen = } \\
\text { Negativkontrolle }\end{array}$ & $\begin{array}{c}\text { 2. Röhrchen = } \\
\text { Isotypenkontrolle }\end{array}$ & $\begin{array}{c}\text { 3. Röhrchen = } \\
\text { Antikörperfärbung }\end{array}$ \\
\hline $\operatorname{lgG} 2 \mathrm{~b}$ к FITC & --- & $5,0 \mu \mathrm{l}$ & --- \\
\hline IgG1 K PE & --- & $5,0 \mu \mathrm{l}$ & --- \\
\hline IgG2а к PerCP-Cy ${ }^{\text {TM}} 5.5$ & --- & $5,0 \mu \mathrm{l}$ & --- \\
\hline $\operatorname{lgG} 2$ а к APC & --- & $5,0 \mu \mathrm{l}$ & --- \\
\hline CD14 FITC & --- & --- & $5,0 \mu \mathrm{l}$ \\
\hline CD16 PE & --- & --- & $5,0 \mu \mathrm{l}$ \\
\hline CD44 PerCP-Cy ${ }^{\mathrm{TM}} 5.5$ & --- & --- & $1,25 \mu \mathrm{l}$ \\
\hline CD195 APC & --- & --- & $5,0 \mu \mathrm{l}$ \\
\hline
\end{tabular}

Tab. 2.4 FACS ${ }^{T M}$-Röhrchenbestückung zur monozytären Subgruppen-, CCR5- und CD44-Detektion

Abk. APC: Allophycocyanin; CCR: CC-Chemokinrezeptor; CD: cluster of differentiation; FACS'M: fluoreszenzaktivierte Zellsortierung; FITC: Fluoresceinisothiocyanat; IgG: Immunglobulin G; PE: Phycoerythrin; PerCPCy ${ }^{\mathrm{TM}}$ 5.5: Peridinin-Chlorophyll-Komplex + Cyanin5.5

Nach der Inkubation werden die ungebundenen Antikörper/Isotypenkontrollen mit einem erneuten Wasch- und Zentrifugationsschritt entfernt und das Zellpellet letztlich mit PBS 1X/BSA 1 \%-Puffer resuspendiert, sodass die Zellen nun für die durchflusszytometrische Analyse fertig aufbereitet sind.

\subsubsection{Detektion der Monozytensubgruppen aus PBMCs und deren KLF4- Expression}

Zur Untersuchung von KLF4 in den drei Monozytensubgruppen werden ebenfalls per Dichtegradientenzentrifugation mittels Leucosep ${ }^{\mathrm{TM}}$-Röhrchen und Histopaque ${ }^{\circledR}$ gewonnene PBMCs genutzt. Nach der bereits beschriebenen Zellaufreinigung erfolgt die erste Antikörperfärbung der in FACS ${ }^{\text {тM }}$ Puffer suspendierten mononukleärer Zellen, indem diese in drei Probenröhrchen mit jeweils $5 \mu l$ CD14- und CD16-Antikörper bzw. den korrespondierenden Isotypenkontrollen zusammengeführt und anschließend für 30 Minuten bei RT im Dunkeln inkubiert werden. Die CD14- und CD16-Antikörper dienen später erneut der qualitativen und quantitativen Monozytensubgruppendiskrimination.

Nach der ersten Inkubation werden die ungebundenen Antikörper in einem Wasch- und Zentrifugationsschritt entfernt. Um KLF4 intrazellulär mit fluorochrombesetzten Antikörpern anfärben zu können, werden die Zellmembranen der mononukleären Zellen mittels Flow Cytometry Permeabilization/Wash Buffer I permeabilisiert. Für eine abermals 30-minütige Permeabilisations- und Inkubationsphase werden die Zellen gleichzeitig mit 2,5 $\mu$ l KLF4-Antikörper bzw. -Isotypenkontrolle bestückt. Der Antikörper gegen KLF4 ist ein intrazellulärer Marker und detektiert v. a. im Zytosol und Kernplasma der Monozyten befindliches KLF4. 
Nach dem zweiten Inkubationsschritt werden die ungebundenen Antikörper erneut mit einem Wasch- und Zentrifugationsschritt entfernt und das Zellpellet mit FACS ${ }^{\mathrm{TM}}$-Puffer resuspendiert, sodass die Zellen nun für die durchflusszytometrische Analyse aufbereitet sind.

\subsubsection{Detektion der monozytären Subgruppen und deren Bildung von Monozyten-Thrombozyten-Aggregaten in citratantikoaguliertem Vollblut}

Drei FACS ${ }^{\mathrm{TM}}$-Röhrchen mit jeweils $200 \mathrm{ml}$ citratantikoaguliertem peripheren Vollblut werden mit $1 \%$ PFA für zehn Minuten bei RT fixiert. Anschließend werden mittels zehnminütiger Inkubation mit BD FACS ${ }^{\text {TM }}$ Lysing Solution die Erythrozyten in den Probenansätzen lysiert, die Proben gewaschen, zentrifugiert und schließlich der Zellüberstand verworfen. Das so gewonnene Zellpellet bestehend aus Leukozyten, Monozyten und Granulozyten sowie Zelldebris wird resuspendiert, nochmals gewaschen und zentrifugiert und anschließend mit fluorochromkonjugierten Antikörpern gefärbt. Es wird das in Tab. 2.5 dargestellte Färbeschema verwendet.

\begin{tabular}{lccc}
\hline Isotypen/Antikörper & $\begin{array}{c}\text { 1. Röhrchen }= \\
\text { Negativkontrolle }\end{array}$ & $\begin{array}{c}\text { 2. Röhrchen } \\
\text { Isotypenkontrolle }\end{array}$ & $\begin{array}{c}\text { 3. Röhrchen }= \\
\text { Antikörperfärbung }\end{array}$ \\
\hline IgG2b K FITC & --- & $5,0 \mu \mathrm{l}$ & --- \\
\hline IgG1 K PE & --- & $5,0 \mu l$ & --- \\
\hline IgG2a k APC & --- & $5,0 \mu l$ & --- \\
\hline CD14 FITC & --- & -- & $5,0 \mu \mathrm{l}$ \\
\hline CD16 PE & --- & --- & $5,0 \mu \mathrm{l}$ \\
\hline CD42b APC & --- & -- & $5,0 \mu \mathrm{l}$ \\
\hline
\end{tabular}

Tab. 2.5 FACS ${ }^{T M}$-Röhrchenbestückung zur MPA-Detektion

Abk. APC: Allophycocyanin; CD: cluster of differentiation; FACS ${ }^{\mathrm{TM}}$ : fluoreszenzaktivierte Zellsortierung; FITC: Fluoresceinisothiocyanat; IgG: Immunglobulin G; MPA: Monozyten-Thromboyten-Aggregat; PE: Phycoerythrin; PerCP-Cy ${ }^{\text {TM }}$ 5.5: Peridinin-Chlorophyll-Komplex + Cyanin5.5

Die CD14- und CD16-Antikörper dienen erneut der Monozytensubgruppendiskrimination. CD42b ist ein Thrombozytenoberflächenmarker und zeigt in Kombination mit den Monozytenmarkern, ob bzw. wie viele Monozyten Komplexe mit Thrombozyten bilden und wie viele Thrombozyten mit einem Monozyt aggregiert sind.

Die Zellen werden anschließend für 30 Minuten bei RT im Dunkeln inkubiert, bevor die Überstände an Antikörpern bzw. Isotypenkontrollen mit einem erneuten Wasch- und Zentrifugationsschritt entfernt werden, das Zellpellet mit FACS ${ }^{\text {TM}}$-Puffer resuspendiert wird und die Zellen nun für die durchflusszytometrischen Analysen fertig aufbereitet sind. 


\subsubsection{Monozytäre CCR5- und KLF4-Expression nach in vitro-Inkubation mit Kontrollprobanden- bzw. KHK-Patientenplasma}

Um den Einfluss im Blutplasma vorkommender Botenstoffe wie Zyto- und Chemokine auf die monozytäre Expression von CCR5 und KLF4 zu untersuchen, werden gemäß dem in Kapitel 2.2.6.2 aufgeführten Protokoll zur Gewinnung mononukleärer Zellen ebendiese von jungen, gesunden Blutspendern $(n=4)$ separiert und nach anschließendem zweimaligen Waschvorgang samt Zentrifugation das gewonnene Zellpellet in Opti-Eagles Minimales Essentielles Medium [MEM] 1X resuspendiert.

Zwischenzeitlich werden zwei PP-Röhrchen mit Opti-MEM ${ }^{\circledR} 1 X$ gefüllt. In eines der beiden Röhrchen wird heparinisiertes Plasma eines gesunden Probanden der Kontrollgruppe und in das andere Röhrchen KHK-Patienten-Plasma gegeben. Beide Versuchsansätze werden gut gemischt, und die OptiMEM $^{\circledR} 1 \mathrm{X} / 10$ \%-Plasma-Mixtur wird anschließend auf jeweils fünf FACS $^{\mathrm{TM}}$-Röhrchen (Negativkontrolle, CCR5- und KLF4-Isotypenkontrolle, CCR5- und KLF4-Antikörperfärbung) verteilt. Dazu werden in jedes Röhrchen die gewonnenen und in Opti-MEM ${ }^{\circledR} 1 \mathrm{X}$ resuspendierten mononukleären Zellen der jungen PBMCs-Spender pipettiert. Die Zellgemische werden vier Stunden in einem Inkubator bei $37^{\circ} \mathrm{C}$ und $5 \%$ Kohlenstoffdioxid [engl. carbon dioxid $\left[\mathrm{CO}_{2}\right]$ ) bebrütet.

Nach einem Waschschritt werden die bebrüteten Zellen analog der bereits beschriebenen Färbeprotokolle für CCR5 (siehe Kapitel 2.2.6.3) sowie KLF4 (siehe Kapitel 2.2.6.4) mit den entsprechenden Antikörpern bestückt, inkubiert und anschließend durchflusszytometrisch analysiert.

\subsubsection{Proteinnachweis mittels ELISA}

\subsubsection{Prinzip eines Sandwich-ELISA}

Das Verfahren des enzymgekoppelten Immunadsorptionstests (engl. enzyme-linked immunosorbent assay [ELISA]) in Sandwichtechnik nutzt (mindestens) zwei verschiedene Antikörper zur Detektion eines Antigens. Beide Antikörper binden spezifisch an dasselbe Antigen, nutzen aber unterschiedliche Epitope, um eine gegenseitige Beeinflussung und Behinderung zu vermeiden (Berg JM et al. 2013; Crowther 2009).

Der erste Antikörper (Fang-/Fängerantikörper, engl. capture oder coat antibody) wird an den Boden einer 96-Loch-Mikrotiterplatte gebunden (siehe Abb. 2.4 a). Die Zugabe und anschließende Inkubation von Probandenmaterial wie Serum oder Plasma führt zur Bindung des Antigens an den am Boden der Mikrotiterplatte fixierten Fangantikörper.

Nach einem Waschschritt, der die ungebundenen Probenbestandteile entfernt, folgt die Inkubation mit dem zweiten, dem Detektionsantikörper (engl. detection antibody). Dieser bindet an ein anderes Epitop des schon mittels Fangantikörper fixierten Antigens, das nun zwischen zwei Antikörpern - 
quasi im Sandwich - in einem Antikörper-Antigen-Antikörper-Komplex gebunden ist. Das andere Ende des Detektionsantikörpers ist mit einem Markerenzym, z. B. Meerrettichperoxidase (engl. horseradish peroxidase [HRP]), bestückt (siehe Abb. 2.4 b). Ein weiterer Waschschritt entfernt die überschüssigen, ungebundenen Detektionsantikörper.

(a)

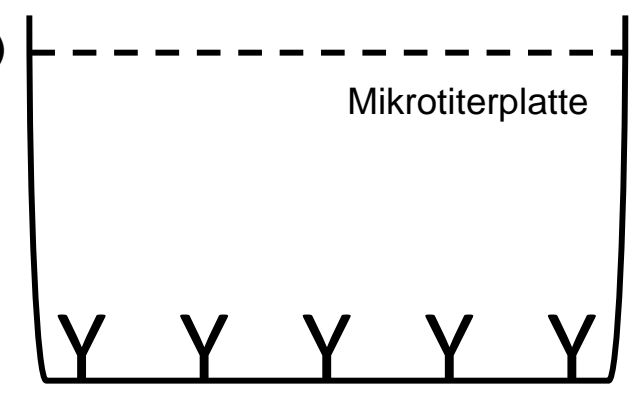

Y gebundener Fangantikörper (b)

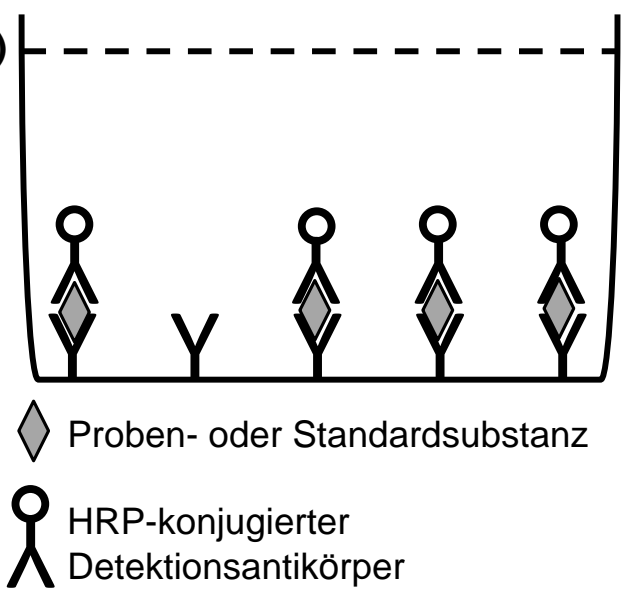

(c)

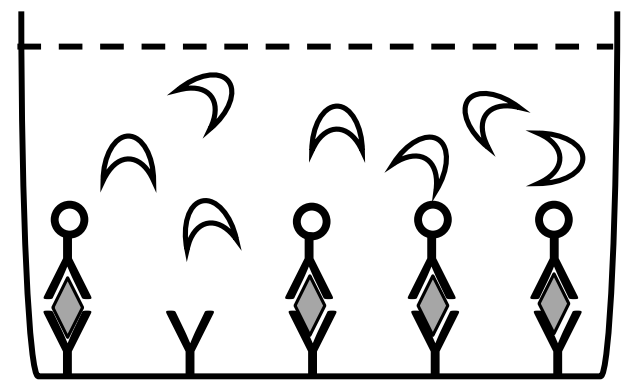

freie, nicht reagierte Substratlösung (d)

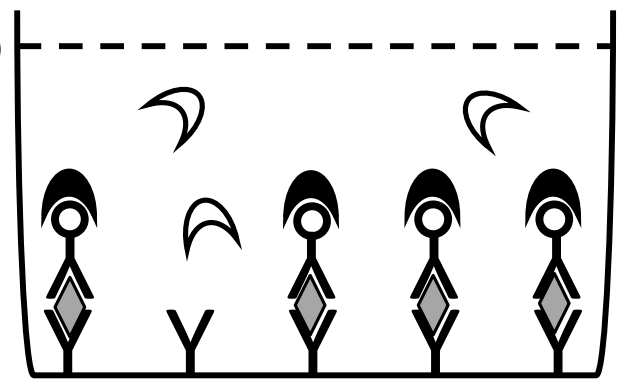

gebundene, reagierte

Substratlösung

\section{Abb. 2.4 Prinzip eines Sandwich-ELISA}

(a) Der Fangantikörper ist an dem Boden der Mikrotiterplatte gebunden. Freie, ungebundene Antikörper werden aus den Plattenfeldern herausgewaschen. (b) In die Mikrotiterplatte werden die Probenflüssigkeiten und die Standardsubstanzen pipettiert und anschließend zusammen mit HRP-konjugierten Detektionsantikörpern inkubiert. (c) Nachdem überschüssige, ungebundene Detektionsantikörper per Waschschritt entfernt wurden, wird die mit dem HRP-Konjugat interagierende Substratlösung zugeführt. (d) Nur die am HRP-Konjugat gebundene Substratlösung zeigt eine Farbumschlagsreaktion, die mittels Stopplösung unterbunden wird, bevor die ELISA-Platten photometrisch analysiert werden können.

Abk. ELISA: enzymgekoppelter Immunadsorptionstest; HRP: Meerrettichperoxidase, TMB: Tetramethylbenzidin

Als letzten Schritt vor der Antigendetektion und -quantifizierung mittels Fluoreszenzmessung erfolgt die Zugabe einer Tetramethylbenzidin [TMB]-Substratlösung, die mit dem am Detektionsantikörper 
gebundenen Markerenzym fluoreszierend reagiert und erst dadurch eine Analyse des Antigens ermöglicht (siehe Abb. $2.4 \mathrm{c}$ und d). Die so bewirkten Substratreaktionen lassen sich nun mittels Photometer analysieren und quantitativ vergleichen.

\subsubsection{Durchführung der verschiedenen ELISA-Versuche}

Die zur Proteinanalyse mittels ELISA eingesetzten Materialien sind im Kapitel 2.1.6 aufgelistet. Versuchsdurchführungen, Reagenzienpräparationen und -verdünnungen erfolgen gemäß der unterschiedlichen Versuchsprotokolle der jeweiligen ELISA-Kit-Hersteller.

Die zum Eiweißnachweis genutzten Analysestoffe, Serum bei löslichem (engl. soluble [s]) Thrombozyten-Endothelzellen-Adhäsionsmolekül (engl. platelet endothelial cell adhesion molecule [PECAM])-1, Thrombozyten-Selektin (engl. platelet-selectin [P-selectin]) und CCL5 sowie EDTA-Plasma bei TNF- $\alpha$, wurden bis zur Testung bei $-80^{\circ} \mathrm{C}$ aserviert. Sämtliche Proben wurden in Doppelbestimmung evaluiert, d. h. zwei Plattenfelder wurden mit derselben Probenflüssigkeit gefüllt und aus beiden Messwerten der Mittelwert der photometrisch detektierten Absorption berechnet.

Für jeden ELISA wird eine standardisierte Verdünnungsreihe, die sogenannte Standardreihe, pipettiert. Diese enthält eine definierte Antigenkonzentration, dient der photometrischen Kalibrierungskurvenerstellung und ist für die quantitative Vergleichsmöglichkeit detektierter Antigenkonzentrationen aus den verschiedenen Proben unabdingbar. Außerdem gibt sie qualitative Aufschlüsse über die Versuchsdurchführung. Zur Erstellung einer Standardreihe wird eine bestimmte Antigenmenge in sechs Schritten je zur Hälfte mit Probenpuffer verdünnt, wodurch sich ihre Konzentration jeweils halbiert (siehe Abb. 2.5).

Neben der Standardreihe werden je zwei Felder der Mikrotiterplatte, welche als Leerwerte und Negativkontrollen dienen, ausschließlich mit Probenpuffer befüllt. Die restlichen Felder der mit dem Fangantikörper versehenen Mikrotiterplatte werden in Doppelbestimmungstechnik mit den Probandenmaterialien bestückt und inkubiert. Nach mehreren Waschschritten erfolgt die Zugabe der HRP-konjugierten Detektionsantikörper. Nachdem auch diese ausreichend Inkubationszeit erhielten, werden die nicht gebundenen Antikörper aus den Plattenfeldern gewaschen und die mit gebundenem HRP reagierende TMB-Substratlösung zugegeben. Daraufhin ändert sich binnen weniger Minuten die Farbe der Proben von hellgelb zu dunkelblau. 


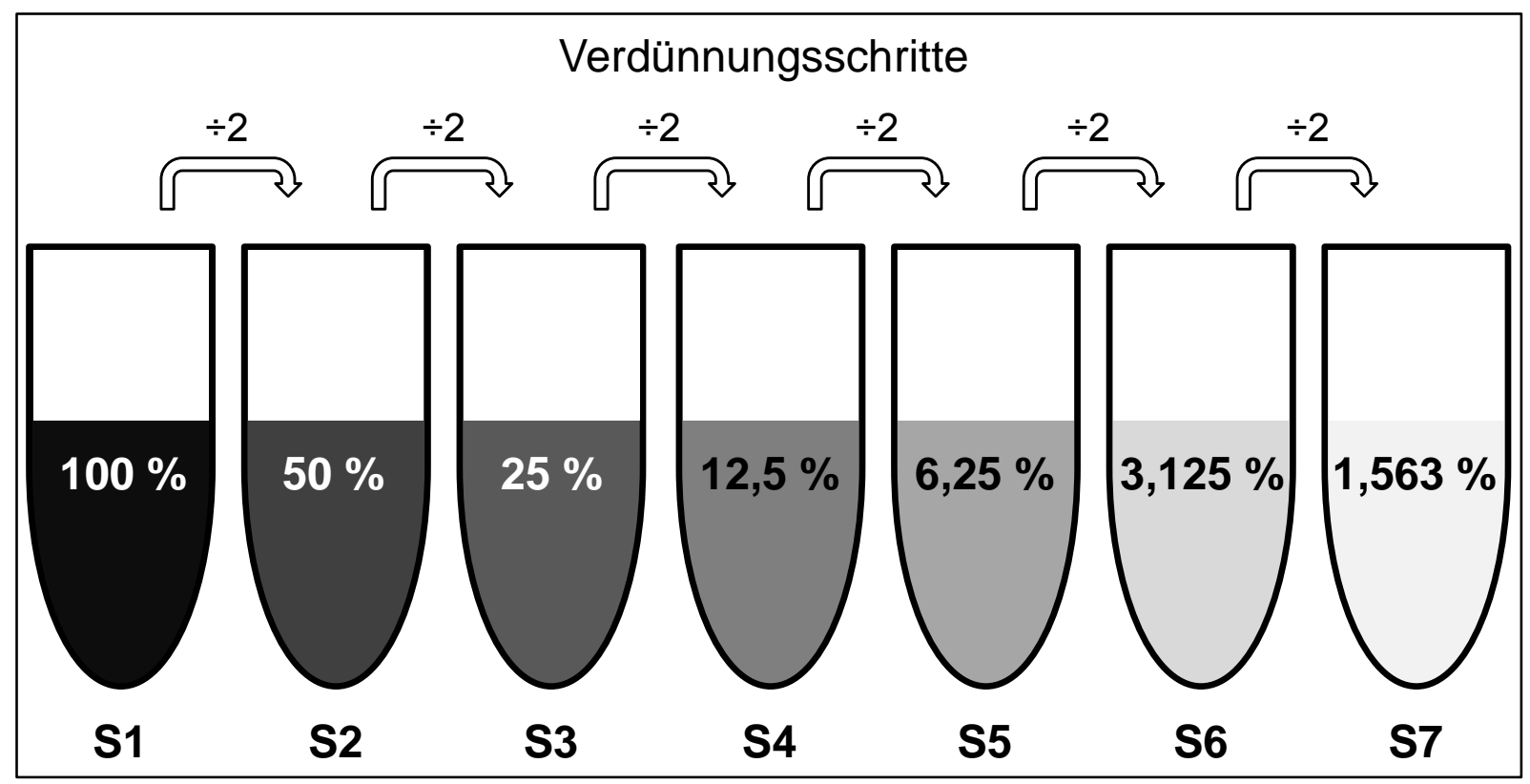

Abb. 2.5 Schematische Darstellung einer standardisierten Verdünnungsreihe

Mit jedem der insgesamt sechs Vermischungsschritte halbiert sich die Antigenkonzentration bei gleichbleibendem Probenvolumen. S1 liegt noch zu 100 \% konzentriert vor, wird aber im Zuge der Verdünnungsreihe auf nur noch ca. 1,56 \% seiner ursprünglichen Konzentration in S7 vermindert sein. Anhand der Standardreihe werden die photometrische Messung kalibriert und eine quantitative Vergleichsmöglichkeit der Proben mittels der gemessenen Absorptionswerte ermöglicht.

Abk. S: Standard

Diese Reaktion wird mit einer speziellen Stopplösung beendet und die ELISA-Platten werden mithilfe eines Photometers analysiert. Dazu wird die fluoreszierende Absorption der Proben mittels eines Lasers bei unterschiedlichen Wellenlängen detektiert. Es folgt die Erstellung einer Standardkurve basierend auf den Ergebnissen der Verdünnungsreihe und die quantitative Auswertung der doppelbestimmten Proben, von denen der Mittelwert in die Datenanalyse aufgenommen wird.

\subsection{Statistische Auswertung}

\subsubsection{Eingesetzte statistische Testverfahren}

Basis der statistischen Analysen bildet in allen Fällen der Versuchsauswertung die Testung der Stichproben auf die Art ihrer Verteilung. Zur Ermittlung des Vorliegens einer Gaußschen Normalverteilung dienen zum einen der Kolmogorow-Smirnow-Test und zum anderen der Shapiro-Wilk-Test, die beide wegen ihrer unterschiedlichen Berechnungsverfahren und Aussagekraft parallel angewandt werden. 
Aufgrund der niemals in allen Stichproben durchgängig gegebenen Normalverteilung werden sämtliche statistische Auswertungen stets mit nicht-parametrischen Tests analysiert. Da der Stichprobenumfang, der in die meisten Tests einfließt, überwiegend bei exakt zwei Variablen liegt, wird als Standardtest der Varianzanalysen der Mann-Whitney U-Test verwendet. Bei einem Stichprobenumfang von > 2 wird auf den Kruskal-Wallis H-Test ausgewichen. Im Fall der stimulierten Monozytenversuche wird mittels Wilcoxon-Test dem Sachverhalt zweier verbundener - bei ansonsten stets unverbundener - Stichproben Rechnung getragen.

Sämtliche Korrelationen werden mit dem ebenfalls nicht-parametrischen Rangkorrelationskoeffizienten Spearmans Rho [r] berechnet, der, zusätzlich zum Wahrscheinlichkeits-/Signifikanzwert $[p]$, bei den Darstellungen der Korrelationsgraden immer ebenso angegeben wird wie die lineare Regressionsgrade.

Die Darstellung der weiteren Ergebnisse erfolgt in Anbetracht der nicht-normal verteilten Datenlage per continuitatem mit an Box-Plots angelehnten Histogrammen, die neben dem Median- auch die unteren und oberen Quartilwerte (0,25- und 0,75-Quartile) - und damit den Interquartilabstand darstellen.

\subsection{2 p-Wert-Berechnung, Konfidenzintervall und Signifikanzniveau}

Der p-Wert wird durchgängig zweiseitig berechnet. Das Konfidenzintervall ist bei allen statistischen Analysen mit $95 \%$ angegeben. Ein $p$-Wert von $\leq 0,05$ ist als statistische Signifikanz ausgewiesen und zieht die Ablehnung der Nullhypothese nach sich.

\subsubsection{Analyse- und Darstellungssoftware}

Die statistische Auswertung erfolgt zum einem mit IBM ${ }^{\circledast}$ SPSS $^{\circledR}$ Statistics (Versionen 20.0 und 22.0; International Business Machines Corp., Armonk, NY, USA), zum anderen mit GraphPad Prism (Versionen 5.01 für Windows ${ }^{\circledR}$ und 6.0f für Mac OS X; GraphPad Software, Inc., La Jolla, CA, USA). Darüber hinaus werden die Daten und diese Arbeit mittels Microsoft ${ }^{\circledast}$ Office Professional Plus 2010 und Microsoft ${ }^{\circledast}$ Office 2011 für Mac (beides: Microsoft Corp.; Redmond, WA, USA) bearbeitet und erstellt. 


\section{ERGEBNISSE}

\subsection{Charakteristika der verschiedenen Studiengruppen}

Die Charakteristika der Studienteilnehmer bezüglich demographischer Angaben, kardiovaskulärer Risikofaktoren, relevanter (Neben-) Diagnosen und Medikamenteneinnahmen finden sich in Tab. 3.1. Hämatologisch und laborchemisch gewonnene Laborparameter sind in Tab. 3.2 dargestellt.

\begin{tabular}{|c|c|c|c|}
\hline & Ktr. $(n=64)$ & KHK $(n=60)$ & p-Wert \\
\hline Männlich, n (\%) & $46(71,9)$ & $46(76,7)$ & 0,544 \\
\hline Alter, Jahre & $53,5[47,0 ; 57,8]$ & $70,0[63,3 ; 73,0]$ & $<0,001$ \\
\hline BMI, $\mathrm{kg} / \mathrm{m}^{2}$ & $25,4[23,6 ; 27,4]$ & $26,4[23,9 ; 30,1]$ & 0,061 \\
\hline Typ-2-Diabetes mellitus, n (\%) & $0(0)$ & $12(20,0)$ & $<0,001$ \\
\hline Arterielle Hypertonie, $\mathrm{n}(\%)$ & $0(0)$ & $49(81,7)$ & $<0,001$ \\
\hline Hypercholesterinämie, $n(\%)$ & $0(0)$ & $37(61,7)$ & $<0,001$ \\
\hline Rauchen, $n(\%)$ & $0(0)$ & $8(13,3)$ & $<0,01$ \\
\hline Koronare Herzkrankheit, $n(\%)$ & $0(0)$ & $60(100,0)$ & $<0,001$ \\
\hline 1-Gefäßerkrankung, n (\%) & $0(0)$ & $17(28,3)$ & $<0,001$ \\
\hline 2-Gefäßerkrankung, n (\%) & $0(0)$ & $14(23,3)$ & $<0,001$ \\
\hline 3-Gefäßerkrankung, n (\%) & $0(0)$ & $29(48,3)$ & $<0,001$ \\
\hline Z. n. operativer Myokardrevaskularisation, $n$ (\%) & $0(0)$ & $24(40,0)$ & $<0,001$ \\
\hline Z. n. Apoplex, n (\%) & $0(0)$ & $4(6,7)$ & $<0,05$ \\
\hline pAVK, n (\%) & $0(0)$ & $2(3,3)$ & 0,142 \\
\hline ACE-Hemmer/AT ${ }_{1}$-Blocker, $n(\%)$ & $0(0)$ & $54(90,0)$ & $<0,001$ \\
\hline Acetylsalicylsäure, $n$ (\%) & $0(0)$ & $49(81,7)$ & $<0,001$ \\
\hline$\beta$-Blocker, n (\%) & $0(0)$ & $49(81,7)$ & $<0,001$ \\
\hline Orale Antidiabetika, n (\%) & $0(0)$ & $11(18,3)$ & $<0,001$ \\
\hline Insulin, $n(\%)$ & $0(0)$ & $3(5,0)$ & 0,071 \\
\hline Phenprocoumon, $\mathrm{n}(\%)$ & $0(0)$ & $18(30,0)$ & $<0,001$ \\
\hline Thienopyridin, n (\%) & $0(0)$ & $11(18,3)$ & $<0,001$ \\
\hline HMG-CoA-Reduktasehemmer, $n$ (\%) & $0(0)$ & $48(80,0)$ & $<0,001$ \\
\hline Ezetimib, $n(\%)$ & $0(0)$ & $11(18,3)$ & $<0,001$ \\
\hline
\end{tabular}

Tab. 3.1 Demographische und klinische Charakteristika der Studiengruppen

Darstellung als mediane Ergebnisse, Quartile $[0,25 ; 0,75]$ oder als Absolut- (n) und Prozentwerte (\%) der Studienteilnehmer (modifiziert nach Czepluch et al. 2014, S. 147).

Abk. ACE: Angiotensinkonversionsenzym; $\mathrm{AT}_{1}$ : Angiotensin-II-Rezeptor-Subtyp-1-Antagonist; BMI: Körpermasseindex; HMG-CoA: 3-Hydroxy-3-Methylglutaryl-Coenzym-A; KHK: koronare Herzkrankheit; Ktr.: Kontrollgruppe; pAVK: periphere arterielle Verschlusskrankheit; Z. n.: Zustand nach 


\begin{tabular}{lccr}
\hline & Ktr. $(\mathbf{n}=\mathbf{6 4})$ & KHK $(\mathbf{n}=\mathbf{6 0})$ & p-Wert \\
\hline \hline Leukozyten, $\times 10^{3} / \mu l$ & $5,9[4,7 ; 6,8]$ & $6,6[5,5 ; 8,0]$ & $<\mathbf{0 , 0 1}$ \\
Monozyten, $\times 10^{3} / \mu l$ & $0,51[0,41 ; 0,63]$ & $0,51[0,41 ; 0,60]$ & 0,750 \\
Hämoglobin, $\mathrm{g} / \mathrm{dl}$ & $14,1[13,5 ; 14,9]$ & $14,1[13,1 ; 15,1]$ & 0,717 \\
Thrombozyten, $\times 10^{3} / \mu l$ & $225[195 ; 275]$ & $200[166 ; 248]$ & $<\mathbf{0 , 0 1}$ \\
\hline \hline hsCRP, $\mathrm{mg} / \mathrm{l}$ & $0,74[0,43 ; 2,00]$ & $2,55[1,23 ; 4,70]$ & $<\mathbf{0 , 0 0 1}$ \\
Kreatinin, mg/dl & $0,88[0,78 ; 0,97]$ & $0,95[0,83 ; 1,09]$ & $<\mathbf{0 , 0 1}$ \\
AST, U/l & $26,5[23,0 ; 33,8]$ & $30,0[24,3 ; 35,5]$ & 0,251 \\
Gesamtcholesterin, mg/dl & $206[183 ; 222]$ & $172[149 ; 211]$ & $<\mathbf{0 , 0 0 1}$ \\
LDL-C, $\mathrm{mg} / \mathrm{dl}^{\text {HDL-C, } \mathrm{mg} / \mathrm{dl}}$ & $120[104 ; 138]$ & $97[78 ; 130]$ & $<\mathbf{0 , 0 1}$ \\
HbA $_{\mathbf{l c}}, \mathrm{mmol} / \mathrm{mol}$ & $58,5[46,5 ; 76,5]$ & $51,0[41,0 ; 61,8]$ & $<\mathbf{0 , 0 5}$ \\
& $37,7[35,5 ; 39,9]$ & $41,0[37,7 ; 44,3]$ & $<\mathbf{0 , 0 0 1}$
\end{tabular}

\section{Tab. 3.2 Hämatologische und laborchemische Charakteristika der Studiengruppen}

Darstellung als mediane Ergebnisse, Quartile $[0,25 ; 0,75]$ oder als Absolut- (n) und Prozentwerte (\%) der Studienteilnehmer. In der Kontrollgruppe fehlen drei Werte die absolute Monozytenzahl und zehn den $\mathrm{HbA}_{1 \mathrm{c}}$-Wert betreffend (modifiziert nach Czepluch et al. 2014, S. 147).

Abk. AST: Aspartataminotransferase; HbA 1 : glykosiliertes Hämoglobin; HDL-C: Lipoprotein hoher DichteCholesterin; hsCRP: hochsensitives C-reaktives Protein; KHK: koronare Herzkrankheit; Ktr.: Kontrollgruppe; LDL-C: Lipoprotein geringer Dichte-Cholesterin

Die Studiengruppen wurden unter Beachtung ihrer biometrischen Eigenschaften bestückt. KHK- und Kontrollgruppe unterscheiden sich nur minim hinsichtlich ihrer Gruppengröße (Ktr.: $n=64$ vs. KHK: $\mathrm{n}=60$ ). Neben einem erhöhten medianen Alter der KHK-Patienten im Vergleich zur Kontrollgruppe (Ktr.: 53,5 Jahre vs. KHK: 70,0 Jahre, $p<0,001$ ) sind darüber hinaus sowohl die Leukozytenzahl als auch der hsCRP-Plasmaspiegel in der Gruppe der KHK-Patienten signifikant höher als bei den Kon-

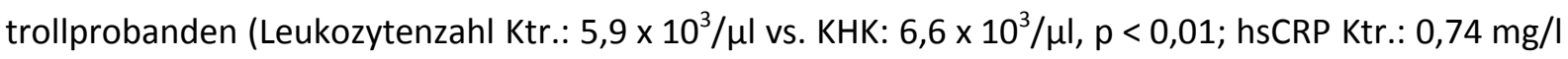
vs. KHK 2,55 mg/l, $\mathrm{p}<0,001)$. Dagegen unterscheiden sich beide Studiengruppen nicht statistisch bedeutsam in ihrem medianen BMI (Ktr.: $25,4 \mathrm{~kg} / \mathrm{m}^{2}$ vs. KHK: $26,4 \mathrm{~kg} / \mathrm{m}^{2}, \mathrm{p}=0,061$ ).

Die Gruppe der altersadaptierten Patienten ohne KHK [aaKtr.] umfasst neun Studienteilnehmer $(\delta=6, q=3)$ und unterscheidet sich hinsichtlich ihres medianen Alters nicht signifikant von dem der KHK-Patienten (aaKtr.: 72,0 Jahre vs. KHK: 70,0 Jahre, $p=0,067$ ). Auch der mediane BMI ist nicht kennzeichnend unterschiedlich zwischen den altersadaptierten Kontrollprobanden und den KHKPatienten (aaKtr.: $24,8 \mathrm{~kg} / \mathrm{m}^{2}$ vs. KHK: $26,4 \mathrm{~kg} / \mathrm{m}^{2}, \mathrm{p}=0,512$ ). 


\subsection{Generelle Gatingstrategien bei der Analyse durchflusszytometrisch gewonnener Ergebnisse}

Weder die Auswahl der verschiedenen Antikörper zur durchflusszytometrischen Monozytenevaluation noch das Gating, d. h. die Detektion und Charakterisierung der verschiedenen korpuskulären Blutprobenbestandteile, sind aktuell in der Wissenschaft methodisch einheitlich festgeschrieben (Appleby et al. 2013). So finden sich Publikationen, in denen sehr eng an den jeweiligen Isotypenkontrollen gegated wird (vergl. Fingerle et al. 1993; Swirski et al. 2007), aber auch weniger konservatives, weiter gefasstes Gating - allerdings immer noch in Abhängigkeit von Isotypenkontrollen - ist vielfach beschrieben (vergl. Heimbeck et al. 2010). Zunehmend findet sich in neueren Publikationen ein sogenanntes immunologisches Gating, das gänzlich auf Isotypenkontrollen verzichtet und die fluoreszenzmarkierten Zellen oder Zellbestandteile anhand unterschiedlicher Charakteristika und ihrer Darstellungen in Histogrammen oder Dot-Plots detektiert und damit definiert (vergl. Heine et al. 2008; Zawada et al. 2011) - wobei gleichzeitig Auto- und Hintergrundfluoreszenz durch unspezifische Antikörperbindungen ausgeschlossen werden können (Hulspas et al. 2009).

\subsection{Detektion der Monozyten per Durchflusszytometrie und ihre Zuordnung zu den drei monozytären Untergruppen}

Das Gating im Rahmen der vorliegenden Studienauswertung erfolgt vollständig unter Einbezug von Negativ- und Isotypenkontrollen, um Autofluoreszenzen und unspezifische Bindungen der sehr reaktiven Monozyten auszuschließen.

Die Auftragung der per Durchflusszytometrie detektierten Zellen und Zellbestandteile sowohl aus lysiertem Vollblut als auch nach PBMC-Gewinnung erfolgt primär anhand ihrer Streulichteigenschaften in charakteristischen Scatter-Plots nach FSC und SSC. Die so erfassten Monozyten werden nachfolgend in Dot-Plot-Darstellungen der Expressionen ihrer Oberflächenmarker CD14 und CD16 den drei beschriebenen Monozytensubgruppen zugeordnet. Anschließend werden die einzelnen monozytären Untergruppen separat hinsichtlich ihrer Expression von CCR5, KLF4, CD42b und CD44 untersucht und dazu mittels Histogrammdarstellungen evaluiert (Czepluch et al. 2013b, 2014).

Die folgende Abbildung visualisiert beispielhaft das Vorgehen der Monozytendetektion mittels Scatter-Plots aus isolierten PBMCs (siehe Abb. 3.1 a) sowie lysiertem Vollblut (siehe Abb. 3.1 b), außerdem die Evaluation der drei Monozytensubgruppen per charakteristischem CD14- und CD16-Gating in einer Dot-Plot-Darstellung (siehe Abb. $3.1 \mathrm{c}$ ). 


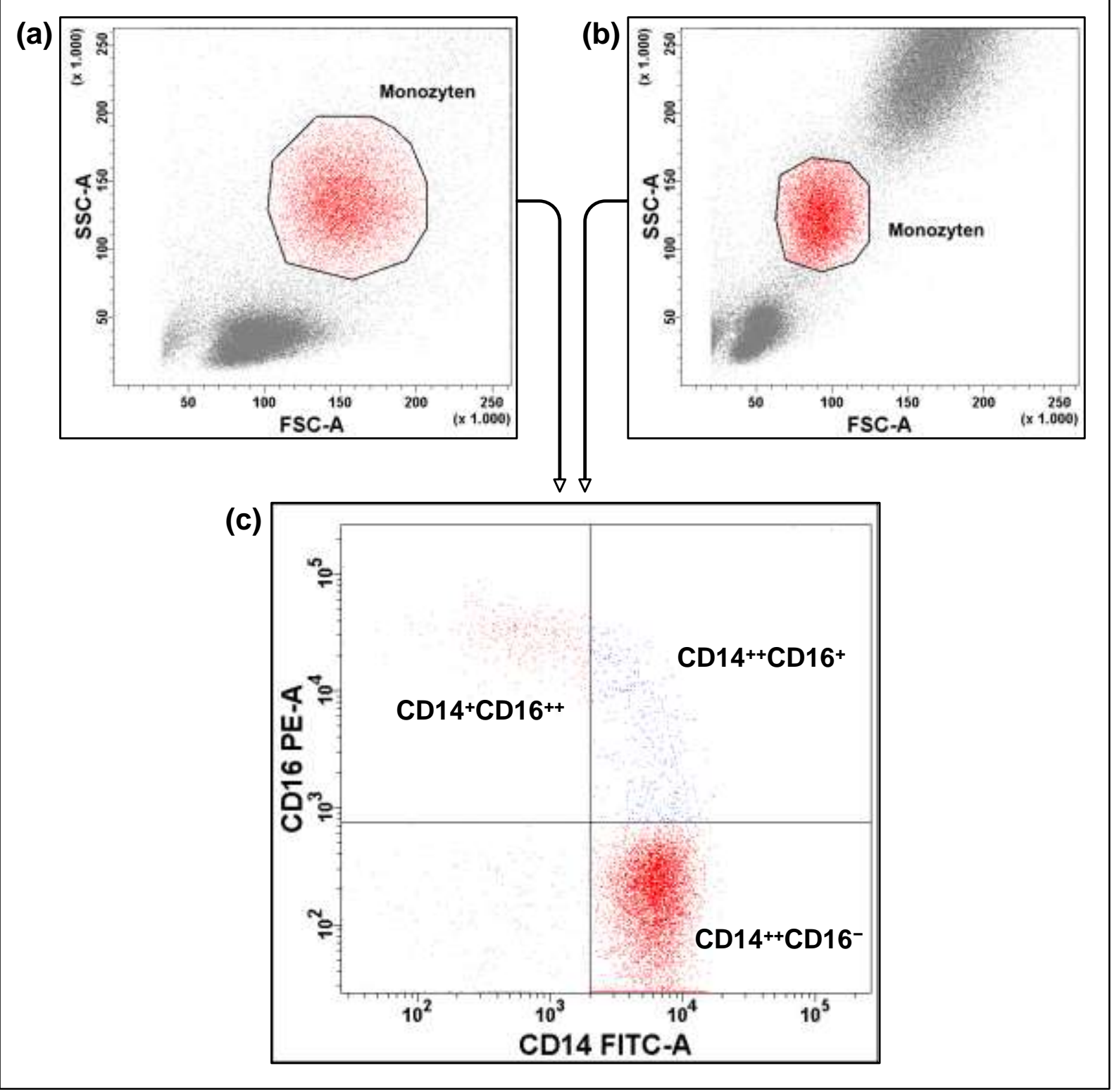

\section{Abb. 3.1 Durchflusszytometrische Monozytendetektion und Evaluation der monozytären Subgruppen}

(a) Gating der Monozytenpopulation aus humanen PBMCs anhand ihrer Streulichteigenschaften. Da die Granulozytenpopulation bei der Probenaufbereitung herausgearbeitet und verworfen wird, finden sich im FACS ${ }^{\text {TM }}$ Bild neben der Monozyten- nur noch eine Lymphozytenwolke. (b) Ebenfalls nach FSC und SSC separierte Zellen einer lysierten humanen Vollblutprobe. Es lassen sich neben den gegateten Monozyten auch die kleineren Lympho- und die größeren Granulozyten detektieren. (c) Auftragung der detektierten Monozytenwolken anhand ihrer Oberflächenrezeptoren CD14 und CD16. Hierbei zeigt sich die typische dreiteilige Separierung der Monozyten in die mit Abstand größte Gruppe der klassischen $\mathrm{CD} 14^{++} \mathrm{CD} 16^{-}$-Monozyten (rot) und die $\mathrm{CD} 16^{+}$Monozyten, die sich nochmals in die intermediären $\mathrm{CD}_{1} 4^{++} \mathrm{CD} 16^{+}$- (blau) und die nicht-klassischen $\mathrm{CD} 14^{+} \mathrm{CD} 16^{++}$-Monozyten (grün) unterteilen lassen.

Abk. CD: cluster of differentiation; FACS ${ }^{\mathrm{TM}}$ : fluoreszenzaktivierte Zellsortierung; FSC: Vorwärtsstreulicht; PBMC: mononukleäre Zelle des peripheren Blutes; SSC: Seitwärtsstreulicht 


\subsection{Verteilung der Monozytensubgruppen bei KHK-Patienten und gesunden Kontrollprobanden}

Abb. 3.2 zeigt die Verteilungsanalyseergebnisse der drei Monozytensubgruppen anhand ihrer CD14und CD16-Expression. Sowohl bei den KHK-Patienten als auch in der Kontrollgruppe findet sich der mit Abstand größte Monozytenanteil im Bereich der klassischen $\mathrm{CD} 14^{++} \mathrm{CD} 16^{-}$-Monozyten, wobei die KHK-Patienten signifikant mehr $\mathrm{CD} 14^{++} \mathrm{CD} 16^{-}$-Monozyten aufweisen als die gesunden Probanden (Ktr.: 84,9\% vs. KHK: 86,6\%, p<0,05). Innerhalb der CD14 ${ }^{++} \mathrm{CD} 16^{+}$-Monozyten sind keine signifikanten Unterschiede zwischen beiden Studienkollektiven festzustellen (Ktr.: 7,1\% vs. KHK: 7,7\%, $p=0,134)$, wohingegen der $C D 14^{+} C D 16^{++}$-Monozytenanteil der KHK-Patientengruppe im Vergleich zu dem der Kontrollprobanden signifikant niedriger ist (Ktr.: 7,8 \% vs. KHK: 5,9\%, p<0,001).

Innerhalb der jeweiligen Studiengruppe finden sich, verglichen mit den klassischen, prozentual deutlich weniger intermediäre und nicht-klassische Monozyten (jeweils $p<0,001$ bei Ktr. und KHK). Die $\mathrm{CD} 14^{++} \mathrm{CD} 16^{+}$-Monozyten weisen innerhalb der Kontrollgruppe eine signifikant geringere Anzahl im Vergleich zu den $C D 14^{+} C D 16^{++}$-Monozyten auf $(p<0,05)$. Genau entgegengesetzt verhält es sich mit den intermediären und nicht-klassischen Monozyten der KHK-Patienten, bei denen erstere eine wesentlich größere Anzahl als letztere ausmachen $(p<0,001)$.

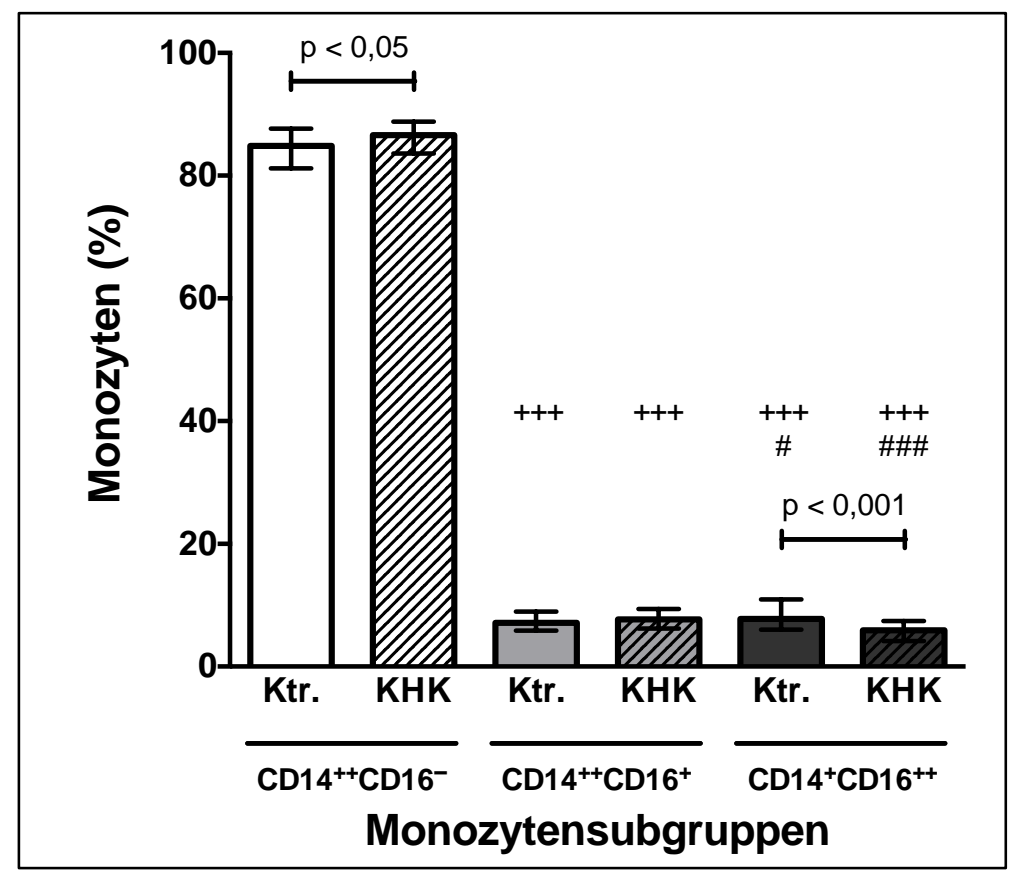

Abb. 3.2 Relativer Anteil der Monozytensubgruppen an der Gesamtmonozytenzahl

Die Histogramme zeigen die Mediane, Quartile und Interquartilabstände. Signifikante Unterschiede zwischen der Kontrollgruppe gesunder Blutspender (Ktr., $\mathrm{n}=64$ ) und den Patienten mit koronarer Herzkrankheit $(K H K, n=60)$ sind als $p$-Werte ausgeschrieben. Divergenzen innerhalb der jeweiligen Studiengruppen sind als +++ $(p<0,001)$ für $\mathrm{CD} 4^{++} \mathrm{CD} 16^{-}$vs. $\mathrm{CD}_{14} 4^{++} \mathrm{CD} 16^{+}$oder $\mathrm{CD} 14^{+} \mathrm{CD} 16^{++}$bzw. \# $(p<0,05)$ oder $\# \# \#(p<0,001)$ für $\mathrm{CD} 14^{++} \mathrm{CD} 16^{+}$vs. $\mathrm{CD} 14^{+} \mathrm{CD} 16^{++}$angegeben (modifiziert nach Czepluch et al. 2014, S. 148).

Die Betrachtung der mittels Differenzialblutbild eruierten absoluten Monozytenzahlen zeigt ein der prozentualen Monozytenverteilung ähnliches Bild (siehe Abb. 3.3). Der Anteil der CD14 $4^{++} \mathrm{CD} 16^{-}$- 
Monozyten ist wiederum in beiden Studienpopulationen am höchsten, weist aber keine bedeutsa-

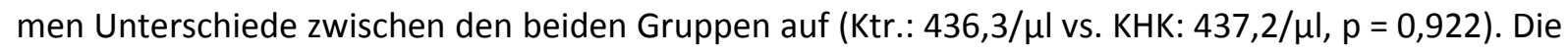
Anzahl intermediärer Monozyten unterscheidet sich ebenfalls nicht eindrücklich zwischen beiden

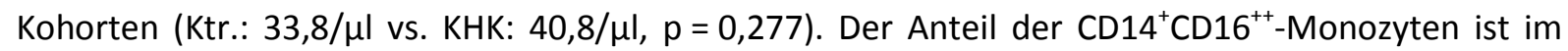
KHK-Patientenkollektiv abermals signifikant niedriger als bei den gesunden Kontrollprobanden (Ktr.: $39,2 / \mu$ vs. KHK: $29,1 / \mu l, p<0,001)$.

Auch die Analyse der absoluten Monozytenzahlen zeigt innerhalb beider Versuchsgruppen wesentlich mehr $\mathrm{CD} 14^{++} \mathrm{CD} 16^{-}$-Monozyten verglichen mit den beiden anderen Monozytensubgruppen (jeweils $p<0,001$ für Ktr. und KHK). Ein signifikanter Unterschied zwischen $\mathrm{CD} 14^{++} \mathrm{CD} 16^{+}-$und $C D 14^{+} C D 16^{++}$-Monozyten innerhalb der Kontrollgruppe ist nicht nachweisbar $(p=0,119)$. Wohingegen zwischen ebendiesen Subgruppen innerhalb des KHK-Kollektivs ein eindrücklich niedrigerer Anteil der nicht-klassischen Monozyten zu finden ist $(p<0,01)$.

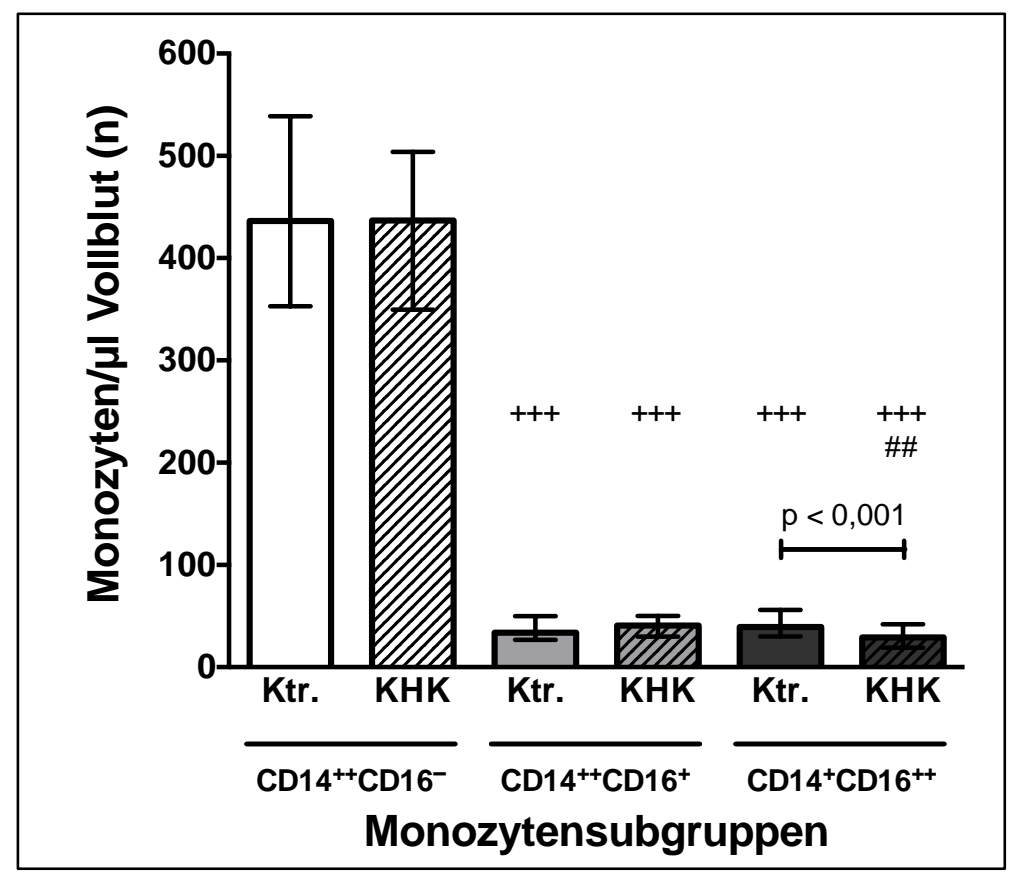

Abb. 3.3 Absolute Monozytenanzahl pro Subgruppe

Die Histogramme zeigen die Mediane, Quartile und Interquartilabstände. Signifikante Unterschiede zwischen der Kontrollgruppe gesunder Blutspender (Ktr., $\mathrm{n}=64$ ) und den Patienten mit koronarer Herzkrankheit (KHK, $n=60$ ) sind als $p$-Werte ausgeschrieben. Divergenzen innerhalb der jeweiligen Studiengruppen sind als +++ $(p<0,001)$ für $\mathrm{CD} 14^{++} \mathrm{CD} 16^{-}$vs. $\mathrm{CD} 14^{++} \mathrm{CD} 16^{+}$oder $\mathrm{CD} 14^{+} \mathrm{CD} 16^{++}$bzw. \#\# $(\mathrm{p}<0,01)$ für $\mathrm{CD} 14^{++} \mathrm{CD} 16^{+}$vs. $\mathrm{CD} 14^{+} \mathrm{CD} 16^{++}$angegeben (modifiziert nach Czepluch et al. 2014, S. 148).

Ein Einfluss des Probandenalters auf die prozentuale oder absolute Monozytenzahl und deren Subgruppenverteilung kann mittels Analyse der altersadaptierten Kontrollprobanden [aaKtr.] nicht nachgewiesen werden (nicht dargestellt). So findet sich auch bei den älteren Studienteilnehmern ohne KHK die größte monozytäre Gruppe im Bereich der klassischen (85,0\% bzw. 492,2/ $\mu$ l), die mittlere

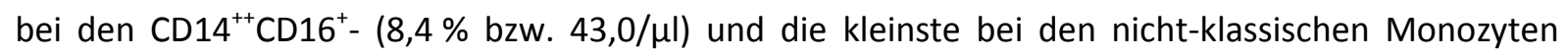

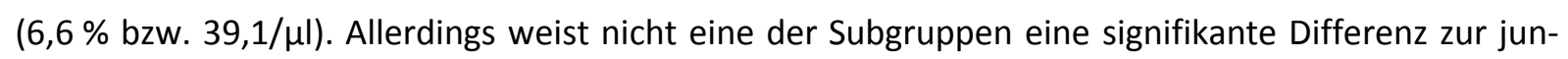
gen Kontroll- oder aber der KHK-Patientengruppe auf. Die Anzahl klassischer Monozyten der alters- 
adapierten Studienteilnehmer differiert dagegen (wie auch die der KHK- und jungen Kontrollgruppe) auffallend deutlich von den intermediären und nicht-klassischen Monozyten (jeweils $p<0,001$ ).

\subsection{Monozytäre CCR5-Expression und CCL5-Serumspiegel}

\subsubsection{Durchflusszytometrische Quantifizierung der monozytären CCR5-Expression}

Die Auswertung der CCR5-Expression, dem Rezeptor des plättchenaktivierenden Chemokins CCL5, auf den Monozytenoberflächen der einzelnen Untergruppen zeigt bei beiden Studiengruppen den deutlich größten Anteil der CCR5 ${ }^{+}$-Monozyten im Bereich der intermediären Monozyten (siehe Abb. 3.4). Der Anteil der $C \mathrm{CR} 5^{+} \mathrm{CD} 14^{++} \mathrm{CD} 16^{+}$-Monozyten liegt bei den KHK-Patienten allerdings signifikant niedriger als bei den gesunden Kontrollprobanden (Ktr.: 38,0 \% vs. KHK: 35,6\%, p<0,05). Die nichtklassische Fraktion weist generell betrachtet den zweitgrößten Anteil CCR5 ${ }^{+}$-Monozyten auf, wobei auch hier der Anteil an $\mathrm{CCR} 5^{+} \mathrm{CD} 14^{+} \mathrm{CD} 16^{++}$-Monozyten bei den KHK-Patienten verglichen mit den gesunden Kontrollprobanden deutlich niedriger ist (Ktr.: 10,9\% vs. KHK: 8,4\%, p<0,001). Der geringste $\mathrm{CCR}^{+}$-Anteil findet sich - ebenfalls beide Studiengruppen betreffend - bei den Monozyten des klassischen Typs. Auch hier ist der relative Anteil der $\mathrm{CCRS}^{+} \mathrm{CD} 14^{++} \mathrm{CD} 16^{-}$-Monozyten bei den KHK-Patienten im Vergleich zur Kontrollgruppe erheblich niedriger (Ktr.: 8,1\% vs. KHK: 5,5\%, $\mathrm{p}<0,001)$.

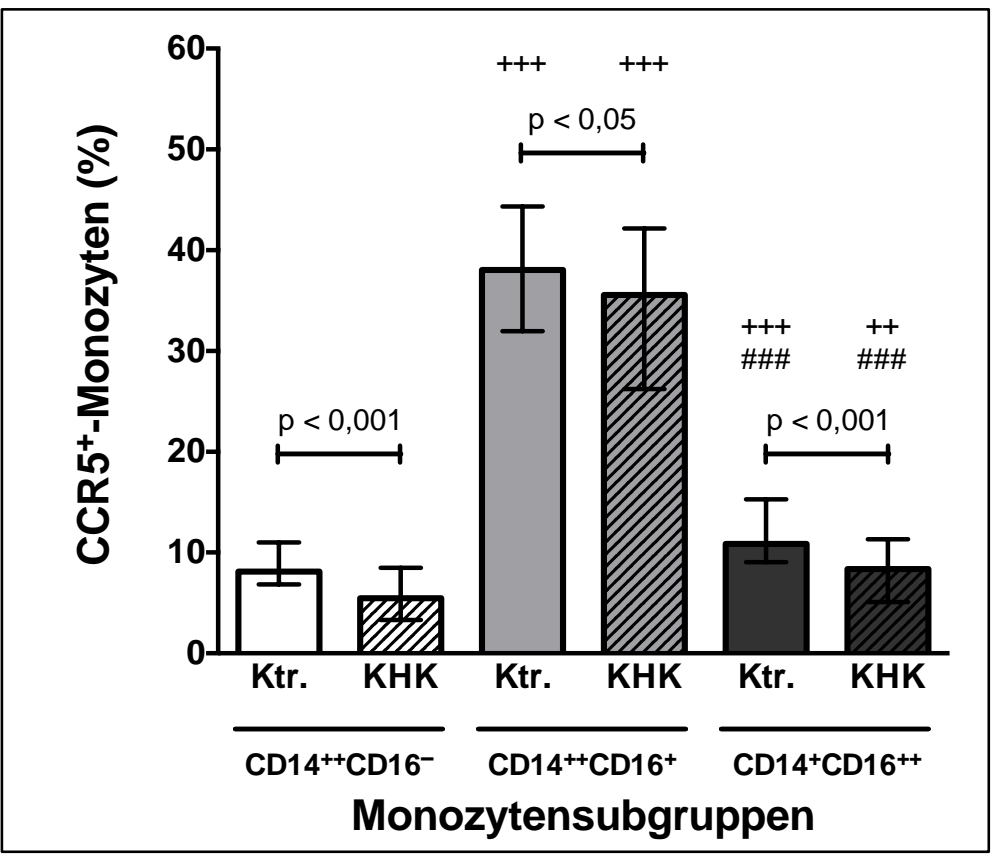

Abb. 3.4 CCR5+-Monozyten und ihre Verteilung auf die Monozytensubgruppen

Die Histogramme zeigen die Mediane, Quartile und Interquartilabstände. Signifikante Unterschiede zwischen der Kontrollgruppe gesunder Blutspender (Ktr., $n=64$ ) und den Patienten mit koronarer Herzkrankheit (KHK, $n=60)$ sind als $p$-Werte ausgeschrieben. Divergenzen innerhalb der jeweiligen Studiengruppen sind als ++ $(p<0,01)$ oder +++ $(p<0,001)$ für $\mathrm{CD}_{14}{ }^{++} \mathrm{CD} 16^{-}$vs. $\mathrm{CD} 14^{++} \mathrm{CD} 16^{+}$oder $\mathrm{CD} 14^{+} \mathrm{CD} 16^{++}$ bzw. \#\#\# (p<0,001) für $\mathrm{CD} 14^{++} \mathrm{CD}_{16}^{+}$vs. $\mathrm{CD} 14^{+} \mathrm{CD} 16^{++}$angegeben (modifiziert nach Czepluch et al. 2014, S. 149). 
Innerhalb der Kontrollgruppe finden sich signifikant mehr CCR5 ${ }^{+}$-Monozyten bei den intermediären Monozyten als bei den zwei anderen Untergruppen (jeweils $p<0,001$ ). Auch ist der Anteil an $\mathrm{CCR}^{+} \mathrm{CD} 14^{++} \mathrm{CD} 16^{-}$-Monozyten bedeutsam niedriger verglichen mit dem der CCR5 ${ }^{+} \mathrm{CD} 14^{+} \mathrm{CD} 16^{++}$Monozyten $(p<0,001)$. Ebenfalls liegt in der KHK-Gruppe der relative $C \mathrm{CR}^{+}{ }^{+}$-Anteil der intermediären Monozyten höher verglichen mit denen der anderen beiden Untergruppen (jeweils $p<0,001$ ). Der relative Anteil der $\mathrm{CCR} 5^{+} \mathrm{CD} 14^{++} \mathrm{CD} 16^{-}$-Monozyten ist darüber hinaus ebenfalls niedriger als jener der $\mathrm{CCR}^{+} \mathrm{CD} 14^{+} \mathrm{CD} 16^{++}$-Monozyten $(\mathrm{p}<0,01)$.

Die mediane Fluoreszenzintensität abzüglich der korrespondierenden Isotypenkontrolle (engl. mean fluorescence intensity-fluorescence minus one [MFI-FMO]) der $\mathrm{CCR}^{+}$-Monozyten unterscheidet sich zwischen keiner der drei Monozytenuntergruppen (siehe Abb. 3.5). Das bedeutet, dass zwar die Anzahl CCR5 ${ }^{+}$-Monozyten in allen drei Monozytenfraktionen der KHK- verglichen mit der Kontrollgruppe signifikant niedriger ist, die mediane Anzahl an CCR5 pro Monozyt aber nicht zwischen KHKPatienten und Kontrollpersonen differiert. Dennoch ist eine wesentlich höhere MFI-FMO der $\mathrm{CD} 14^{++} \mathrm{CD} 16^{+}$- verglichen mit den $\mathrm{CD} 14^{++} \mathrm{CD} 16^{-}$-Monozyten beider Studiengruppen festzustellen (jeweils $p<0,001)$. Darüber hinaus weisen innerhalb der KHK-Gruppe auch die $\mathrm{CD} 14^{+} \mathrm{CD} 16^{++}$Monozyten im Vergleich zu den intermediären Monozyten eine signifikant niedrigere MFI-FMO auf $(p<0,001)$.

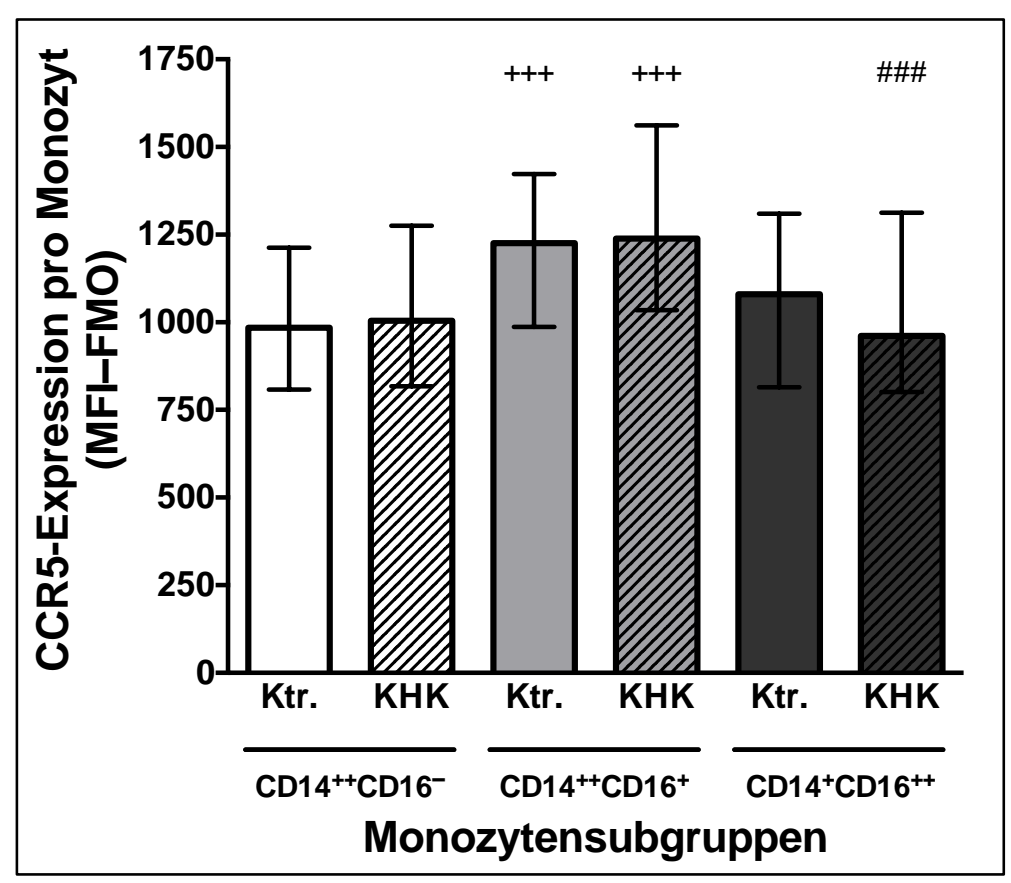

Abb. $3.5 \quad$ CCR5-MFI-FMO pro Monozytensubgruppe

Die Histogramme zeigen die Mediane, Quartile und Interquartilabstände. Signifikante Unterschiede zwischen der Kontrollgruppe gesunder Blutspender (Ktr., $\mathrm{n}=64$ ) und den Patienten mit koronarer Herzkrankheit $(K H K, n=60)$ finden sich nicht. Divergenzen innerhalb der jeweiligen Studiengruppen sind als +++ ( $p<0,001)$ für $\mathrm{CD}^{+++} 4^{++} \mathrm{CD} 16^{-}$vs. $\mathrm{CD} 14^{++} \mathrm{CD} 16^{+}$bzw. \#\#\# $(\mathrm{p}<0,001)$ für $\mathrm{CD} 14^{++} \mathrm{CD} 16^{+}$vs. $\mathrm{CD} 14^{+} \mathrm{CD} 16^{++}$ angegeben (modifiziert nach Czepluch et al. 2014, S. 149).

Die Analyse der CCR5 ${ }^{+}$-Monozyten bei der altersadaptierten Kontrollgruppe ohne KHK zeigt ähnliche Ergebnisse, wie der Vergleich von KHK- und junger Kontrollgruppe (siehe Abb. 3.6). Die 
$\mathrm{CCR}^{+} \mathrm{CD} 14^{++} \mathrm{CD} 16^{+}$-Monozyten stellen auch hier die mit Abstand größte Gruppe, die sich allerdings kaum vom KHK-Patientenkollektiv unterscheidet (aaKtr.: 35,8\%, $p=0,72$ vs. KHK). Die nichtklassischen stellen die zweitgrößte Gruppe an $\mathrm{CCR}^{+}$-Monozyten und weisen - wenn auch nicht signifikant auf Basis der maximal zulässigen Irrtumswahrscheinlichkeit - einen deutlichen Trend verglichen mit der geringeren Anzahl an $\mathrm{CCRS}^{+} \mathrm{CD} 14^{+} \mathrm{CD} 16^{++}$-Monozyten der KHK-Gruppe auf (aaKtr.: $12,4 \%, p=0,07$ vs. KHK). Ebenfalls die geringste CCR5 ${ }^{+}$-Expression in der altersangepassten Kontrollgruppe weisen die klassischen Monozyten auf, die aber im Vergleich zu denen der KHK-Gruppe dennoch signifikant mehr CCR5 ${ }^{+}$-Monozyten besitzen (aaKtr.: 7,4 \%, $p<0,05$ vs. KHK).

Statistisch bedeutsame Unterschiede zwischen der jungen und der altersadaptierten/älteren Kontrollgruppe finden sich in keiner der drei Monozytensubgruppen (nicht dargestellt).

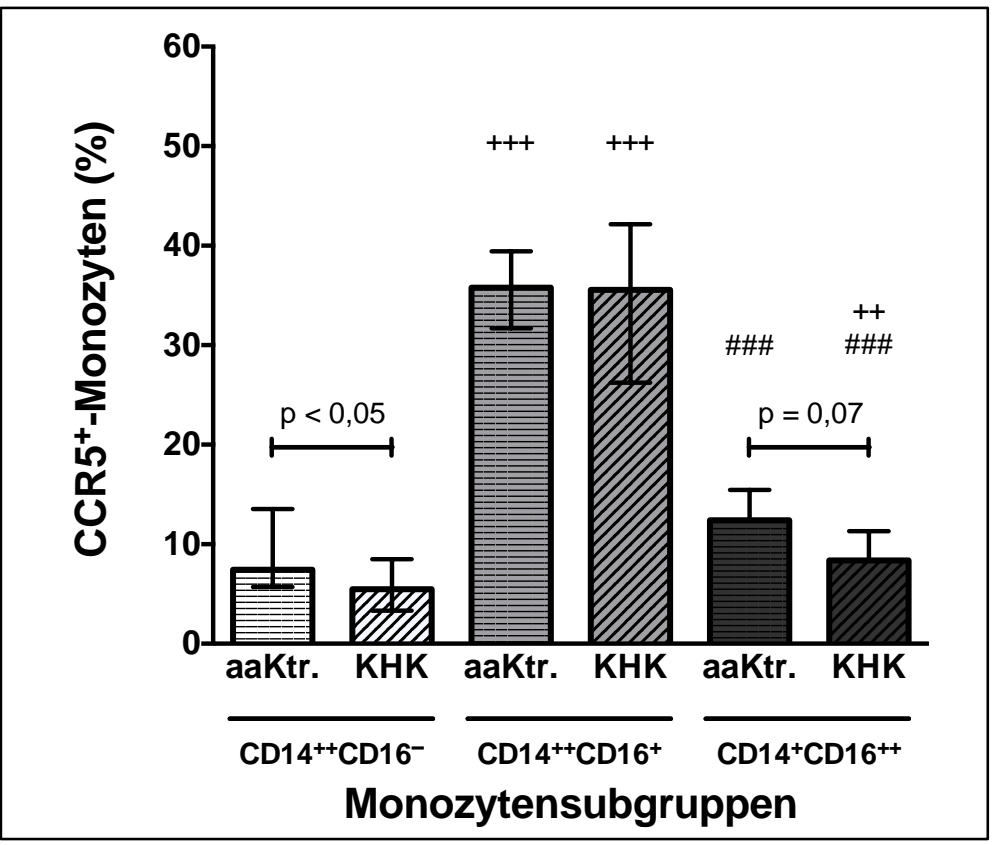

\begin{abstract}
Abb. 3.6 CCR5+-Monozyten und deren Verteilung bei altersadaptierten Kontrollprobanden

Die Histogramme zeigen die Mediane, Quartile und Interquartilabstände. Signifikante Unterschiede bzw. Tendenzen zwischen der altersadaptierten Kontrollgruppe ohne KHK (aaKtr., $\mathrm{n}=9$ ) und den Patienten mit koronarer Herzkrankheit (KHK, $n=60$ ) sind als $p$-Werte ausgeschrieben. Divergenzen innerhalb der jeweiligen Studiengruppen sind als $++(p<0,01)$ oder $+++(p<0,001)$ für $\mathrm{CD} 14^{++} \mathrm{CD} 16^{-}$vs. $\mathrm{CD} 14^{++} \mathrm{CD} 16^{+}$ oder $\mathrm{CD}_{14}^{+} \mathrm{CD} 16^{++}$bzw. \#\#\# $(p<0,001)$ für $\mathrm{CD}_{14}{ }^{++} \mathrm{CD} 16^{+}$vs. $\mathrm{CD} 14^{+} \mathrm{CD} 16^{++}$angegeben.
\end{abstract}

\title{
3.5.2 Einfluss der in vitro-Plasmastimulierung auf die monozytäre CCR5-Expression
}

Schließlich zeigt auch die in Abb. 3.6 dargestellte Auswertung der CCR5-Expression auf Monozyten gesunder, junger Blutspender $(n=4)$ nach vorangegangener vierstündiger in vitro-Inkubation mit Blutplasma von KHK-Patienten bzw. gesunden Kontrollprobanden einen signifikant niedrigeren relativen Anteil $\mathrm{CCR}^{+}$-Gesamtmonozyten nach Inkubation mit KHK-Patientenplasma im Vergleich zur 
Behandlung mit Plasma der gesunden Kontrollpersonen (Ktr.-Plasma: 30,5 \% vs. KHK-Plasma: 23,1 \%, $p<0,05)$.

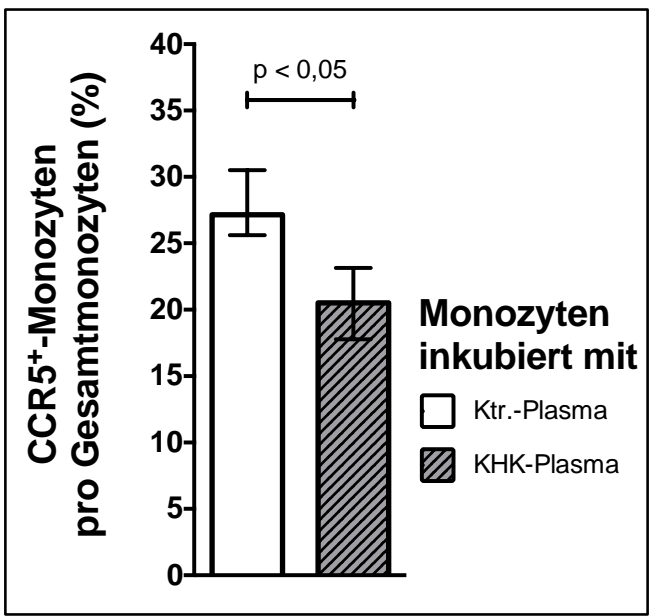

Abb. 3.7 Prozentualer Anteil CCR5+-Monozyten nach Inkubation gesunder Blutspendermonozyten mit Kontrollprobandenplasma vs. KHK-Patientenplasma

Die Histogramme zeigen die Mediane, Quartile und Interquartilabstände. Der signifikante Unterschied zwischen der Inkubationsgruppe mit Plasma gesunder Kontrollprobanden [Ktr., $\mathrm{n}=4$ ] und der mit Plasma von KHK-Patienten [KHK, $\mathrm{n}=4$ ] ist als $\mathrm{p}$-Wert ausgeschrieben (modifiziert nach Czepluch et al. 2014, S. 150).

Die MFI-FMO der monozytären CCR5-Expression zeigt keinen statistisch bedeutsamen Unterschied zwischen beiden Versuchsgruppen (Ktr.-Plasma: 408,5 MFI-FMO vs. KHK-Plasma: 467,0 MFI-FMO, $p=0,829 ;$ nicht dargestellt).

\subsubsection{CCL5-Serumspiegel}

Die per ELISA detektierten CCL5-Spiegel im Blutserum der Studienteilnehmer zeigen keine wesentlichen Unterschiede zwischen KHK-Patienten und Kontrollprobanden (Ktr.: 0,52 ng/ml vs. KHK: 0,52 $\mathrm{ng} / \mathrm{ml}, \mathrm{p}=0,775 ;$ nicht dargestellt).

\subsubsection{Einfluss cholesterinsenkender Medikation auf die Verteilung der monozytären Untergruppen und deren CCR5-Expression}

\subsubsection{Therapie mit HMG-CoA-Reduktasehemmern und ihre Auswirkungen auf die monozytäre CCR5-Expression}

Während ihrer Studienteilnahme werden 48 der 60 KHK-Patienten, d.h. $80 \%$, mit einem 3-Hydroxy-3-Methylglutaryl-Coenzym-A [HMG-CoA]-Reduktasehemmer (Synonym: Statin) behandelt. In Anbetracht des großen Einflusses von Statinen auf Therapie und Prognose bei atherosklerotischen Erkrankungen wie der KHK wird im Rahmen der vorliegenden Studie untersucht, inwieweit sich der relative Anteil $\mathrm{CCR}^{+}{ }^{+}$-Monozyten zwischen der KHK-Patientengruppe mit Statinmedikation und jener ohne unterscheidet (siehe Abb. 3.8). 
Die größten Anteile an $\mathrm{CCR5}^{+}$-Monozyten finden sich in beiden Versuchskollektiven bei der $\mathrm{CD} 14^{++} \mathrm{CD} 16^{+}$-Untergruppe, wobei die KHK-Patienten, die regelmäßig ein Statin einnehmen, signifikant mehr $\mathrm{CCRS}^{+} \mathrm{CD} 14^{++} \mathrm{CD} 16^{+}$-Monozyten aufweisen als jene Patienten ohne Statindauermedikation (Statin: $37,4 \%$ vs. kein Statin: 26,9\%, p <0,001). Die zweitmeisten CCR5 ${ }^{+}$-Monozyten finden sich bei den nicht-klassischen Monozyten beider Studiengruppen. Auch hier ist der relative Anteil an $\mathrm{CCR}^{+} \mathrm{CD} 14^{+} \mathrm{CD} 16^{++}$-Monozyten in der statintherapierten Gruppe der KHK-Patienten signifikant gröBer als in jener ohne Statinmedikation (Statin: 9,0\% vs. kein Statin: 6,0\%, $p<0,05$ ). Auch die relative Anzahl an $\mathrm{CCRS}^{+} \mathrm{CD} 14^{++} \mathrm{CD} 16^{-}$-Monozyten ist bei den Patienten mit Statineinnahme eindrücklich höher als bei jenen ohne (Statin: 6,5\% vs. kein Statin: 3,1\%, $p<0,01$ ).

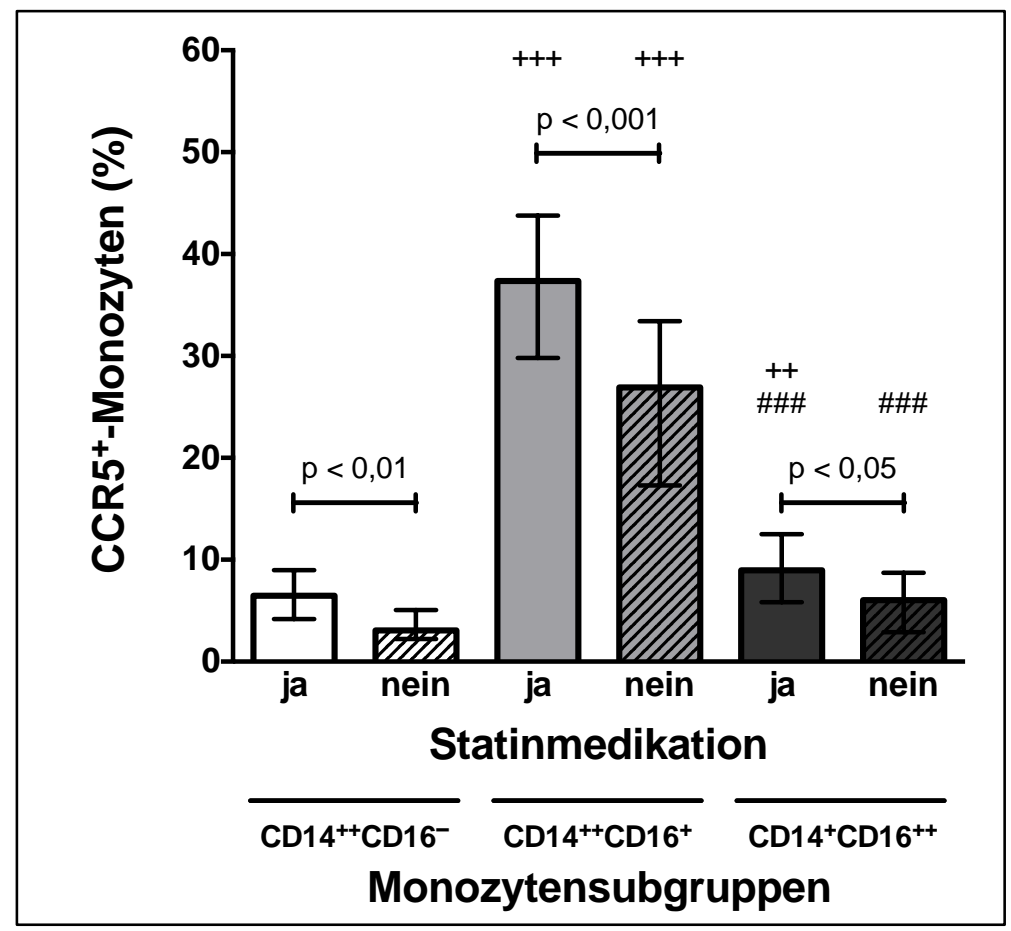

Abb. 3.8 Einfluss der Statinmedikation auf die CCR5-Expression der Monozytensubgruppen

Die Histogramme zeigen die Mediane, Quartile und Interquartilabstände. Signifikante Unterschiede zwischen der Gruppe von KHKPatienten, die mit einem Statin behandelt werden ( $\mathrm{ja}, \mathrm{n}=48$ ) und der Gruppe ohne Statinmedikation (nein, $\mathrm{n}=12$ ) sind als $\mathrm{p}$-Werte ausgeschrieben. Divergenzen innerhalb der jeweiligen Studiengruppen sind als $++(p<0,01)$ und $+++(p<0,001)$ für $\mathrm{CD} 14^{++} \mathrm{CD} 16^{-}$vs. $\mathrm{CD} 14^{++} \mathrm{CD} 16^{+}$ oder $\mathrm{CD}_{14}{ }^{+} \mathrm{CD} 16^{++}$bzw. \#\#\# $(p<0,001)$ für $\quad \mathrm{CD} 14^{++} \mathrm{CD} 16^{+}$vs. $\mathrm{CD} 14^{+} \mathrm{CD} 16^{++}$angegeben (modifiziert nach Czepluch et al. 2014, S. 149).

Die Analyse der monozytären CCR5-Expression zeigt in diesem Zusammenhang ein ähnliches Verteilungsmuster von $\mathrm{CCR}^{+}{ }^{-}$-Monozyten wie beim Vergleich gesunder Kontrollprobanden mit der Gesamtheit der KHK-Patienten (siehe Kapitel 3.5.1). Die CCR5-Expressionsmuster der KHK-Patienten unter Statindauermedikation ähneln hierbei jenen der gesunden Kontrollprobanden. In diesem Kontext ist außerdem deckungsgleich, dass sowohl bei den Patienten mit als auch bei jenen ohne Medikation mit einem HMG-CoA-Reduktasehemmer die Anzahl der $\mathrm{CCR} 5^{+} \mathrm{CD} 14^{++} \mathrm{CD} 16^{-}$-Monozyten im Vergleich zu der der $\mathrm{CCR}^{+} \mathrm{CD} 14^{++} \mathrm{CD} 16^{+}$-Monozyten signifikant niedriger ist (jeweils $p<0,001$ für Statin und kein Statin). Bei den $\mathrm{CD} 14^{+} \mathrm{CD} 16^{++}$-Monozyten findet sich nur in der unter Medikation stehenden Patientengruppe ein deutlich größerer Anteil an $\mathrm{CCR}^{+}{ }^{-}$-Monozyten verglichen mit den klassi- 
schen Monozyten ( $p<0,01$ für Statin; $p=0,14$ für kein Statin). Darüber hinaus ist der $\mathrm{CCR}^{+}$-Anteil bei den $\mathrm{CD} 14^{+} \mathrm{CD} 16^{++}$-Monozyten beider Versuchsgruppen signifikant niedriger als jener der intermediären Monozyten (jeweils $p<0,001$ für Statin und kein Statin).

\subsubsection{Einfluss von Ezetimib auf die prozentuale Verteilung der Monozytensub- gruppen}

Wie in Abb. 3.9 dargestellt, zeigen KHK-Patienten, die mit dem Cholesterinaufnahmehemmer Ezetimib - als Monotherapie oder in Kombination mit einem Statin - behandelt werden $(n=12)$, im Vergleich zu Patienten ohne Ezetimibmedikation $(n=48)$ eine signifikant vermehrte Anzahl an $\mathrm{CD} 14^{++} \mathrm{CD} 16^{-}$-Monozyten (Ezetimib: 88,5\% vs. kein Ezetimib: 85,4\%, $\mathrm{p}<0,05$ ). Die Monozytenzahl in der intermediären Subgruppe unterscheidet sich nicht zwischen beiden Kohorten, wohingegen sich ein auffallend verminderter Anteil an $\mathrm{CD} 14^{+} \mathrm{CD} 16^{++}$-Monozyten bei Patienten mit regelmäßiger Ezetimibeinnahme verglichen mit jenen, die das Medikament nicht einnehmen, finden lässt (Ezetimib: 3,9 $\%$ vs. kein Ezetimib: $6,3 \%, p<0,01$ ).

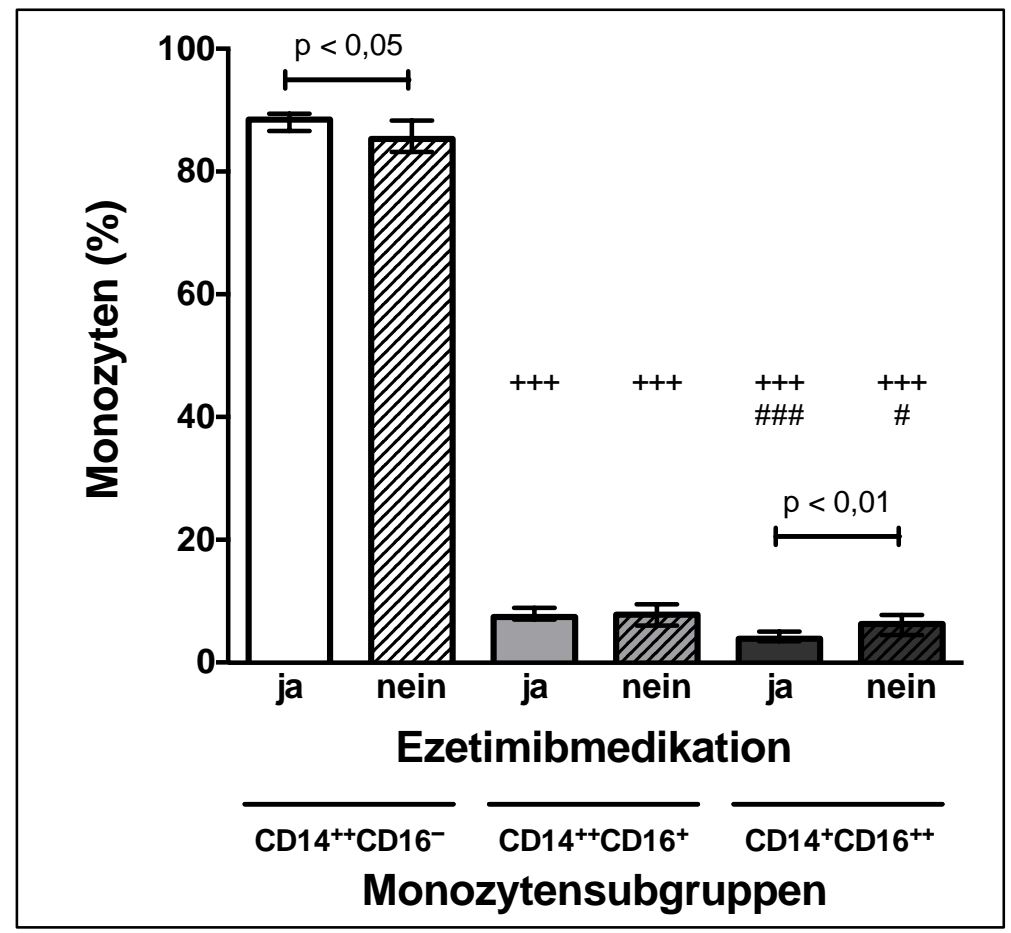

Abb. 3.9 Einfluss von Ezetimib auf die prozentuale Verteilung der Monozytensubgruppen

Die Histogramme zeigen die Mediane, Quartile und Interquartilabstände. Signifikante Unterschiede zwischen der Gruppe von KHKPatienten die mit Ezetimib behandelt werden (ja, $n=12$ ) und der Gruppe ohne Ezetimibmedikation (nein, $n=48$ ) sind als $p$-Werte ausgeschrieben. Divergenzen innerhalb der jeweiligen Studiengruppen sind als $+++(p<0,001)$ für $\mathrm{CD} 14^{++} \mathrm{CD} 16^{-}$ vs. $\mathrm{CD} 14^{++} \mathrm{CD} 16^{+}$oder $\mathrm{CD} 14^{+} \mathrm{CD} 16^{++}$ bzw. \# $(p<0,05)$ oder \#\#\# $(p<0,001)$ für $\mathrm{CD}^{++} 4^{++} \mathrm{CD} 16^{+}$vs. $\mathrm{CD} 14^{+} \mathrm{CD} 16^{++}$angegeben.

Um nachzuweisen, dass die gefundenen monozytären Verteilungsmuster wirklich ezetimibabhängig sind und nicht einen Scheinzusammenhang aufgrund reduzierter LDL-C-Blutwerte darstellen, erfolgt die nähere Betrachtung der LDL-C-Werte im Kontext des monozytären Subgruppenvorkommens. Dabei sind signifikante Korrelationen des LDL-C-Blutwertes mit dem relativen Monozytenanteil pro 
Untergruppe in keiner der drei Subklassen erkennbar $\left(C D 14^{++} \operatorname{CD} 16^{-}: r=0,100, p=0,449\right.$; $\mathrm{CD}_{14}{ }^{++} \mathrm{CD} 16^{+}: r=-0,007, p=0,955 ; \mathrm{CD}^{+} 4^{+} \mathrm{CD} 16^{++}: r=-0,141, p=0,281 ;$ nicht dargestellt). Ebenso wenig findet sich ein Unterschied in der prozentualen Verteilung der Monozytenuntergruppen zwischen jenen KHK-Patienten mit einem LDL-C-Wert $>100 \mathrm{mg} / \mathrm{dl}$ und solchen unter optimaler Therapie mit LDL-C-Werten $\leq 100 \mathrm{mg} / \mathrm{dl}\left(\mathrm{CD} 14^{++} \mathrm{CD} 16^{-}\right.$: LDL-C $<100 \mathrm{mg} / \mathrm{dl}: 86,6 \%$ vs. LDL-C $\geq 100 \mathrm{mg} / \mathrm{dl}$ : 86,6 \%, $p=0,564 ;$ CD14 ${ }^{++}$CD16 ${ }^{+}:$LDL-C $<100 \mathrm{mg} / \mathrm{dl}:$ 7,7\% vs. LDL-C $\geq 100 \mathrm{mg} / \mathrm{dl}: 7,7 \%, p=0,912$; $\mathrm{CD}_{14}{ }^{+} \mathrm{CD} 16^{++}:$LDL-C $<100 \mathrm{mg} / \mathrm{dl}: 6,2 \%$ vs. LDL-C $\geq 100 \mathrm{mg} / \mathrm{dl}: 5,8 \%, \mathrm{p}=0,473$; nicht dargestellt), sodass davon ausgegangen werden kann, dass die Monozytensubgruppenverteilung von Ezetimib direkt und nicht von einem LDL-C-abhängigen Scheinfaktor beeinflusst wird.

\subsection{Quantifizierung der monozytären CD44-Expression}

Bei der Expressionsanalyse von CD44 auf den verschiedenen Untergruppen zeigen die Monozyten in sämtlichen Messungen beider Studienkohorten durchgängig eine CD44-Expression von $100 \%$, sodass auf die graphische Darstellung dieser Ergebnisse verzichtet wird.

Die MFI-FMO-Werte der CD44-Expression pro Monozyt unterscheiden sich zwischen beiden Studienkohorten ebenfalls in keiner der drei monozytären Subgruppen signifikant. Es lässt sich allerdings feststellen, dass die größten MFI-FMO-Werte sowohl der KHK- als auch der Kontrollgruppe bei den intermediären Monozyten zu finden sind (siehe Abb. 3.10).

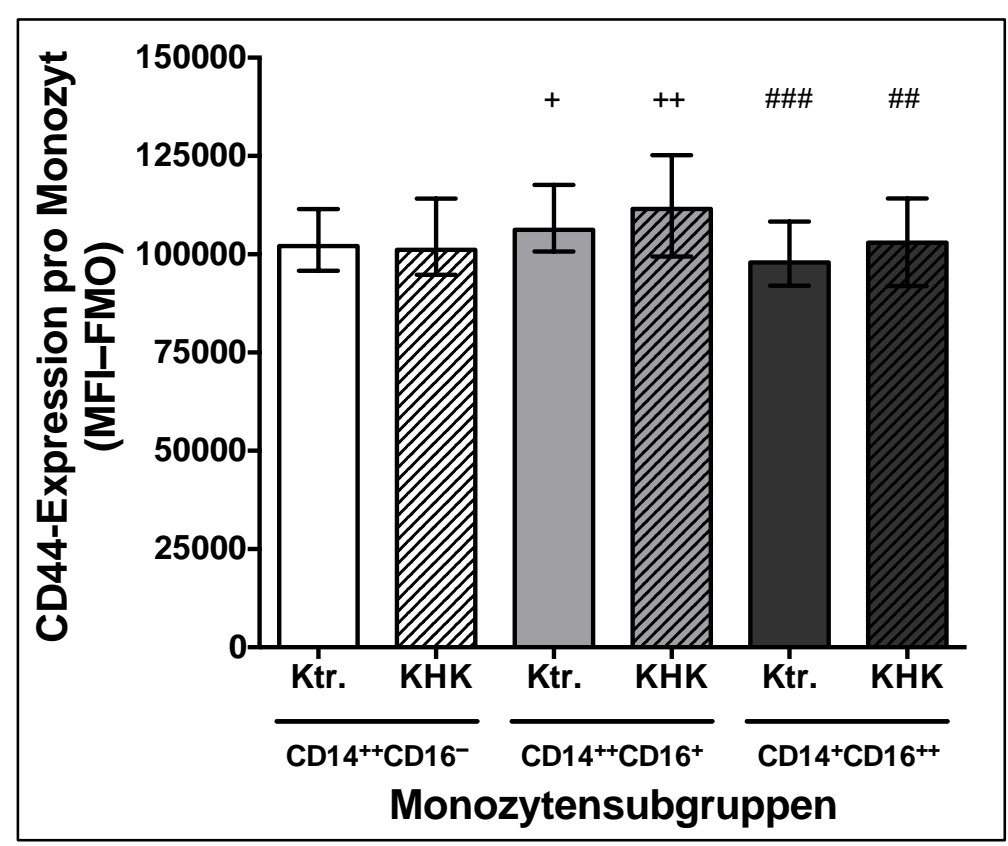

Abb. 3.10 CD44-MFI-FMO pro Monozytensubgruppe

Die Histogramme zeigen die Mediane, Quartile und Interquartilabstände. Signifikante Unterschiede zwischen der Kontrollgruppe gesunder Blutspender (Ktr., $n=64$ ) und den Patienten mit koronarer Herzkrankheit (KHK, $n=60$ ) lassen sich nicht nachweisen. Divergenzen innerhalb der jeweiligen Studiengruppen sind als $+(p<0,05)$ oder $++(p<0,01)$ für $\mathrm{CD} 14^{++} \mathrm{CD} 16^{-}$vs. $\mathrm{CD} 14^{++} \mathrm{CD} 16^{+}$oder CD14 ${ }^{+} \mathrm{CD} 16^{++}$bzw. \#\# $(p<0,01)$ oder \#\#\# ( $p<0,001)$ für $\mathrm{CD} 14^{++} \mathrm{CD} 16^{+}$vs. $\mathrm{CD} 14^{+} \mathrm{CD} 16^{++}$angegeben. 
So ist die MFI-FMO der $\mathrm{CD} 14^{++} \mathrm{CD} 16^{+}$-Monozyten der Kontrollprobanden sowohl im Vergleich zu den klassischen als auch zu den nicht-klassischen Monozyten erhöht (CD14 ${ }^{++}$CD16 $6^{+}: 106220 \mathrm{MFI-FMO} \mathrm{vs.}$ $\mathrm{CD}_{14} 4^{++} \mathrm{CD} 16^{-}$: $102064 \mathrm{MFI}-\mathrm{FMO}, \mathrm{p}<0,05$; $\mathrm{CD} 14^{++} \mathrm{CD} 16^{+}$vs. $\mathrm{CD}_{14}{ }^{+} \mathrm{CD} 16^{++}$: $97870 \mathrm{MFI-FMO}$, $\mathrm{p}<0,001)$. Ähnliche Ergebnisse finden sich auch innerhalb der KHK-Patientengruppe, deren signifikant größter MFI-FMO-Wert ebenfalls in der intermediären Monozytensubgruppe zu finden ist (CD14 ${ }^{++}$CD16 : 111519 MFI-FMO vs. CD14 ${ }^{++}$CD16 : 101152 MFI-FMO, $p<0,01$; CD14 $4^{++}$CD16 vs. CD14 $\left.4^{+} \mathrm{CD} 16^{++}: 102957 \mathrm{MFI}-\mathrm{FMO}, \mathrm{p}<0,01\right)$.

\subsection{Analyse der intrazellulären KLF4-Expression humaner Monozyten}

\subsubsection{KLF4+-Monozyten und ihre Subgruppenverteilung}

Die Analyse des relativen Anteils von KLF4+-Monozyten zeigt über alle drei Subgruppen hinweg signifikant mehr KLF4 ${ }^{+}$-Monozyten in der Gruppe gesunder Blutspender im Vergleich zur KHKPatientenfraktion (siehe Abb. 3.11).

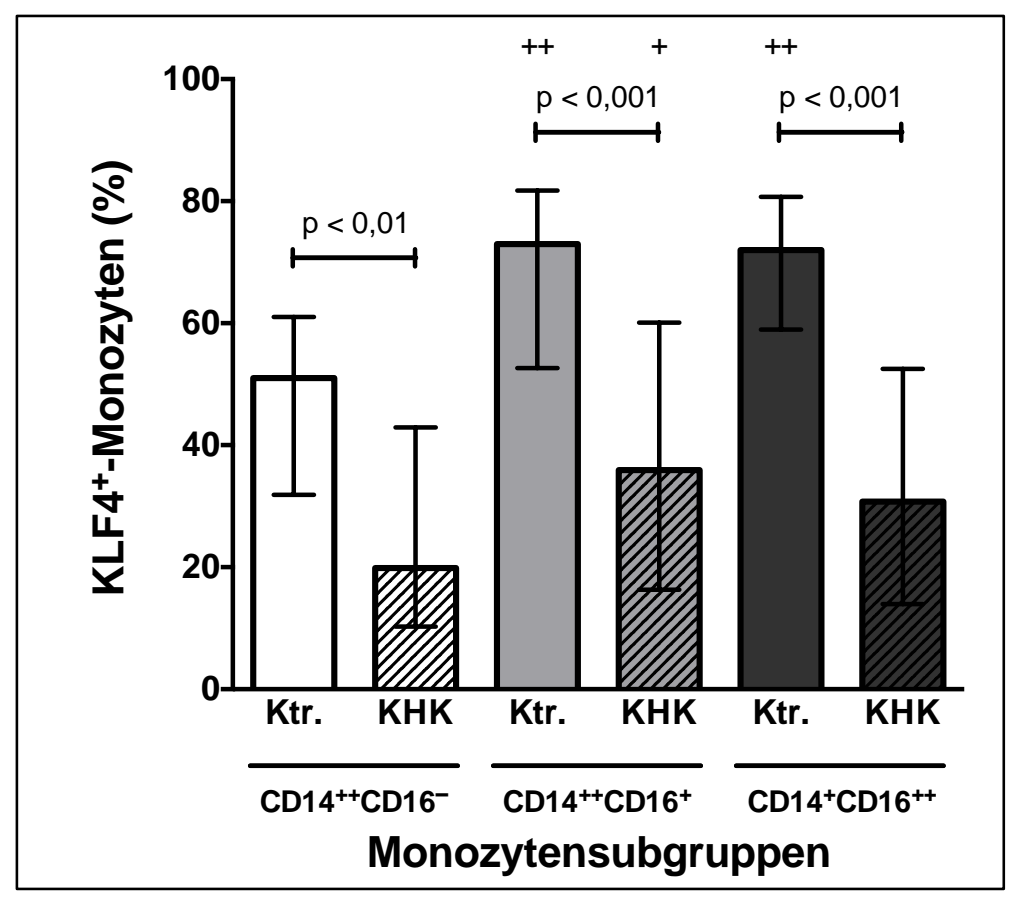

Abb. 3.11 Prozentuale Verteilung der KLF4+-Monozyten pro Monozytensubgruppe

Die Histogramme zeigen die Mediane, Quartile und Interquartilabstände. Signifikante Unterschiede zwischen der Kontrollgruppe gesunder Blutspender (Ktr., $n=18$ ) und den Patienten mit koronarer Herzkrankheit $(K H K, n=60)$ sind als $p$-Werte ausgeschrieben. Divergenzen innerhalb der jeweiligen Studiengruppen sind als $+(p<0,05)$ oder ++ $(p<0,01)$ für $\mathrm{CD}^{\prime+1} 4^{++} \mathrm{CD} 16^{-}$vs. $\mathrm{CD} 14^{++} \mathrm{CD} 16^{+}$oder $\mathrm{CD} 14^{+} \mathrm{CD} 16^{++}$angegeben (modifiziert nach Czepluch et al. 2013b, S. 1081).

In den Subgruppen beider Studienkollektive ist der Anteil an $\mathrm{KLF} 4^{+} \mathrm{CD} 14^{++} \mathrm{CD} 16^{+}$-Monozyten jeweils am höchsten, wobei die gesunden Blutspender wesentlich mehr KLF4 ${ }^{+}$-Monozyten aufweisen als die KHK-Patienten (Ktr.: 73,0 \% vs. KHK: 35,9\%, p<0,001). Ähnliche Ergebnisse fördert die Analyse der 
$\mathrm{KLF}^{+} \mathrm{CD} 14^{+} \mathrm{CD} 16^{++}$-Monozyten zutage, bei denen die KHK-Patienten verglichen mit den gesunden Blutspendern ebenfalls deutlich weniger KLF4+-Monozyten aufweisen (Ktr.: 72,0 \% vs. KHK: 30,8 \%, $p<0,001)$. Auch wenn diese Unterschiede bei den klassischen Monozyten nicht ganz so eindrücklich ausfallen, wie bei den anderen beiden Untergruppen, finden sich dennoch auch hier signifikant mehr KLF4 ${ }^{+} \mathrm{CD} 14^{++} \mathrm{CD} 16^{-}$-Monozyten in der Kontroll- als in der Patientengruppe (Ktr.: $51,0 \%$ vs. KHK: $19,9 \%, p<0,01)$.

Auch innerhalb des Kontrollkollektivs sind statistisch bedeutsam mehr KLF4 ${ }^{+}$-Monozyten bei den intermediären und nicht-klassischen als bei den $\mathrm{CD} 14^{++} \mathrm{CD} 16^{-}$-Monozyten nachweisbar (jeweils $p<0,01)$. Diese Resultate lassen sich die KHK-Patientengruppe betrachtend nicht so nachdrücklich feststellen, da hier nur die CD14 ${ }^{++} \mathrm{CD} 16^{+}$-Monozyten signifikant mehr KLF4 aufweisen als die $\mathrm{CD} 14^{++} \mathrm{CD} 16^{-}$-Monozyten $(p<0,05)$.

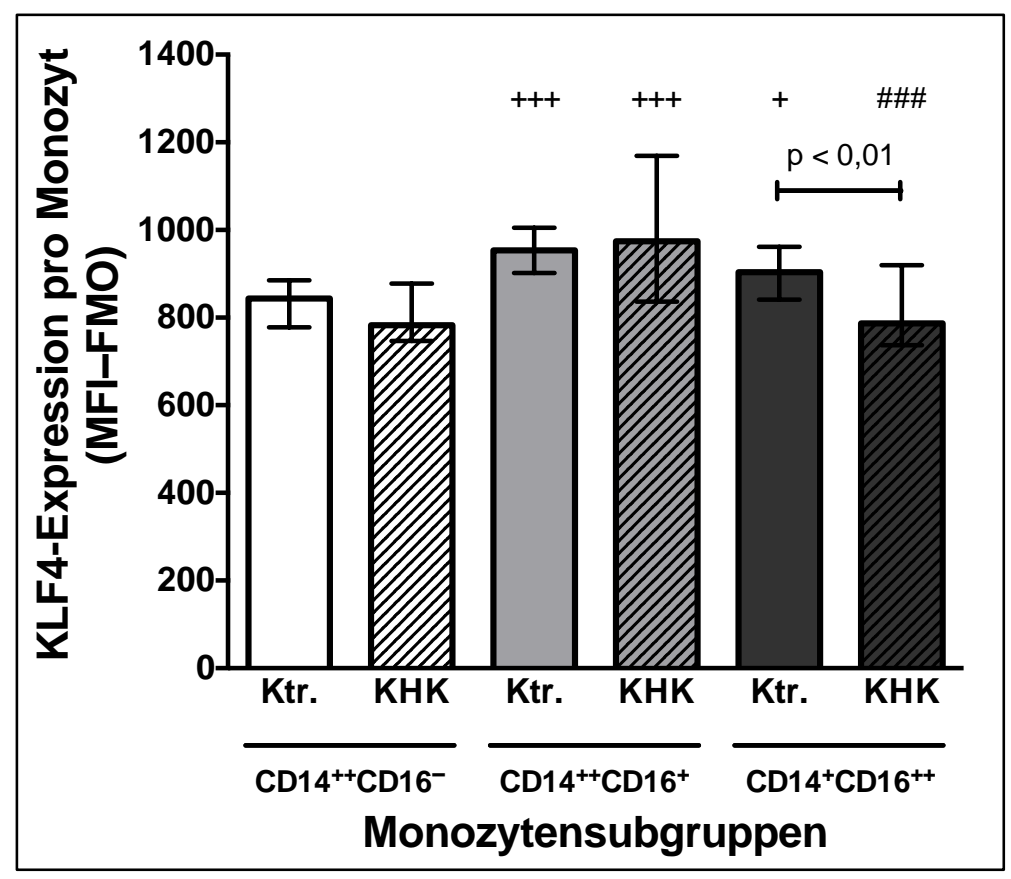

Abb. 3.12 KLF4-MFI-FMO pro Monozytensubgruppe

Die Histogramme zeigen die Mediane, Quartile und Interquartilabstände. Signifikante Unterschiede zwischen der Kontrollgruppe gesunder Blutspender (Ktr., $\mathrm{n}=18$ ) und den Patienten mit koronarer Herzkrankheit (KHK, $n=60)$ sind als $p$-Werte ausgeschrieben. Divergenzen innerhalb der jeweiligen Studiengruppen sind als $+(p<0,05)$ oder +++ $(p<0,001)$ für $\mathrm{CD} 14^{++} \mathrm{CD} 16^{-}$vs. $\mathrm{CD} 14^{++} \mathrm{CD} 16^{+}$oder $\mathrm{CD} 14^{+} \mathrm{CD} 16^{++}$ bzw. \#\#\# (p<0,001) für $\mathrm{CD} 14^{++} \mathrm{CD}_{16}^{+}$vs. $\mathrm{CD} 14^{+} \mathrm{CD} 16^{++}$angegeben (modifiziert nach Czepluch et al. 2013b, S. 1081).

Die MFI-FMO der KLF4-Expression folgt in ihrer Verteilung nicht dem prozentualen Verteilungsmuster der KLF4+-Monozyten (siehe Abb. 3.12). So finden sich signifikante Unterschiede der MFI-FMOWerte zwischen KHK-Patienten und gesunden Kontrollprobanden nur bei den $\mathrm{CD} 14^{+} \mathrm{CD} 16^{++}$Monozyten (Ktr.: 903,5 MFI-FMO vs. KHK: 786,5 MFI-FMO, p<0,01). Weiterhin sind sowohl in der Kontrollgruppe die niedrigsten MFI-FMO-Werte der KLF4-Expression pro Monozyt bei den klassischen Monozyten zu finden $\left(C D 14^{++} \mathrm{CD} 16^{-}\right.$: 843,5 MFI-FMO vs. CD14 ${ }^{++} \mathrm{CD} 16^{+}$: 953,5 MFI-FMO, $\mathrm{p}<0,001 ; \mathrm{CD} 14^{++} \mathrm{CD} 16^{-}$vs. CD14 $\left.{ }^{+} \mathrm{CD} 16^{++}: 903,5 \mathrm{MFI}-\mathrm{FMO}, \mathrm{p}<0,05\right)$ als auch in der Gruppe der KHK- 
Patienten (CD14 ${ }^{++}$CD16- 782,5 MFI-FMO vs. CD14 ${ }^{++}$CD16 $6^{+}:$974,0 MFI-FMO, $p<0,001$ ). Außerdem ist innerhalb der KHK-Gruppe die mediane Fluoreszenzintensität der $\mathrm{CD} 14^{+} \mathrm{CD} 16^{++}$-Monozyten wesentlich niedriger als bei den intermediären Monozyten (CD14 ${ }^{++} \mathrm{CD} 16^{+}$vs. $\mathrm{CD} 14^{+} \mathrm{CD} 16^{++}$: 786,5 MFI-FMO, $\mathrm{p}<0,001)$.

Aus dieser Analyse lässt sich ableiten, dass zwar generell mehr Monozyten der Kontrollgruppe KLF4 exprimieren, die Monozyten beider Studiengruppen aber - so sie denn KLF4 aufweisen - quantitativ nicht in ihrem KLF4-Gehalt differieren.

\subsubsection{Einfluss der in vitro-Plasmastimulierung auf die monozytäre KLF4-Expression}

Die folgende Abb. 3.13 präsentiert die Auswertung der KLF4-Expression in Monozyten gesunder junger Blutspender $(n=4)$ nach vorangegangener vierstündiger in vitro-Inkubation mit Blutplasma von KHK-Patienten bzw. gesunden Kontrollprobanden. Es zeigt sich ein signifikant niedrigerer relativer Anteil KLF4 ${ }^{+}$-Gesamtmonozyten nach Inkubation mit KHK-Patientenplasma im Vergleich zur Bebrütung mit Blutplasma der Kontrollgruppe (Ktr.-Plasma: 49,2 \% vs. KHK-Plasma: 40,4 \%, p<0,05).

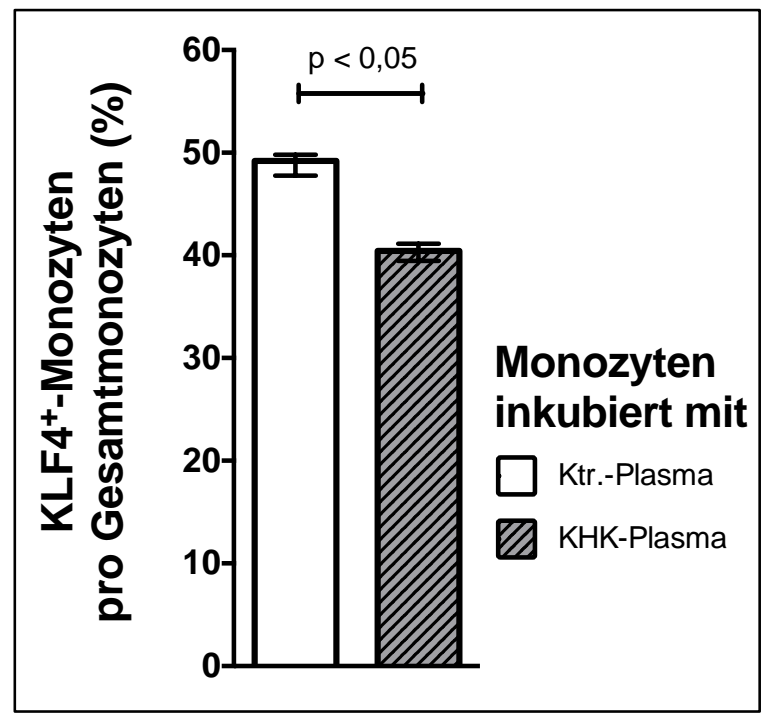

Abb. 3.13 Anteil KLF4+-Monozyten nach Monozyteninkubation mit heparinisiertem Plasma gesunder Blutspender vs. KHK-Patientenplasma

Die Histogramme zeigen die Mediane, Quartile und Interquartilabstände. Der signifikante Unterschied zwischen der Inkubationsgruppe mit Plasma gesunder Kontrollprobanden (Ktr., $\mathrm{n}=4$ ) und der mit Plasma von KHK-Patienten (KHK, $n=4)$ ist als $p$-Wert ausgeschrieben (modifiziert nach Czepluch et al. 2013b, S. 1081).

\subsubsection{Einfluss kardiovaskulärer Risikofaktoren auf die monozytäre KLF4-Expression}

Bei näherer Betrachtung der beiden kardiovaskulären Risikofaktoren arterielle Hypertonie und Typ-2Diabetes mellitus und deren Bedeutung für die KLF4-Expression in humanen Monozyten zeigt sich, 
dass Monozyten von KHK-Patienten, die an keinem der beiden Risikofaktoren leiden ( $n=10)$, prozentual gesehen den relativ größten Anteil an KLF4+-Gesamtmonozyten aufweisen (49,1\%). Hypertoniepatienten ohne Erkrankung an Typ-2-Diabetes mellitus ( $n=31$ ) weisen dagegen mit 31,4 \% signifikant weniger KLF4 ${ }^{+}$-Monozyten auf $(p<0,01)$. Der mit 15,6\% niedrigste Wert an KLF4 ${ }^{+}$-Monozyten findet sich bei den KHK-Patienten, die sowohl an arterieller Hypertonie als auch an Typ-2-Diabetes mellitus erkrankt sind $(n=10)$. Deren relativer monozytärer KLF4-Anteil ist sowohl gegenüber jenem der Patienten ohne beiderlei Risikofaktor $(p<0,001)$ als auch gegenüber den KLF4-Werten der KHKPatienten leidend an arterieller Hypertonie, nicht aber zusätzlich an Typ-2-Diabetes mellitus, deutlich vermindert $(p<0,05)$. Die Analysen der kardiovaskulären Risikofaktoren Rauchen und Hyperlipoproteinämie sowie Übergewicht/Adipositas lassen keine ähnlich gearteten Ergebnisse erkennen (nicht dargestellt).

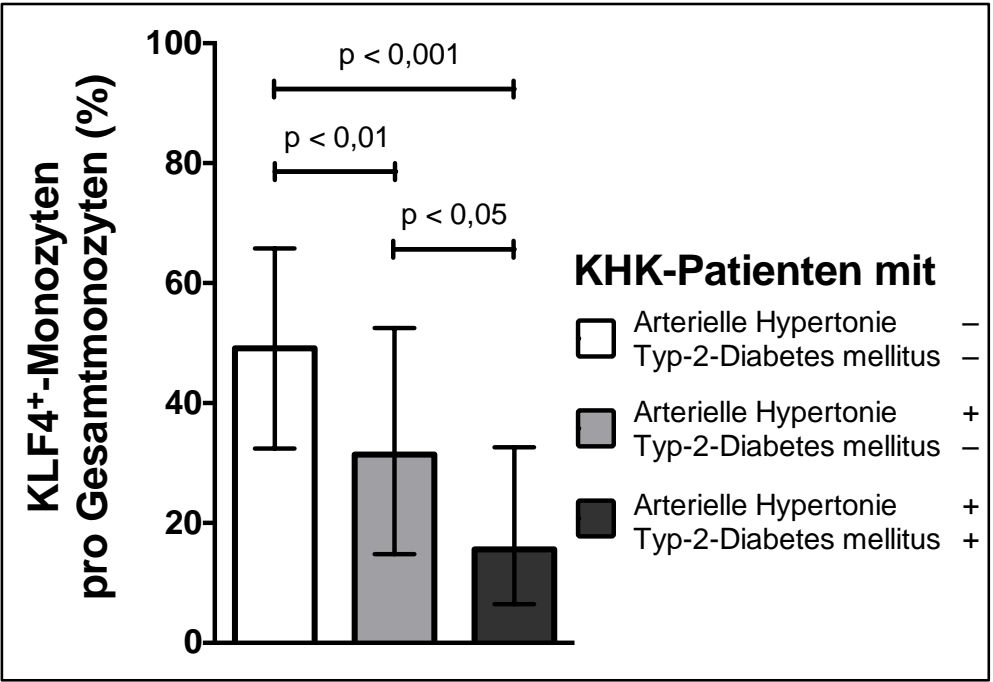

Abb. $3.14 \mathrm{KLF4}^{+}$-Monozyten in Abhängigkeit kardiovaskulärer Risikofaktoren

Die Histogramme zeigen die Mediane, Quartile und Interquartilabstände. Signifikante Unterschiede zwischen der Gruppe von KHKPatienten, die weder an arterieller Hypertonie noch an Typ-2-Diabetes mellitus leiden ( $n=10)$, und solchen, die eine arterielle Hypertonie, aber keinen Typ-2-Diabetes mellitus ( $n=31$ ) bzw. beide kardiovaskulären Risikofaktoren aufweisen $(n=10)$, sind als $p$-Werte ausgeschrieben (modifiziert nach Czepluch et al. 2013b, S. 1081).

\subsubsection{Zusammenhang zwischen KLF4+-Monozyten und Leukozytenzahl}

Im Rahmen der Studie konnte gezeigt werden, dass der Anteil der KLF4 ${ }^{+}$-Monozyten aller drei Subgruppen beider Studienkollektive zusammen genommen $(n=80)$ negativ mit den per Blutbild detektierten Leukozytenzahlen korreliert (siehe Abb. 3.15). Diese inverse Korrelation ist bei den $\mathrm{CD}_{14}{ }^{++} \mathrm{CD} 16^{+}-$Monozyten mit $r=-0,430$ und $\mathrm{p}<0,001$ am stärksten ausgeprägt. Aber auch bei den anderen beiden monozytären Subgruppen zeigen diese Korrelationen eindrückliche Ergebnisse $\left(\mathrm{CD} 14^{++} \mathrm{CD}_{16}^{-}: r=-0,375, \mathrm{p}<0,01 ; \mathrm{CD}^{-} 4^{+} \mathrm{CD} 16^{++}: r=-0,412, \mathrm{p}<0,001\right)$. 
(a)

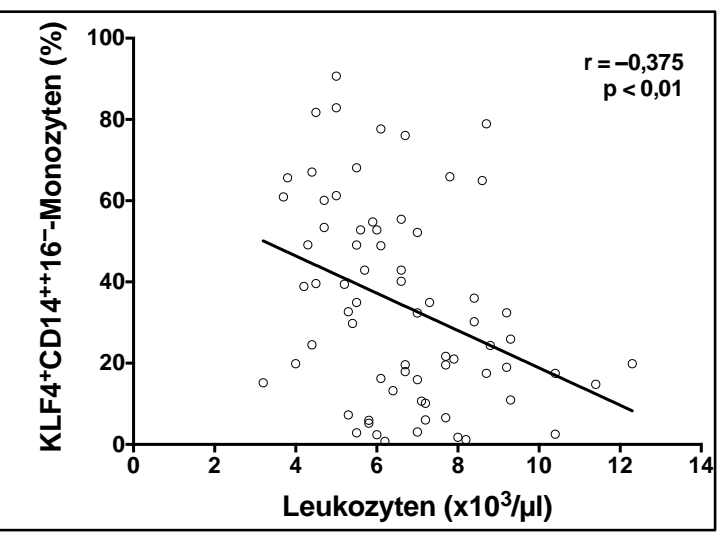

(c)

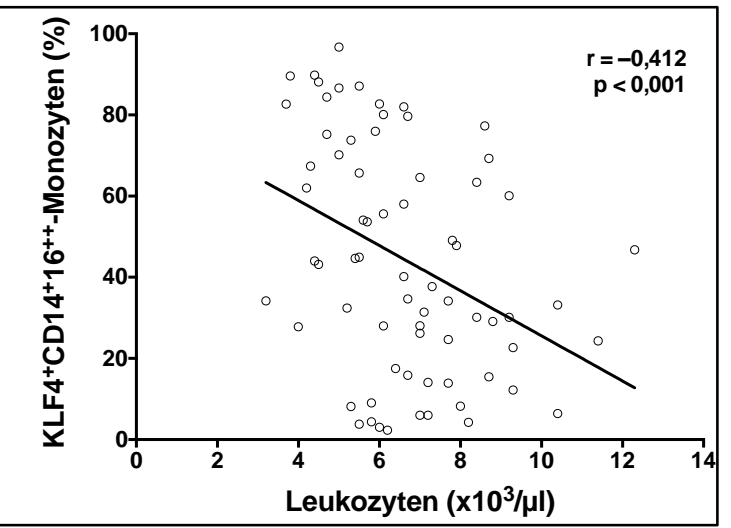

(b)

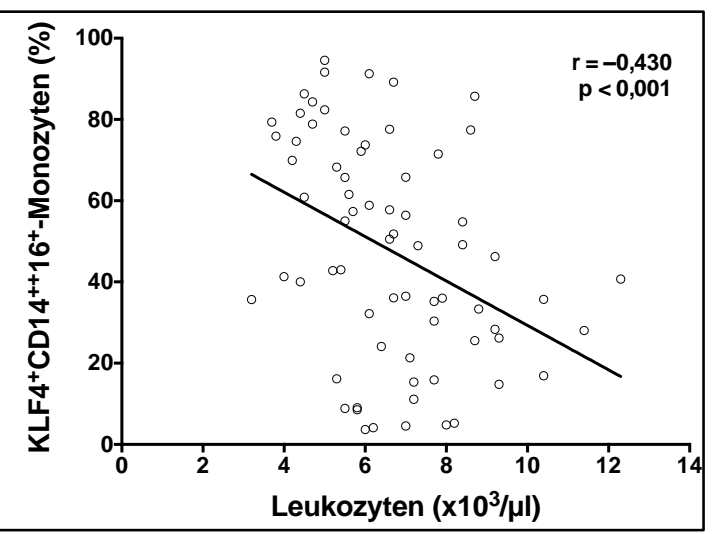

Abb. 3.15 Korrelation der Leukozytenzahlen mit der relativen Anzahl KLF4+-Monozyten

Korrelationsdarstellungen $(n=80)$ mit Rangkorrelationskoeffizienten $r$, $p$-Werten und linearen Regressionsgraden. (a) Korrelation der Leukozytenzahlen mit der relativen Anzahl an klassischen $\mathrm{KLF}^{+}$-Monozyten. (b) Korrelation der Leukozytenzahlen mit der relativen Anzahl an intermediären $\mathrm{KLF}^{+}$-Monozyten. (c) Korrelation der Leukozytenzahlen mit der relativen Anzahl an nicht-klassischen $\mathrm{KLF}^{+}$-Monozyten.

\subsection{Quantifizierung der Monozyten-Thrombozyten-Aggregat- bildung}

Die Untersuchung der MPA-Bildung - Ausdruck pathologisch-chronischer thrombozytärer Aktivierung im Rahmen der atherosklerotischen Genese - ergibt, dass die Monozyten aller drei Untergruppen der KHK-Patienten generell mehr MPAs bilden als diejenigen der Kontrollprobanden (siehe Abb. 3.16). Bei den $\mathrm{CD} 14^{++} \mathrm{CD} 16^{-}$-Monozyten beider Versuchsgruppen finden sich die relativ wenigsten MPAs, wobei die gesunden Blutspender von ebendiesen bedeutsam weniger aufweisen als die KHKPatienten (Ktr.: 15,0 \% vs. KHK: 20,1\%, p<0,001). Die MPA-Bildung der intermediären Monozyten der Kontroll- ist im Vergleich zur KHK-Gruppe ebenfalls signifikant vermindert (Ktr.: 18,7 \% vs. KHK: $21,7 \%, p<0,05)$ und auch bei den $\mathrm{CD} 14^{+} \mathrm{CD} 16^{++}$-Monozyten der gesunden Probanden finden sich mit $17,8 \%$ eindrücklich weniger MPAs als bei den KHK-Patienten mit $22,5 \%(p<0,01)$.

Beide monozytäre $\mathrm{CD} 16^{+}$-Subgruppen der Kontrollkohorte weisen - verglichen mit den klassischen Monozyten - vermehrt MPAs auf (jeweils $p<0,01$ ). Wohingegen in der Gruppe der KHK-Patienten nur die $\mathrm{CD} 14^{+} \mathrm{CD} 16^{++}$- im Vergleich mit den $\mathrm{CD} 14^{++} \mathrm{CD} 16^{-}$-Monozyten signifikant mehr relative MPAs 
bilden $(p<0,05)$. Die relative MPA-Bildung der beiden CD16 ${ }^{+}$-Monozytensubgruppen unterscheidet sich innerhalb beider Studiengruppe nicht statistisch bedeutsam.

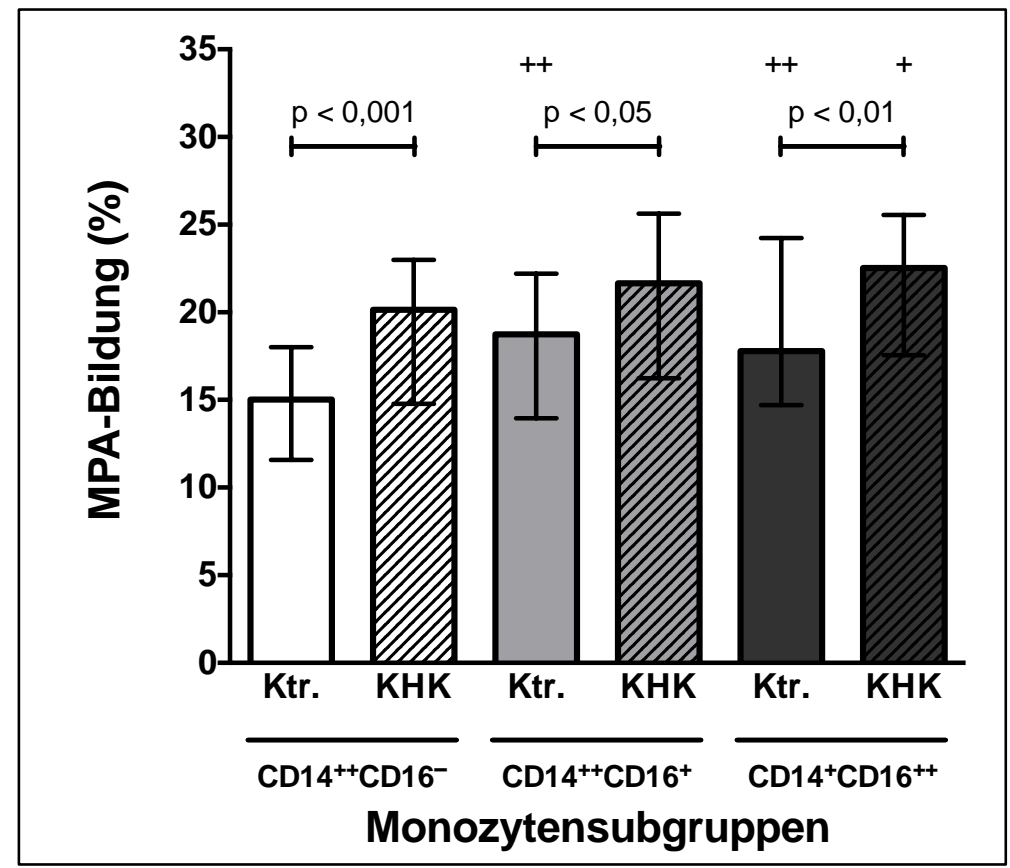

Abb. 3.16 Relativer Anteil an MPA-Bildung pro Monozytensubgruppe

Die Histogramme zeigen die Mediane, Quartile und Interquartilabstände. Signifikante Unterschiede zwischen der Kontrollgruppe gesunder Blutspender (Ktr., $\mathrm{n}=64$ ) und den Patienten mit koronarer Herzkrankheit $(K H K, n=60)$ sind als $p$-Werte ausgeschrieben. Divergenzen innerhalb der jeweiligen Studiengruppen sind als $+(p<0,05)$ oder ++

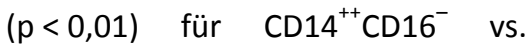
$\mathrm{CD}_{14} 4^{++} \mathrm{CD} 16^{+}$oder $\mathrm{CD} 14^{+} \mathrm{CD} 16^{++}$angegeben (modifiziert nach Czepluch et al. 2014, S. 149).

Die in Abb. 3.17 dargestellte Auswertung der CD42b-Expression als MFI-FMO-Wert zeigt bei den an Thrombozyten gebundenen Monozyten in keiner der drei Subgruppen einen relevanten Unterschied zwischen gesunden Blutspendern und Patienten mit KHK. Allerdings findet sich bei der Kontrollprobandenkohorte ein signifikant niedrigerer MFI-FMO-Wert bei den $\mathrm{CD} 14^{++} \mathrm{CD} 16^{-}$-Monozyten sowohl im Vergleich zu den intermediären (CD14 ${ }^{++}$CD16 $: 4981$ MFI-FMO vs. CD14 ${ }^{++}$CD16 ${ }^{+}$: 6144 MFI-FMO, $\mathrm{p}<0,05)$ als auch zu den nicht-klassischen Monozyten $\left(\mathrm{CD} 14^{++} \mathrm{CD} 16^{-}\right.$vs. $\mathrm{CD} 14^{+} \mathrm{CD} 16^{++}: 5823 \mathrm{MFI}-$ FMO, $p<0,05)$. Ähnliche Ergebnisse präsentieren sich in der Gruppe der KHK-Patienten, bei denen die MFI-FMO der CD42b-Expression ebenfalls bei den klassischen Monozyten signifikant niedrigere Werte aufweist als bei den intermediären (CD14 ${ }^{++} \mathrm{CD} 16^{-}: 5347 \mathrm{MFI-FMO}$ vs. CD14 ${ }^{++} \mathrm{CD} 16^{+}: 6685 \mathrm{MFI}-$ FMO, $p<0,001)$ und nicht-klassischen Monozyten $\left(\mathrm{CD} 14^{++} \mathrm{CD} 16^{-}\right.$vs. $\mathrm{CD} 14^{+} \mathrm{CD} 16^{++}: 5978 \mathrm{MFI}-\mathrm{FMO}$, $\mathrm{p}<0,05)$. 


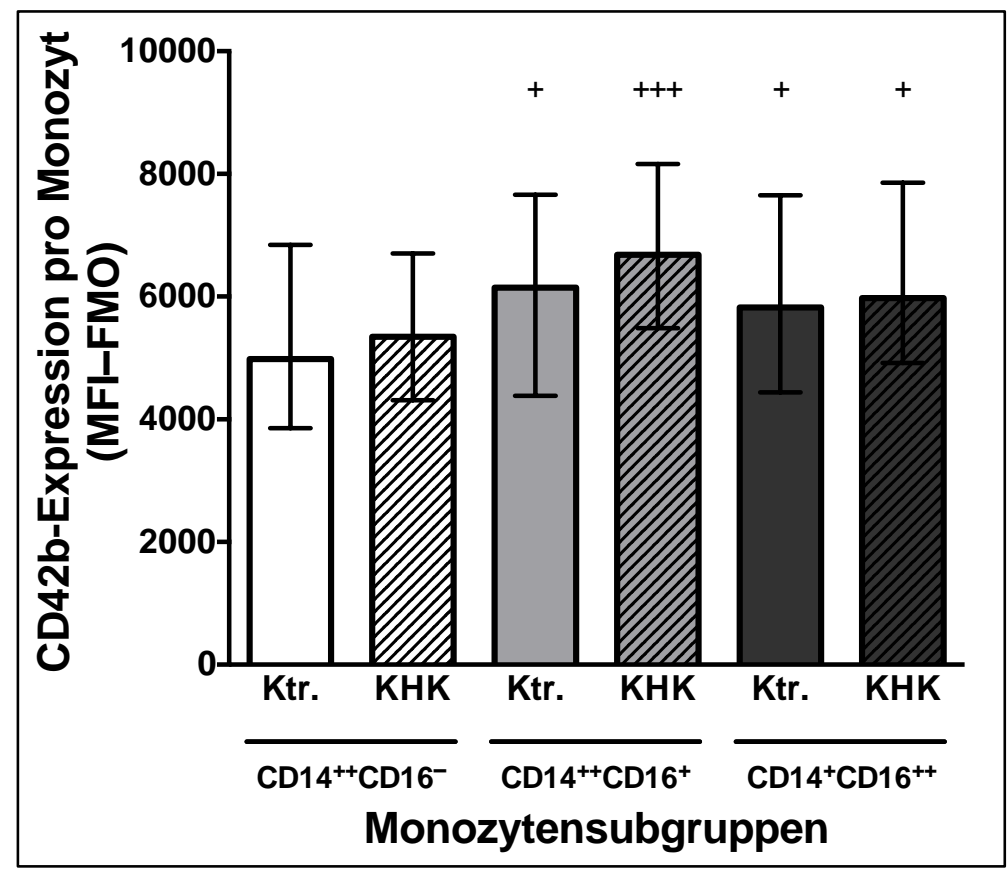

Abb. 3.17 CD42b-MFI-FMO pro Monozytensubgruppe

Die Histogramme zeigen die Mediane, Quartile und Interquartilabstände. Signifikante Unterschiede zwischen der Kontrollgruppe gesunder Blutspender (Ktr., $n=64$ ) und den Patienten mit koronarer Herzkrankheit (KHK, $n=60)$ sind als $p$-Werte ausgeschrieben. Divergenzen innerhalb der jeweiligen Studiengruppen sind als $+(p<0,05)$ oder +++ $(p<0,001)$ für $\mathrm{CD} 14^{++} \mathrm{CD} 16^{-}$vs. $\mathrm{CD} 14^{++} \mathrm{CD} 16^{+}$oder $\mathrm{CD} 14^{+} \mathrm{CD} 16^{++}$angegeben (modifiziert nach Czepluch et al. 2014, S. 149).

Um Unterschiede der MPA-Formierung zwischen Kontroll- und Patientengruppe aufgrund der Altersdifferenz zwischen beiden Gruppen auszuschließen, wurde auch bei der Gruppe altersangepasster Kontrollpatienten, bei denen eine KHK koronarangiographisch ausgeschlossen worden war, die MPABildung der einzelnen Monozytenuntergruppen evaluiert (siehe Abb. 3.18).

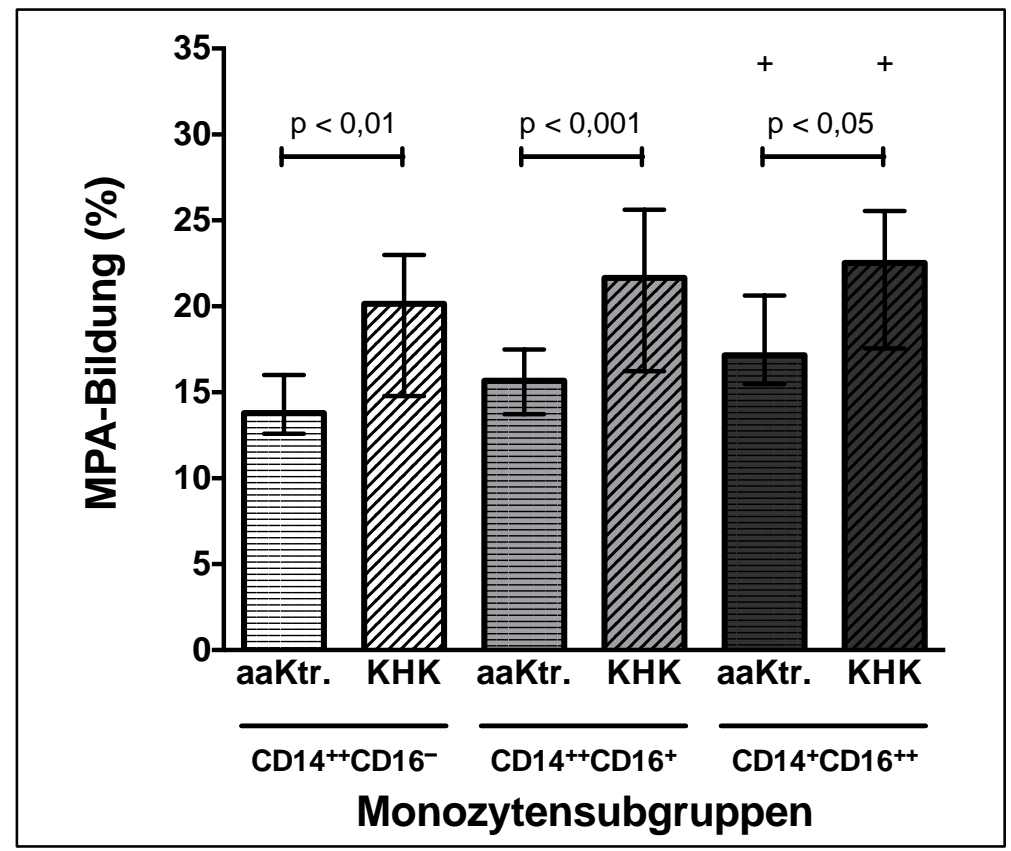

Abb. 3.18 Relativer Anteil an MPA-Bildung pro Monozytensubgruppe bei altersadaptierten Kontrollprobanden ohne KHK

Die Histogramme zeigen die Mediane, Quartile und Interquartilabstände. Signifikante Unterschiede zwischen der altersadaptierten Kontrollgruppe ohne KHK (aaKtr., $n=9$ ) und den Patienten mit koronarer Herzkrankheit (KHK, $n=60$ ) sind als $\mathrm{p}$-Werte ausgeschrieben. Divergenzen innerhalb der jeweiligen Studiengruppen sind als $+(p<0,05)$ für $\mathrm{CD} 14^{++} \mathrm{CD} 16^{-}$vs. $\mathrm{CD} 14^{+} \mathrm{CD} 16^{++}$angegeben. 
Hierbei zeigt sich ferner - wiederum in allen drei Monozytensubgruppen - eine vermehrte MPABildung bei den KHK-Patienten im Vergleich zur altersadaptierten Kontrollgruppe. So finden sich sowohl bei den $\mathrm{CD} 14^{++} \mathrm{CD} 16^{-}$-Monozyten der KHK-Patienten auffallend mehr MPAs als bei den altersadaptierten Kontrollprobanden ohne KHK (aaKtr.: 13,8 \% vs. KHK: 20,1\%, p<0,01), als auch bei den CD14 ${ }^{++}$CD16 ${ }^{+}$- (aaKtr.: 15,5\% vs. KHK: 21,7 \%, p < 0,001) und CD14 ${ }^{+}$CD16 ${ }^{++}$-Monozyten (aaKtr.: 17,2 \% vs. KHK: $22,5 \%, p<0,05)$.

Innerhalb der altersangepassten Kontrollprobanden finden sich - dasselbe gilt für die KHKPatientengruppe - bei den nicht-klassischen signifikant mehr MPAs als bei den klassischen Monozyten (jeweils $p<0,05$ für aaKtr. und KHK). Die MPA-Bildung der altersadaptierten Kontrollprobanden unterscheidet sich dabei in keiner der drei Subgruppen statistisch bedeutsam von jener der Kontrollgruppe junger gesunder Blutspender (nicht dargestellt).

Korrelative Analysen zwischen den per Blutbilduntersuchung bestimmten absoluten Thrombozytenzahlen und der durchflusszytometrisch detektierten Anzahl an MPAs zeigen ausschließlich innerhalb der KHK-Gruppe, dort aber in jeder monozytären Subgruppe, hoch signifikante, positive Korrelationen zwischen beiden Parametern $\left(C D 14^{++} C D 16^{-}: r=0,575, p<0,001 ; C D 14^{++} C D 16^{+}: r=0,434\right.$, $p<0,001 ; C D 14^{+} C D 16^{++}: r=0,539, p<0,001 ;$ nicht dargestellt).

\subsubsection{Einfluss von Vorhofflimmern auf die Bildung von Monozyten- Thrombozyten-Aggregaten}

Zusätzlich zu den verengten Herzkranzgefäßen leiden 21 der KHK-Patienten an einer der drei etablierten Formen (paroxysmal, persistierend, permanent) von Vorhofflimmern [VHF]. Die in Abb. 3.19 dargestellte Analyse der MPA-Bildung dieser Patienten zeigt in allen drei Monozytensubgruppen einen signifikant geringeren Anteil relativer MPA-Bildung als bei den KHK-Patienten ohne VHF. Der größte Intergruppenunterschied in Bezug auf den relativen Anteil an MPAs findet sich bei den intermediären Monozyten (VHF: 16,6 \% vs. kein VHF: 21,0 \%, p<0,001), gefolgt von den klassischen (VHF: 14,4 \% vs. kein VHF: 19,6\%, p<0,01) und schließlich den nicht-klassischen Monozyten (VHF: 15,6\% vs. kein VHF: $21,5 \%, p<0,05)$. Innerhalb der jeweiligen Untersuchungsgruppen finden sich keine relevanten Unterschiede zwischen den einzelnen Monozytensubgruppen. 


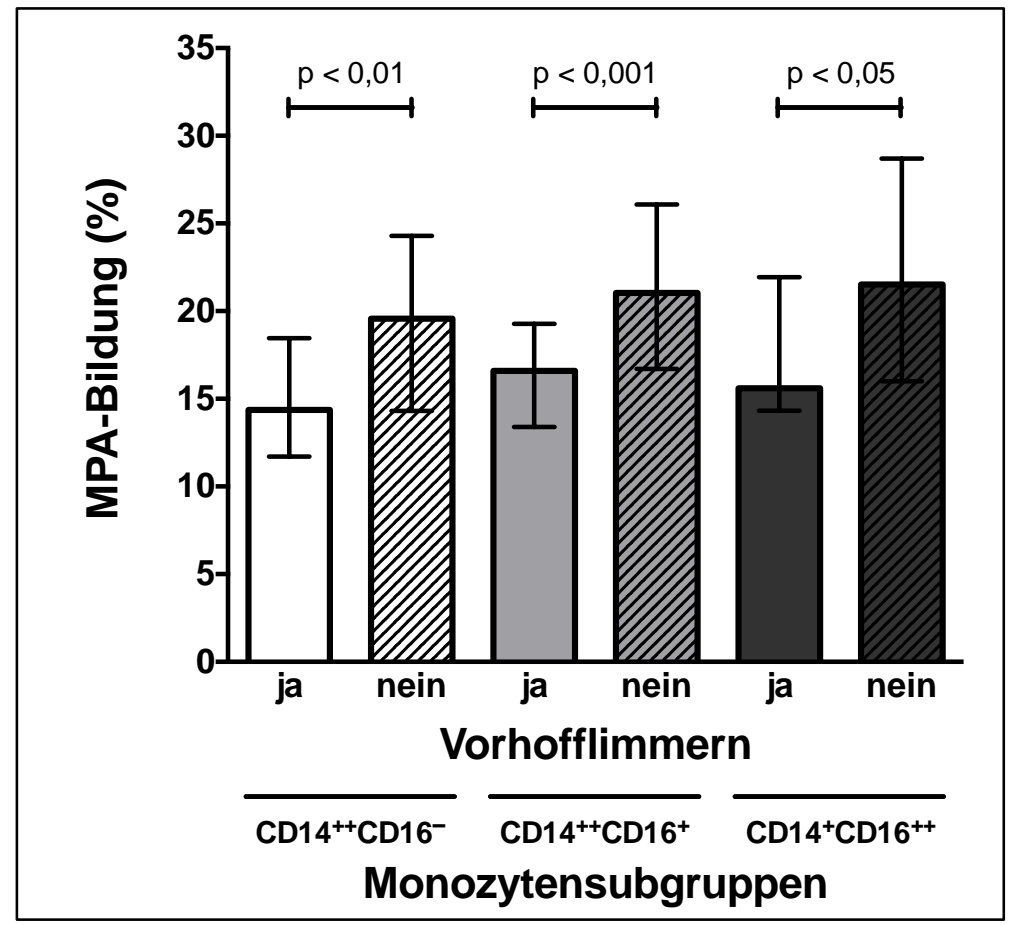

Abb. 3.19 Relativer Anteil an MPA-Bildung in Abhängigkeit von Vorhofflimmern

Die Histogramme zeigen die Mediane, Quartile und Interquartilabstände. Signifikante Unterschiede zwischen der Gruppe von KHKPatienten die an VHF leiden (ja, $n=21$ ) und solchen ohne VHF (nein, $n=37$ ) sind als $p$-Werte ausgeschrieben. Divergenzen innerhalb der jeweiligen Studiengruppen werden nicht gefunden.

\section{9 sPECAM-1- und sP-selectin-Serumspiegel}

Schließlich erfolgt die quantitative Analyse der Plättchenaktivitätsmarker SPECAM-1 und SP-selectin per ELISA aus bei $-80^{\circ} \mathrm{C}$ aserviertem Blutserum (siehe Abb. 3.20). Die Gruppe der gesunden Blutspender umfasst 64, die der KHK-Patienten 60 gemessene Werte.

(a)

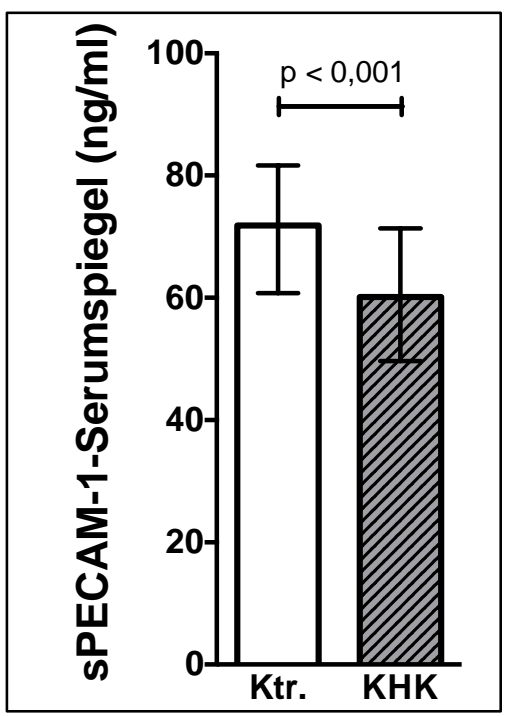

(b)

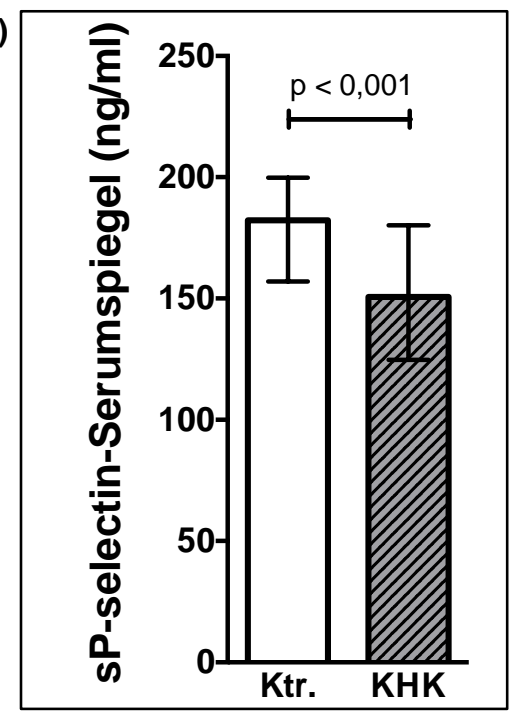

Abb. 3.20 Serumspiegel von (a) SPECAM-1 und (b) $s P$-selectin

Die Histogramme zeigen die Mediane, Quartile und Interquartilabstände. Signifikante Unterschiede zwischen der Kontrollgruppe gesunder Blutspender (Ktr., $n=64$ ) und den Patienten mit koronarer Herzkrankheit (KHK, $\mathrm{n}=60$ ) sind als $\mathrm{p}$-Werte ausgeschrieben (modifiziert nach Czepluch et al. 2014, S. 150). 
Im Gegensatz zu den Ergebnissen der durchflusszytometrisch evaluierten MPAs als Ausdruck einer Thrombozytenaktivierung finden sich bei der Kontrollgruppe signifikant höhere SPECAM-1Plasmaspiegel als bei den KHK-Patienten (Ktr.: $71,8 \mathrm{ng} / \mathrm{ml}$ vs. KHK: $60,1 \mathrm{ng} / \mathrm{ml}, \mathrm{p}<0,001$ ). Auch die Blutserumspiegel an löslichem P-selectin weisen bei den gesunden Blutspender bedeutsam höhere Werte auf als bei der KHK-Patientengruppe (Ktr.: $182 \mathrm{ng} / \mathrm{ml}$ vs. KHK: $151 \mathrm{ng} / \mathrm{ml}, \mathrm{p}$ <0,001). Außerdem findet sich eine in Abb. 3.21 (a) dargestellte positive Korrelation zwischen der Höhe der sPECAM-1- und SP-selectin-Serumspiegel beider Studienkohorten $(n=124)$ zusammengenommen $(r=0,369, p<0,001)$, die auch Bestand hat, wenn ausschließlich die KHK-Patientengruppe $(n=60)$ Betrachtung findet $(r=0,276, p<0,05 ;$ nicht dargestellt).

(a)

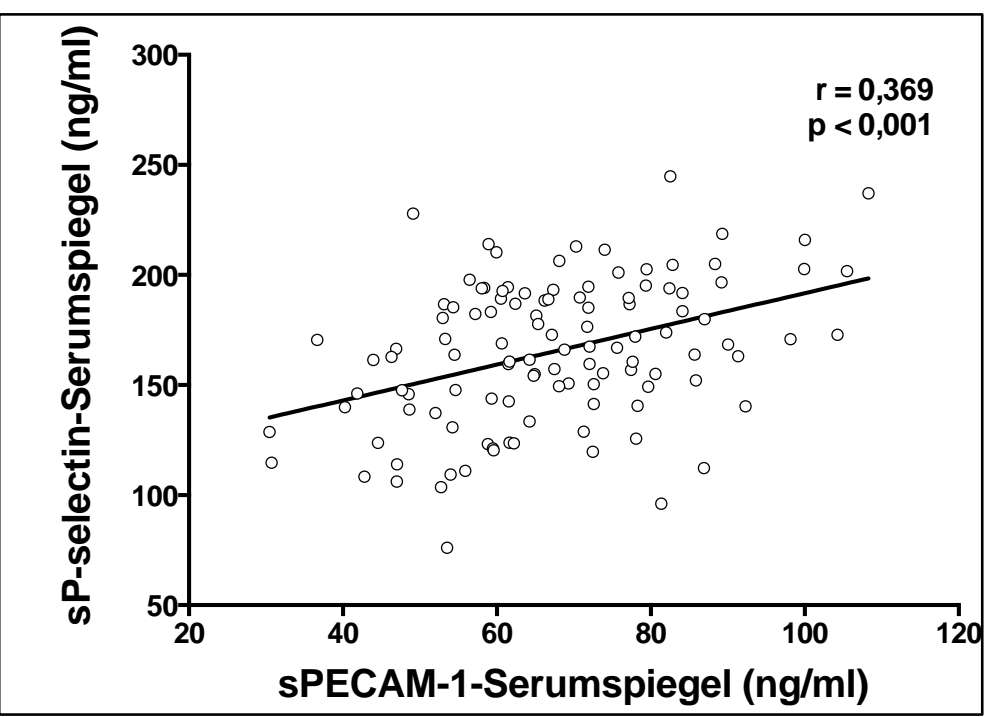

(b)

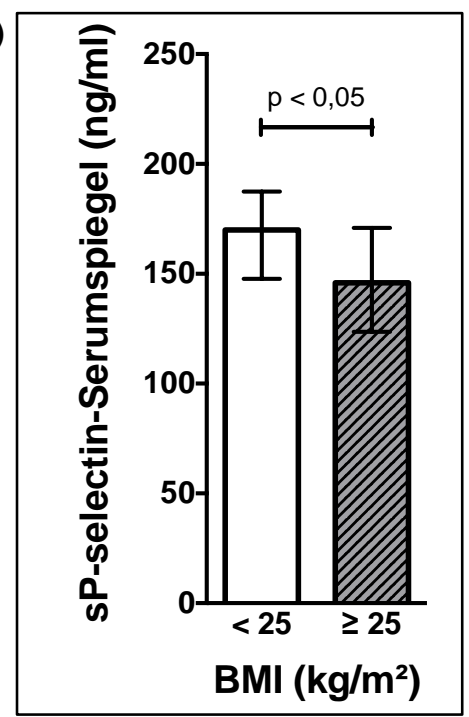

Abb. 3.21 (a) Korrelation der sP-selectin- und SPECAM-1-Serumspiegel und (b) Einfluss des BMI auf die sP-selectin-Serumspiegel

(a) Korrelationsdarstellung mit Rangkorrelationskoeffizient $r$, p-Wert und linearer Regressionsgraden. (b) Die Histogramme zeigen die Mediane, Quartile und Interquartilabstände. Der signifikante Unterschied zwischen der Gruppe von KHK-Patienten mit normalgewichtiger Konstitution (BMI $\left.<25 \mathrm{~kg} / \mathrm{m}^{2}, \mathrm{n}=24\right)$ und solchen mit übergewichtigem bzw. adipösem Habitus (BMI $\geq 25 \mathrm{~kg} / \mathrm{m}^{2}, \mathrm{n}=36$ ) ist als $p$-Wert ausgeschrieben.

Auch wird der Einfluss des BMI auf den sP-selectin-Serumspiegel der Studienteilnehmer der KHKGruppe analysiert. Abb. 3.21 (b) zeigt einen signifikant höheren Spiegel des plättchenaktivierenden Proteins bei Probanden, die normal- oder untergewichtig sind, d. h. deren BMI $<25 \mathrm{~kg} / \mathrm{m}^{2}$ ist $(n=24)$, verglichen mit den 36 übergewichtigen und adipösen Studienteilnehmern, deren BMI definitionsgemäß $\geq 25 \mathrm{~kg} / \mathrm{m}^{2}$ liegt (BMI $<25 \mathrm{~kg} / \mathrm{m}^{2}: 169,9 \mathrm{ng} / \mathrm{ml}$ vs. $\left.B M I \geq 25 \mathrm{~kg} / \mathrm{m}^{2}: 145,9 \mathrm{ng} / \mathrm{ml}, \mathrm{p}<0,05\right)$. Da Übergewicht ein Ausschlusskriterium für die Versuchsteilnahme innerhalb der Kontrollgruppe ist, erübrigt sich eine entsprechende Analyse für diese Studienkohorte. 
Ähnliche Ergebnisse zeigt auch die Evaluation der sP-selectin-Serum- in Abhängigkeit von den hsCRPPlasmaspiegeln. Dazu werden zum einen die laborchemisch bestimmten hsCRP-Werte der KHKPatienten mit den per ELISA detektierten sP-selectin-Spiegeln korreliert, wobei sich eine signifikante negative Korrelation mit einem Rangkorrelationskoeffizient nach Spearman von $r=-0,353$ bei $p<0,01$ finden lässt (siehe Abb. 3.22 a).

Des Weiteren werden die KHK-Patienten anhand ihrer hsCRP-Werte in > bzw. $\leq 3 \mathrm{mg}$ hsCRP/dl eingeteilt (siehe Abb. 3.22 b). Da hsCRP als Marker kardiovaskulären Risikos gilt, geht man ab einem chronisch erhöhten hsCRP von $3 \mathrm{mg} / \mathrm{dl}$ von einem hohen, unter $1 \mathrm{mg} / \mathrm{dl}$ von einem geringen und zwischen 1 und 3 mg/dl von einem mittleren kardiovaskulären Risiko aus. Bei der Auswertung dieser so stratifizierten Daten zeigt sich, dass KHK-Patienten mit einem hsCRP-Plasmawert $>3 \mathrm{mg} / \mathrm{dl}(\mathrm{n}=21)-$ und damit hohem kardiovaskulären Risiko - deutlich weniger sP-selectin im Serum aufweisen als jene 39 KHK-Patienten, deren hsCRP-Wert $\leq 3,0 \mathrm{mg} / \mathrm{dl}$ ist (hsCRP $\leq 3,0 \mathrm{mg} / \mathrm{dl}$ : $165,3 \mathrm{ng} / \mathrm{ml}$ vs. hsCRP > 3,0 mg/dl: 143,6 ng/ml, p < 0,05).

(a)

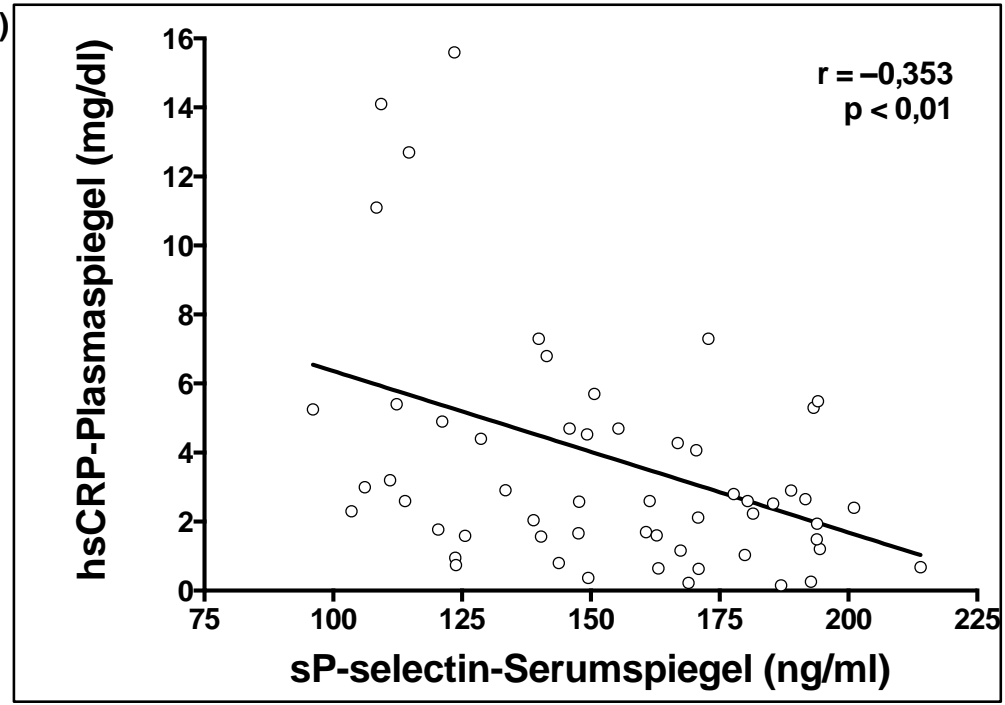

(b)

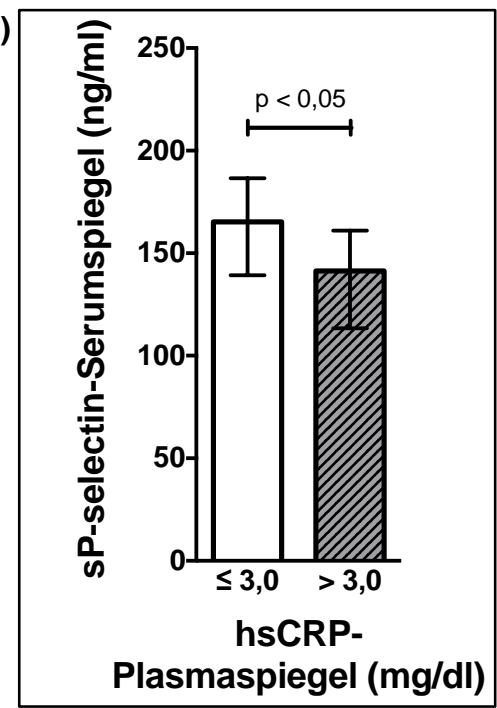

Abb. 3.22 (a) Korrelation der sP-selectin- und hsCRP-Spiegel und (b) Einfluss des hsCRP auf die sP-selectin-Serumspiegel

(a) Korrelationsdarstellung mit Rangkorrelationskoeffizient $r, p$-Wert und linearer Regressionsgraden. (b) Die Histogramme zeigen die Mediane, Quartile und Interquartilabstände. Der signifikante Unterschied zwischen der Gruppe von KHK-Patienten mit niedrigen hsCRP-Werten (hsCRP $\leq 3,0 \mathrm{mg} / \mathrm{dl}, \mathrm{n}=36$ ) und solchen mit höheren (hsCRP > 3,0 mg/dl, $n=24$ ) ist als $p$-Wert ausgeschrieben. 


\subsection{TNF- $\alpha$-Plasmaspiegel}

Da das proinflammatorische Zytokin TNF- $\alpha$ Einfluss auf die KLF4-Expression von Makrophagen und Monozyten hat (Sharma et al. 2012), wurde ergänzend zu den durchflusszytometrischen KLF4+Monozytenanalysen (siehe Kapitel 3.7) der TNF- $\alpha$-Spiegel der KHK- und Kontrollgruppe per ELISA aus EDTA-antikoaguliertem Blutplasma bestimmt (siehe Abb. 3.23 a). Es zeigt sich ein signifikant höherer TNF- $\alpha$-Spiegel im Blutplasma der KHK-Patienten verglichen mit dem der gesunden Kontrollprobanden (Ktr.: 0,036 pg/ml vs. KHK: 0,238 pg/ml, p<0,01).

Darüber hinaus findet sich - dargestellt in Abb. 3.23 b - eine inverse Korrelation der detektierten TNF- $\alpha$-Plasmaspiegel mit der relativen Anzahl an KLF4 ${ }^{+}$-Gesamtmonozyten $(r=-0,275, p<0,05)$.

(a)

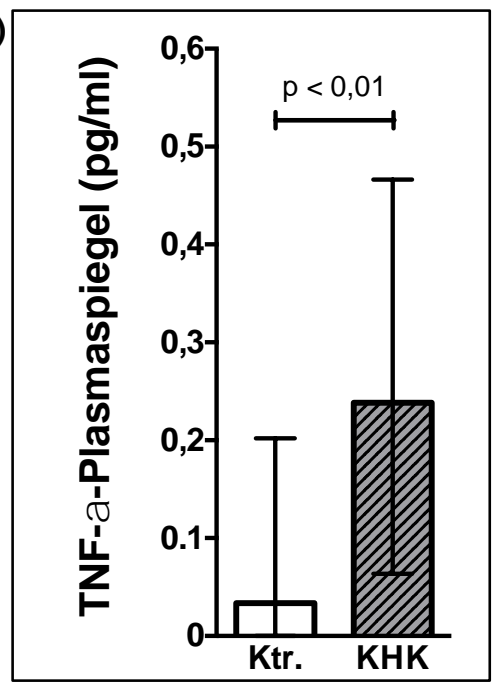

(b)

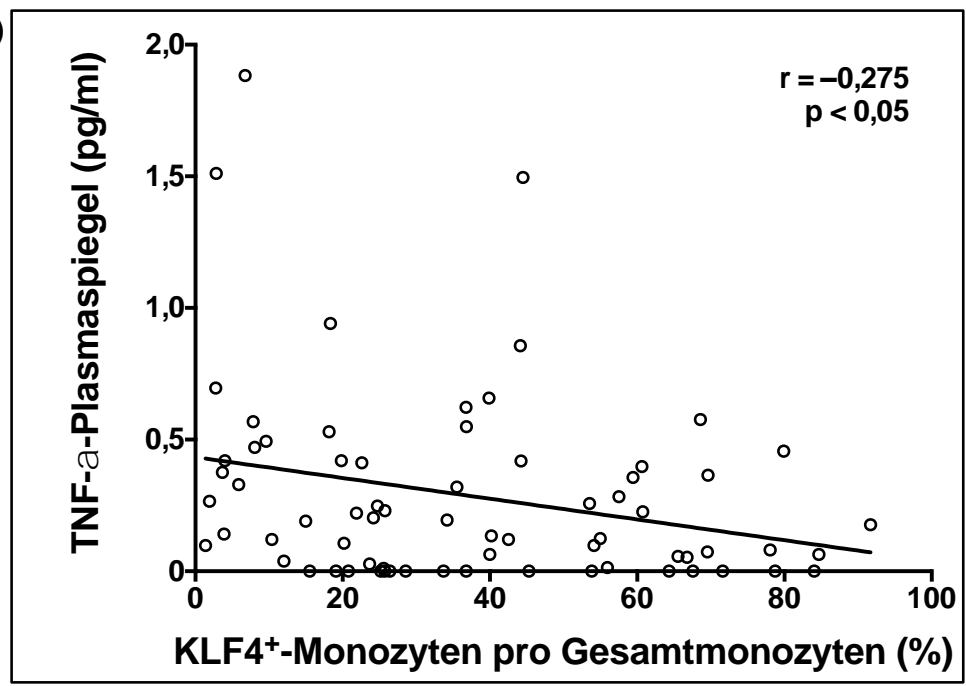

Abb. 3.23 (a) TNF- $\alpha$-Blutplasmaspiegel und deren (b) Korrelation mit dem relativen Anteil an KLF4'-Monozyten

(a) Die Histogramme zeigen die Mediane, Quartile und Interquartilabstände. Der signifikante Unterschied zwischen der Kontrollgruppe gesunder Probanden (Ktr., $n=64)$ und den Patienten mit koronarer Herzkrankheit (KHK, $n=60$ ) ist als $p$-Wert ausgeschrieben. (b) Korrelationsdarstellung mit Rangkorrelationskoeffizient $r$, p-Wert und linearer Regressionsgraden (modifiziert nach Czepluch et al. 2013b, S. 1081). 


\section{DISKUSSION}

\section{1 Übersicht}

Die Analyse der verschiedenen Monozytenuntergruppen ist in den letzten Jahren stetig vorangeschritten. So erbrachten bspw. Mausstudien wichtige Einblicke in die subtypenspezifischen Charakteristika der verschiedenen Monozyten. Außerdem wurde das Verständnis für die Bedeutung der Monozyten im Allgemeinen und ihrer Untergruppen im Speziellen im Kontext der Entstehung und Progredienz atherosklerotischer Läsionen kontinuierlich vergrößert. Dennoch zeigt sich, dass Ergebnisse muriner Forschung nicht eins-zu-eins auf den Menschen übertragbar sind, weswegen auch heute noch Einfluss und Funktionen der drei verschiedenen, von Ziegler-Heitbrock et al. 2010 definierten, Monozytenuntergruppen (Ziegler-Heitbrock et al. 2010) nicht gänzlich geklärt sind. Bis zum aktuellen Zeitpunkt gibt es nicht ausreichend viele Studien, die sich mit Monozytensubgruppen von Patienten befassen, die an einer KHK - und damit einer chronisch-inflammatorischen Erkrankung - leiden. Noch weniger als die monozytären Untergruppen per se sind Rezeptoren und deren Botenstoffe als Initiatoren, Mediatoren oder Inhibitoren inflammatorischer Prozesse rund um die KHK und deren Evaluation in Kontext einzelner Monozytensubgruppen ausreichend erforscht, um aus den in Laboren gewonnenen Erkenntnissen in naher Zukunft neue therapeutische Möglichkeiten eröffnen zu können.

Im Rahmen der vorliegenden Studie werden die Oberflächenrezeptoren CCR5 und CD44 auf Monozyten und deren Untergruppen sowie die MPA-Bildung als Ausdruck thrombozytärer Aktivierung bei Patienten mit KHK durchflusszytometrisch evaluiert. Auch steht die intrazelluläre KLF4-Expression der Monozyten im Fokus der Forschung. Die gewonnenen Ergebnisse werden abschließend mit ELISA-Nachweisen proinflammatorischer Chemokine gekoppelt und ergänzt und ermöglichen neue Einsichten in die Bedeutung der verschiedenen Monozytensubgruppen für Genese und Progredienz der Atherosklerose.

Die vorliegenden Studiendaten zeigen, dass die Anzahl klassischer Monozyten bei KHK-Patienten verglichen mit gesunden Blutspendern signifikant größer ist. Gegenteiliges findet sich bei den $\mathrm{CD} 14^{+} \mathrm{CD} 16^{++}$-Monozyten. Darüber hinaus detektieren die Versuchsergebnisse in allen drei monozytären Subgruppen der KHK-Patienten verglichen mit denen der Kontrollprobanden bedeutsam weniger $\mathrm{CCR5}^{+}$-Monozyten sowie vermehrte MPA-Formierung bei - im Gegensatz zu höheren TNF- $\alpha$ Spiegeln - verminderten Serumspiegeln der proinflammatorischen Proteine SPECAM-1 und sP-selectin. Dagegen weisen die CCL5-Serumspiegel- und CD44-Rezeptoranalysen keine wesentlichen Unterschiede zwischen beiden Studiengruppen auf. Der Anteil an $\mathrm{KLF}^{+}$-Monozyten ist in allen drei 
Monozytensubgruppen der KHK-Patienten im Vergleich zu den gesunden Kontrollpersonen vermindert, was sich mittels der Ergebnisse der durchgeführten Inkubationsversuche weiter untermauern lässt. Es zeigt sich auch, dass eine medikamentöse Therapie mit Statinen und Ezetimib auf die monozytäre Verteilung und den Anteil an CCR5 ${ }^{+}$-Monozyten einwirkt und dass das Vorhandensein der kardialen Risikofaktoren arterielle Hypertonie und Typ-2-Diabetes mellitus einen negativen Einfluss auf den Anteil der KLF4 ${ }^{+}$-Monozyten hat.

\subsection{Einordung relevanter klinisch-chemischer und hämo- staseologischer Blutparameter in den klinischen Kontext}

\subsubsection{Leukozytenzahl}

Die Laboranalysen der Probandenblutproben zeigen signifikant höhere Leukozytenzahlen im Blut der KHK-Patienten verglichen mit den gesunden Kontrollpersonen. Diese Leukozytenzahlerhöhung liegt mit medianen 6600 Leukozyten/ $\mu$ l Vollblut gänzlich innerhalb der gängigen Normwerte (Dormann et al. 2014). Mehrere Arbeitsgruppen konnten bislang die (prognostische) Bedeutung erhöhter Leukozytenwerte im Blut für die Ausbildung einer KHK belegen. So zeigen bereits ältere Studien, dass die Höhe der peripheren Leukozytenspiegel mit dem Risiko, eine KHK auszubilden, ebenso positiv korreliert (Sweetnam et al. 1997) wie mit der KHK-Inzidenz (Prentice et al. 1982) oder dem Schweregrad einer ebensolchen (Kostis et al. 1984). Generell weisen KHK-Patienten höhere Leukozytenspiegel als koronargesunde Probanden auf (Kostis et al. 1984). Untersuchungen an Patienten mit akutem Koronarsyndrom zeigen, dass eine stark erhöhte Leukozytenzahl mit einem bis zu acht Mal höheren Risiko eines erneuten, schweren kardiovaskulären Ereignisses verglichen mit niedrigen Leukozytenwerten vergesellschaftet ist (Zouridakis et al. 2000). Im Zuge dessen können die im Rahmen der vorliegenden Studie gemessenen peripheren Leukozytenzahlen als moderat und nicht erhöht, aber dennoch signifikant höher als die des gesunden Kontrollkollektives betrachtet werden. Eine unterschiedliche große Monozytenanzahl, die ebenfalls als prädiktiver Marker einer KHK beschrieben ist (Olivares et al. 1993), lässt sich dagegen nicht nachweisen.

\subsection{2 hsCRP}

In der vorliegenden Studie erbrachten die laborchemischen Analysen auffallend höhere hsCRP-Werte in der Gruppe der KHK-Patienten verglichen mit den gesunden Kontrollprobanden. Diese Ergebnisse sind schlüssig und decken sich mit der gängigen Literatur, denn hsCRP kommt als prognostischer Marker der KHK große Bedeutung zu. So ist CRP nicht nur als Akute-Phase-Protein von klinischer Be- 
deutung, sondern es ist auch in die chronisch-inflammatorische Genese der Atherosklerose eingebunden (Inoue et al. 2005) und - neben im Blut zirkulierenden Anteilen - direkt in atherosklerotischen Läsionen nachweisbar (Ishikawa et al. 2003). Folglich zeigen sich erhöhte CRP-Werte bei Probanden mit kardiovaskulären Risikofaktoren (Cook et al. 2000; Mendall et al. 1996), und eine Studie mit über 2000 Teilnehmern findet bei Patienten mit Angina pectoris eine deutliche Assoziation zwischen dem Anstieg basaler hsCRP-Werte und dem Risiko, innerhalb zweier Jahre an plötzlichem Herztod oder einem Myokardinfarkt zu versterben (Haverkate et al. 1997). Letztlich scheint den hsCRPBlutwerten eine prognostisch größere Bedeutung für das Auftreten und Überleben kardiovaskulärer Ereignisse zuzukommen als LDL-C-Werten (Ridker et al. 2002). Möglicherweise sind die in der vorliegenden Studie gefundenen medianen hsCRP-Werte von 2,55 mg/l in der Gruppe der KHK-Patienten medikamentös bereits deutlich gesenkt worden, da u. a. die PRINCE- und die JUPITER-Studie nachweisen konnten, dass Statinmedikationen, die in der vorliegenden Studie immerhin 80 \% der KHKPatienten regelmäßig einnehmen, zu einer hsCRP-Minderung führen (Albert et al. 2001; Ridker et al. 2008).

\subsection{3 $\mathrm{HbA}_{1 \mathrm{c}}$}

Die laborchemischen Analysen ergeben darüber hinaus im Vergleich zur Kontrollgruppe signifikant höhere $\mathrm{HbA}_{1 c}$-Blutwerte beim KHK-Patientenkollektiv. Letztlich spiegeln diese erhöhten $\mathrm{HbA}_{1 c}$-Werte der KHK-Gruppe nicht nur eine (prä-) diabetogene Stoffwechsellage (Koenig RJ et al. 1976; Rahbar et al. 1969) - die immerhin bei $20 \%$ der Studienpatienten diagnostiziert ist -, sondern sie dienen per se auch als Verlaufsparameter und Therapiekontrolle eines Diabetes mellitus (Bundesärztekammer et al. 2013, zuletzt geändert: November 2014; Uebel 2014). So gesehen liegen die medianen $\mathrm{HbA}_{1 c^{-}}$ Werte der KHK-Gruppe (als Kollektiv betrachtet) mit 41,0 mmol/mol bzw. 5,9\% sogar noch unterhalb des von der aktuellen Nationalen Versorgungsleitlinie empfohlenen $\mathrm{HbA}_{1 c}$-Zielkorridors von $6,5 \%$ bis 7,5 \% für Erwachsene mit Typ-2-Diabetes mellitus (Bundesärztekammer et al. 2013, zuletzt geändert: November 2014). Studien an japanischen Probanden haben gezeigt, dass hohe $\mathrm{HbA}_{1 c}$-Werte mit einer verminderten Reduktion atherosklerotischer Plaques unter Statintherapie korrelieren (Daida et al. 2012). Ebenso sind hohe $\mathrm{HbA}_{1 c}$-Blutwerte bei Patienten mit KHK und Typ-2-Diabetes mellitus vergesellschaftet mit erhöhten Werten der proinflammatorischen Moleküle MCP-1 und IL-6 (BernalLopez et al. 2013). Alles in allem kommen erhöhten Blutglukose- und damit erhöhten $\mathrm{HbA}_{1 c}$-Werten prognostische Bedeutung für die Entwicklung einer KHK und das Risiko, Myokardinfarkte zu erleiden bzw. daran zu versterben, zu (Goldbourt et al. 1993; Kannel und McGee 1979a; Nathan et al. 2005). Die im Rahmen der vorliegenden Studie ermittelten $\mathrm{HbA}_{1 \mathrm{c}}$-Blutwerte sind folglich in ihrer Relation zwischen KHK- und Kontrollgruppe zu erwarten gewesen. 


\subsection{Prozentuales Vorkommen der drei Monozytensub- gruppen im Kontext der aktuellen Forschung}

Die große Bedeutung von Leukozyten - insbesondere Monozyten - für die Entstehung und das Fortschreiten der Atherosklerose ist unzweifelhaft (Plutzky 2003; Swirski und Nahrendorf 2013). Eine Zunahme im Blut zirkulierender Monozyten und deren Invasion in entzündete Gewebe sind schon 1985 beschrieben worden (van Furth 1985). Verschiedene Arbeitsgruppen konnten in Mausstudien die funktionellen Rollen der verschiedenen Monozytensubgruppen für die Atheroskleroseentstehung näher beschreiben (Geissmann et al. 2003; Swirski et al. 2007).

Weniger eindeutig ist der Beitrag humaner Monozytenuntergruppen zur Genese der Atherosklerose. Studien zeigen zwar eine vermehrte Anzahl der CD16 -Monozyten bei Patienten mit KHK (Schlitt et al. 2004), bei vorhandenen vulnerablen Plaques (Kashiwagi et al. 2010) und eine Assoziation zwischen dem Vorhandensein von CD16 -Monozyten und der Dicke der fibrösen Kappe einer atherosklerotischen Läsion (Imanishi et al. 2010), aber in diesen Studien finden sich keine weiteren Unterscheidungen der CD16 ${ }^{+}$-Monozyten anhand ihrer CD14-Expressionsmuster in intermediäre und nichtklassische Monozyten. Andere Studien zeigen einen Anstieg der CD14 $4^{++} \mathrm{CD} 16^{+}$- und $\mathrm{CD} 14^{+} \mathrm{CD} 16^{++}$Monozyten bei Probanden mit den kardiovaskulären Risikofaktoren Übergewicht und Hyperglykämie (Poitou et al. 2011) bzw. bei Patienten mit peripherer arterieller Verschlusskrankheit [pAVK] (Dopheide et al. 2012). Rogacev et al. konnten in einer großen Studie mit über 950 Studienteilnehmern zeigen, dass die Anzahl der $\mathrm{CD} 14^{++} \mathrm{CD} 16^{+}$-Monozyten als prädiktiver Marker zukünftiger kardiovaskulärer Ereignisse gelten kann (Rogacev et al. 2012). Auch bei Dialysepatienten scheint die Anzahl der $\mathrm{CD} 14^{+} \mathrm{CD} 16^{++}$-Monozyten prädiktive Auskunft über zukünftige kardiovaskuläre Ereignisse geben zu können (Heine et al. 2008). In diesen Kontext passend, finden sich vermehrt nicht-klassische Monozyten bei KHK-Patienten mit niedrigen HDL-C-Spiegeln (Krychtiuk et al. 2014). So wird auf der einen Seite die Bedeutung der CD16 ${ }^{+}$-Monozyten für die Atherosklerose wegen ihrer proinflammatorischen und proatherogenen Eigenschaften ebenso hervorgehoben (Ziegler-Heitbrock 2007) wie ihre endothelialen und thrombozytären Bindungseigenschaften (Passacquale et al. 2011), auf der anderen Seite fanden mehrere Studien aber auch eine vermehrte Anzahl von CD14 $4^{++} \mathrm{CD} 16^{-}$-Monozyten bei KHK-Patienten mit mehr als fünf vorhandenen kardiovaskulären Risikofaktoren oder positiver Familienanamnese (Hristov et al. 2010) sowie in retrospektiven Studien bei Patienten mit kardiovaskulären Ereignissen verglichen mit ereignisfreien Probanden (Berg KE et al. 2012). Ebenfalls konnten Untersuchungen an Patienten, die zusätzlich zu einer KHK noch an Stenosen der Arteriae carotides litten, erhöhte Prozentsätze klassischer CD16-Monozyten nachweisen (Jaipersad et al. 2014). 
Auch in der vorliegenden Studie zeigt sich eine prozentual vermehrte Anzahl der $C D 14^{++} C D 16^{-}-$ Monozyten und eine verminderte Anzahl der $\mathrm{CD} 14^{+} \mathrm{CD} 16^{++}$-Monozyten bei Patienten mit KHK verglichen mit gesunden Kontrollprobanden. Bezogen auf die absolut detektierten Monozytenzahlen lässt sich dieses Ergebnis nur bei den signifikant weniger vorhandenen nicht-klassischen Monozyten der KHK-Patienten finden.

Untersuchungen an Patienten, die an systemischem Lupus erythematodes [SLE] - und damit an einer ebenfalls chronisch-inflammatorischen Erkrankung - leiden, zeigen, dass eine Medikation mit Fluvastatin antioxidative und antiinflammatorische Effekte auf die untersuchten Monozyten ausübt (RuizLimon et al. 2014). Da auch 48 der 60 in die vorliegende Studie eingeschlossenen KHK-Patienten, d. h. $80,0 \%$, eine dauerhafte Statinmedikation erhalten, lässt sich dadurch eine Reduktion der $\mathrm{CD} 14^{+} \mathrm{CD} 16^{++}$- bzw. eine vermehrte Anzahl $\mathrm{CD} 14^{++} \mathrm{CD} 16^{-}$-Monozyten möglicherweise erklären. Die Patientengruppe der vorliegenden Arbeit erhält eine detektable und suffizient cholesterinsenkende Medikation, was sich in den verglichen mit der Kontrollgruppe signifikant niedrigeren Blutwerten für Gesamtcholesterin und LDL-C zeigt.

Dass die cholesterinsenkende Medikation einen Einfluss auf die Verteilung der Monozytensubgruppen hat, lässt sich mit im Rahmen dieser Untersuchung beschriebenen Beobachtungen bei Patienten, die regelmäßig ein lipidsenkendes und antiinflammatorisches Ezetimibpräparat erhalten haben, untermauern: Auch hier finden sich vermehrt klassische, v. a. aber weniger nicht-klassische Monozyten verglichen mit den Patienten, die kein Ezetimib einnehmen. Diese Daten werden von externen Studien gestützt, mittels derer gezeigt werden konnte, dass Ezetimib bei Ratten neben der Lipidsenkung zu verminderter Plaqueinflammation und Monozytenrekrutierung führt (Gomez-Garre et al. 2009), sowie Einfluss auf die MPA-abhängige Monozyten-/Makrophagendifferenzierung nimmt (MunozPacheco et al. 2012).

\subsection{Bedeutung der CCR5-Expression auf den verschiedenen Monozytensubgruppen sowie der im Blut detektierten CCL5-Serumspiegel}

Die Rekrutierung von Monozyten und ihren Untergruppen in atherosklerotische Läsionen erfolgt über zytokine Reize, eine monozytäre Reaktion auf ebendiese sowie die Expression spezifischer Chemokinrezeptoren (Eriksson et al. 2001; Lusis 2000; Ross 1999; Weber C et al. 2004). Aktivierte, am Endothel adhärierte Thrombozyten unterstützen die Rekrutierung, das Passieren der Gefäßwand und damit das Vordringen von Monozyten und anderer Leukozyten an Orte atherosklerotischer Läsionen (da Costa Martins et al. 2006; Kuckleburg et al. 2011; Massberg et al. 2002; McEver 2001; 
Totani und Evangelista 2010). Eines der vorrangigen an der Monozytenrekrutierung beteiligten Chemokine ist CCL5, das u. a. von aktivierten Thrombozyten und Lymphozyten sezerniert wird (Gleissner et al. 2008; Kameyoshi et al. 1992; Pattison et al. 1996) und dessen Spiegel in atherosklerotischen Plaques heraufreguliert ist (Martin et al. 2004; Wilcox et al. 1994). Eine vermehrte Interaktion mit CCL5 resultiert in verstärktem Arrest am Endothel und transmigratorischem Verhalten der Monozyten (Huo et al. 2003; von Hundelshausen et al. 2001; Weber C 2005). Verschiedene Studien an Mäusen konnten zeigen, dass eine Blockade des CCL5-Rezeptors CCR5 bzw. eine Deletion des CCR5-Gens zu einer Reduktion bzw. zu vermindertem Auftreten von Atherosklerose führt, was zum einen an einer reduzierten Anzahl zirkulierender, proinflammatorischer Monozyten liegt, zum anderen auf eine verringerte Monozytenrekrutierung in die Gefäßwände zurückzuführen ist (Combadiere et al. 2008; Koenen et al. 2009; Schober et al. 2002; Veillard et al. 2004b). Murine Studien konnten darüber hinaus zeigen, dass auch eine Blockade der CCR5-ähnlichen Rezeptoren CCR2 und CX3CR1 das Ausmaß atherosklerotischer Läsionen signifikant verringert (Boring et al. 1998; Saederup et al. 2008) und dass die zusätzliche Blockade von CCR5 zu einer maximalen Reduktion atherosklerotischer Plaqueformierung bei Mäusen führt (Combadiere et al. 2008). Ebenfalls zeigen Versuche an Apolipoprotein E [ApoE]-defizienten Mäusen mit dem für die HIV-Therapie zugelassenen CCR5Antagonisten Maraviroc (Celsentri ${ }^{\circledR}$, Pfizer), dass die Atheroskleroseentstehung signifikant vermindert wird, ohne den Statinspiegel eindrücklich zu senken (Cipriani et al. 2013).

In früheren Studien konnte gezeigt werden, dass CCR5 vor allem auf CD16 ${ }^{+}$-Monozyten - insbesondere dem intermediären Subtyp - stark exprimiert wird (Ancuta et al. 2003; Rogacev et al. 2011; Weber C et al. 2000). Diese Ergebnisse decken sich mit den Daten der vorliegenden Studie, die sowohl in der KHK- als auch der Kontrollgruppe den signifikant größten relativen Anteil an $\mathrm{CCR5}^{+}$-Monozyten in ebendieser Subgruppe lokalisieren. In Anbetracht der Schlüsselrolle, die CCR5 bei der Entstehung und Progredienz der Atherosklerose einnimmt, liegt der Schluss nahe, dass auch den intermediären Monozyten eine besonders wichtige Stellung bei der Genese atherosklerotischer Erkrankungen zuteil ist, die die Bedeutung der nicht-klassischen Monozyten in den Hintergrund drängen könnte. Der Mechanismus, wonach der Anteil der $\mathrm{CCR}^{+}$-Monozyten in allen drei Subgruppen der KHK-Patienten niedriger ist als beim Kollektiv der gesunden Blutspender, lässt sich anhand des Studiendesign und der durchgeführten Versuche nicht näher erklären. Möglicherweise bewirkt, wie bei Czepluch et al. diskutiert, eine vermehrte Rekrutierung von $\mathrm{CCRS}^{+}$-Monozyten an Orte atherosklerotischer Läsionen und inflammatorischer Milieus bei Patienten mit KHK eine verringerte Anzahl an $\mathrm{CCRS}^{+}$-Zellen im peripheren Blut (Czepluch et al. 2014). Diese These lässt sich mittels der erhöhten $\mathrm{HbA}_{1 c}$ - und hsCRPWerte sowie der Leukozytenzahlen im Probandenblut stützen, die die entzündliche Grundsituation der KHK-Patienten wiedergeben. 
Um die Ursache der Herunterregulation der $\mathrm{CCR}^{+}{ }^{-}$-Monozyten im peripheren Blut der KHK-Patienten näher zu beleuchten, wurde in der vorliegenden Studie der CCL5-Serumspiegel beider Probandengruppen untersucht. Da keine signifikanten Differenzen zwischen KHK-Patienten und gesunden Kontrollprobanden gefunden wurden, lässt sich ein quantitativer Abfall der CCR5 ${ }^{+}$-Monozyten als Antwort auf chronisch erhöhte CCL5-Blutserumspiegel nahezu ausschließen. Möglich ist aber dennoch eine kompensatorische Herunterregulation der $\mathrm{CCR}^{+}$-Monozyten aufgrund einer häufig schon viele Jahre bestehenden KHK mit initial erhöhten CCL5-Spiegeln. Diese Theorie wurde allerdings nicht weiter verfolgt bzw. hinterfragt, da die gefundenen Ergebnisse im Kontrast zu erhöhten CCL5-Spiegeln bei Patienten mit KHK stehen, die in anderen Studien beschrieben werden (Koh et al. 2009). Diese Differenzen zu Befunden anderer Forschungsgruppen sind eventuell auch einer guten (medikamentösen) Begleittherapie geschuldet, die die Studienteilnehmer mit KHK dauerhaft erhalten.

Möglicherweise ist die reduzierte Anzahl an $\mathrm{CCR5}^{+}$-Monozyten bei den KHK-Patienten auch auf andere, bislang nicht näher analysierte Zyto- oder Chemokine zurückzuführen. Diese Theorie lässt sich mittels der durchgeführten Inkubationsversuche stützen, bei denen Monozyten gesunder, junger Blutspender nach Inkubation mit heparinisiertem Blutplasma von KHK-Patienten ebenfalls weniger CCR5 aufweisen als nach Inkubation mit Kontrollprobandenplasma.

\subsection{Cholesterinsenkende Medikation und ihr Einfluss auf die monozytäre CCR5-Expression sowie den prozentualen Anteil der Monozytensubgruppen}

\subsubsection{Statine und ihr Einfluss auf den Anteil CCR5+-Monozyten}

Einer der wichtigsten konservativen Therapieansätze bei Patienten mit KHK und besonders bei Z. n. Myokardinfarkt ist die Senkung des Blutcholesterols. Da dieses allein mit herkömmlichen ernährungs- und lebensumstellenden Maßnahmen nur selten ausreichend und/oder dauerhaft umsetzbar ist (Jeffery et al. 2000; Rothman 2000), empfehlen ESC (Reiner et al. 2011), DGK (Koenig W et al. 2012) und andere Fachgesellschaften (Perk et al. 2012) die frühzeitige Therapieeinleitung mit einem HMG-CoA-Reduktasehemmer (Synonym: Statin). Die HMG-CoA-Reduktase dient der Katalyse von HMG-CoA zu Mevalonsäure im Zytosol und ist der geschwindigkeitsbestimmende Schritt der Cholesterolsynthese (Löffler G 2014). Durch die Hemmung dieses Enzyms mittels eines Statins wird folglich die körpereigene Cholesterolsynthese vermindert. Auf die vermeintliche Cholesterolunterversorgung wird die LDL-C-Rezeptorexpression vieler Zellen heraufreguliert, sodass vermehrt freies LDL-C über die hohe Rezeptorendichte gebunden und per Endozytose internalisiert wird, was zu einer Reduktion des freien, stark atherogenen LDL-Cs führt (Keller 2013). Außerdem können Statine auf diese Weise 
nicht nur die Größe atherosklerotischer Plaques reduzieren (Lima et al. 2004; Nicholls et al. 2011; Nissen et al. 2006), sondern auch die Menge an oxidiertem LDL-C und deren Einlagerung in ebendiese Läsionen (Choi et al. 2008; Ky et al. 2008) und führen möglicherweise dadurch zu einer Plaquestabilisierung (Crisby et al. 2001).

Aufgrund dieses antiinflammatorischen Effekts der Statine ist nicht auszuschließen, dass die herunterregulierte Anzahl an $\mathrm{CCR}^{+}{ }^{-}$Monozyten bei den Studienteilnehmern mit KHK in den vorliegenden Untersuchungen auf die Statinmedikationen zurückzuführen ist, die immerhin 80 \% der Patienten dauerhaft erhalten. Veillard et al. konnten zeigen, dass eine in vitro-Behandlung humaner Makrophagen und Endothelzellen mit Simvastatin zu einer verminderten CCR5-Expression führt, ohne den CCL5-Spiegel signifikant zu verändern (Veillard et al. 2006). Die Ergebnisse der Stimulationsversuche der vorliegenden Studie lassen sich damit ebenfalls erläutern, da alle KHK-Patienten, deren Plasma zur Monozyteninkubation verwendet wurde, eine Dauermedikation mit HMG-CoA-Reduktasehemmern erhalten und Monozyten nach Inkubation mit ebendiesem (statintherapierten) Patientenplasma weniger CCR5 aufweisen als nach Behandlung mit Plasma gesunder Kontrollprobanden.

Passend dazu zeigt die nähere Betrachtung, dass die 48 KHK-Patienten unter Statinmedikation bedeutsam mehr $\mathrm{CCR}^{+}$-Monozyten in allen drei monozytären Untergruppen verglichen mit Patienten ohne HMG-CoA-Reduktasehemmer aufweisen. Auch in dieser Auswertung finden sich die mit Abstand meisten $\mathrm{CCR}^{+}{ }^{+}$Monozyten in der intermediären Monozytengruppe. Auch wenn sich diese Befunde mit dem Vergleich der monozytären CCR5-Expression zwischen Kontrollprobanden und KHKPatienten deckt, bei denen die Kontrollprobanden in allen drei Monozytenuntergruppen mehr $\mathrm{CCR5}^{+}$-Monozyten aufweisen als die KHK-Patienten, so legen sie dennoch den Schluss nahe, dass entsprechend der bereits in Kapitel 4.4 geäußerten Theorie - weitere im peripheren Blut gelöste Faktoren Einfluss auf die monozytäre CCR5-Expression haben.

\subsubsection{Ezetimibe reduzieren den relativen Anteil nicht-klassischer Monozyten}

Da zur prognoserelevanten Cholesterinsenkung bei Patienten mit KHK, Hypercholesterinämie und/ oder Z. n. Myokardinfarkt nicht nur Statine von der Europäischen Arzneimittelagentur zugelassen sind, stehen weitere Medikamente mit unterschiedlichen Wirkungsweisen zur Verfügung (Arzneimittelkommission der Deutschen Ärzteschaft 2012). Eines der mittlerweile vermehrt, v. a. bei unzureichendem Erfolg, Kontraindikationen oder Komplikationen einer Statintherapie, eingesetzten Mittel ist der Wirkstoff Ezetimib. Ezetimib inaktiviert vollständig den erst 2004 entdeckten Cholesteroltransporter Niemann-Pick C1-ähnliches Protein 1 (engl. Niemann-Pick C1-like protein 1 [NPC1L1]), der, v. a. in Dünndarmenterozyten und der Leber vorkommend, maßgeblich an der Cho- 
lesterinaufnahme in die Zellen und damit an erhöhten Cholesterinspiegeln im Blut beteiligt ist (Altmann et al. 2004) und senkt so u. a. den LDL-C-Blutspiegel - sowohl in Mono- als auch in Kombinationstherapie mit Statinen (Davis HR et al. 2011; Rosenblum et al. 1998; Toth und Davidson 2005). Die verminderte intestinale Cholesterinaufnahme führt zu einer hepatischen Leerung der Cholesterinspeicher und dadurch - ähnlich der Statinwirkung - zur vermehrten zellulären Expression des LDLC-Rezeptors, welcher über gesteigerte LDL-C-Aufnahme in die Zellen den LDL-C-Blutspiegel weiter verringert (Temel et al. 2007). Ezetimib vermindert die über den Bürstensaum der Dünndarmzotten aufgenommene Cholesterinmenge laut Sudhop et al. um mehr als 50 \% (Keller 2013; Sudhop et al. 2002).

Diese antiinflammatorischen Einflüsse des Ezetimib finden sich auch in den Ergebnissen der vorliegenden Studie wieder. So zeigt sich eine signifikant erhöhte Anzahl an $\mathrm{CD} 14^{++} \mathrm{CD} 16^{-}$-Monozyten bei KHK-Patienten mit Ezetimibmedikation im Vergleich zu solchen ohne. Auch ist die Anzahl proinflammatorischer $\mathrm{CD} 14^{+} \mathrm{CD} 16^{++}$-Monozyten bei Patienten unter dauerhafter Ezetimibeinnahme statistisch bedeutend vermindert im Vergleich zu jenen, die kein Ezetimib verschrieben bekommen haben.

\subsection{CD44 auf Monozyten - Verbesserung der durchflusszyto- metrischen Monozytendetektion mithilfe von CD44?}

OPN stellt als Chemoattraktanz einen starken Migrationsstimulus für im Blut zirkulierende Monozyten dar (Scatena et al. 2007; Wang und Denhardt 2008) und ist - neben vielen weiteren chronischoder akut-inflammatorischen Erkrankungen - im Plasma von Patienten mit KHK erhöht (Ohmori et al. 2003), sodass davon ausgegangen wird, dass OPN eine wichtige proinflammatorische Mediatorfunktion für die Genese der Atherosklerose zukommt.

In diesem Sinne konnte mittels in vitro-Studien bereits gezeigt werden, dass die Bindung von OPN an seinen Rezeptor CD44 zu einer verminderten Genexpression des atheroprotektiven IL-10 führt, während IL-12 und TNF- $\alpha$, die beide proinflammatorische Eigenschaften besitzen, vermehrt exprimiert werden (Ashkar et al. 2000; Weber GF et al. 2002). Mausversuche zeigen, dass OPN-Überexpression bei atherosklerotischen Läsionen zu einer verstärkten Zunahme der Tunica media und übersteigerter Neointimabildung führt und die SMC-Proliferation und -Migration heraufreguliert wird (Isoda et al. 2002). Außerdem fanden Humanstudien heraus, dass OPN die Expression von CD40L und IFN- $\gamma$, welche beide proinflammatorisch und makrophagenaktivierend wirken, auf humanen T-Zellen heraufreguliert (O'Regan et al. 2000). Tierversuche zeigen darüber hinaus signifikant weniger atherosklerotische Läsionen bei OPN-defizienten Mäusen im Vergleich zu Kontrollgruppen (Matsui et al. 2003). Untersuchungen am Herzen eines an einem Myokardinfarkt verstorbenen Patienten zeigten 1994 
erstmals vermehrte OPN-Expression in geschädigten Myokardbereichen, wohingegen sich in gesunden Myokardabschnitten keine vermehrten Mengen an OPN finden ließen (Murry et al. 1994). Dass Murry et al. die vermehrte OPN-Expression am achten Tag postinfarziell immunhistochemisch gefunden haben, deckt sich mit den Ergebnissen einer post mortem-Analyse, bei der in humanen Herzen ebenfalls erst im Stadium eines subakuten Myokardinfarktes, $d$. h. drei bis 14 Tage nach dem infarziellen Ereignis, eine erhöhte OPN-Expression gefunden wurde (Czepluch et al. 2013a).

Die Daten der vorliegenden Studie geben keinen Hinweis auf die differenzielle Bedeutung des OPNRezeptors CD44 auf den verschiedenen Monozytenuntergruppen, da sämtliche Monozyten CD44 exprimieren. Auch die Analyse der CD44-Anzahl pro Monozyt lässt keine Rückschlüsse auf deren Bedeutung im Kontext der Monozytenaktivierung und Atherosklerose zu.

Dennoch zeigt sich bei der durchflusszytometrischen Analyse der CD44-Expression, dass Monozyten detektabel mehr CD44 exprimieren als andere CD44+-PBMCs. Wird bei der FACS ${ }^{\text {TM }}$-Auswertung primär der Bereich erfasst, der sowohl die Monozytenwolke in der Scatter-Plot-Darstellung detektiert, als auch sekundär jener als markante Spitze darstellbare Abschnitt der CD44-Expressionsauftragung, der die höchsten Werte für CD44 präsentiert, können irrtümlicherweise im SSC- und FSC-Feld inkludierte, nicht monozytäre Zellen sehr exakt aus der Datenanalyse ausgeschlossen werden. Diese Entdeckung lässt sich im Rahmen des Monozytengatings nutzen, wie Abb. 4.1 (a) und (b) zeigen.

Dennoch bedarf es weiterer Analysen um Nutzen und Anwendbarkeit dieser neuen monozytären Gatingstrategie zu evaluieren. Besonders im Fokus sollten dabei durchflusszytometrische Vergleiche bereits etablierter/angewendeter Methoden der Monozytendetektion stehen, bei denen CD14, CD16, humanes Leukozytenantigen-DR (engl. human leukocyte antigen-DR [HLA-DR]), CD36, CCR2, CD45, Lipoprotein niedriger Dichte-Cholesterin-Rezeptor-verbundenes Protein 1 (engl. low density lipoprotein receptor-related protein 1 [LRP1]; Synonym: CD91) und viele weitere (Monozyten-) Marker Verwendung finden (vergl. Abeles et al. 2012; Appleby et al. 2013; Faucher et al. 2007; Ferrer et al. 2014). 


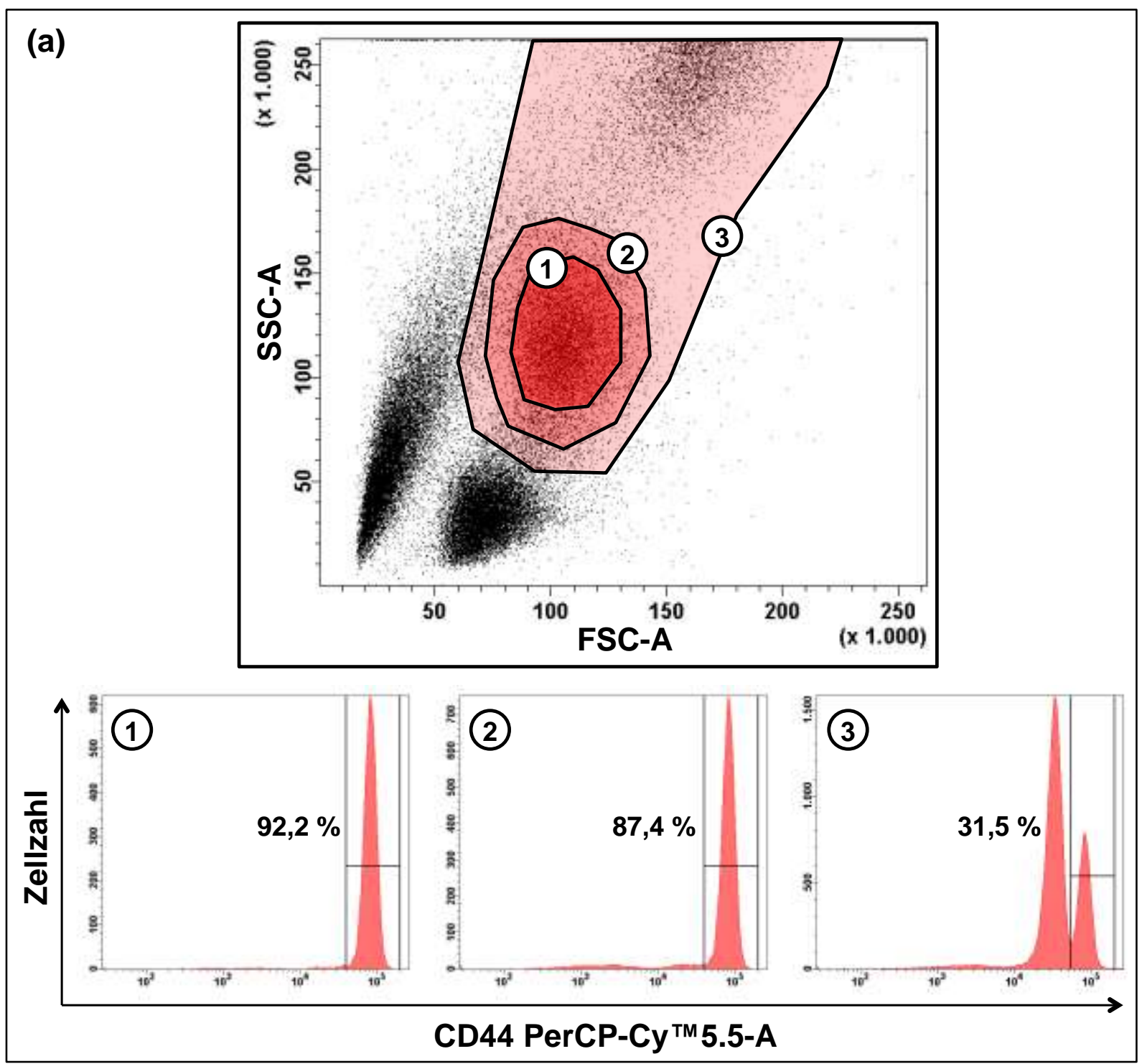

\section{Abb. 4.1 Monozytenseparation und -detektion anhand der CD44-Expression}

(a) In der Scatter-Plot-Darstellung finden sich drei unterschiedlich weit gefasste Gates, die allesamt die Monozytenwolke einschließen. Gate 1 erfasst diese sehr eng, sodass im stark postiven (Monozyten-) Bereich der Histogrammabbildung für CD44 92,2 \% der ursprünglich detektierten Zellen liegen. Gate 2 ist etwas weiter um die Monozytenwolke herumgelegt und detektiert möglicherweise bereits Lymphozyten und Granulozyten, was dazu führt, dass der Anteil der stark CD44 ${ }^{+}$-PBMCs im Histogramm auf 87,4 \% der ursprünglich gegateten Zellen absinkt. Das dritte Gate erfasst neben Monozyten ebenfalls Granulozyten und einen Teil der Lymphozytenwolke und dient einzig und allein der Ergebniserläuterung. Bei der Histogrammauftragung der Zellen dieses Gates anhand ihrer CD44-Expression findet sich nun neben der bereits bekannten Zacke der stark $\mathrm{CD}_{4} 4^{+}$-Zellen ein weiterer Gipfel von etwas weniger stark $\mathrm{CD} 44^{+}$-Zellen. Die ursprünglich betrachtete Zacke weist in diesem Fall mit 31,5\% stark CD44 ${ }^{+}$-Zellen nur noch etwa $1 / 3$ der von Gate 3 erfassten Zellen als Monozyten aus.

Abk. CD: cluster of differentiation; FSC: Vorwärtsstreulicht; PBMC: mononukleäre Zelle des peripheren Blutes;

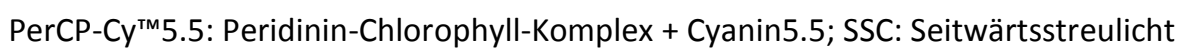




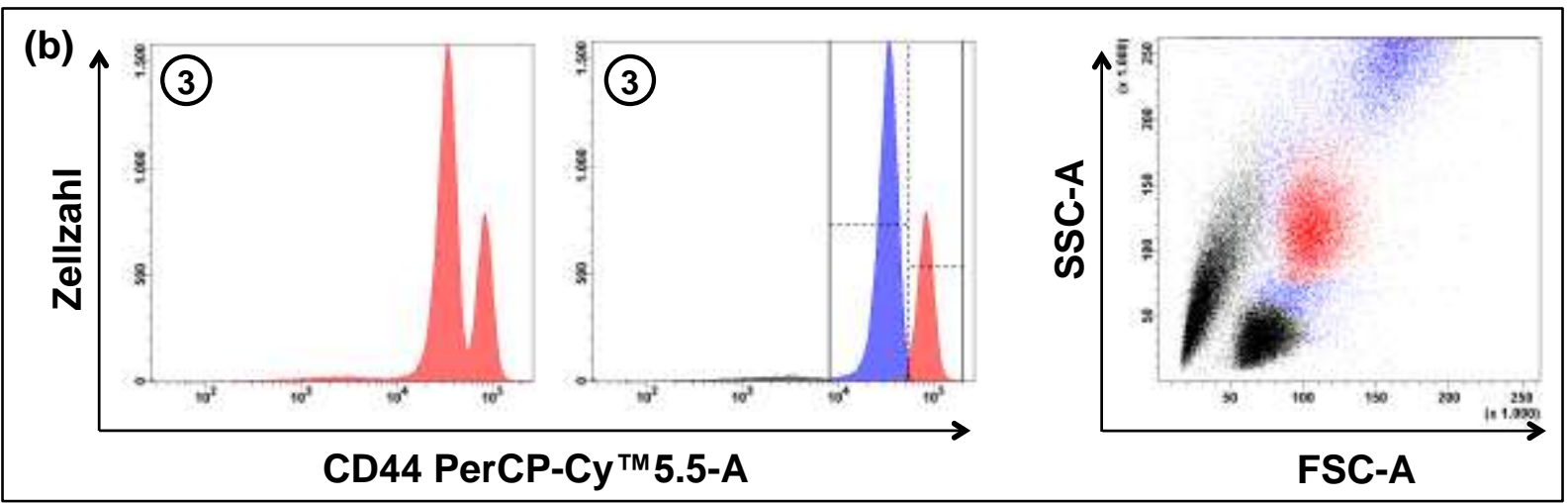

(b) Die mittels Gate 3 (aus Abb. 4.1 a) detektierten Zellen lassen sich anhand der Zweigipfligkeit in der Histogrammauftragung ihrer CD44-Expression differenzieren. Es lässt sich eine stark CD44 ${ }^{++}$-Fraktion (rote Farbe) und eine weniger stark $\mathrm{CD} 44^{+}$-Gruppe (blaue Farbe) definieren. Die farbliche Analyse dieser beiden Gruppen im Scatter-Plot zeigt, dass sich die roten CD44 ${ }^{++}$-Zellen ausnahmslos im Bereich der nach FSC und SSC zu gatenden Monozyten befinden, wohingegen die $\mathrm{CD} 44^{+}$-Zellen der blauen Gruppe perimonozytär v. a. im Bereich der Granulozyten und Lymphozyten liegen.

Abk. CD: cluster of differentiation; FSC: Vorwärtsstreulicht; PerCP-Cy ${ }^{\text {TM } 5.5: ~ P e r i d i n i n-C h l o r o p h y l l-K o m p l e x ~+~}$ Cyanin5.5; SSC: Seitwärtsstreulicht

\subsection{Bedeutung der KLF4-Expression in Monozyten und ihre Beziehung zu den detektierten TNF- $\alpha$-Plasmaspiegeln}

KLF4 ist als Transkriptionsfaktor in verschiedenste monozytäre Differenzierungs-, Proliferations- und Aktivierungsprozesse, wie bspw. die Expression des Oberflächenrezeptors CD14, eingebunden (Cao et al. 2010; Feinberg et al. 2007), und in in vivo-Tierstudien konnte nachgewiesen werden, dass die Differenzierung muriner Monozyten in pro- und antiinflammatorische Phänotypen in Abhängigkeit von KLF4 geschieht (Alder et al. 2008). Inwieweit KLF4 aber als Transkriptionsaktivator oder -hemmer seine Funktionen ausübt, hängt von dessen Interaktionen mit diversen weiteren Co-Faktoren der Transkription ab (Liao et al. 2011; Zhou et al. 2012).

In Tierversuchen konnte gezeigt werden, dass KLF4-defiziente Makrophagen einen proinflammatorischen Phänotyp annehmen (Liao et al. 2011; Sharma et al. 2012) und Hemizygotie für KLF2, dem für endotheliale Funktionen ähnliche Eigenschaften zukommen wie KLF4, zu vermehrter Plaquebildung führt (Atkins et al. 2008), während eine KLF4-Überexpression protektive Auswirkungen auf die Gefäße ausübt (Zhou et al. 2012). Sharma et al. konnten mit einem ApoE-Modell zeigen, dass Mäuse mit myeloischer KLF4-Defizienz im Vergleich zu Kontrollen signifikant mehr Gefäßinflammation und atherosklerotische Läsionen aufweisen (Sharma et al. 2012). Yoshida et al. fanden, dass KLF4 bei Mäusen einer vermehrten Neointimaproliferation vorbeugt (Yoshida et al. 2008). Ebenfalls mittels 
muriner Versuche konnte gezeigt werden, dass KLF4 in vivo und in vitro zu reduziertem Entzündungsgeschehen und verringerten Thromboseraten führt (Zhou et al. 2012).

Die in den Mausstudien beschriebenen antiinflammatorischen, antiproliferatorischen und antithrombotischen Effekte des KLF4 (Yoshida und Hayashi 2014) decken sich gut mit den Resultaten der vorliegenden Studie. Diese zeigt in allen drei Monozytensubgruppen der KHK-Patienten eine signifikant geringere Anzahl an KLF4+-Monozyten im Vergleich zur gesunden Kontrollgruppe. Die Resultate hängen möglicherweise - analog zu den Mausstudienergebnissen - mit einer Herunterregulation des KLF4 aufgrund der steigenden Zahl inflammatorischer Monozytenphänotypen, einer vermehrten Anzahl proinflammatorischer Zytokine im peripheren Blut und einer Zunahme atherosklerotischer Läsionen zusammen. Auch Untersuchungen an zirkulierenden Endothelzellen von KHK-Patienten zeigen eine signifikant verminderte Anzahl von $\mathrm{KLF}^{+}$-Endothelzellen verglichen mit einer gesunden Kontrollgruppe (Czepluch et al. 2015) und stützen die vorliegenden Ergebnisse.

Diese Theorie wird von den Ergebnissen der Inkubationsversuche untermauert, die zeigen, dass Monozyten nach Inkubation mit Plasma von KHK-Patienten signifikant weniger KLF4+-Monozyten aufweisen als nach Inkubation mit Plasma herzgesunder Probanden, was ebenfalls auf eine vermehrte Anzahl zirkulierender proinflammatorischer Botenstoffe im peripheren Blut der KHK-Patienten hinweist. In diesem Kontext wurde von anderen Arbeitsgruppen herausgefunden, dass bei KHKPatienten erhöhte TNF- $\alpha$-Spiegel im Blutplasma nachweisbar sind (Sels et al. 2012) - ein Feststellung, die sich auch mit den Ergebnissen der vorliegenden Untersuchungen deckt. Sharma et al. konnten darüber hinaus zeigen, dass erhöhte Spiegel proinflammatorischer Zytokine, wie bspw. TNF- $\alpha$, zu einer verminderten KLF4-Expression auf Makrophagen führen (Sharma et al. 2012). Die Tatsache, dass in den vorliegenden Studienergebnissen der relative Anteil an $\mathrm{KLF}^{+}$-Monozyten invers mit den im Blutplasma detektierten TNF- $\alpha$-Spiegeln korreliert, stützt die Vermutung, dass eine erhöhte Anzahl proinflammatorischer Zytokine - ob ausschließlich TNF- $\alpha$ oder aber viele weitere mehr - zu einer Herunterregulation des antiinflammatorischen KLF4 in Monozyten führt.

Dass bei KHK-Patienten ein inflammatorisches Milieu vorliegt, ist seit Längerem bekannt (Libby 2002). In Addition zu der Theorie, dass zirkulierende proinflammatorische Zytokine die KLF4Expression in Monozyten herunterregulieren, zeigt die vorliegende Studie, dass die kardiovaskulären Risikofaktoren arterielle Hypertonie und Typ-2-Diabetes mellitus ebenfalls Einfluss auf den relativen Anteil an $\mathrm{KLF}^{+}$-Monozyten besitzen. KHK-Patienten, die an diesen beiden Risikofaktoren leiden und damit per se ein größeres Progressions- und Komplikationsrisiko bei inflammatorischeren Verhältnissen besitzen als Patienten ohne diese beiden Risikofaktoren (Kannel und McGee 1979b; Kannel et al. 1980) -, weisen den vorliegenden Daten nach einen signifikant niedrigeren Anteil an $\mathrm{KLF}^{+}-$-Monozyten auf als KHK-Patienten ohne Risikofaktoren und solche, die zwar an arterieller Hy- 
pertonie, nicht aber an Typ-2-Diabetes mellitus erkrankt sind. Patienten mit Typ-2-Diabetes mellitus ohne arterielle Hypertonie zeigen dagegen nicht signifikant mehr KLF4+-Monozyten als jene Patienten mit beiden Risikofaktoren, sodass auch die Art der kardiovaskulären Risikofaktoren eine Rolle für die monozytäre KLF4-Expression zu spielen scheint. Auch zeigen die präsentierten Studiendaten, dass der Anteil an KLF4 ${ }^{+}$-Monozyten jeder Subgruppe negativ mit der Anzahl der im Blut detektierter Leukozyten korreliert, die ebenfalls Ausdruck entzündlichen Geschehens sind.

\subsection{Die Bildung von Monozyten-Thrombozyten-Aggregaten als Ausdruck chronisch-pathologischer Plättchenakti- vierung im Kontext zirkulierender Thrombozyten- aktivitätsmarker}

\subsubsection{Aktivierte Thrombozyten und ihre Interaktion mit Monozyten}

Die Bindung von Monozyten an Thrombozyten und Bildung sogenannter MPAs ist nicht nur ein Marker pathologischer Thrombozytenaktivierung in vivo (Michelson et al. 2001), sondern MPAs sind auch direkt an Inflammation und Atheroskleroseentstehung beteiligt (Huo et al. 2003). Aktivierte Thrombozyten sind allerdings nicht nur in der Initialphase einer akuten Gefäßläsion von Bedeutung (Marshall 1986). Da sie reich an nicht-verestertem Cholesterin sind (Shattil et al. 1975), können Thrombozyten auch die Schaumzellbildung stimulieren (Mendelsohn und Loscalzo 1988). Ergänzend dazu konnte schon vor längerer Zeit gezeigt werden, dass eine Hemmung der Thrombozytenfunktion im Tiermodel zu einer verminderten Atheromentstehung führt (Friedman et al. 1977). Neuere Studien zeigen in vivo und in vitro, dass oxidiertes LDL-C zu einer vermehrten MPA-Bildung präferenziell der CD16 ${ }^{+}$-Monozyten, zu vermehrter monozytärer Extravasation und Phänotypenwechsel sowie zu gesteigerter Schaumzellbildung führt (Badrnya et al. 2014).

In mehreren Studien konnten erhöhte Spiegel aktivierter Thrombozyten bei Patienten mit instabiler (Becker et al. 1994; Fitzgerald et al. 1986) und stabiler KHK (Furman et al. 1998), ischämisch bedingter Herzinsuffizienz (Wrigley et al. 2013) sowie den kardiovaskulären Hauptrisikofaktoren Hypercholesterinämie (Broijersen et al. 1998), arterielle Hypertonie (Gkaliagkousi et al. 2009), Diabetes mellitus (Harding et al. 2004a) und Rauchen (Harding et al. 2004b) nachgewiesen werden. Diese bilden mit Monozyten und anderen Leukozyten Aggregate (Furman et al. 1998; Rinder et al. 1992) und setzen proinflammatorische Zytokine, z. B. CD40L (Henn et al. 1998), IL-1ß (Hawrylowicz et al. 1991) oder das ebenfalls den endothelialen Monozytenarrest triggernde CCL5 (von Hundelshausen et al. 2001), frei. Die MPA-Bildung führt aber auch direkt zu einer vermehrten Zytokinproduktion der Mo- 
nozyten (Weyrich et al. 1996) und induziert bei diesen einen inflammatorischen Phänotyp (Passacquale et al. 2011).

In Anbetracht der Studienlage und der inflammatorischen Grundsituation der KHK-Patienten sind die im Vergleich zur gesunden Kontrollkohorte bei allen drei Monozytensubgruppen vermehrt detektablen MPA-bildenden Monozyten der vorliegend erhobenen Studiendaten nachvollziehbar. Der Argumentationskette folgend, ist auch schlüssig, dass die sogenannten proinflammatorischen CD16 ${ }^{+}-$ Monozyten im Rahmen der präsentierten Untersuchungsergebnisse mehr zu MPA-Bildung neigen als die $\mathrm{CD} 14^{++} \mathrm{CD} 16^{-}$-Monozyten, wenngleich diese Befunde v. a. in der Gruppe der gesunden Blutspender, die generell vermeintlich wenig inflammatorisches Potenzial aufweisen, eindrücklich sind. Ebenfalls deckungsgleich mit diesen Überlegungen ist die Tatsache, dass die $\mathrm{CD} 14^{+} \mathrm{CD} 16^{++}$, , besonders aber die $\mathrm{CD} 14^{++} \mathrm{CD} 16^{+}$-Monozyten beider Studiengruppen, mehr CD42b pro Monozyt aufweisen als die klassischen Monozyten, was erklären könnte, warum diese Monozyten auch vermehrt Thrombozyten binden und als MPAs zu detektieren sind.

Die Hypothese, dass erhöhte Thrombozytenzahlen im peripheren Blut zwangsläufig zu einer vermehrten Bildung von MPAs führen, kann aufgrund der korrelativen Ergebnisanalysen zwischen detektierten absoluten Thrombozytenzahlen und den durchflusszytometrisch gemessenen MPAs als nicht zutreffend verworfen werden.

Die Tatsache, dass die Monozyten der KHK-Patienten, die zusätzlich an VHF leiden, in allen drei Monozytensubgruppen weniger MPA-Bildung aufweisen als die derjenigen ohne VHF, ist möglicherweise der antikoagulatorischen Medikation mit Phenprocoumonen geschuldet, die immerhin mehr als $2 / 3$ der KHK-Patienten mit VHF erhalten. Die Feststellung, dass zwar eine antithrombozytäre, nicht aber eine antikoagulatorische Therapie zu einer Reduktion der Monozyten-Thrombozyten-Interaktion führt, wie May et al. und andere Arbeitsgruppen gezeigt haben (Gawaz et al. 1996; May et al. 1997; Neumann et al. 1997), lässt sich in der vorliegende Studie nicht nachvollziehen - sicherlich mitbedingt von der Tatsache, dass nur drei der Patienten mit VHF einen Thrombozytenaggregationshemmer erhalten und kein entsprechendes Matching bezüglich der Medikamentenanamnese und Begleiterkrankungen im Vorfeld der Datenerhebung stattgefunden hat.

\subsubsection{Zirkulierende Thrombozytenaktivitätsmarker und ihre Bedeu- tung im Rahmen der Atherosklerose}

Im Gegensatz zu den Ergebnissen der MPA-Bildung finden sich in der vorliegenden Studie verminderte per ELISA detektierte Serumspiegel zirkulierender Thrombozytenaktivierungsmarker in der Gruppe der Patienten mit KHK verglichen mit der gesunden Kontrollkohorte. Sowohl sP-selectin 
als auch sPECAM-1 sind im Serum der KHK-Patienten weniger häufig zu finden als in dem der Kontrollprobanden.

Lösliche Adhäsionsmoleküle und deren Interaktionen mit verschiedenen Zellen und Blutbestandteilen sind bislang noch nicht weitreichend untersucht worden, sodass auch ihre Produktion und ihr Katabolismus noch nicht in Gänze verstanden sind (Blankenberg et al. 2003), wenn gleich bekannt ist, dass die monozytäre Zytokinproduktion von P-selectin-abhängiger Zelladhäsion gesteigert wird (Suzuki et al. 2013).

Bei Patienten mit akutem Myokardinfarkt oder instabiler Angina pectoris finden sich verglichen mit gesunden Probanden oder Patienten mit stabiler KHK erhöhte sP-selectin-Spiegel (Atalar et al. 2001; Guray et al. 2004; Ikeda et al. 1994; Ikeda et al. 1995; Mizia-Stec et al. 2002; Parker C et al. 2001) als mögliche Hinweise auf eine Plaquedestabilisierung (Draz et al. 2003). Zwar konnten auch einige Studien erhöhte sP-selectin-Blutspiegel bei Rauchern (Barbaux et al. 2001; Blann et al. 1997a; Takeuchi et al. 2002), Patienten mit insulinpflichtigem Diabetes mellitus (Jilma et al. 1996), arterieller Hypertonie (Verhaar et al. 1998) sowie Hypercholesterinämie (Parissis et al. 2001) nachweisen, bei Kindern mit arterieller Hypertonie und/oder Diabetes mellitus und solchen ohne kardiovaskuläre Risikofaktoren fanden sich dagegen keine unterschiedlich hohen SP-selectin-Spiegel im peripheren Blut (Glowinska et al. 2005). Blann et. al fanden in Kontrast zu vielen anderen Studien keine korrelatorischen Zusammenhänge zwischen sP-selectin-Spiegeln und den kardiovaskulären Risikofaktoren Rauchen, arterielle Hypertonie und LDL-C-Blutspiegel (Blann et al. 1997c), aber im erhöhten sP-selectin Hinweise auf eine Progredienz der KHK nach überlebtem Myokardinfarkt (Blann et al. 1997b). Die im Rahmen der vorliegenden Studie erhobenen Daten zeigen, dass übergewichtige und adipöse KHKPatienten und solche mit höheren CRP-Werten signifikant weniger sP-selectin im Serum aufweisen als normalgewichtige Patienten bzw. solche mit niedrigen CRP-Werten. Diese Befunde sind möglicherweise auf einen erhöhten Verbrauch/Umsatz von sP-selectin im Rahmen der häufig schon jahrelang bestehenden inflammatorischen Gesamtsituation zurückzuführen, die bei den meisten KHKPatienten vorliegt. Möglicherweise sind die in der vorliegenden Studie niedrigeren sP-selectin-Spiegel der KHK-Patienten aber auch durch regelmäßige Medikationen mit u. a. antiinflammatorischem Potenzial zu erklären, da Studien belegen, dass eine antiglykämische Therapie mit Insulinen ebenso zu verminderten Spiegeln an zirkulierendem sP-selectin führt (Jilma et al. 1996) wie eine Statinmedikation (Barbaux et al. 2001; Bickel et al. 2002; Marschang et al. 2006; Romano et al. 2000). Ein anderer, im Rahmen der vorliegenden Studie allerdings nicht weiter untersuchter Grund für erhöhte sP-selectin-Spiegel könnte in einem häufig auftretenden Polymorphismus des SP-selectin-Gens liegen, der in Studien zu einem starken Anstieg des sP-selectin-Spiegels geführt hat (Barbaux et al. 2001). 
Barbaux et al. zeigen in einer Studie, dass sich der sP-selectin-Spiegel nicht zwischen der Gesamtstudienpopulation an KHK-Patienten und Kontrollprobanden unterscheidet, es aber altersabhängige Unterschiede der Serumspiegel gibt: So fanden sie bei jungen Kontrollprobanden ( $\leq 55$ Jahre) einen im Vergleich zur Patientenkohorte erhöhten, bei älteren Probanden (> 65 Jahre) dagegen einen statistisch bedeutsam niedrigeren sP-selectin-Spiegel im Blut (Barbaux et al. 2001). Diese Erkenntnisse decken sich mit der Tatsache, dass in der vorliegenden Studie eine negativ-inverse Korrelation zwischen dem sP-selectin-Serumspiegel und dem Alter der KHK-Patienten zu finden ist. Eine ebensolche signifikante Korrelation konnte bei den gesunden Kontrollprobanden allerdings nicht nachgewiesen werden.

Eine ähnlich unvollständige Charakterisierung wie beim sP-selectin findet sich auch beim Transmigrationsprotein SPECAM-1. So zeigen Studien einen höheren Plasmaspiegel zirkulierenden SPECAM-1 bei KHK-Patienten als bei gesunden Kontrollen (Wei et al. 2004), wobei im Gegensatz zur vorliegenden Studie sowohl instabile als auch stabile Angina pectoris-Patienten analysiert wurden. Wei et al. konnten ebenfalls Zusammenhänge zwischen einem Polymorphismus im PECAM-1-Gen, der Höhe der sPECAM-1-Spiegel sowie dem Auftreten und der Ausprägung einer KHK nachweisen, was auch Studien anderer Arbeitsgruppen suggerieren (Listi et al. 2004; Sasaoka et al. 2001; Wei et al. 2004). Eine auf einer deutschen Studienkohorte basierende Untersuchung konnte allerdings keinen Anhalt dafür finden, dass ein solcher Polymorphismus einen unabhängigen Risikofaktor für eine KHK darstellt (Gardemann et al. 2000). In Mausversuchen konnte gezeigt werden, dass PECAM-1-defiziente Tiere nicht nur weniger atherosklerotische Läsionen aufweisen und weniger Makrophageninfiltration in diese Läsionen stattfindet, sondern auch die Spiegel an zirkulierendem SP-selectin vermindert sind (Harry et al. 2008).

Auch in den vorliegenden Daten ist möglicherweise eine Herunterregulation des zirkulierenden SPECAM-1 bei den KHK-Patienten auf pleiotrope Effekte der häufig verabreichten Statinmedikation zurückzuführen, die schon in anderen Studien belegt wurde (Moraes et al. 2013). Ebenso wie Wei et al. zeigen die vorliegend evaluierten Daten eine positive Korrelation der Höhe detektierter sPECAM-1- mit sP-selectin-Serumspiegeln bei Patienten mit KHK (Wei et al. 2004).

\subsection{Ausblick und Perspektiven}

Die vorliegende Studie konnte erstmals Einblicke in die differenzielle Expression der proatherogenen Zellmarker CCR5, CD44 und CD42b auf Monozytensubpopulationen bei Patienten mit stabiler KHK geben. Ebenfalls wurden Erkenntnisse über die subgruppenspezifische monozytäre KLF4 ${ }^{+}$-Expression und thrombozytenaktivierende lösliche Botenstoffe bei KHK-Patienten gewonnen. 
Aufgrund der Tatsache, dass zwar Vorkommen, Eigenschaften und Funktion muriner Monozyten und deren Subgruppen bereits in vielfältiger Weise erforscht wurden, diese Daten aber nur bedingt auf den Menschen übertragbar sind, ist die vorliegende experimentelle Datenerhebung an zwei humanen Studienkollektiven ein weiterer Schritt, Monozyten (-subgruppen) und deren Beteiligung an der Atherosklerose zu erforschen. So konnte erstmalig die bei KHK-Patienten im Vergleich zu gesunden Kontrollprobanden verminderte Anzahl CCR5 ${ }^{+}$-Monozyten in allen drei Subgruppen sowie deren ebenfalls verminderte KLF4-Expression präsentiert werden. Auch die Resultate der MPABildungseigenschaften der unterschiedlichen monozytären Untergruppen birgen neu gewonnene Erkenntnisse. Schließlich gelang zugleich die Einordnung dieser Ergebnisse im Kontext zirkulierender inflammatorischer Zytokine sowie deren Abhängigkeit von kardiovaskulären Risikofaktoren und hämatologischen und laborchemischen Parametern.

Dennoch bleiben auf der einen Seite noch einige Fragen offen, auf der anderen kommen aufgrund der präsentierten Befunde sogar neue hinzu. So stellt die innerhalb der KHK-Gruppe verglichen mit den Kontrollprobanden verminderte Anzahl an $\mathrm{CCR5}^{+}$-Monozyten ebenso ein noch nicht in Gänze aufgeklärtes bzw. erklärbares Phänomen dar, wie der Zusammenhang zwischen der vermehrten MPA-Bildung der KHK-Patienten mit den erniedrigten sP-selectin- und SPECAM-1-Spiegel innerhalb dieser Gruppe. Zugleich stellt sich die Frage, warum zwar arterielle Hypertonie und Typ-2-Diabetes mellitus Einfluss auf die Anzahl der KLF4+ ${ }^{+}$Monozyten besitzen, weiteren etablierten kardiovaskulären Risikofaktoren im Rahmen der vorgelegten Daten ähnliche Bedeutungen aber nicht zukommen.

Zur weiteren Analyse der bereits präsentierten Daten würde ein zusätzlicher Vergleich mit Patienten, die einen akuten Myokardinfarkt erlitten haben, sicherlich weitere Erkenntnis über die einzelnen Monozytensubgruppen und deren Oberflächenrezeptoren bringen, da zu vermuten ist, dass nicht nur chronisch- sondern auch akut-inflammatorische Prozesse Einfluss auf die Rezeptorstruktur von Monozyten nehmen können. Ob dies auch auf den akuten Myokardinfarkt und die monozytäre Expression von CCR5 oder KLF4 zutrifft und wenn ja, welche Monozytensubgruppe besondere Wandelfähigkeit aufweist, ist daher ein interessanter Forschungsansatz für zukünftige Studien. Auch könnte die immunhistochemische Untersuchung atherosklerotischer Plaques - ob im Tierversuch oder an Humangewebe post mortem oder interventionem - auf die monozytären Zielstrukturen CCR5 und KLF4 oder aber der Nachweis von MPAs in atherosklerotisch veränderten Gefäßstrukturen weiteren Aufschluss über die monozytäre Bedeutung im Rahmen der Atherosklerose geben.

Diese und weitere Ansätze, Fragen und Erkenntnisse der präsentierten Studienergebnisse müssen noch detaillierter und intensiver untersucht werden, um in Zukunft Monozyten bzw. deren Untergruppen und Rezeptorprofile als Modulatoren und pharmakologische Angriffspunkte der Atherosklerosetherapie nutzbar machen zu können. Dass über monozytäre Oberflächenrezeptoren auf 
selektive Art und Weise in den menschlichen Organismus eingegriffen werden kann, um insbesondere inflammatorische Krankheiten zu bekämpfen, zeigt das Beispiel des in der HIV-Therapie seit einiger Zeit eingesetzten selektiven CCR5-Inhibitors Maraviroc. Ähnlich wirksame Therapieoptionen könnten in Zukunft die Behandlung der KHK revolutionieren bzw. deren Entstehung hinauszögern oder im optimalsten Fall sogar verhindern. 


\section{ZUSAMMENFASSUNG}

Die KHK als Manifestation atherosklerotisch veränderter Herzkranzgefäße stellt in den Industrienationen weltweit die häufigste Todesursache dar und besitzt große sozioökonomische Bedeutung. Bei Entstehung und Progredienz der Atherosklerose spielen sowohl Monozyten als auch Thrombozyten eine wichtige Rolle. Humane Monozyten lassen sich anhand ihrer Oberflächenrezeptoren CD14 und $\mathrm{CD} 16$ in drei verschiedene Subgruppen unterteilen: die klassischen $\mathrm{CD} 14^{++} \mathrm{CD} 16^{-}$-, die intermediären $\mathrm{CD} 14^{++} \mathrm{CD} 16^{+}$- und die nicht-klassischen $\mathrm{CD} 14^{+} \mathrm{CD} 16^{++}$-Monozyten. Funktionen und Aufgaben der verschiedenen Untergruppen sind bislang noch nicht hinreichend erforscht, es wird aber angenommen, dass den intermediären und nicht-klassischen Monozyten vornehmlich proinflammatorische, den klassischen dagegen antiinflammatorische und proangiogenetische Eigenschaften zukommen. Auch der proinflammatorisch agierende monozytäre Oberflächenrezeptor CCR5 und das intrazelluläre, antiinflammatorisch wirkende KLF4 sind an den Entzündungsprozessen im Rahmen der Atherosklerose beteiligt. Als Ausdruck der inflammatorischen Prozesse im Rahmen der Atherosklerose lassen sich auch MPAs bestimmen, die auf eine pathologisch-chronische Thrombozytenaktivierung hinweisen.

Ziel der durchgeführten Arbeit war es, Vorkommen und Verteilung der verschiedenen Monozytensubgruppen sowie deren Expression von KLF4 und CCR5 bei KHK-Patienten und gesunden Kontrollprobanden zu evaluieren, um zu sehen, ob die KHK zu Veränderungen dieser Parameter führt. Aus selbigem Grund wurden bei den Studienkohorten die MPA-Bildung als Ausdruck mono- und thrombozytärer Aktivierung und Interaktion sowie proinflammatorische Mediatoren im Blut bestimmt.

Zu diesem Zweck wurden 64 gesunde Blutspender und 60 Patienten mit stabiler KHK rekrutiert. Den Studienteilnehmern wurde peripher-venöses Blut entnommen, welches mit fluoreszierenden Antikörpern gefärbt und anschließend durchflusszytometrisch analysiert wurde. Darüber hinaus wurden Blutspendermonozyten mit Plasma beider Gruppen inkubiert und anschließend deren CCR5- und KLF4-Expression ermittelt. Die Detektion der SPECAM-1, sP-selectin und CCL5-Spiegel erfolgte mittels ELISA-Untersuchungen aus aliquotierten Serum- und Plasmaproben der Studienteilnehmer.

Für beide Studienkohorten ergeben die $\mathrm{CD} 14^{++} \mathrm{CD} 16^{-}$-Monozyten die größte Monozytenfraktion, gefolgt mit weitem Abstand von den beiden CD16 ${ }^{+}$-Subgruppen. Die KHK-Patienten weisen mehr klassische $(p<0,05)$ und weniger nicht-klassische Monozyten $(p<0,001)$ auf als die Kontrollprobanden. Alle Monozytensubgruppen der KHK-Patienten zeigen darüber hinaus weniger $\mathrm{CCR}^{+}$-Monozyten als die gesunden Kontrollprobanden $\left(p<0,05\right.$ für $\mathrm{CD} 14^{++} \mathrm{CD} 16^{+} ; p<0,001$ für $\mathrm{CD} 14^{++} \mathrm{CD} 16^{-}$und $\mathrm{CD} 14^{+} \mathrm{CD} 16^{++}$). Die intermediären Monozyten beider Studiengruppen präsentieren die signifikant meisten $\mathrm{CCR}^{+}$-Monozyten $\left(\mathrm{p}<0,001\right.$ für $\mathrm{CD} 14^{++} \mathrm{CD} 16^{+}$vs. $\mathrm{CD} 14^{++} \mathrm{CD} 16^{-}$bzw. 
$\left.\mathrm{CD} 14^{+} \mathrm{CD} 16^{++}\right)$. Die Inkubation gesunder Blutspendermonozyten mit KHK-Patientenplasma führt zu einer signifikant verminderten Anzahl der $\mathrm{CCR}^{+}$-Monozyten im Vergleich zur Inkubation mit Plasma gesunder Kontrollprobanden $(p<0,05)$ und die Daten legen dar, dass alle drei monozytären Subgruppen der KHK-Patienten im Vergleich zur Kontrollgruppe signifikant weniger KLF4 ${ }^{+}$-Monozyten aufweisen ( $p<0,01$ für $\mathrm{CD} 14^{++} \mathrm{CD} 16^{-} ; \mathrm{p}<0,001$ für $\mathrm{CD} 14^{++} \mathrm{CD} 16^{+}$und $\mathrm{CD} 14^{+} \mathrm{CD} 16^{++}$). Der Anteil der $\mathrm{KLF}^{+}-$Monozyten ist nach Inkubation mit KHK-Patientenplasma signifikant niedriger als nach Inkubation mit Plasma gesunder Kontrollprobanden $(p<0,05)$. Ebenfalls zeigen die Studienergebnisse, dass arterielle Hypertonie und Typ-2-Diabetes mellitus bei KHK-Patienten zu einer verminderten Anzahl an $\mathrm{KLF}^{+}$-Monozyten führen. Die Monozyten der KHK-Patienten weisen des Weiteren in allen drei Untergruppen signifikant mehr MPAs auf als jene der Kontrollprobanden $\left(p<0,001\right.$ für $\mathrm{CD} 14^{++} \mathrm{CD} 16^{-}$; $p<0,05$ für CD14 ${ }^{++} \mathrm{CD} 16^{+} ; \mathrm{p}<0,01$ für $\left.\mathrm{CD} 14^{+} \mathrm{CD} 16^{++}\right)$. Die Serumspiegel von sPECAM-1 und sP-selectin sind bei den KHK-Patienten signifikant niedriger als bei den Kontrollprobanden (jeweils $p<0,001$ ).

Die Versuchsergebnisse suggerieren, dass die geringere Anzahl CCR5 ${ }^{+}$-Monozyten der KHK-Patienten möglicherweise auf eine Rekrutierung der $\mathrm{CCR}^{+}$-Monozyten in atherosklerotische Läsionen zurückzuführen ist bzw. eine Herunterregulation ebendieser Zellen stattfindet, die von zirkulierenden Faktoren gesteuert wird, deren Quelle im chronisch-inflammatorischen Milieu der Atherosklerose zu liegen scheint. Möglicherweise ist ebenso die verminderte Anzahl KLF4 ${ }^{+}$-Monozyten bei Patienten mit stabiler KHK auf zirkulierende Mediatoren zurückzuführen. Die vermehrte Anzahl an MPAs, wie sie bei den KHK-Patienten gefunden wird, könnte zur Progredienz der KHK beigetragen haben bzw. weiterhin beitragen. Dass dagegen SP-selectin und SPECAM-1 bei KHK-Patienten weniger im Serum vorkommen als bei den gesunden Probanden, ist möglicherweise auf eine Herunterregulation aufgrund chronisch-inflammatorischer Reize oder aber auf die antiinflammatorische Statinmedikation zurückzuführen, die die allermeisten KHK-Patienten erhalten.

Alles in Allem präsentieren die Forschungsergebnisse neue Einblicke in die monozytäre Rezeptorexpression auf den drei verschiedene Subgruppen sowie das Vorkommen $\mathrm{KLF}^{+}$-Monozyten bei Patienten mit stabiler KHK. Die Analysen der MPA-Bildung deuten darauf hin, dass trotz antiinflammatorischer Therapien und ohne klinische Anzeichen chronisch-inflammatorische Milieus im Rahmen der KHK vorliegen, die nicht nur die Anzahl, sondern auch die Subgruppenverteilung der Monozyten und deren Rezeptorexpressionen beeinflussen könnten. So zeigen die erhobenen Daten, dass die Monozytensubgruppen anhand ihrer CD14- und CD16-Expression nicht ohne Weiteres in pro- und antiinflammatorische Phänotypen unterteilt werden können, sondern die differenzielle - und sich im Laufe pathologischer Prozesse möglicherweise ändernde - Expression oberflächlicher und intrazellulärer Rezeptoren bzw. intranukleärer Transkriptionsfaktoren wie KLF4 die Bedeutung der Monozyten maßgeblich beeinflussen. 


\section{LITERATURVERZEICHNIS}

Abeles RD, McPhail MJ, Sowter D, Antoniades CG, Vergis N, Vijay GK, Xystrakis E, Khamri W, Shawcross DL, Ma Y et al. (2012): CD14, CD16 and HLA-DR reliably identifies human monocytes and their subsets in the context of pathologically reduced HLA-DR expression by CD14(hi)/CD16(neg) monocytes: Expansion of CD14(hi)/CD16(pos) and contraction of CD14(lo)/CD16(pos) monocytes in acute liver failure. Cytometry A $\underline{81}$, 823-834

Abildstrom SZ, Rasmussen S, Rosen M, Madsen M (2003): Trends in incidence and case fatality rates of acute myocardial infarction in Denmark and Sweden. Heart 89, 507-511

Achenbach S, Szardien S, Zeymer U, Gielen S, Hamm CW (2012): Kommentar zu den Leitlinien der Europäischen Gesellschaft für Kardiologie (ESC) zur Diagnostik und Therapie des akuten Koronarsyndroms ohne persistierende ST-Streckenhebung. Der Kardiologe $\underline{6}$, 283-301

Ait-Oufella H, Mallat Z, Tedgui A: Mediators of Vascular Inflammation. In: Wick G, Grundtman C (Hrsg.): Inflammation and Atherosclerosis. 1. Auflage; Springer, Wien [u. a.] 2012, 197-217

Albert MA, Danielson E, Rifai N, Ridker PM, Investigators P (2001): Effect of statin therapy on Creactive protein levels: the pravastatin inflammation/CRP evaluation (PRINCE): a randomized trial and cohort study. JAMA $\underline{286}, 64-70$

Alder JK, Georgantas RW III, Hildreth RL, Kaplan IM, Morisot S, Yu X, McDevitt M, Civin Cl (2008): Kruppel-like factor 4 is essential for inflammatory monocyte differentiation in vivo. J Immunol 180, 5645-5652

Altmann SW, Davis HR Jr, Zhu L, Yao X, Hoos LM, Tetzloff G, Iyer SP, Maguire M, Golovko A, Zeng M et al. (2004): Niemann-Pick C1 Like 1 protein is critical for intestinal cholesterol absorption. Science $\underline{303}, 1201-1204$

Ancuta P, Wang J, Gabuzda D (2006): CD16+ monocytes produce IL-6, CCL2, and matrix metalloproteinase-9 upon interaction with CX3CL1-expressing endothelial cells. J Leukoc Biol 80, 1156-1164

Ancuta P, Rao R, Moses A, Mehle A, Shaw SK, Luscinskas FW, Gabuzda D (2003): Fractalkine preferentially mediates arrest and migration of CD16+ monocytes. J Exp Med 197, 1701-1707

Antman EM, Selwyn AP, Braunwald E, Loscalzo J: Ischemic Heart Disease. In: Loscalzo J (Hrsg.): Harrison's cardiovascular medicine. 1. Auflage; McGraw-Hill, Maidenhead 2010, 366-386

Appleby LJ, Nausch N, Midzi N, Mduluza T, Allen JE, Mutapi F (2013): Sources of heterogeneity in human monocyte subsets. Immunol Lett 152, 32-41

Arzneimittelkommission der Deutschen Ärzteschaft: Empfehlungen zur Therapie von Fettstoffwechselstörungen. 3. Auflage; Arzneiverordnungen in der Praxis, Band 39, Sonderheft 1 (Therapieempfehlungen), Köln 2012

Ashkar S, Weber GF, Panoutsakopoulou V, Sanchirico ME, Jansson M, Zawaideh S, Rittling SR, Denhardt DT, Glimcher MJ, Cantor H (2000): Eta-1 (osteopontin): an early component of type-1 (cell-mediated) immunity. Science $\underline{287}, 860-864$

Assmann G, Carmena R, Cullen P, Fruchart JC, Jossa F, Lewis B, Mancini M, Paoletti R (1999): Coronary heart disease: reducing the risk: a worldwide view. International Task Force for the Prevention of Coronary Heart Disease. Circulation 100, 1930-1938

Atalar E, Aytemir K, Haznedaroglu I, Ozer N, Ovunc K, Aksoyek S, Kes S, Kirazli S, Ozmen F (2001): Increased plasma levels of soluble selectins in patients with unstable angina. Int J Cardiol $\underline{78}$, $69-73$ 
Atkins GB, Wang Y, Mahabeleshwar GH, Shi H, Gao H, Kawanami D, Natesan V, Lin Z, Simon DI, Jain MK (2008): Hemizygous deficiency of Kruppel-like factor 2 augments experimental atherosclerosis. Circ Res 103, 690-693

Auffray C, Sieweke MH, Geissmann F (2009): Blood monocytes: development, heterogeneity, and relationship with dendritic cells. Annu Rev Immunol 27, 669-692

Auffray C, Fogg D, Garfa M, Elain G, Join-Lambert O, Kayal S, Sarnacki S, Cumano A, Lauvau G, Geissmann $F$ (2007): Monitoring of blood vessels and tissues by a population of monocytes with patrolling behavior. Science $\underline{317}, 666-670$

Autieri MV (2008): Kruppel-like factor 4: transcriptional regulator of proliferation, or inflammation, or differentiation, or all three? Circ Res 102, 1455-1457

Badimon L, Vilahur G (2014): Thrombosis formation on atherosclerotic lesions and plaque rupture. J Intern Med 276, 618-632

Badrnya S, Schrottmaier WC, Kral JB, Yaiw KC, Volf I, Schabbauer G, Soderberg-Naucler C, Assinger A (2014): Platelets mediate oxidized low-density lipoprotein-induced monocyte extravasation and foam cell formation. Arterioscler Thromb Vasc Biol 34, 571-580

Bandosz P, O'Flaherty M, Drygas W, Rutkowski M, Koziarek J, Wyrzykowski B, Bennett K, Zdrojewski T, Capewell S (2012): Decline in mortality from coronary heart disease in Poland after socioeconomic transformation: modelling study. BMJ $\underline{344}$, d8136

Barbaux SC, Blankenberg S, Rupprecht HJ, Francomme C, Bickel C, Hafner G, Nicaud V, Meyer J, Cambien F, Tiret L (2001): Association between P-selectin gene polymorphisms and soluble P-selectin levels and their relation to coronary artery disease. Arterioscler Thromb Vasc Biol $\underline{21}, 1668-1673$

Bazan JF, Bacon KB, Hardiman G, Wang W, Soo K, Rossi D, Greaves DR, Zlotnik A, Schall TJ (1997): A new class of membrane-bound chemokine with a CX3C motif. Nature $\underline{385}, 640-644$

Becker RC, Tracy RP, Bovill EG, Mann KG, Ault K (1994): The clinical use of flow cytometry for assessing platelet activation in acute coronary syndromes. TIMI-III Thrombosis and Anticoagulation Group. Coron Artery Dis $\underline{5}$, 339-345

Behr R, Deller C, Godmann M, Muller T, Bergmann M, Ivell R, Steger K (2007): Kruppel-like factor 4 expression in normal and pathological human testes. Mol Hum Reprod 13, 815-820

Belge KU, Dayyani F, Horelt A, Siedlar M, Frankenberger M, Frankenberger B, Espevik T, ZieglerHeitbrock L (2002): The proinflammatory CD14+CD16+DR++ monocytes are a major source of TNF. J Immunol 168, 3536-3542

Berg JM, Tymoczko JL, Stryer L: Erforschung der Proteine und Proteome. In: Berg JM, Tymoczko JL, Stryer L (Hrsg.): Biochemie. Springer Spektrum, Berlin [u. a.] 2013, 66-109

Berg KE, Ljungcrantz I, Andersson L, Bryngelsson C, Hedblad B, Fredrikson GN, Nilsson J, Bjorkbacka H (2012): Elevated CD14++CD16- monocytes predict cardiovascular events. Circ Cardiovasc Genet $\underline{5}, 122-131$

Bernal-Lopez MR, Llorente-Cortes V, Calleja F, Lopez-Carmona D, Mayas MD, Gomez-Huelgas R, Badimon L, Tinahones FJ (2013): Effect of different degrees of impaired glucose metabolism on the expression of inflammatory markers in monocytes of patients with atherosclerosis. Acta Diabetol $\underline{50}$, 553-562

Bickel C, Rupprecht HJ, Blankenberg S, Espinola-Klein C, Rippin G, Hafner G, Lotz J, Prellwitz W, Meyer $J$ (2002): Influence of HMG-CoA reductase inhibitors on markers of coagulation, systemic

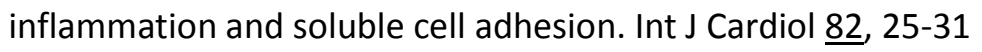


Blankenberg S, Barbaux S, Tiret L (2003): Adhesion molecules and atherosclerosis. Atherosclerosis $\underline{170}, 191-203$

Blann AD, Steele C, McCollum CN (1997a): The influence of smoking on soluble adhesion molecules and endothelial cell markers. Thromb Res $\underline{85}, 433-438$

Blann AD, Faragher EB, McCollum CN (1997b): Increased soluble P-selectin following myocardial infarction: a new marker for the progression of atherosclerosis. Blood Coagul Fibrinolysis $\underline{8}$, 383-390

Blann AD, Goode GK, Miller JP, McCollum CN (1997c): Soluble P-selectin in hyperlipidaemia with and without symptomatic vascular disease: relationship with von Willebrand factor. Blood Coagul Fibrinolysis $\underline{8}$, 200-204

Bonzel T, Erbel R, Hamm CW, Levenson B, Neumann FJ, Rupprecht HJ, Zahn R (2008): Percutaneous coronary interventions (PCI). Clin Res Cardiol 97, 513-547

Boring L, Gosling J, Cleary M, Charo IF (1998): Decreased lesion formation in CCR2-/- mice reveals a role for chemokines in the initiation of atherosclerosis. Nature $\underline{394}, 894-897$

Bouchard BA, Butenas S, Mann KG, Tracy PB: Interactions Between Platelets and the Coagulation System. In: Michelson AD (Hrsg.): Platelets. 2. Auflage; Elsevier, Academic Press, Amsterdam [u. a.] 2007, 377-402

Braunersreuther V, Mach F, Steffens S (2007): The specific role of chemokines in atherosclerosis. Thromb Haemost 97, 714-721

Broijersen A, Hamsten A, Eriksson M, Angelin B, Hjemdahl P (1998): Platelet activity in vivo in hyperlipoproteinemia--importance of combined hyperlipidemia. Thromb Haemost $\underline{79}$, 268275

Bundesärztekammer, Kassenärztliche Bundesvereinigung, Arbeitsgemeinschaft der Wissenschaftlichen Medizinischen Fachgesellschaften (2013, zuletzt geändert: November 2014): Nationale VersorgungsLeitlinie Therapie des Typ-2-Diabetes - Langfassung. 1. Auflage, Version 4, http://www.dm-therapie.versorgungsleitlinien.de; [Zugriff: 10.03.2015]

Bundesärztekammer, Kassenärztliche Bundesvereinigung, Arbeitsgemeinschaft der Wissenschaftlichen Medizinischen Fachgesellschaften (2014): Nationale VersorgungsLeitlinie Chronische KHK - Langfassung. 3. Auflage, Version 1, http://www.khk.versorgungsleitlinien.de; [Zugriff: 11.03.2015]

Cannon CP, Braunwald E: Unstable Angina and Non-ST-Elevation Myocardial Infarction. In: Braunwald E, Bonow RO, Mann DL, Zipes DP, Libby P (Hrsg.): Braunwald's heart disease. A textbook of cardiovascular medicine. 9. Auflage; Elsevier, Saunders, Philadelphia 2012, 387-394

Cao Z, Sun X, Icli B, Wara AK, Feinberg MW (2010): Role of Kruppel-like factors in leukocyte development, function, and disease. Blood 116, 4404-4414

Capewell S, O'Flaherty M (2008): What explains declining coronary mortality? Lessons and warnings. Heart $\underline{94}, 1105-1108$

Caro CG, Fitz-Gerald JM, Schroter RC (1969): Arterial wall shear and distribution of early atheroma in man. Nature $\underline{223}, 1159-1160$

Castelli WP, Garrison RJ, Wilson PW, Abbott RD, Kalousdian S, Kannel WB (1986): Incidence of coronary heart disease and lipoprotein cholesterol levels. The Framingham Study. JAMA $\underline{256}$, 2835-2838

Chen ZY, Shie J, Tseng C (2000): Up-regulation of gut-enriched kruppel-like factor by interferongamma in human colon carcinoma cells. FEBS Lett $\underline{477}$, 67-72 
Chen ZY, Shie JL, Tseng CC (2002): STAT1 is required for IFN-gamma-mediated gut-enriched Kruppellike factor expression. Exp Cell Res 281, 19-27

Choi SH, Chae A, Miller E, Messig M, Ntanios F, DeMaria AN, Nissen SE, Witztum JL, Tsimikas S (2008): Relationship between biomarkers of oxidized low-density lipoprotein, statin therapy, quantitative coronary angiography, and atheroma: volume observations from the REVERSAL (Reversal of Atherosclerosis with Aggressive Lipid Lowering) study. J Am Coll Cardiol 52, 2432

Cipriani S, Francisci D, Mencarelli A, Renga B, Schiaroli E, D'Amore C, Baldelli F, Fiorucci S (2013): Efficacy of the CCR5 antagonist maraviroc in reducing early, ritonavir-induced atherogenesis and advanced plaque progression in mice. Circulation $\underline{127}, 2114-2124$

Comabella M, Pericot I, Goertsches R, Nos C, Castillo M, Navarro JB, Rio J, Montalban X (2005): Plasma osteopontin levels in multiple sclerosis. J Neuroimmunol 158, 231-239

Combadiere C, Potteaux S, Rodero M, Simon T, Pezard A, Esposito B, Merval R, Proudfoot A, Tedgui A, Mallat Z (2008): Combined inhibition of CCL2, CX3CR1, and CCR5 abrogates Ly6C(hi) and Ly6C(lo) monocytosis and almost abolishes atherosclerosis in hypercholesterolemic mice. Circulation 117, 1649-1657

Cook DG, Mendall MA, Whincup PH, Carey IM, Ballam L, Morris JE, Miller GJ, Strachan DP (2000): Creactive protein concentration in children: relationship to adiposity and other cardiovascular risk factors. Atherosclerosis $\underline{149}, 139-150$

Coskun S, Atalar E, Ozturk E, Yavuz B, Ozer N, Goker H, Ovunc K, Aksoyek S, Kes S, Sivri B et al. (2006): Plasma osteopontin levels are elevated in non-ST-segment elevation acute coronary syndromes. J Natl Med Assoc 98, 1746-1750

Crawford HC, Matrisian LM, Liaw L (1998): Distinct roles of osteopontin in host defense activity and tumor survival during squamous cell carcinoma progression in vivo. Cancer Res $\underline{58}$, 52065215

Crisby M, Nordin-Fredriksson G, Shah PK, Yano J, Zhu J, Nilsson J (2001): Pravastatin treatment increases collagen content and decreases lipid content, inflammation, metalloproteinases, and cell death in human carotid plaques: implications for plaque stabilization. Circulation $\underline{103}, 926-933$

Crowther JR: The ELISA guidebook. In: Springer Protocols (Hrsg.): Methods in molecular biology, Vol. 516. Humana Press, Totowa, NJ 2009

Czepluch FS, Olieslagers S, van Hulten R, Voo SA, Waltenberger J (2011): VEGF-A-induced chemotaxis of $\mathrm{CD} 16+$ monocytes is decreased secondary to lower VEGFR-1 expression. Atherosclerosis $\underline{215}, 331-338$

Czepluch FS, Schlegel M, Bremmer F, Behnes CL, Hasenfuss G, Schäfer K (2013a): Stage-dependent detection of CD14+ and CD16+ cells in the human heart after myocardial infarction. Virchows Arch 463 , 459-469

Czepluch FS, Kuschicke H, Dellas C, Riggert J, Hasenfuss G, Schäfer K (2013b): Atheroprotective Kruppel-like factor 4 is downregulated in monocyte subsets of patients with coronary artery disease. Thromb Haemost $110,1080-1082$

Czepluch FS, Kuschicke H, Dellas C, Riggert J, Hasenfuss G, Schäfer K (2014): Increased proatherogenic monocyte-platelet cross-talk in monocyte subpopulations of patients with stable coronary artery disease. J Intern Med $\underline{275}$, 144-154

Czepluch FS, Vogler M, Kuschicke H, Meier J, Gogiraju R, Katschinski DM, Riggert J, Hasenfuss G, Schäfer K (2015): Circulating endothelial cells expressing the angiogenic transcription factor 
Kruppel-like factor 4 are decreased in patients with coronary artery disease. Microcirculation, Epub ahead of print

da Costa Martins PA, van Gils JM, Mol A, Hordijk PL, Zwaginga JJ (2006): Platelet binding to monocytes increases the adhesive properties of monocytes by up-regulating the expression and functionality of beta1 and beta2 integrins. J Leukoc Biol $\underline{79}$, 499-507

Daida H, Takayama T, Hiro T, Yamagishi M, Hirayama A, Saito S, Yamaguchi T, Matsuzaki M (2012): High HbA1c levels correlate with reduced plaque regression during statin treatment in patients with stable coronary artery disease: results of the coronary atherosclerosis study measuring effects of rosuvastatin using intravascular ultrasound in Japanese subjects (COSMOS). Cardiovasc Diabetol $\underline{11}, 87$

Dalager-Pedersen S, Ravn HB, Falk E (1998): Atherosclerosis and acute coronary events. Am J Cardiol $\underline{82}, 37 \mathrm{~T}-40 \mathrm{~T}$

Davies MJ (2000): The pathophysiology of acute coronary syndromes. Heart $\underline{83}, 361-366$

Davis HR J, Tershakovec AM, Tomassini JE, Musliner T (2011): Intestinal sterol transporters and cholesterol absorption inhibition. Curr Opin Lipidol 22, 467-478

Dopheide JF, Obst V, Doppler C, Radmacher MC, Scheer M, Radsak MP, Gori T, Warnholtz A, Fottner C, Daiber A et al. (2012): Phenotypic characterisation of pro-inflammatory monocytes and dendritic cells in peripheral arterial disease. Thromb Haemost 108, 1198-1207

Dormann AJ, Heer C, Isermann B: Laborwerte. 6. Auflage; Elsevier, Urban \& Fischer, München 2014

Draz N, Hamdy MS, Gomaa Y, Ramzy AA (2003): Soluble P-selectin is a marker of plaque destabilization in unstable angina. Egypt J Immunol 10, 83-87

Duff GL, McMillan GC (1951): Pathology of atherosclerosis. Am J Med 11, 92-108

Eriksson EE, Xie X, Werr J, Thoren P, Lindbom L (2001): Direct viewing of atherosclerosis in vivo: plaque invasion by leukocytes is initiated by the endothelial selectins. FASEB J $\underline{15}, 1149-1157$

Etsuda H, Mizuno K, Arakawa K, Satomura K, Shibuya T, Isojima K (1993): Angioscopy in variant angina: coronary artery spasm and intimal injury. Lancet $342,1322-1324$

Falk E (1991): Coronary thrombosis: pathogenesis and clinical manifestations. Am J Cardiol $\underline{68}$, 28b$35 b$

Falk E, Shah PK, Fuster V (1995): Coronary plaque disruption. Circulation 92, 657-671

Faucher JL, Lacronique-Gazaille C, Frebet E, Trimoreau F, Donnard M, Bordessoule D, Lacombe F, Feuillard J (2007): "6 markers/5 colors" extended white blood cell differential by flow cytometry. Cytometry A $\underline{71}$, 934-944

Faxon DP, Fuster V, Libby P, Beckman JA, Hiatt WR, Thompson RW, Topper JN, Annex BH, Rundback JH, Fabunmi RP et al. (2004): Atherosclerotic Vascular Disease Conference: Writing Group III: pathophysiology. Circulation 109, 2617-2625

Fedarko NS, Jain A, Karadag A, Van Eman MR, Fisher LW (2001): Elevated serum bone sialoprotein and osteopontin in colon, breast, prostate, and lung cancer. Clin Cancer Res $\underline{7}$, 4060-4066

Feinberg MW, Cao Z, Wara AK, Lebedeva MA, Senbanerjee S, Jain MK (2005): Kruppel-like factor 4 is a mediator of proinflammatory signaling in macrophages. J Biol Chem $\underline{280}, 38247-38258$

Feinberg MW, Wara AK, Cao Z, Lebedeva MA, Rosenbauer F, Iwasaki H, Hirai H, Katz JP, Haspel RL, Gray $S$ et al. (2007): The Kruppel-like factor KLF4 is a critical regulator of monocyte differentiation. EMBO J 26, 4138-4148 
Ferrer DG, Jaldin-Fincati JR, Amigone JL, Capra RH, Collino CJ, Albertini RA, Chiabrando GA (2014): Standardized flow cytometry assay for identification of human monocytic heterogeneity and LRP1 expression in monocyte subpopulations: decreased expression of this receptor in nonclassical monocytes. Cytometry A $\underline{85}, 601-610$

Fingerle G, Pforte A, Passlick B, Blumenstein M, Strobel M, Ziegler-Heitbrock HW (1993): The novel subset of $\mathrm{CD} 14+/ \mathrm{CD} 16+$ blood monocytes is expanded in sepsis patients. Blood 22 , 31703176

Fitzgerald DJ, Roy L, Catella F, FitzGerald GA (1986): Platelet activation in unstable coronary disease. N Engl J Med 315, 983-989

Fowler SD, Mayer EP, Greenspan P (1985): Foam cells and atherogenesis. Ann N Y Acad Sci 454, 79-90

Franzen A, Heinegard D (1985): Isolation and characterization of two sialoproteins present only in bone calcified matrix. Biochem J 232, 715-724

Friedman RJ, Stemerman MB, Wenz B, Moore S, Gauldie J, Gent M, Tiell ML, Spaet H (1977): The effect of thrombocytopenia on experimental arteriosclerotic lesion formation in rabbits. Smooth muscle cell proliferation and re-endothelialization. J Clin Invest $\underline{60}, 1191-1201$

Furberg CD, Adams HP Jr, Applegate WB, Byington RP, Espeland MA, Hartwell T, Hunninghake DB, Lefkowitz DS, Probstfield J, Riley WA et al. (1994): Effect of lovastatin on early carotid atherosclerosis and cardiovascular events. Asymptomatic Carotid Artery Progression Study (ACAPS) Research Group. Circulation 90, 1679-1687

Furman MI, Benoit SE, Barnard MR, Valeri CR, Borbone ML, Becker RC, Hechtman HB, Michelson AD (1998): Increased platelet reactivity and circulating monocyte-platelet aggregates in patients with stable coronary artery disease. J Am Coll Cardiol 31, 352-358

Fuster V, Badimon L, Badimon JJ, Chesebro JH (1992): The pathogenesis of coronary artery disease and the acute coronary syndromes (1). N Engl J Med $\underline{326}$, 242-250

Gaber E: Sterblichkeit, Todesursachen und regionale Unterschiede. In: Robert Koch-Institut (Hrsg.): Gesundheitsberichterstattung des Bundes. Heft 52; Robert Koch-Institut, Berlin 2011

Gardemann A, Knapp A, Katz N, Tillmanns H, Haberbosch W (2000): No evidence for the CD31 C/G gene polymorphism as an independent risk factor of coronary heart disease. Thromb Haemost 83,629

Garrett-Sinha LA, Eberspaecher H, Seldin MF, de Crombrugghe B (1996): A gene for a novel zincfinger protein expressed in differentiated epithelial cells and transiently in certain mesenchymal cells. J Biol Chem 271, 31384-31390

Garvey SM, Sinden DS, Schoppee Bortz PD, Wamhoff BR (2010): Cyclosporine up-regulates Kruppellike factor-4 (KLF4) in vascular smooth muscle cells and drives phenotypic modulation in vivo. J Pharmacol Exp Ther $\underline{333}$, 34-42

Gasteiger G, Rudensky AY (2014): Interactions between innate and adaptive lymphocytes. Nat Rev Immunol 14, 631-639

Gawaz M, Neumann FJ, Ott I, May A, Schomig A (1996): Platelet activation and coronary stent implantation. Effect of antithrombotic therapy. Circulation 94, 279-285

Geissmann F, Jung S, Littman DR (2003): Blood monocytes consist of two principal subsets with distinct migratory properties. Immunity $\underline{19}$, 71-82

Gerszten RE, Garcia-Zepeda EA, Lim YC, Yoshida M, Ding HA, Gimbrone MA Jr, Luster AD, Luscinskas FW, Rosenzweig A (1999): MCP-1 and IL-8 trigger firm adhesion of monocytes to vascular endothelium under flow conditions. Nature $\underline{398}, 718-723$ 
Ghattas A, Griffiths HR, Devitt A, Lip GY, Shantsila E (2013): Monocytes in coronary artery disease and atherosclerosis: where are we now? J Am Coll Cardiol 62, 1541-1551

Giachelli CM, Liaw L, Murry CE, Schwartz SM, Almeida M (1995): Osteopontin expression in cardiovascular diseases. Ann N Y Acad Sci $\underline{760}, 109-126$

Giachelli CM, Bae N, Almeida M, Denhardt DT, Alpers CE, Schwartz SM (1993): Osteopontin is elevated during neointima formation in rat arteries and is a novel component of human atherosclerotic plaques. J Clin Invest 92, 1686-1696

Gimbrone MA Jr (1999): Vascular endothelium, hemodynamic forces, and atherogenesis. Am J Pathol $\underline{155}, 1-5$

Gkaliagkousi E, Corrigall V, Becker S, de Winter P, Shah A, Zamboulis C, Ritter J, Ferro A (2009): Decreased platelet nitric oxide contributes to increased circulating monocyte-platelet aggregates in hypertension. Eur Heart J 30, 3048-3054

Gleissner CA, von Hundelshausen P, Ley K (2008): Platelet chemokines in vascular disease. Arterioscler Thromb Vasc Biol 28, 1920-1927

Glowinska B, Urban M, Peczynska J, Florys B (2005): Soluble adhesion molecules (sICAM-1, sVCAM-1) and selectins (sE selectin, sP selectin, sL selectin) levels in children and adolescents with obesity, hypertension, and diabetes. Metabolism 54, 1020-1026

Goldbourt U, Yaari S, Medalie JH (1993): Factors predictive of long-term coronary heart disease mortality among 10,059 male Israeli civil servants and municipal employees. A 23-year mortality follow-up in the Israeli Ischemic Heart Disease Study. Cardiology 82, 100-121

Goldschmidt PJ, Lopes N, Crawford LE, Becker RC: Atherothrombosis and Coronary Artery Disease. In: Michelson AD (Hrsg.): Platelets. 2. Auflage; Elsevier, Academic Press, Amsterdam [u. a.] 2007, 629-656

Goldstein JL, Brown MS (1975): Lipoprotein receptors, cholesterol metabolism, and atherosclerosis. Arch Pathol 99, 181-184

Goldstein JL, Brown MS (1977): Atherosclerosis: the low-density lipoprotein receptor hypothesis. Metabolism 26, 1257-1275

Goldstein JL, Ho YK, Basu SK, Brown MS (1979): Binding site on macrophages that mediates uptake and degradation of acetylated low density lipoprotein, producing massive cholesterol deposition. Proc Natl Acad Sci U S A $\underline{76}$, 333-337

Golledge J, Muller J, Shephard N, Clancy P, Smallwood L, Moran C, Dear AE, Palmer L, Norman PE (2007): Association between osteopontin and human abdominal aortic aneurysm. Arterioscler Thromb Vasc Biol 27, 655-660

Gomez-Ambrosi J, Catalan V, Ramirez B, Rodriguez A, Colina I, Silva C, Rotellar F, Mugueta C, Gil MJ, Cienfuegos JA et al. (2007): Plasma osteopontin levels and expression in adipose tissue are increased in obesity. J Clin Endocrinol Metab 92, 3719-3727

Gomez-Garre D, Munoz-Pacheco P, Gonzalez-Rubio ML, Aragoncillo P, Granados R, Fernandez-Cruz A (2009): Ezetimibe reduces plaque inflammation in a rabbit model of atherosclerosis and inhibits monocyte migration in addition to its lipid-lowering effect. Br J Pharmacol $\underline{156}, 1218$ 1227

Gordon S, Taylor PR (2005): Monocyte and macrophage heterogeneity. Nat Rev Immunol $\underline{5}$, 953-964

Gößwald A, Schienkiewitz A, Nowossadeck E, Busch MA (2013): Prevalence of myocardial infarction and coronary heart disease in adults aged 40-79 years in Germany: results of the German Health Interview and Examination Survey for Adults (DEGS1). Bundesgesundheitsblatt Gesundheitsforschung - Gesundheitsschutz $\underline{56}$, 650-655 
Gulbins E, Lang KS: Immunsystem. In: Schmidt RF, Lang F, Heckmann M (Hrsg.): Physiologie des Menschen mit Pathophysiologie. 31., überarbeitete und aktualisierte Auflage; Springer Medizin, Heidelberg 2010, 503-514

Guray U, Erbay AR, Guray Y, Yilmaz MB, Boyaci AA, Sasmaz H, Korkmaz S, Kutuk E (2004): Levels of soluble adhesion molecules in various clinical presentations of coronary atherosclerosis. Int J Cardiol 96, 235-240

Hamik A, Lin Z, Kumar A, Balcells M, Sinha S, Katz J, Feinberg MW, Gerzsten RE, Edelman ER, Jain MK (2007): Kruppel-like factor 4 regulates endothelial inflammation. J Biol Chem 282, 1376913779

Hamm CW, Bassand JP, Agewall S, Bax J, Boersma E, Bueno H, Caso P, Dudek D, Gielen S, Huber K et al. (2011): ESC Guidelines for the management of acute coronary syndromes in patients presenting without persistent ST-segment elevation: The Task Force for the management of acute coronary syndromes (ACS) in patients presenting without persistent ST-segment elevation of the European Society of Cardiology (ESC). Eur Heart J 32, 2999-3054

Hammond EC, Horn D (1988): Smoking and death rates--report on forty-four months of follow-up of 187,783 men. By E. Cuyler Hammond and Daniel Horn, 1958. CA Cancer J Clin 38, 28-58

Han KH, Chang MK, Boullier A, Green SR, Li A, Glass CK, Quehenberger O (2000): Oxidized LDL reduces monocyte CCR2 expression through pathways involving peroxisome proliferatoractivated receptor gamma. J Clin Invest $\underline{106}$, 793-802

Hansson GK, Libby P, Schonbeck U, Yan ZQ (2002): Innate and adaptive immunity in the pathogenesis of atherosclerosis. Circ Res 91, 281-291

Harding SA, Sommerfield AJ, Sarma J, Twomey PJ, Newby DE, Frier BM, Fox KA (2004a): Increased CD40 ligand and platelet-monocyte aggregates in patients with type 1 diabetes mellitus. Atherosclerosis $\underline{176}, 321-325$

Harding SA, Sarma J, Josephs DH, Cruden NL, Din JN, Twomey PJ, Fox KA, Newby DE (2004b): Upregulation of the CD40/CD40 ligand dyad and platelet-monocyte aggregation in cigarette smokers. Circulation $\underline{109}$, 1926-1929

Harry BL, Sanders JM, Feaver RE, Lansey M, Deem TL, Zarbock A, Bruce AC, Pryor AW, Gelfand BD, Blackman BR et al. (2008): Endothelial cell PECAM-1 promotes atherosclerotic lesions in areas of disturbed flow in ApoE-deficient mice. Arterioscler Thromb Vasc Biol 28, 2003-2008

Haverkate F, Thompson SG, Pyke SD, Gallimore JR, Pepys MB (1997): Production of C-reactive protein and risk of coronary events in stable and unstable angina. European Concerted Action on Thrombosis and Disabilities Angina Pectoris Study Group. Lancet 349, 462-466

Hawrylowicz CM, Howells GL, Feldmann M (1991): Platelet-derived interleukin 1 induces human endothelial adhesion molecule expression and cytokine production. J Exp Med 174, 785-790

He J, Chen Y, Farzan M, Choe H, Ohagen A, Gartner S, Busciglio J, Yang X, Hofmann W, Newman W et al. (1997): CCR3 and CCR5 are co-receptors for HIV-1 infection of microglia. Nature $\underline{385}$, 645-649

Heimbeck I, Hofer TP, Eder C, Wright AK, Frankenberger M, Marei A, Boghdadi G, Scherberich J, Ziegler-Heitbrock L (2010): Standardized single-platform assay for human monocyte subpopulations: Lower CD14+CD16++ monocytes in females. Cytometry A $\underline{77}$, 823-830

Heine GH, Ulrich C, Seibert E, Seiler S, Marell J, Reichart B, Krause M, Schlitt A, Kohler H, Girndt M (2008): CD14(++)CD16+ monocytes but not total monocyte numbers predict cardiovascular events in dialysis patients. Kidney Int $\underline{73}, 622-629$ 
Henn V, Slupsky JR, Grafe M, Anagnostopoulos I, Forster R, Muller-Berghaus G, Kroczek RA (1998): CD40 ligand on activated platelets triggers an inflammatory reaction of endothelial cells. Nature $\underline{391}, 591-594$

Hilgendorf I, Swirski FK (2012): Making a difference: monocyte heterogeneity in cardiovascular disease. Curr Atheroscler Rep 14, 450-459

Hilgendorf I, Swirski FK, Robbins CS (2015): Monocyte fate in atherosclerosis. Arterioscler Thromb Vasc Biol 35, 272-279

Hristov M, Leyendecker T, Schuhmann C, von Hundelshausen P, Heussen N, Kehmeier E, Krotz F, Sohn HY, Klauss V, Weber C (2010): Circulating monocyte subsets and cardiovascular risk factors in coronary artery disease. Thromb Haemost $\underline{104}$, 412-414

Hulspas R, O'Gorman MR, Wood BL, Gratama JW, Sutherland DR (2009): Considerations for the control of background fluorescence in clinical flow cytometry. Cytometry B Clin Cytom $\underline{76}$, 355-364

Huo Y, Schober A, Forlow SB, Smith DF, Hyman MC, Jung S, Littman DR, Weber C, Ley K (2003): Circulating activated platelets exacerbate atherosclerosis in mice deficient in apolipoprotein E. Nat Med $\underline{9}, 61-67$

Ikeda H, Nakayama H, Oda T, Kuwano K, Muraishi A, Sugi K, Koga Y, Toshima H (1994): Soluble form of P-selectin in patients with acute myocardial infarction. Coron Artery Dis $\underline{5}, 515-518$

Ikeda H, Takajo Y, Ichiki K, Ueno T, Maki S, Noda T, Sugi K, Imaizumi T (1995): Increased soluble form of P-selectin in patients with unstable angina. Circulation 92, 1693-1696

Imai T, Hieshima K, Haskell C, Baba M, Nagira M, Nishimura M, Kakizaki M, Takagi S, Nomiyama H, Schall TJ et al. (1997): Identification and molecular characterization of fractalkine receptor CX3CR1, which mediates both leukocyte migration and adhesion. Cell 91, 521-530

Imanishi T, Ikejima H, Tsujioka H, Kuroi A, Ishibashi K, Komukai K, Tanimoto T, Ino Y, Takeshita T, Akasaka T (2010): Association of monocyte subset counts with coronary fibrous cap thickness in patients with unstable angina pectoris. Atherosclerosis 212, 628-635

Imhof BA, Aurrand-Lions M (2004): Adhesion mechanisms regulating the migration of monocytes. Nat Rev Immunol 4 , 432-444

Ingersoll MA, Spanbroek R, Lottaz C, Gautier EL, Frankenberger M, Hoffmann R, Lang R, Haniffa M, Collin M, Tacke F et al. (2010): Comparison of gene expression profiles between human and mouse monocyte subsets. Blood $\underline{115}$, e10-19

Inoue $T$, Kato T, Uchida T, Sakuma M, Nakajima A, Shibazaki M, Imoto $Y$, Saito M, Hashimoto S, Hikichi $Y$ et al. (2005): Local release of C-reactive protein from vulnerable plaque or coronary arterial wall injured by stenting. J Am Coll Cardiol $\underline{46}$, 239-245

Ishikawa T, Hatakeyama K, Imamura T, Date H, Shibata Y, Hikichi Y, Asada Y, Eto T (2003): Involvement of C-reactive protein obtained by directional coronary atherectomy in plaque instability and developing restenosis in patients with stable or unstable angina pectoris. Am J Cardiol 91, 287-292

Isoda K, Nishikawa K, Kamezawa Y, Yoshida M, Kusuhara M, Moroi M, Tada N, Ohsuzu F (2002): Osteopontin plays an important role in the development of medial thickening and neointimal formation. Circ Res 91, 77-82

Jaipersad AS, Shantsila A, Lip GY, Shantsila E (2014): Expression of monocyte subsets and angiogenic markers in relation to carotid plaque neovascularization in patients with pre-existing coronary artery disease and carotid stenosis. Ann Med $\underline{46}$, 530-538 
Jeffery RW, Drewnowski A, Epstein LH, Stunkard AJ, Wilson GT, Wing RR, Hill DR (2000): Long-term maintenance of weight loss: current status. Health Psychol 19, 5-16

Jelkmann W: Blut. In: Schmidt RF, Lang F, Heckmann M (Hrsg.): Physiologie des Menschen mit Pathophysiologie. 31., überarbeitete und aktualisierte Auflage; Springer Medizin, Heidelberg 2010, 477-502

Jilma B, Fasching P, Ruthner C, Rumplmayr A, Ruzicka S, Kapiotis S, Wagner OF, Eichler HG (1996): Elevated circulating P-selectin in insulin dependent diabetes mellitus. Thromb Haemost $\underline{76}$, 328-332

Kameyoshi Y, Dorschner A, Mallet Al, Christophers E, Schroder JM (1992): Cytokine RANTES released by thrombin-stimulated platelets is a potent attractant for human eosinophils. J Exp Med $176,587-592$

Kannel WB, McGee DL (1979a): Diabetes and cardiovascular disease. The Framingham study. Jama $\underline{241}, 2035-2038$

Kannel WB, McGee DL (1979b): Diabetes and cardiovascular risk factors: the Framingham study. Circulation 59, 8-13

Kannel WB, Dawber TR, McGee DL (1980): Perspectives on systolic hypertension. The Framingham study. Circulation $\underline{61}, 1179-1182$

Karnoub AE, Dash AB, Vo AP, Sullivan A, Brooks MW, Bell GW, Richardson AL, Polyak K, Tubo R, Weinberg RA (2007): Mesenchymal stem cells within tumour stroma promote breast cancer metastasis. Nature $\underline{449}$, 557-563

Karshovska E, Weber C, von Hundelshausen P (2013): Platelet chemokines in health and disease. Thromb Haemost 110, 894-902

Kashiwagi M, Imanishi T, Tsujioka H, Ikejima H, Kuroi A, Ozaki Y, Ishibashi K, Komukai K, Tanimoto T, Ino $Y$ et al. (2010): Association of monocyte subsets with vulnerability characteristics of coronary plaques as assessed by 64-slice multidetector computed tomography in patients with stable angina pectoris. Atherosclerosis 212, 171-176

Kato R, Momiyama Y, Ohmori R, Tanaka N, Taniguchi H, Arakawa K, Kusuhara M, Nakamura H, Ohsuzu $F$ (2006): High plasma levels of osteopontin in patients with restenosis after percutaneous coronary intervention. Arterioscler Thromb Vasc Biol 26, e1-2

Keller C: Fettstoffwechsel; Lipidsenker - Pharmakotherapie bei Fettstoffwechselstörungen. In: Aktories K, Förstermann U, Hofmann F, Starke K (Hrsg.): Allgemeine und spezielle Pharmakologie und Toxikologie. 11., überarbeitete Auflage; Elsevier, Urban \& Fischer, München 2013, 569-583

Keys A, Fidanza F, Karvonen MJ, Kimura N, Taylor HL (1972): Indices of relative weight and obesity. J Chronic Dis $\underline{25}$, 329-343

Kim S, Iwao H (2000): Molecular and cellular mechanisms of angiotensin II-mediated cardiovascular and renal diseases. Pharmacol Rev $\underline{52}, 11-34$

Koenen RR, von Hundelshausen P, Nesmelova IV, Zernecke A, Liehn EA, Sarabi A, Kramp BK, Piccinini AM, Paludan SR, Kowalska MA et al. (2009): Disrupting functional interactions between platelet chemokines inhibits atherosclerosis in hyperlipidemic mice. Nat Med $\underline{15}, 97-103$

Koenig RJ, Peterson CM, Jones RL, Saudek C, Lehrman M, Cerami A (1976): Correlation of glucose regulation and hemoglobin Alc in diabetes mellitus. N Engl J Med 295, 417-420

Koenig W, Marx N, Thiery J, Klose G (2012): Kommentar zu den neuen Leitlinien (2011) der Europäischen Gesellschaft für Kardiologie zum Management von Dyslipidämien. Der Kardiologe $\underline{6}$, 210-216 
Koh SJ, Kim JY, Hyun YJ, Park SH, Chae JS, Park S, Kim JS, Youn JC, Jang Y, Lee JH (2009): Association of serum RANTES concentrations with established cardiovascular risk markers in middle-aged subjects. Int J Cardiol 132, 102-108

Kostis JB, Turkevich D, Sharp J (1984): Association between leukocyte count and the presence and extent of coronary atherosclerosis as determined by coronary arteriography. Am J Cardiol $\underline{53}$, 997-999

Krychtiuk KA, Kastl SP, Pfaffenberger S, Pongratz T, Hofbauer SL, Wonnerth A, Katsaros KM, Goliasch G, Gaspar L, Huber K et al. (2014): Small high-density lipoprotein is associated with monocyte subsets in stable coronary artery disease. Atherosclerosis 237, 589-596

Kuch B, Heier M, von Scheidt W, Kling B, Hoermann A, Meisinger C (2008): 20-year trends in clinical characteristics, therapy and short-term prognosis in acute myocardial infarction according to presenting electrocardiogram: the MONICA/KORA AMI Registry (1985-2004). J Intern Med 264, 254-264

Kuckleburg CJ, Yates CM, Kalia N, Zhao Y, Nash GB, Watson SP, Rainger GE (2011): Endothelial cellborne platelet bridges selectively recruit monocytes in human and mouse models of vascular inflammation. Cardiovasc Res 91, 134-141

Ky B, Burke A, Tsimikas S, Wolfe ML, Tadesse MG, Szapary PO, Witztum JL, FitzGerald GA, Rader DJ (2008): The influence of pravastatin and atorvastatin on markers of oxidative stress in hypercholesterolemic humans. J Am Coll Cardiol 51, 1653-1662

Lang F, Murer H: Kalzium-, Magnesium- und Phosphathaushalt. In: Schmidt RF, Lang F, Heckmann M (Hrsg.): Physiologie des Menschen mit Pathophysiologie. 31., überarbeitete und aktualisierte Auflage; Springer Medizin, Heidelberg 2010, 682-693

Lange C, Ziese T: Koronare Herzkrankheit. Faktenblatt zu GEDA 2012: Ergebnisse der Studie "Gesund-heit in Deutschland aktuell 2012«. In: Robert Koch--Institut (Hrsg.): Beiträge zur Gesundheitsberichterstattung des Bundes. Berlin 2014

Le Y, Zhou Y, Iribarren P, Wang J (2004): Chemokines and chemokine receptors: their manifold roles in homeostasis and disease. Cell Mol Immunol $\underline{1}$, 95-104

Leach $M$, Drummond M, Doig A: Principles of Flow Cytometry. In: Leach M, Drummond M, Doig A (Hrsg.): Practical Flow Cytometry in Haematology Diagnosis. 1. Auflage; Wiley-Blackwell, Oxford 2013, 3-19

Liao X, Sharma N, Kapadia F, Zhou G, Lu Y, Hong H, Paruchuri K, Mahabeleshwar GH, Dalmas E, Venteclef $\mathrm{N}$ et al. (2011): Kruppel-like factor 4 regulates macrophage polarization. J Clin Invest 121, 2736-2749

Liaw L, Almeida M, Hart CE, Schwartz SM, Giachelli CM (1994): Osteopontin promotes vascular cell adhesion and spreading and is chemotactic for smooth muscle cells in vitro. Circ Res $\underline{74}$, 214224

Liaw L, Skinner MP, Raines EW, Ross R, Cheresh DA, Schwartz SM, Giachelli CM (1995): The adhesive and migratory effects of osteopontin are mediated via distinct cell surface integrins. Role of alpha $v$ beta 3 in smooth muscle cell migration to osteopontin in vitro. J Clin Invest $\underline{95}$, 713724

Libby P (2000): Changing concepts of atherogenesis. J Intern Med 247, 349-358

Libby P (2002): Inflammation in atherosclerosis. Nature $\underline{420}, 868-874$

Libby P: The Vascular Biology of Atherosclerosis. In: Braunwald E, Bonow RO, Mann DL, Zipes DP, Libby P (Hrsg.): Braunwald's heart disease. A textbook of cardiovascular medicine. 9. Auflage; Elsevier, Saunders, Philadelphia 2012, 897-913 
Libby P, Ridker PM, Hansson GK (2011): Progress and challenges in translating the biology of atherosclerosis. Nature $\underline{473}, 317-325$

Libby P, Ordovas JM, Birinyi LK, Auger KR, Dinarello CA (1986): Inducible interleukin-1 gene expression in human vascular smooth muscle cells. J Clin Invest $\underline{78}, 1432-1438$

Lima JA, Desai MY, Steen H, Warren WP, Gautam S, Lai S (2004): Statin-induced cholesterol lowering and plaque regression after 6 months of magnetic resonance imaging-monitored therapy. Circulation 110, 2336-2341

Listi F, Candore G, Lio D, Cavallone L, Colonna-Romano G, Caruso M, Hoffmann E, Caruso C (2004): Association between platelet endothelial cellular adhesion molecule 1 (PECAM-1/CD31) polymorphisms and acute myocardial infarction: a study in patients from Sicily. Eur J Immunogenet $\underline{31}, 175-178$

Liu Y, Zheng B, Zhang XH, Nie CJ, Li YH, Wen JK (2013): Localization and function of KLF4 in cytoplasm of vascular smooth muscle cell. Biochem Biophys Res Commun 436, 162-168

Löffler G: Stoffwechsel von Cholesterin. In: Heinrich PC, Müller M, Graeve L (Hrsg.): Löffler/Petrides Biochemie und Pathobiochemie. 9., vollständig überarbeitete Auflage; Springer, Berlin [u. a.] 2014, 292-299

Löffler H, Rastetter J, Haferlach T: Atlas der klinischen Hämatologie. 6., vollständig überarbeitete Auflage; Springer, Berlin [u. a.] 2004

Löwel H, Meisinger C, Heier M, Hormann A (2005): The population-based acute myocardial infarction (AMI) registry of the MONICA/KORA study region of Augsburg. Gesundheitswesen 67 Suppl 1, S31-37

Löwel H, Hörmann A, Döring A, Heier M, Meisinger C, Schneider A, Kaup U, Gösele U, Hymer H: Koronare Herzkrankheit und akuter Myokardinfarkt. In: Robert Koch-Institut (Hrsg.): Gesundheitsberichterstattung des Bundes, Heft 33. Robert Koch-Institut, Berlin 2006

Lusis AJ (2000): Atherosclerosis. Nature $\underline{407}$, 233-241

Macey MG: Principles of Flow Cytometry. In: Macey MG (Hrsg.): Flow cytometry. Principles and applications. 1. Auflage; Humana Press, Totowa 2010, 1-15

Mack M, Cihak J, Simonis C, Luckow B, Proudfoot AE, Plachy J, Bruhl H, Frink M, Anders HJ, Vielhauer $\checkmark$ et al. (2001): Expression and characterization of the chemokine receptors CCR2 and CCR5 in mice. J Immunol $\underline{166}$, 4697-4704

Marschang P, Friedrich GJ, Ditlbacher H, Stoeger A, Nedden DZ, Kirchmair R, Dienstl A, Pachinger O, Patsch JR (2006): Reduction of soluble P-selectin by statins is inversely correlated with the progression of coronary artery disease. Int J Cardiol 106, 183-190

Marshall M (1986): Ultrastructural findings on platelet depositions in initial atherogenesis. Wien Klin Wochenschr $\underline{\text { 98, }}$, 212-214

Martin G, Dol F, Mares AM, Berezowski V, Staels B, Hum DW, Schaeffer P, Herbert JM (2004): Lesion progression in apoE-deficient mice: implication of chemokines and effect of the AT1 angiotensin II receptor antagonist irbesartan. J Cardiovasc Pharmacol 43, 191-199

Massberg S, Brand K, Gruner S, Page S, Muller E, Muller I, Bergmeier W, Richter T, Lorenz M, Konrad I et al. (2002): A critical role of platelet adhesion in the initiation of atherosclerotic lesion formation. J Exp Med 196, 887-896

Mathers CD, Loncar D (2006): Projections of global mortality and burden of disease from 2002 to 2030. PLoS Med $\underline{3}$, e442 
Matsui Y, Rittling SR, Okamoto H, Inobe M, Jia N, Shimizu T, Akino M, Sugawara T, Morimoto J, Kimura C et al. (2003): Osteopontin deficiency attenuates atherosclerosis in female apolipoprotein E-deficient mice. Arterioscler Thromb Vasc Biol 233, 1029-1034

May AE, Neumann FJ, Gawaz M, Ott I, Walter H, Schomig A (1997): Reduction of monocyte-platelet interaction and monocyte activation in patients receiving antiplatelet therapy after coronary stent implantation. Eur Heart J 18, 1913-1920

McEver RP (2001): Adhesive interactions of leukocytes, platelets, and the vessel wall during hemostasis and inflammation. Thromb Haemost $\underline{86}$, 746-756

Meade TW, Mellows S, Brozovic M, Miller GJ, Chakrabarti RR, North WR, Haines AP, Stirling Y, Imeson JD, Thompson SG (1986): Haemostatic function and ischaemic heart disease: principal results of the Northwick Park Heart Study. Lancet 2, 533-537

Mendall MA, Patel P, Ballam L, Strachan D, Northfield TC (1996): C reactive protein and its relation to cardiovascular risk factors: a population based cross sectional study. BMJ 312, 1061-1065

Mendelsohn ME, Loscalzo J (1988): Role of platelets in cholesteryl ester formation by U-937 cells. J Clin Invest $\underline{81}, 62-68$

Michelson AD, Barnard MR, Krueger LA, Valeri CR, Furman MI (2001): Circulating Monocyte-Platelet Aggregates Are a More Sensitive Marker of In Vivo Platelet Activation Than Platelet Surface P-Selectin: Studies in Baboons, Human Coronary Intervention, and Human Acute Myocardial Infarction. Circulation 104, 1533-1537

Mizia-Stec K, Zahorska-Markiewicz B, Mandecki T, Janowska J, Szulc A, Jastrzebska-Maj E (2002): Serum levels of selected adhesion molecules in patients with coronary artery disease. Int J Cardiol 83, 143-150

Montalescot G, Sechtem U, Achenbach S, Andreotti F, Arden C, Budaj A, Bugiardini R, Crea F, Cuisset T, Di Mario C et al. (2013): 2013 ESC guidelines on the management of stable coronary artery disease: the Task Force on the management of stable coronary artery disease of the European Society of Cardiology. Eur Heart J 34, 2949-3003

Moraes LA, Vaiyapuri S, Sasikumar P, Ali MS, Kriek N, Sage T, Gibbins JM (2013): Antithrombotic actions of statins involve PECAM-1 signaling. Blood 122, 3188-3196

Muller-Riemenschneider F, Andersohn F, Willich SN (2010): Trends in age-standardised and agespecific mortality from ischaemic heart disease in Germany. Clin Res Cardiol 99, 545-551

Munoz-Pacheco P, Ortega-Hernandez A, Miana M, Cachofeiro V, Fernandez-Cruz A, Gomez-Garre D (2012): Ezetimibe inhibits PMA-induced monocyte/macrophage differentiation by altering microRNA expression: a novel anti-atherosclerotic mechanism. Pharmacol Res $\underline{66}, 536-543$

Murphy KP, Janeway CA Jr, Travers P, Walport M, Mowat A, Weaver CT: Janeway's immunobiology. 8. Auflage; Garland Science, London 2012

Murry CE, Giachelli CM, Schwartz SM, Vracko R (1994): Macrophages express osteopontin during repair of myocardial necrosis. Am J Pathol $\underline{145}, 1450-1462$

Nahrendorf M, Swirski FK, Aikawa E, Stangenberg L, Wurdinger T, Figueiredo JL, Libby P, Weissleder R, Pittet MJ (2007): The healing myocardium sequentially mobilizes two monocyte subsets with divergent and complementary functions. J Exp Med 204, 3037-3047

Napoli C, D'Armiento FP, Mancini FP, Postiglione A, Witztum JL, Palumbo G, Palinski W (1997): Fatty streak formation occurs in human fetal aortas and is greatly enhanced by maternal hypercholesterolemia. Intimal accumulation of low density lipoprotein and its oxidation precede monocyte recruitment into early atherosclerotic lesions. J Clin Invest $\underline{100}$, 26802690 
Nathan DM, Cleary PA, Backlund JY, Genuth SM, Lachin JM, Orchard TJ, Raskin P, Zinman B (2005): Intensive diabetes treatment and cardiovascular disease in patients with type 1 diabetes. $\mathrm{N}$ Engl J Med $\underline{353}$, 2643-2653

Neumann FJ, Gawaz M, Dickfeld T, Wehinger A, Walter H, Blasini R, Schomig A (1997): Antiplatelet effect of ticlopidine after coronary stenting. J Am Coll Cardiol 29, 1515-1519

Nicholls SJ, Borgman M, Nissen SE, Raichlen JS, Ballantyne C, Barter P, Chapman MJ, Erbel R, Libby P (2011): Impact of statins on progression of atherosclerosis: rationale and design of SATURN (Study of Coronary Atheroma by InTravascular Ultrasound: effect of Rosuvastatin versus AtorvastatiN). Curr Med Res Opin 27, 1119-1129

Nissen SE, Nicholls SJ, Sipahi I, Libby P, Raichlen JS, Ballantyne CM, Davignon J, Erbel R, Fruchart JC, Tardif JC et al. (2006): Effect of very high-intensity statin therapy on regression of coronary atherosclerosis: the ASTEROID trial. Jama $\underline{295}$, 1556-1565

Noppa H, Bengtsson C, Wedel H, Wilhelmsen L (1980): Obesity in relation to morbidity and mortality from cardiovascular disease. Am J Epidemiol 111, 682-692

Nording HM, Seizer P, Langer HF (2015): Platelets in inflammation and atherogenesis. Front Immunol 6, 98

O'Regan AW, Hayden JM, Berman JS (2000): Osteopontin augments CD3-mediated interferongamma and CD40 ligand expression by $\mathrm{T}$ cells, which results in IL-12 production from peripheral blood mononuclear cells. J Leukoc Biol $\underline{68}$, 495-502

Ohmori R, Momiyama Y, Taniguchi H, Takahashi R, Kusuhara M, Nakamura H, Ohsuzu F (2003): Plasma osteopontin levels are associated with the presence and extent of coronary artery disease. Atherosclerosis $\underline{170}$, 333-337

Olivares R, Ducimetiere P, Claude JR (1993): Monocyte count: a risk factor for coronary heart disease? Am J Epidemiol 137, 49-53

Palmieri L, Bennett K, Giampaoli S, Capewell S (2010): Explaining the decrease in coronary heart disease mortality in Italy between 1980 and 2000. Am J Public Health $\underline{100}$, 684-692

Parissis JT, Venetsanou KF, Mentzikof DG, Kalantzi MV, Georgopoulou MV, Chrisopoulos N, Karas SM (2001): Plasma levels of soluble cellular adhesion molecules in patients with arterial hypertension. Correlations with plasma endothelin-1. Eur J Intern Med 12, 350-356

Parker C III, Vita JA, Freedman JE (2001): Soluble adhesion molecules and unstable coronary artery disease. Atherosclerosis $\underline{156}$, 417-424

Passacquale G, Vamadevan P, Pereira L, Hamid C, Corrigall V, Ferro A (2011): Monocyte-platelet interaction induces a pro-inflammatory phenotype in circulating monocytes. PLoS One $\underline{6}$, e25595

Passlick B, Flieger D, Ziegler-Heitbrock HW (1989): Identification and characterization of a novel monocyte subpopulation in human peripheral blood. Blood 74 , 2527-2534

Pattison JM, Nelson PJ, Huie P, Sibley RK, Krensky AM (1996): RANTES chemokine expression in transplant-associated accelerated atherosclerosis. J Heart Lung Transplant $\underline{15}$, 1194-1199

Paulus JM (1975): Platelet size in man. Blood 46, 321-336

Pei J, Grishin NV (2013): A new family of predicted Kruppel-like factor genes and pseudogenes in placental mammals. PLoS One $\underline{8}$, e81109

Perk J, De Backer G, Gohlke H, Graham I, Reiner Z, Verschuren M, Albus C, Benlian P, Boysen G, Cifkova $R$ et al. (2012): European Guidelines on cardiovascular disease prevention in clinical practice (version 2012). The Fifth Joint Task Force of the European Society of Cardiology and 
Other Societies on Cardiovascular Disease Prevention in Clinical Practice (constituted by representatives of nine societies and by invited experts). Eur Heart J $\underline{33}$, 1635-1701

Plutzky J (2003): The vascular biology of atherosclerosis. Am J Med 115 Suppl 8A, 55s-61s

Poitou C, Dalmas E, Renovato M, Benhamo V, Hajduch F, Abdennour M, Kahn JF, Veyrie N, Rizkalla S, Fridman WH et al. (2011): CD14dimCD16+ and CD14+CD16+ monocytes in obesity and during weight loss: relationships with fat mass and subclinical atherosclerosis. Arterioscler Thromb Vasc Biol 31, 2322-2330

Prentice RL, Szatrowski TP, Fujikura T, Kato H, Mason MW, Hamilton HH (1982): Leukocyte counts and coronary heart disease in a Japanese cohort. Am J Epidemiol 116, 496-509

Pries AR, Zakrzewicz A: Abwehr und Immunität. In: Speckmann E-J, Hescheler J, Köhling R (Hrsg.): Physiologie. 5. Auflage; Elsevier, Urban \& Fischer, München [u. a.] 2008, 345-388

Rahbar S, Blumenfeld O, Ranney HM (1969): Studies of an unusual hemoglobin in patients with diabetes mellitus. Biochem Biophys Res Commun $\underline{36}$, 838-843

Rahman M (2014): Introduction to Flow Cytometry. Bio-Rad AbD Serotec Ltd.: http://static.abdserotec.com/Lit-pdfs/Brochures1/flowcytometry.pdf; [Zugriff: 02.02.2015]

Rainer C, Kawanishi DT, Chandraratna PA, Bauersachs RM, Reid CL, Rahimtoola SH, Meiselman HJ (1987): Changes in blood rheology in patients with stable angina pectoris as a result of coronary artery disease. Circulation $\underline{76}, 15-20$

Reiner Z, Catapano AL, De Backer G, Graham I, Taskinen MR, Wiklund O, Agewall S, Alegria E, Chapman MJ, Durrington P et al. (2011): ESC/EAS Guidelines for the management of dyslipidaemias: the Task Force for the management of dyslipidaemias of the European Society of Cardiology (ESC) and the European Atherosclerosis Society (EAS). Eur Heart J $\underline{32}$, $1769-1818$

Ridker PM, Libby P: Risk Markers for Atherothrombotic Disease. In: Braunwald E, Bonow RO, Mann DL, Zipes DP, Libby $P$ (Hrsg.): Braunwald's heart disease. A textbook of cardiovascular medicine. Elsevier, Saunders, Philadelphia 2012, 914-934

Ridker PM, Rifai N, Rose L, Buring JE, Cook NR (2002): Comparison of C-reactive protein and lowdensity lipoprotein cholesterol levels in the prediction of first cardiovascular events. N Engl J Med 347, 1557-1565

Ridker PM, Danielson E, Fonseca FA, Genest J, Gotto AM Jr, Kastelein JJ, Koenig W, Libby P, Lorenzatti AJ, MacFadyen JG et al. (2008): Rosuvastatin to prevent vascular events in men and women with elevated C-reactive protein. N Engl J Med 359, 2195-2207

Rinder CS, Bonan JL, Rinder HM, Mathew J, Hines R, Smith BR (1992): Cardiopulmonary bypass induces leukocyte-platelet adhesion. Blood 79, 1201-1205

Robert Koch-Institut (2011): Public health requirements in punctures and injections. Bundesgesundheitsblatt - Gesundheitsforschung - Gesundheitsschutz 54, 1135-1144

Rogacev KS, Seiler S, Zawada AM, Reichart B, Herath E, Roth D, Ulrich C, Fliser D, Heine GH (2011): CD14++CD16+ monocytes and cardiovascular outcome in patients with chronic kidney disease. Eur Heart J $\underline{32}$, 84-92

Rogacev KS, Cremers B, Zawada AM, Seiler S, Binder N, Ege P, Grosse-Dunker G, Heisel I, Hornof F, Jeken J et al. (2012): CD14++CD16+ monocytes independently predict cardiovascular events: a cohort study of 951 patients referred for elective coronary angiography. J Am Coll Cardiol $\underline{60}, 1512-1520$ 
Romano M, Mezzetti A, Marulli C, Ciabattoni G, Febo F, Di lenno S, Roccaforte S, Vigneri S, Nubile G, Milani $M$ et al. (2000): Fluvastatin reduces soluble P-selectin and ICAM-1 levels in hypercholesterolemic patients: role of nitric oxide. J Investig Med 4ㅇ, 183-189

Rosenblum SB, Huynh T, Afonso A, Davis HR Jr, Yumibe N, Clader JW, Burnett DA (1998): Discovery of 1-(4-fluorophenyl)-(3R)-[3-(4-fluorophenyl)-(3S)-hydroxypropyl]-(4S)-(4 -hydroxyphenyl)-2azetidinone (SCH 58235): a designed, potent, orally active inhibitor of cholesterol absorption. J Med Chem 41, 973-980

Ross R (1976): Atherosclerosis: the role of endothelial injury, smooth muscle proliferation and platelet factors. Triangle $\underline{15}, 45-51$

Ross R (1979): The pathogenesis of atherosclerosis. Mech Ageing Dev $\underline{9}$, 435-440

Ross R (1999): Atherosclerosis - an inflammatory disease. N Engl J Med 340, 115-126

Ross R, Glomset JA (1973): Atherosclerosis and the arterial smooth muscle cell: Proliferation of smooth muscle is a key event in the genesis of the lesions of atherosclerosis. Science $\underline{180}$, 1332-1339

Ross R, Harker L (1976): Hyperlipidemia and atherosclerosis. Science 193, 1094-1100

Ross R, Glomset JA (1976a): The pathogenesis of atherosclerosis (second of two parts). N Engl J Med $\underline{295}, 420-425$

Ross R, Glomset JA (1976b): The pathogenesis of atherosclerosis (first of two parts). N Engl J Med $\underline{295}, 369-377$

Ross R, Harker L (1978): Platelets, endothelium, and smooth muscle cells in atherosclerosis. Adv Exp Med Biol 102, 135-141

Ross R, Glomset J, Harker L (1977): Response to injury and atherogenesis. Am J Pathol 86, 675-684

Ross R, Faggiotto A, Bowen-Pope D, Raines E (1984): The role of endothelial injury and platelet and macrophage interactions in atherosclerosis. Circulation $\underline{70}$, 11177-82

Rothman AJ (2000): Toward a theory-based analysis of behavioral maintenance. Health Psychol $\underline{19}$, 64-69

Ruiz-Limon P, Barbarroja N, Perez-Sanchez C, Aguirre MA, Bertolaccini ML, Khamashta MA, Rodriguez-Ariza A, Almaden Y, Segui P, Khraiwesh H et al. (2014): Atherosclerosis and cardiovascular disease in systemic lupus erythematosus: effects of in vivo statin treatment. Ann Rheum Dis, Published online first: [21.03.2014]

Sacks FM, Pfeffer MA, Moye LA, Rouleau JL, Rutherford JD, Cole TG, Brown L, Warnica JW, Arnold JM, Wun CC et al. (1996): The effect of pravastatin on coronary events after myocardial infarction in patients with average cholesterol levels. Cholesterol and Recurrent Events Trial investigators. N Engl J Med 335, 1001-1009

Saederup N, Chan L, Lira SA, Charo IF (2008): Fractalkine deficiency markedly reduces macrophage accumulation and atherosclerotic lesion formation in CCR2-/- mice: evidence for independent chemokine functions in atherogenesis. Circulation $\underline{117}, 1642-1648$

Sagastagoitia JD, Saez Y, Vacas M, Narvaez I, de Lafuente JP, Molinero E, Escobar A, Lafita M, Iriarte JA (2008): Acute versus chronic myocardial ischemia: a differential biological profile study. Pathophysiol Haemost Thromb 36, 91-97

Sales KJ, Adefuye A, Nicholson L, Katz AA (2014): CCR5 expression is elevated in cervical cancer cells and is up-regulated by seminal plasma. Mol Hum Reprod 20, 1144-1157

Samson M, Labbe O, Mollereau C, Vassart G, Parmentier M (1996): Molecular cloning and functional expression of a new human CC-chemokine receptor gene. Biochemistry $\underline{35}$, 3362-3367 
Santos-Gallego CG, Picatoste B, Badimon JJ (2014): Pathophysiology of acute coronary syndrome. Curr Atheroscler Rep 16, 401

Sasaoka T, Kimura A, Hohta SA, Fukuda N, Kurosawa T, Izumi T (2001): Polymorphisms in the plateletendothelial cell adhesion molecule-1 (PECAM-1) gene, Asn563Ser and Gly670Arg, associated with myocardial infarction in the Japanese. Ann N Y Acad Sci 947, 259-269; discussion 269270

Scatena M, Liaw L, Giachelli CM (2007): Osteopontin: a multifunctional molecule regulating chronic inflammation and vascular disease. Arterioscler Thromb Vasc Biol 27, 2302-2309

Schlitt A, Heine GH, Blankenberg S, Espinola-Klein C, Dopheide JF, Bickel C, Lackner KJ, Iz M, Meyer J, Darius $\mathrm{H}$ et al. (2004): CD14+CD16+ monocytes in coronary artery disease and their relationship to serum TNF-alpha levels. Thromb Haemost $\underline{92}$, 419-424

Schober A, Manka D, von Hundelshausen P, Huo Y, Hanrath P, Sarembock IJ, Ley K, Weber C (2002): Deposition of platelet RANTES triggering monocyte recruitment requires $\mathrm{P}$-selectin and is involved in neointima formation after arterial injury. Circulation 106, 1523-1529

Sels JW, Elsenberg EH, Hoefer IE, van Zonneveld AJ, Kuiper J, Jukema JW, Pijls NH, Pasterkamp G (2012): Fractional flow reserve is not associated with inflammatory markers in patients with stable coronary artery disease. PLoS One $\underline{7}$, e46356

Seropian IM, Sonnino C, Van Tassell BW, Biasucci LM, Abbate A (2015): Inflammatory markers in STelevation acute myocardial infarction. Eur Heart J Acute Cardiovasc Care, Published online first: [15.02.2015]

Sharma N, Lu Y, Zhou G, Liao X, Kapil P, Anand P, Mahabeleshwar GH, Stamler JS, Jain MK (2012): Myeloid Kruppel-like factor 4 deficiency augments atherogenesis in ApoE-/- mice--brief report. Arterioscler Thromb Vasc Biol 32, 2836-2838

Shattil SJ, Anaya-Galindo R, Bennett J, Colman RW, Cooper RA (1975): Platelet hypersensitivity induced by cholesterol incorporation. J Clin Invest $\underline{55}$, 636-643

Shields JM, Christy RJ, Yang VW (1996): Identification and characterization of a gene encoding a gutenriched Kruppel-like factor expressed during growth arrest. J Biol Chem 271, 20009-20017

Shirpoor A, Salami S, Khadem Ansari MH, Ilkhanizadeh B, Abdollahzadeh N (2013): Ethanol promotes rat aortic vascular smooth muscle cell proliferation via increase of homocysteine and oxidized-low-density lipoprotein. J Cardiol 62, 374-378

Simeoni E, Winkelmann BR, Hoffmann MM, Fleury S, Ruiz J, Kappenberger L, Marz W, Vassalli G (2004): Association of RANTES G-403A gene polymorphism with increased risk of coronary arteriosclerosis. Eur Heart J $\underline{25}$, 1438-1446

Smolina K, Wright FL, Rayner M, Goldacre MJ (2012): Determinants of the decline in mortality from acute myocardial infarction in England between 2002 and 2010: linked national database study. BMJ $\underline{344}$, d8059

Sobel M: Peripheral Vascular Disease. In: Michelson AD (Hrsg.): Platelets. 2. Auflage; Elsevier, Academic Press, Amsterdam [u. a.] 2007, 685-696

Solomon M, Balasa B, Sarvetnick N (2010): CCR2 and CCR5 chemokine receptors differentially influence the development of autoimmune diabetes in the NOD mouse. Autoimmunity $\underline{43}$, 156-163

Soria G, Ben-Baruch A (2008): The inflammatory chemokines CCL2 and CCL5 in breast cancer. Cancer Lett 267, 271-285

Spyropoulos B (2011): 50 years LASERS: in vitro diagnostics, clinical applications and perspectives. Clin Lab 57, 131-142 
Stamler J, Stamler R, Neaton JD (1993): Blood pressure, systolic and diastolic, and cardiovascular risks. US population data. Arch Intern Med 153, 598-615

Stary HC, Chandler AB, Glagov S, Guyton JR, Insull W Jr, Rosenfeld ME, Schaffer SA, Schwartz CJ, Wagner WD, Wissler RW (1994): A definition of initial, fatty streak, and intermediate lesions of atherosclerosis. A report from the Committee on Vascular Lesions of the Council on Arteriosclerosis, American Heart Association. Circulation 89, 2462-2478

Stary HC, Chandler AB, Dinsmore RE, Fuster V, Glagov S, Insull W Jr, Rosenfeld ME, Schwartz CJ, Wagner WD, Wissler RW (1995): A definition of advanced types of atherosclerotic lesions and a histological classification of atherosclerosis. A report from the Committee on Vascular Lesions of the Council on Arteriosclerosis, American Heart Association. Circulation 92, 13551374

Statistisches Bundesamt: Fachserie 12: Gesundheit, Reihe 7.2: Krankheitskosten - Tabellen zur Krankheitskostenrechnung mit methodischer Beschreibung des Rechensystems für die Jahre 2002, 2004, 2006 und 2008. Statistisches Bundesamt, Wiesbaden 2010

Statistisches Bundesamt: Fachserie 12: Gesundheit, Reihe 4 Todesursachen in Deutschland 2013 Sterbefälle nach ausgewählten Todesursachen, Altersgruppen und Geschlecht; Gestorbene in Deutschland. Statistisches Bundesamt, Wiesbaden 2014

Steg PG, James SK, Atar D, Badano LP, Blomstrom-Lundqvist C, Borger MA, Di Mario C, Dickstein K, Ducrocq G, Fernandez-Aviles F et al. (2012): ESC Guidelines for the management of acute myocardial infarction in patients presenting with ST-segment elevation. Eur Heart J $\underline{33}$, 25692619

Stephen J, Emerson B, Fox KA, Dransfield I (2013): The uncoupling of monocyte-platelet interactions from the induction of proinflammatory signaling in monocytes. J Immunol $\underline{191}, 5677-5683$

Sudhop T, Lutjohann D, Kodal A, Igel M, Tribble DL, Shah S, Perevozskaya I, von Bergmann K (2002): Inhibition of intestinal cholesterol absorption by ezetimibe in humans. Circulation 106, $1943-$ 1948

Sunderkotter C, Nikolic T, Dillon MJ, Van Rooijen N, Stehling M, Drevets DA, Leenen PJ (2004): Subpopulations of mouse blood monocytes differ in maturation stage and inflammatory response. J Immunol 172, 4410-4417

Suzuki J, Hamada E, Shodai T, Kamoshida G, Kudo S, Itoh S, Koike J, Nagata K, Irimura T, Tsuji T (2013): Cytokine secretion from human monocytes potentiated by P-selectin-mediated cell adhesion. Int Arch Allergy Immunol 160, 152-160

Sweetnam PM, Thomas HF, Yarnell JW, Baker IA, Elwood PC (1997): Total and differential leukocyte counts as predictors of ischemic heart disease: the Caerphilly and Speedwell studies. Am J Epidemiol 145, 416-421

Swirski FK, Nahrendorf M (2013): Leukocyte behavior in atherosclerosis, myocardial infarction, and heart failure. Science $\underline{339}, 161-166$

Swirski FK, Libby P, Aikawa E, Alcaide P, Luscinskas FW, Weissleder R, Pittet MJ (2007): Ly-6Chi monocytes dominate hypercholesterolemia-associated monocytosis and give rise to macrophages in atheromata. J Clin Invest $\underline{117}$, 195-205

Swirski FK, Nahrendorf M, Etzrodt M, Wildgruber M, Cortez-Retamozo V, Panizzi P, Figueiredo JL, Kohler RH, Chudnovskiy A, Waterman P et al. (2009): Identification of splenic reservoir monocytes and their deployment to inflammatory sites. Science $\underline{325}, 612-616$

Syverson von Gemmingen-Guttenberg D: Theorien zur Pathogenese der Arteriosklerose. Med. Diss. Berlin 2013 
Takeuchi N, Kawamura T, Kanai A, Nakamura N, Uno T, Hara T, Sano T, Sakamoto N, Hamada Y, Nakamura J et al. (2002): The effect of cigarette smoking on soluble adhesion molecules in middle-aged patients with Type 2 diabetes mellitus. Diabet Med $\underline{19}$, 57-64

Tegos TJ, Kalodiki E, Sabetai MM, Nicolaides AN (2001): The genesis of atherosclerosis and risk factors: a review. Angiology $\underline{52}, 89-98$

Temel RE, Tang W, Ma Y, Rudel LL, Willingham MC, loannou YA, Davies JP, Nilsson LM, Yu L (2007): Hepatic Niemann-Pick C1-like 1 regulates biliary cholesterol concentration and is a target of ezetimibe. J Clin Invest 117, 1968-1978

The Pooling Project Research Group (1978): Relationship of blood pressure, serum cholesterol, smoking habit, relative weight and ECG abnormalities to incidence of major coronary events: final report of the pooling project. J Chronic Dis 31, 201-306

Thygesen K, Alpert JS, Jaffe AS, Simoons ML, Chaitman BR, White HD, Thygesen K, Alpert JS, White HD, Jaffe AS et al. (2012): Third universal definition of myocardial infarction. Eur Heart J $\underline{33}$, 2551-2567

Totani L, Evangelista V (2010): Platelet-leukocyte interactions in cardiovascular disease and beyond. Arterioscler Thromb Vasc Biol 30, 2357-2361

Toth PP, Davidson MH (2005): Cholesterol absorption blockade with ezetimibe. Curr Drug Targets Cardiovasc Haematol Disord $\underline{5}$, 455-462

Uebel T (2014): Vom HbA1c zum Gesamtrisiko. Der Diabetologe 10, 217-222

Unal B, Critchley JA, Capewell S (2004): Explaining the decline in coronary heart disease mortality in England and Wales between 1981 and 2000. Circulation 109, 1101-1107

van der Laan AM, Ter Horst EN, Delewi R, Begieneman MP, Krijnen PA, Hirsch A, Lavaei M, Nahrendorf M, Horrevoets AJ, Niessen HW et al. (2014): Monocyte subset accumulation in the human heart following acute myocardial infarction and the role of the spleen as monocyte reservoir. Eur Heart J $\underline{35}$, 376-385

van Furth R (1985): Monocyte production during inflammation. Comp Immunol Microbiol Infect Dis 8, 205-211

van Gils JM, Zwaginga JJ, Hordijk PL (2009): Molecular and functional interactions among monocytes, platelets, and endothelial cells and their relevance for cardiovascular diseases. J Leukoc Biol $\underline{85}, 195-204$

Veillard NR, Steffens S, Burger F, Pelli G, Mach F (2004a): Differential expression patterns of proinflammatory and antiinflammatory mediators during atherogenesis in mice. Arterioscler Thromb Vasc Biol 24, 2339-2344

Veillard NR, Kwak B, Pelli G, Mulhaupt F, James RW, Proudfoot AE, Mach F (2004b): Antagonism of RANTES receptors reduces atherosclerotic plaque formation in mice. Circ Res $\underline{94}$, 253-261

Veillard NR, Braunersreuther V, Arnaud C, Burger F, Pelli G, Steffens S, Mach F (2006): Simvastatin modulates chemokine and chemokine receptor expression by geranylgeranyl isoprenoid pathway in human endothelial cells and macrophages. Atherosclerosis $\underline{188}, 51-58$

Verhaar MC, Beutler JJ, Gaillard CA, Koomans HA, Fijnheer R, Rabelink TJ (1998): Progressive vascular damage in hypertension is associated with increased levels of circulating P-selectin. J Hypertens $\underline{16}, 45-50$

Virchow R: Gesammelte Abhandlungen zur wissenschaftlichen Medicin. Meidinger, Frankfurt a. M. 1856 
von Hundelshausen P, Schmitt MM (2014): Platelets and their chemokines in atherosclerosis-clinical applications. Front Physiol $\underline{5}, 294$

von Hundelshausen P, Weber KSC, Huo Y, Proudfoot AEI, Nelson PJ, Ley K, Weber C (2001): RANTES Deposition by Platelets Triggers Monocyte Arrest on Inflamed and Atherosclerotic Endothelium. Circulation 103, 1772-1777

Wang KX, Denhardt DT (2008): Osteopontin: role in immune regulation and stress responses. Cytokine Growth Factor Rev 19 , 333-345

Wang N, Tabas I, Winchester R, Ravalli S, Rabbani LE, Tall A (1996): Interleukin 8 is induced by cholesterol loading of macrophages and expressed by macrophage foam cells in human atheroma. J Biol Chem 271, 8837-8842

Wang X, Louden C, Ohlstein EH, Stadel JM, Gu JL, Yue TL (1996): Osteopontin expression in plateletderived growth factor-stimulated vascular smooth muscle cells and carotid artery after balloon angioplasty. Arterioscler Thromb Vasc Biol 16, 1365-1372

Weber C (2005): Platelets and chemokines in atherosclerosis: partners in crime. Circ Res $\underline{96}, 612-616$

Weber C, Schober A, Zernecke A (2004): Chemokines: key regulators of mononuclear cell recruitment in atherosclerotic vascular disease. Arterioscler Thromb Vasc Biol 24, 1997-2008

Weber C, Draude G, Weber KS, Wubert J, Lorenz RL, Weber PC (1999): Downregulation by tumor necrosis factor-alpha of monocyte CCR2 expression and monocyte chemotactic protein-1induced transendothelial migration is antagonized by oxidized low-density lipoprotein: a potential mechanism of monocyte retention in atherosclerotic lesions. Atherosclerosis $\underline{145}$, $115-123$

Weber C, Belge KU, von Hundelshausen P, Draude G, Steppich B, Mack M, Frankenberger M, Weber KS, Ziegler-Heitbrock HW (2000): Differential chemokine receptor expression and function in human monocyte subpopulations. J Leukoc Biol 67, 699-704

Weber GF, Ashkar S, Glimcher MJ, Cantor H (1996): Receptor-ligand interaction between CD44 and osteopontin (Eta-1). Science 271, 509-512

Weber GF, Zawaideh S, Hikita S, Kumar VA, Cantor H, Ashkar S (2002): Phosphorylation-dependent interaction of osteopontin with its receptors regulates macrophage migration and activation. J Leukoc Biol $\underline{72}$, 752-761

Wei H, Fang L, Chowdhury SH, Gong N, Xiong Z, Song J, Mak KH, Wu S, Koay E, Sethi S et al. (2004): Platelet-endothelial cell adhesion molecule-1 gene polymorphism and its soluble level are associated with severe coronary artery stenosis in Chinese Singaporean. Clin Biochem $\underline{37}$, 1091-1097

Weintraub AS, Giachelli CM, Krauss RS, Almeida M, Taubman MB (1996): Autocrine secretion of osteopontin by vascular smooth muscle cells regulates their adhesion to collagen gels. Am J Pathol 149, 259-272

Weyrich AS, Elstad MR, McEver RP, McIntyre TM, Moore KL, Morrissey JH, Prescott SM, Zimmerman GA (1996): Activated platelets signal chemokine synthesis by human monocytes. J Clin Invest $\underline{97}, 1525-1534$

White JG: Platelet Structure. In: Michelson AD (Hrsg.): Platelets. 2. Auflage; Elsevier, Academic Press, Amsterdam [u. a.] 2007, 45-74

Wilcox JN, Nelken NA, Coughlin SR, Gordon D, Schall TJ (1994): Local expression of inflammatory cytokines in human atherosclerotic plaques. J Atheroscler Thromb 1 Suppl 1, S10-13

Williams MW, Guiffre AK, Fletcher JP (2014): Platelets and smooth muscle cells affecting the differentiation of monocytes. PLoS One $\underline{9}$, e88172 
Woenckhaus C, Kaufmann A, Bussfeld D, Gemsa D, Sprenger H, Grone HJ (1998): Hypochloritemodified LDL: chemotactic potential and chemokine induction in human monocytes. Clin

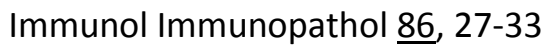

Wong CK, Lit LC, Tam LS, Li EK, Lam CW (2005): Elevation of plasma osteopontin concentration is correlated with disease activity in patients with systemic lupus erythematosus. Rheumatology (Oxford) 44, 602-606

Wong KL, Yeap WH, Tai JJ, Ong SM, Dang TM, Wong SC (2012): The three human monocyte subsets: implications for health and disease. Immunol Res $\underline{53}$, 41-57

Wong KL, Tai JJ, Wong WC, Han H, Sem X, Yeap WH, Kourilsky P, Wong SC (2011): Gene expression profiling reveals the defining features of the classical, intermediate, and nonclassical human monocyte subsets. Blood 118, e16-31

World Health Organization: Global status report on noncommunicable diseases 2010. WHO Library, Genf 2011

World Health Organization (2014): The top 10 causes of death. Fact sheet No 310, http://www.who.int/mediacentre/factsheets/fs310/en/; [Zugriff: 02.02.2015].

World Medical Association (2013): World Medical Association Declaration of Helsinki: ethical principles for medical research involving human subjects. JAMA $\underline{310}$, 2191-2194

Wrigley BJ, Shantsila E, Tapp LD, Lip GY (2013): Increased formation of monocyte-platelet aggregates in ischemic heart failure. Circ Heart Fail $\underline{6}, 127-135$

Yarnell JW, Baker IA, Sweetnam PM, Bainton D, O'Brien JR, Whitehead PJ, Elwood PC (1991): Fibrinogen, viscosity, and white blood cell count are major risk factors for ischemic heart disease. The Caerphilly and Speedwell collaborative heart disease studies. Circulation $\underline{83}$, 836-844

Yoshida T, Hayashi M (2014): Role of Kruppel-like factor 4 and its binding proteins in vascular disease. J Atheroscler Thromb 21, 402-413

Yoshida T, Kaestner KH, Owens GK (2008): Conditional deletion of Kruppel-like factor 4 delays downregulation of smooth muscle cell differentiation markers but accelerates neointimal formation following vascular injury. Circ Res 102, 1548-1557

Zawada AM, Rogacev KS, Rotter B, Winter P, Marell RR, Fliser D, Heine GH (2011): SuperSAGE evidence for CD14++CD16+ monocytes as a third monocyte subset. Blood $\underline{118}$, e50-61

Zhou G, Hamik A, Nayak L, Tian H, Shi H, Lu Y, Sharma N, Liao X, Hale A, Boerboom L et al. (2012): Endothelial Kruppel-like factor 4 protects against atherothrombosis in mice. J Clin Invest $\underline{122}$, 4727-4731

Zhu SN, Chen M, Jongstra-Bilen J, Cybulsky MI (2009): GM-CSF regulates intimal cell proliferation in nascent atherosclerotic lesions. J Exp Med 206, 2141-2149

Ziegler-Heitbrock L (2007): The CD14+ CD16+ blood monocytes: their role in infection and inflammation. J Leukoc Biol 81, 584-592

Ziegler-Heitbrock L, Ancuta P, Crowe S, Dalod M, Grau V, Hart DN, Leenen PJ, Liu YJ, MacPherson G, Randolph GJ et al. (2010): Nomenclature of monocytes and dendritic cells in blood. Blood $\underline{116}, \mathrm{e} 74-80$

Zouridakis EG, Garcia-Moll X, Kaski JC (2000): Usefulness of the blood lymphocyte count in predicting recurrent instability and death in patients with unstable angina pectoris. Am J Cardiol $\underline{86}$, 449-451 


\section{ABBILDUNGSVERZEICHNIS}

Abb. 1.1 Einfluss- und Modulationsmöglichkeiten proinflammatorischer Mediatoren im Rahmen der Atheroskleroseentwicklung 1

Abb. 1.2 Schematische Darstellung der Entstehung einer atherosklerotischen Plaque ${ }^{2}$.............. 4

Abb. 1.3 Monozyt im Blutausstrich ${ }^{3}$

Abb. 2.1 Schematischer Aufbau eines Durchflusszytometers 4

Abb. 2.2 Durchflusszytometrische Darstellung der morphologischen Charakteristika humaner Vollblutbestandteile nach Lyse anhand ihrer Streulichteigenschaften .......23

Abb. 2.3 Leucosep ${ }^{\text {TM}}$-Röhrchen zur PBMC-Gewinnung....................................................................... 25

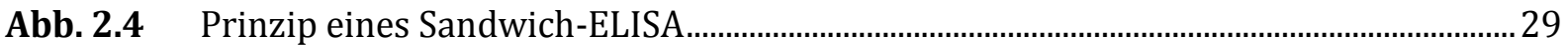

Abb. 2.5 Schematische Darstellung einer standardisierten Verdünnungsreihe ............................. 31

Abb. 3.1 Durchflusszytometrische Monozytendetektion und Evaluation der monozytären Subgruppen ................................................................................................... 36

Abb. 3.2 Relativer Anteil der Monozytensubgruppen an der Gesamtmonozytenzahl ${ }^{5}$.............. 37

Abb. 3.3 Absolute Monozytenanzahl pro Subgruppe 5 ………....................................................... 38

Abb. 3.4 CCR5+-Monozyten und ihre Verteilung auf die Monozytensubgruppen ${ }^{6}$........................ 39

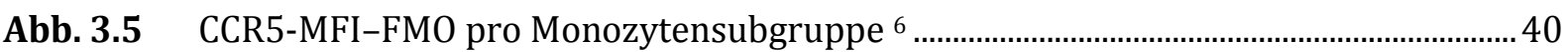

Abb. 3.6 CCR5+-Monozyten und deren Verteilung bei altersadaptierten Kontrollprobanden

Abb. 3.7 Prozentualer Anteil CCR5+-Monozyten nach Inkubation gesunder Blutspendermonozyten mit Kontrollprobandenplasma vs. KHK-Patientenplasma ${ }^{7}$.

Abb. 3.8 Einfluss der Statinmedikation auf die CCR5-Expression der Monozytensubgruppen ${ }^{6}$

Abb. 3.9 Einfluss von Ezetimib auf die prozentuale Verteilung der Monozytensubgruppen... 44

Abb. 3.10 CD44-MFI-FMO pro Monozytensubgruppe ………………………………............................ 45

Abb. 3.11 Prozentuale Verteilung der KLF4+-Monozyten pro Monozytensubgruppe ${ }^{8}$................ 46

Abb. 3.12 KLF4-MFI-FMO pro Monozytensubgruppe ${ }^{8}$.

Abb. 3.13 Anteil KLF4+-Monozyten nach Monozyteninkubation mit heparinisiertem Plasma gesunder Blutspender vs. KHK-Patientenplasma ${ }^{8}$

Abb. 3.14 $\mathrm{KLF}^{+}{ }^{+}$Monozyten in Abhängigkeit kardiovaskulärer Risikofaktoren ${ }^{8}$. 49

Abb. 3.15 Korrelation der Leukozytenzahlen mit der relativen Anzahl KLF4+-Monozyten.........50

Abb. 3.16 Relativer Anteil an MPA-Bildung pro Monozytensubgruppe 6 51

Abb. 3.17 CD42b-MFI-FMO pro Monozytensubgruppe 6 52 
Abb. 3.18 Relativer Anteil an MPA-Bildung pro Monozytensubgruppe bei altersadaptierten Kontrollprobanden ohne KHK

Abb. 3.19 Relativer Anteil an MPA-Bildung in Abhängigkeit von Vorhofflimmern 54

Abb. 3.20 Serumspiegel von (a) sPECAM-1 und (b) sP-selectin 7

Abb. 3.21 (a) Korrelation der sP-selectin- und sPECAM-1-Serumspiegel und (b) Einfluss des BMI auf die sP-selectin-Serumspiegel

Abb. 3.22 (a) Korrelation der sP-selectin- und hsCRP-Spiegel und (b) Einfluss des hsCRP auf die sP-selectin-Serumspiegel.

Abb. 3.23 (a) TNF- $\alpha$-Blutplasmaspiegel und deren (b) Korrelation mit dem relativen Anteil an KLF4+-Monozyten 8

Abb. 4.1 Monozytenseparation und -detektion anhand der CD44-Expression $68 \mathrm{f}$.

${ }^{1}$ modifiziert nach Ait-Oufella H, Mallat Z, Tedgui A: Mediators of Vascular Inflammation. In: Wick G, Grundtman C (Hrsg.): Inflammation and Atherosclerosis. 1. Auflage; Springer, Wien [u. a.] 2012, S. 207. Mit freundlicher Genehmigung von Springer.

${ }^{2}$ modifiziert nach Libby P: The Vascular Biology of Atherosclerosis. In: Braunwald E, Bonow RO, Mann DL, Zipes DP, Libby P (Hrsg.): Braunwald's heart disease. A textbook of cardiovascular medicine. 9. Auflage; Elsevier, Saunders, Philadelphia 2012, S. 902. Mit freundlicher Genehmigung von Elsevier, Saunders und Peter Libby.

${ }^{3}$ modifiziert nach Löffler H, Rastetter J, Haferlach T: Atlas der klinischen Hämatologie. 6., vollständig überarbeitete Auflage; Springer, Berlin [u. a.] 2004, S. 55. Mit freundlicher Genehmigung von Springer.

${ }^{4}$ modifiziert nach Rahman M (2014): Introduction to Flow Cytometry. Bio-Rad AbD Serotec Ltd.: http://static.abdserotec.com/Lit-pdfs/Brochures1 /flowcytometry.pdf; [Zugriff: 02.02.2015], S. 7. Mit freundlicher Genehmigung von Bio-Rad AbD Serotec Ltd.

${ }^{5}$ modifiziert nach Czepluch FS, Kuschicke H, Dellas C, Riggert J, Hasenfuss G, Schäfer K (2014): Increased proatherogenic monocyte-platelet cross-talk in monocyte subpopulations of patients with stable coronary artery disease. J Intern Med $\underline{275}$, S. 148. Mit freundlicher Genehmigung von Wiley.

${ }^{6}$ modifiziert nach Czepluch FS, Kuschicke H, Dellas C, Riggert J, Hasenfuss G, Schäfer K (2014): Increased proatherogenic monocyte-platelet cross-talk in monocyte subpopulations of patients with stable coronary artery disease. J Intern Med 275, S. 149. Mit freundlicher Genehmigung von Wiley.

${ }^{7}$ modifiziert nach Czepluch FS, Kuschicke H, Dellas C, Riggert J, Hasenfuss G, Schäfer K (2014): Increased proatherogenic monocyte-platelet cross-talk in monocyte subpopulations of patients with stable coronary artery disease. J Intern Med $\underline{275}$, S. 150. Mit freundlicher Genehmigung von Wiley.

${ }^{8}$ modifiziert nach Czepluch FS, Kuschicke H, Dellas C, Riggert J, Hasenfuss G, Schäfer K (2013): Atheroprotective Kruppel-like factor 4 is downregulated in monocyte subsets of patients with coronary artery disease. Thromb Haemost $\underline{110}$, S. 1081. Mit freundlicher Genehmigung von Wiley. 


\section{TABELLENVERZEICHNIS}

Tab. 2.1 Studienausschlusskriterien der KHK-Patienten-Versuchsgruppe .................................18

Tab. 2.2 Studienausschlusskriterien des Versuchskollektivs gesunder Blutspender................. 19

Tab. 2.3 Verwendete Fluorochrome, deren detektable Wellenlängen sowie die generierten Wellenlängen der genutzten Laser.

Tab. 2.4 FACS ${ }^{\text {TM }}$-Röhrchenbestückung zur monozytären Subgruppen-, CCR5- und

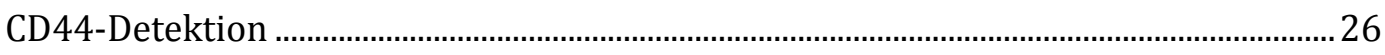

Tab. 2.5 FACS ${ }^{\mathrm{TM}}$-Röhrchenbestückung zur MPA-Detektion............................................................... 27

Tab. 3.1 Demographische und klinische Charakteristika der Studiengruppen ${ }^{1}$.......................... 33

Tab. 3.2 Hämatologische und laborchemische Charakteristika der Studiengruppen ${ }^{1}$.............. 34

${ }^{1}$ modifiziert nach Czepluch FS, Kuschicke H, Dellas C, Riggert J, Hasenfuss G, Schäfer K (2014): Increased proatherogenic monocyte-platelet cross-talk in monocyte subpopulations of patients with stable coronary artery disease. J Intern Med 275, S. 147. Mit freundlicher Genehmigung von Wiley. 


\section{DANKSAGUNG}

Bei der Erstellung dieser Arbeit habe ich von vielen Menschen Unterstützung, Hilfe und Beratung auf verschiedenste Art und Weise erhalten, wofür ich jedem einzelnen sehr dankbar bin.

Mein größter Dank gilt meiner Doktormutter Frau PD Dr. med. Frauke S. Czepluch, die mich während der Durchführung der Studien und der Erstellung dieser Dissertation stets engagiert unterstützt hat. Sie stand mir bei fachlichen und konzeptionellen Fragen zur Seite und hat mich immer wieder zu wissenschaftlichem Denken und Überdenken angeregt. Unser Austausch über die Studienergebnisse und deren Interpretation hat mich und diese Arbeit maßgeblich beeinflusst.

Ein besonderer Dank gebührt darüber hinaus Frau Prof. Dr. med. Katrin Schäfer, deren Arbeitsgruppe ich mich anschließen durfte und die mir ebenfalls mit Rat und Tat zur Seite stand - ob bei methodischen Fragestellungen oder inhaltlichen Diskussionen. Sie bot mir die Möglichkeit, kardiovaskuläre Grundlagenforschung zu betreiben, verschiedenste Forschungsmethoden zu erlernen und die Ergebnisse meiner Arbeiten auf nationalen und internationalen Kongressen zu präsentieren.

Ein großer Dank gilt darüber hinaus Herr Prof. Dr. med. Gerd Hasenfuß, Direktor der Klinik für Kardiologie und Pneumologie an der UMG sowie Vorsitzender des Herzforschungszentrums Göttingen, an dessen Klinik ich meine Dissertation erstellen und dessen Mitarbeiterinnen und Mitarbeiter sowie Forschungseinrichtungen ich in Anspruch nehmen durfte.

Ebenfalls bedanken möchte ich mich bei unseren beiden MTAs Sarah Barke und Anika Hunold, die mich in die Methodik der Laborarbeiten eingearbeitet und immer wieder mit ihren Tipps und Tricks rund um die verschiedensten Versuchsdurchführungen verblüfft haben. Für die Einarbeitung und technische Assistenz am BD FACSCanto ${ }^{\mathrm{TM}}$ II bedanke ich mich ganz herzlich bei Sabrina Becker, MTA der Klinik für Hämatologie und Medizinische Onkologie der UMG.

Ilsabe Arnold-Dielewicz, StD a. D., danke ich für die ausführliche Korrektur dieser Arbeit und ihre stilistischen, formalen sowie inhaltlichen Anmerkungen und Empfehlungen.

Experimentelle Laborarbeit nimmt viel Zeit in Anspruch, läuft selten reibungslos und kann frustrieren. Ich bin sehr froh, dass Frau Dr. med. Magdalena Beham sowie Sebastian Herzberg und Markus Bernhardt mit mir in der Forschungsgruppe experimentell gearbeitet haben und wir uns gegenseitig motivieren, aufbauen und unsere Themen, Methodiken und Interpretationen konstruktiv diskutieren konnten, wodurch mit der Zeit wunderbare Freundschaften entstanden sind. 


\title{
PublikationsVerzeichnis
}

\author{
Originalpublikationen
}

- Czepluch FS, Vogler M, Kuschicke H, Meier J, Gogiraju R, Katschinski DM, Riggert J, Hasenfuss G, Schäfer K (2015): Circulating endothelial cells expressing the angiogenic transcription factor Kruppel-like factor 4 are decreased in patients with coronary artery disease. Microcirculation, Epub ahead of print

- Czepluch FS, Bernhardt M, Kuschicke H, Gogiraju R, Schroeter MR, Riggert J, Hasenfuss G, Schäfer K (2014): In vitro and in vivo effects of human monocytes and their subsets on new vessel formation. Microcirculation $\underline{21}, 148-158$

- Czepluch FS, Kuschicke H, Dellas C, Riggert J, Hasenfuss G, Schäfer K (2014): Increased proatherogenic monocyte-platelet crosstalk in monocyte subpopulations of patients with stable coronary artery disease. J Intern Med 275, 144-154

- Czepluch FS, Kuschicke H, Dellas C, Riggert J, Hasenfuss G, Schäfer K (2013): Atheroprotective Krueppel-like factor 4 is downregulated in monocyte subsets of patients with coronary artery disease. Thromb Haemost $\underline{110}$, 1080-1082

Kongressbeiträge

- Czepluch FS, Vogler M, Kuschicke H, Meier J, Gogiraju R, Katschinski D, Riggert J, Hasenfuss G, Schaefer K (2013): The transcription factor Krueppel-like factor 4 is a positive regulator of angiogenic properties in endothelial cells. Eur Heart J 34, Suppl 1, August 2013, P5664. European Society of Cardiology Congress 2013, Amsterdam, NL, 31.08. - 04.09.2013

- Czepluch FS, Kuschicke H, Dellas C, Riggert J, Hasenfuß G, Schäfer K (2013): Verminderte Expression des atheroprotektiven Transkriptionsfaktors Krüppel-Like Factor 4 in zirkulierenden Monozyten-Subgruppen von Patienten mit koronarer Herzkrankheit. Clin Res Cardiol 102, Suppl 1, April 2013, P1800. 79. Jahrestagung der Deutschen Gesellschaft für Kardiologie Herz- und Kreislaufforschung, Mannheim, 03. -06.04.2013 
- Czepluch FS, Vogler M, Kuschicke H, Meier J, Katschinski D, Riggert J, Hasenfuß G, Schäfer K (2013): Bedeutung des Transkriptionsfaktors Krüppel-Like Factor 4 für die Endothelzellfunktion und Gefäßneubildung. Clin Res Cardiol 102, Suppl 1, April 2013, V506. 79. Jahrestagung der Deutschen Gesellschaft für Kardiologie - Herz- und Kreislaufforschung, Mannheim, 03. -06.04 .2013$

- Czepluch FS, Kuschicke H, Schlegel M, Mueller M, Bernhardt M, Bremmer F, Riggert J, Hasenfuss G, Schaefer K (2012): Krueppel-like factor 4 is downregulated in circulating monocyte subsets of patients with coronary artery disease. Eur Heart J $\underline{33}$, Suppl 1, August 2012, P4327. European Society of Cardiology Congress 2012, München, 25. - 29.08.2012

- Czepluch FS, Bernhardt M, Kuschicke H, Riggert J, Hasenfuß G, Schäfer K (2012): Gefäßwachstum-fördernde Eigenschaften humaner CD16-negativer und CD16-positiver Monozyten. Clin Res Cardiol 101, Suppl 1, April 2012, V501. 78. Jahrestagung der Deutschen Gesellschaft für Kardiologie - Herz- und Kreislaufforschung, Mannheim, 11. - 14.04.2012

- Czepluch FS, Kuschicke H, Riggert J, Hasenfuß G, Schäfer K (2012): Vermehrtes Vorkommen von zirkulierenden $\mathrm{CD} 14++\mathrm{CD} 16+$ und $\mathrm{CD} 14(+) \mathrm{CD} 16+$ Monozyten-Plättchen-Aggregaten bei Patienten mit stabiler koronarer Herzkrankheit. Clin Res Cardiol 101, Suppl 1, April 2012, P1741. 78. Jahrestagung der Deutschen Gesellschaft für Kardiologie - Herz- und Kreislaufforschung, Mannheim, 11. - 14.04.2012 